\title{
High-Temperature Hardness and Wear Resistance of Stellite Alloys
}

\author{
by
}

Samit Kapoor

A thesis submitted to the Faculty of Graduate and Postdoctoral Affairs in partial fulfillment of the requirements for the degree of

Master of Applied Science

in

Mechanical Engineering

Carleton University

Ottawa, Ontario

(C) 2012, Samit Kapoor 
Library and Archives

Canada

Published Heritage

Branch

395 Wellington Street

Ottawa ON K1A ON4

Canada
Bibliothèque et

Archives Canada

Direction du

Patrimoine de l'édition

395 , rue Wellington

Ottawa ON K1A ON4

Canada
Your file Votre référence

ISBN: 978-0-494-91596-7

Our file Notre référence

ISBN: 978-0-494-91596-7
NOTICE:

The author has granted a nonexclusive license allowing Library and Archives Canada to reproduce, publish, archive, preserve, conserve, communicate to the public by telecommunication or on the Internet, loan, distrbute and sell theses worldwide, for commercial or noncommercial purposes, in microform, paper, electronic and/or any other formats.

The author retains copyright ownership and moral rights in this thesis. Neither the thesis nor substantial extracts from it may be printed or otherwise reproduced without the author's permission.
AVIS:

L'auteur a accordé une licence non exclusive permettant à la Bibliothèque et Archives Canada de reproduire, publier, archiver, sauvegarder, conserver, transmettre au public par télécommunication ou par l'Internet, prêter, distribuer et vendre des thèses partout dans le monde, à des fins commerciales ou autres, sur support microforme, papier, électronique et/ou autres formats.

L'auteur conserve la propriété du droit d'auteur et des droits moraux qui protege cette thèse. $\mathrm{Ni}$ la thèse ni des extraits substantiels de celle-ci ne doivent être imprimés ou autrement reproduits sans son autorisation.
In compliance with the Canadian Privacy Act some supporting forms may have been removed from this thesis.

While these forms may be included in the document page count, their removal does not represent any loss of content from the thesis.
Conformément à la loi canadienne sur la protection de la vie privée, quelques formulaires secondaires ont été enlevés de cette thèse.

Bien que ces formulaires aient inclus dans la pagination, il n'y aura aucun contenu manquant. 


\section{Abstract}

Stellite alloys are a family of cobalt-based superalloys that are designed for use in various industries, primarily for wear applications involving unlubricated systems or elevated temperatures. In this research a group of Stellite alloys that cover the main features of the Stellite alloy family are studied for hardness and wear resistance. The emphasis of the research is on the variations of these performances with temperature. These alloys are classified into low-carbon, medium-carbon and high-carbon Stellite alloys, respectively. The hardness of carbides and the hardness of cobalt solid solution for each alloy at both room temperature and elevated temperatures up to $650^{\circ} \mathrm{C}$ are investigated using a micro-hardness tester with a hot stage attached. The wear resistance of each alloy is evaluated at both room temperature and elevated temperatures up to $450^{\circ} \mathrm{C}$ using a pin-on-disc tribometer equipped with a heating device. It has been found that the hardness and wear resistance of Stellite alloys behave differently at room temperature and at high temperatures $\left(<500^{\circ} \mathrm{C}\right)$. The solid solutions of Stellite alloys are softened at elevated temperatures and are hardened by a heating/cooling cycle (up to $650^{\circ} \mathrm{C}$ ) but the carbides are less sensitive to temperature variations. The wear resistance of Stellite alloys at room temperature is mainly dependent on their carbon content and also influenced by tungsten content. However, at high temperatures the wear mechanisms of Stellite alloys become more complex, involving multiple factors such as oxidation of the material surface, cracking/fracture/spalling-off of carbides, surface hardening, etc. The relationships between chemical composition, microstructure, hardness and wear resistance of these alloys, are studied, with the focus on the temperature effect on these relations. 


\section{Acknowledgements}

It is with great pleasure to take this opportunity to thank the many people who made this thesis possible.

First, I would like to thank my advisor, Professor Rong Liu, for her guidance during my research and study at Carleton University. Her patience, flexibility and guidance have allowed me to take on the work independently around my full-time job. In addition, she was always accessible and willing to provide input.

I would also like to thank my employer, Defence Construction Canada, for giving me significant flexibility in my working schedule to attend classes, experiments and seminars during regular working hours.

As well, I would like to thank the many people at NRC specifically $\mathrm{Dr}$. Wu, Olga Lupandina, Robert McKellar and David Chow. I appreciate their assistance in providing me the instruments and technical experience during my time at NRC.

I would also like to thank retired professor Susan Logie from the Thesis Writing Workshop held through the Department of Engineering for taking the time to review my writing. Your help has enabled me to develop a clearer and more concise method to my writing. These lessons, while put to work here, will last far beyond my thesis.

In addition, I would like to thank Deloro Stellite in Belleville. Matthew Yao and Rachael Collier were instrumental in assisting me in figuring out the initial problems with the pin-on-disk apparatus, and ensuring spare parts were machined and available. I greatly appreciate their help.

Lastly, I would like to thank Cassandra for her patience. I promise we will go on vacation soon. 


\section{Table of Contents}

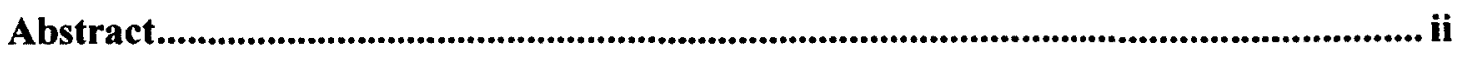

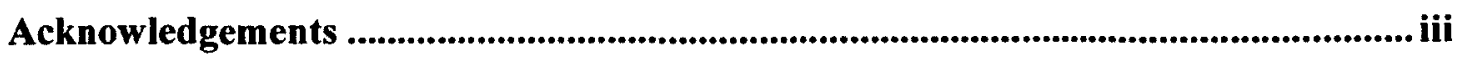

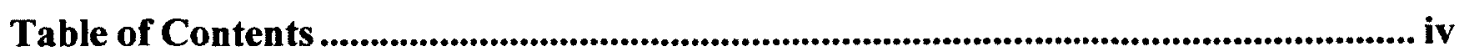

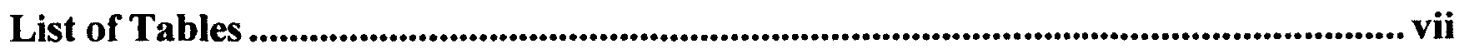

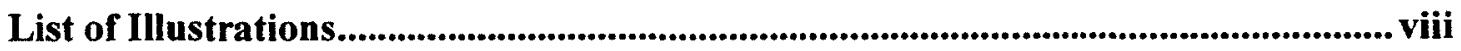

List of Appendices........................................................................................................ xvi

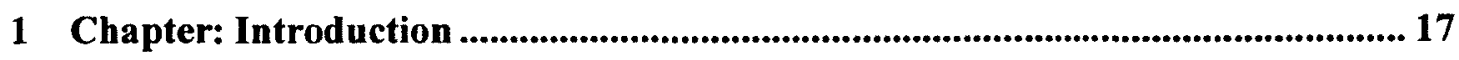

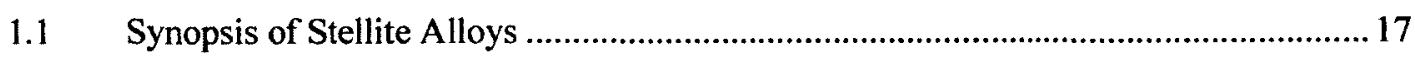

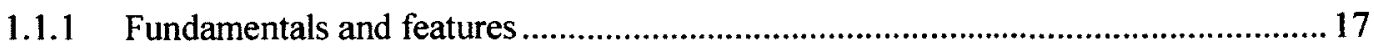

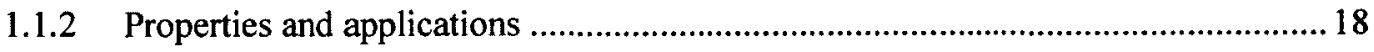

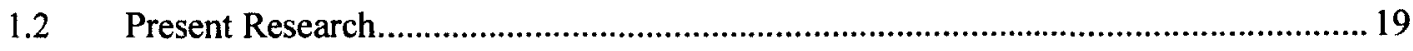

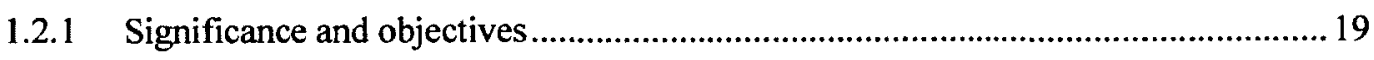

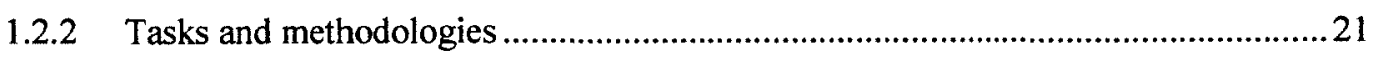

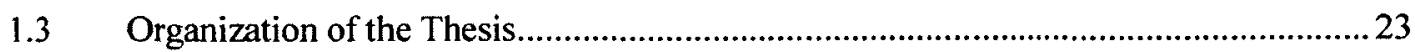

2 Chapter: Literature Review...................................................................................... 26

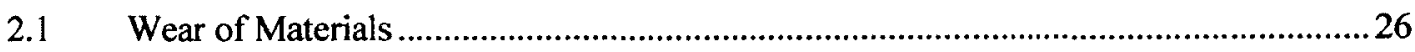

2.1.1 Mechanical components in wear environments ....................................................26

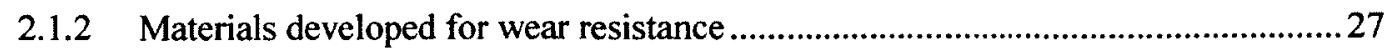

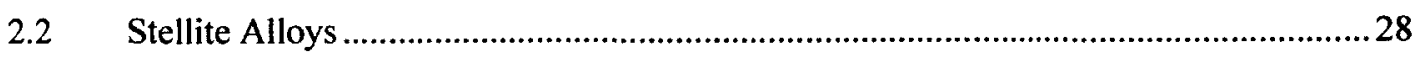

2.2.1 Chemical compositions and microstructures....................................................28

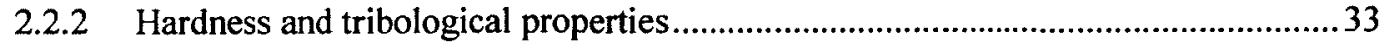

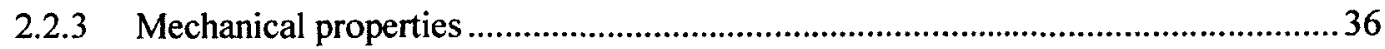

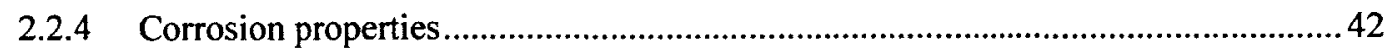

2.3 Research in Wear Behaviour of Stellite Alloys ........................................................ 48 
2.3.1 Room-temperature wear............................................................................... 48

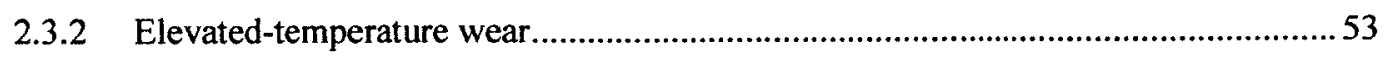

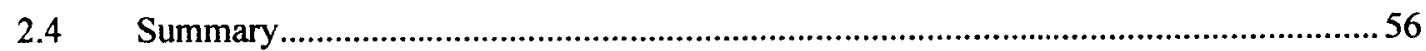

3 Chapter: Microstructural Characterization …...................................................... 58

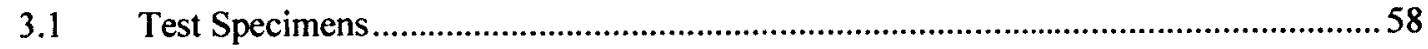

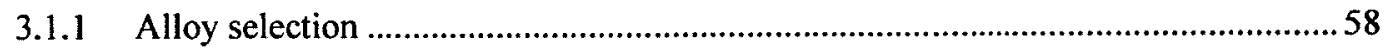

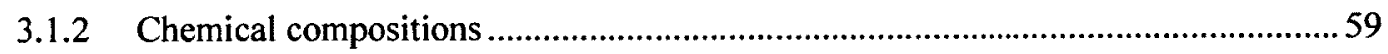

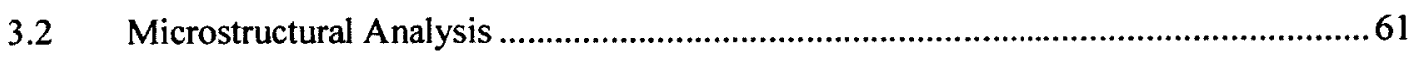

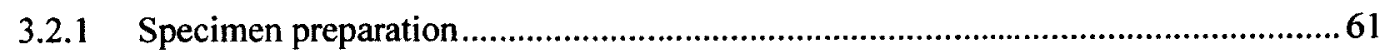

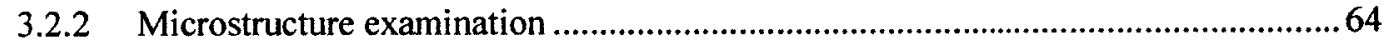

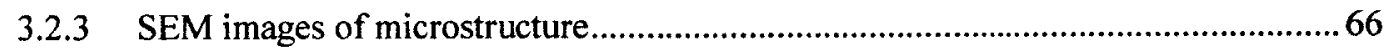

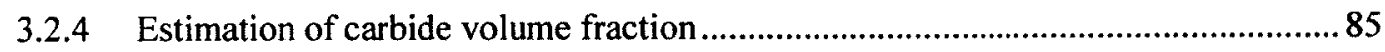

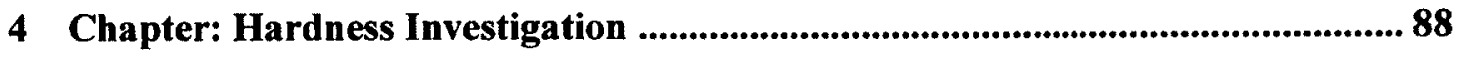

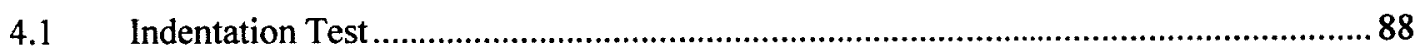

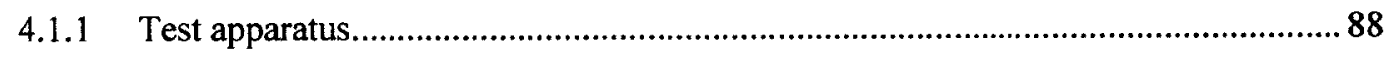

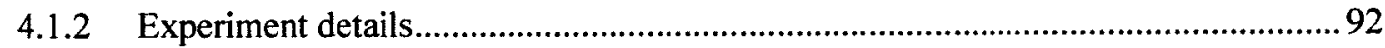

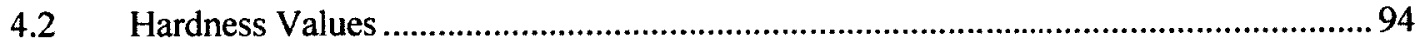

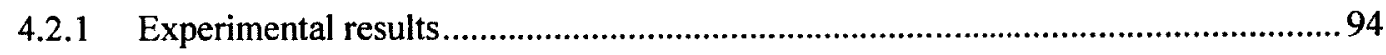

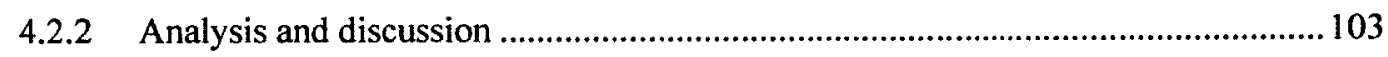

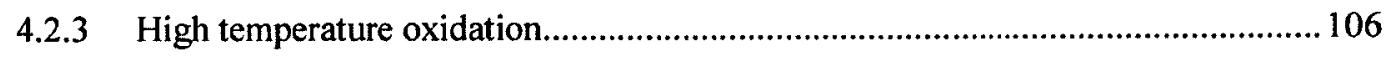

5 Chapter: Wear Resistance Evaluation .................................................................. 108

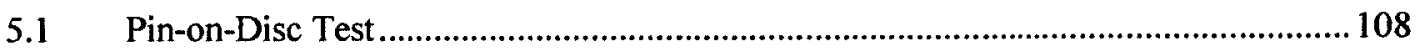

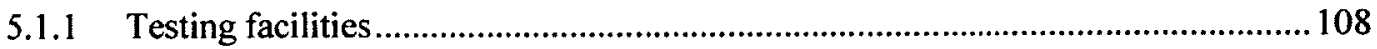

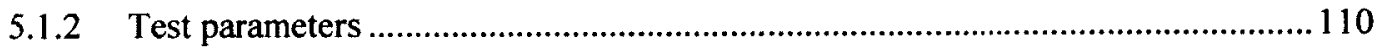

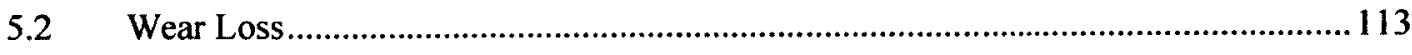


5.2.1 Wear track analysis

5.2.2 Wear resistence

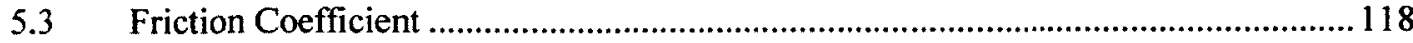

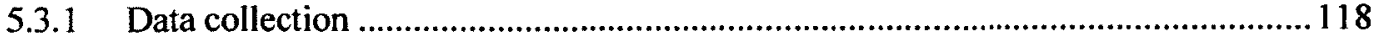

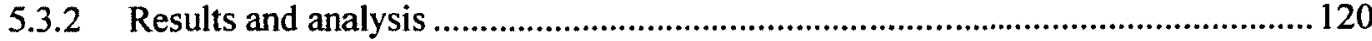

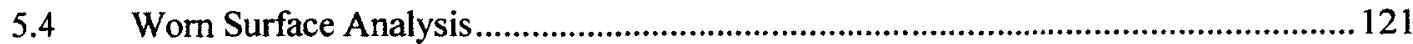

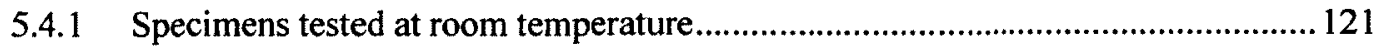

5.4.2 Specimens tested at elevated temperatures ............................................................ 129

6 Chapter: Discussion on Results and Correlations ................................................ 144

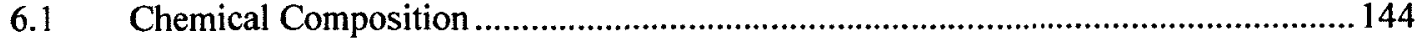

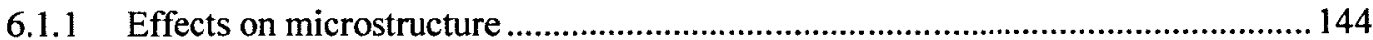

6.1.2 Relationship between microstructure and hardness ............................................ 145

6.1.3 Relationship between microstructure and wear resistance...................................147

6.1.4 Relationship between hardness and wear resistance ........................................148

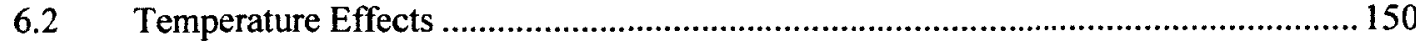

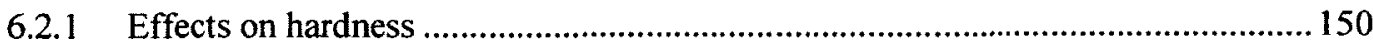

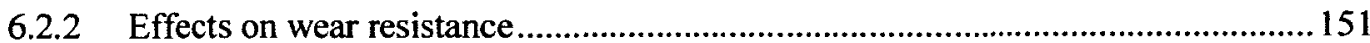

7 Chapter: Conclusions and Further Work ................................................................ 158

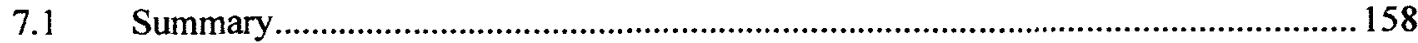

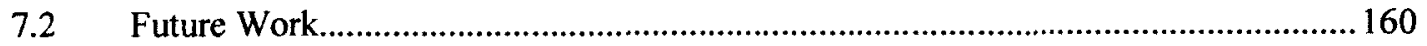

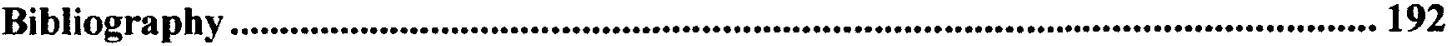




\section{List of Tables}

Table 2-1: Compositions (wt\%, Co in balance) of Stellite alloys for corrosion tests 44

Table 3-1: Chemical compositions (wt $\%$, Co in balance) of Stellite alloys 60

Table 3-2: Quantities of Carbides in Stellite Alloys $\quad 87$

Table 4-1: Summary of micro hardness test specifications 93

Table 4-2: Average hardness values (HV) of solid solution and carbides 103

Table 4-3: Average hardness values (HV) of mixtures 104

Table 4-4: Temperature-dependences of hardness for solid solution and carbides $\quad 106$

Table 5-1: Pin-on-disc wear test parameters $\quad 110$ 


\section{List of Illustrations}

Figure 2-1: Microstructure of Stellite $6(1.2 \mathrm{wt} \% \mathrm{C})$ - a hypo-eutectic microstructure. .. 31

Figure 2-2: Microstructure of Stellite $3(2.4 \mathrm{wt} \% \mathrm{C})$ - a hyper-eutectic microstructure. 31

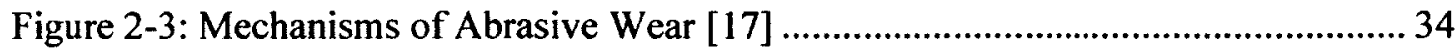

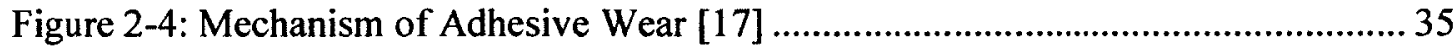

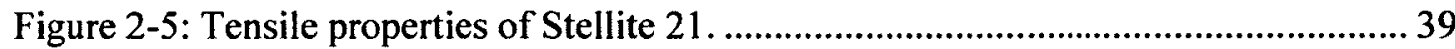

Figure 2-6: Work hardening behaviour of Stellite alloys and nickel-based alloy [18]..... 39

Figure 2-7: Room-temperature $0.2 \%$ yield strength versus percent cold work of Stellite alloys and nickel-based alloy [18].

Figure 2-8: Room-temperature tensile elongation versus percent cold work of Stellite alloys and nickel-based alloy [18].

Figure 2-9: Weight gain in thermal gravimetric analysis (TGA) of tested materials as a function of temperature [19].

Figure 2-10: Change in hardness of tested materials with increasing number of thermal fatigue cycle [19].

Figure 2-11: Corrosion resistance of Stellite alloys with varying $\mathrm{Ni}, \mathrm{Cu}$ and Mo contents: (a) at room temperature and (b) at $60^{\circ}$ in $28 \% \mathrm{P} 2 \mathrm{O} 4+13 \% \mathrm{H} 2 \mathrm{SO} 4+2 \% \mathrm{HF}$ [20] 46

Figure 2-12: Hot corrosion of Stellite alloys in $50 \mathrm{ppm}$ salt/0.4\% sulphur fuel medium. 47 Figure 2-13: Dry sliding wear map for Stellite 6 against a WC-Co 90/10 disc [12] ........ 49 Figure 2-14: Erosion test curves of Stellite alloys [7]. 51

Figure 2-15: Influence of yttrium additive on wear behavior of Stellite 6 at elevated temperatures [25] 
Figure 2-16: Effects of silicon additive on wear resistance of Stellite 6 at elevated

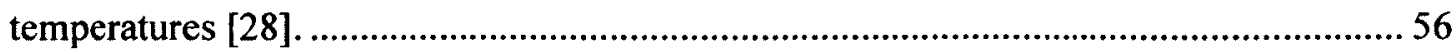

Figure 3-1: LaboPress-3 mounting press (Courtesy of Struers Co.)................................62 62

Figure 3-2: Buehler Ecomet-4 semiautomatic grinder polisher..................................63

Figure 3-3: Hitachi Model S-570 Scanning Electron Microscope (SEM) with energy

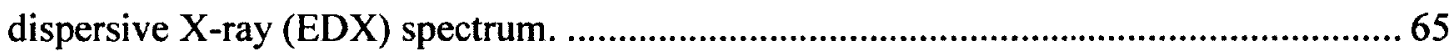

Figure 3-4: Philips XL30S FEG Scanning Electron microscope (SEM) with an EDAX

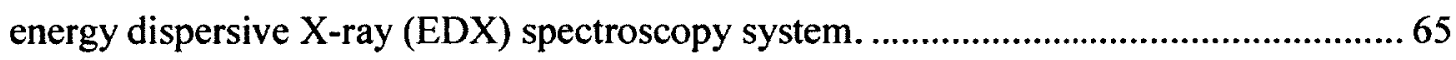

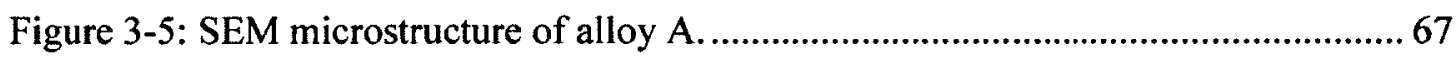

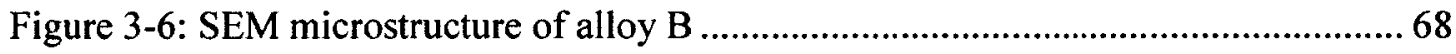

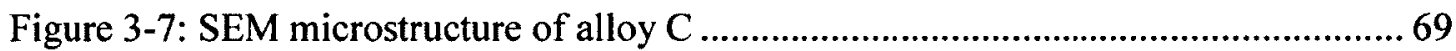

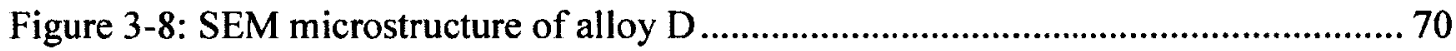

Figure 3-9: SEM images of microstructure of alloy E used for EDX analysis................ 73

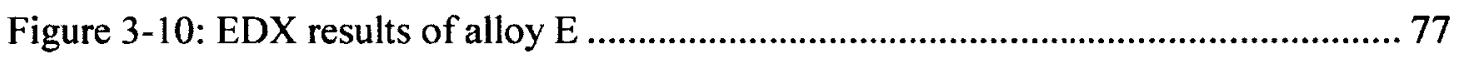

Figure 3-11: SEM images of microstructure of alloy $F$ used for EDX analysis.............. 79

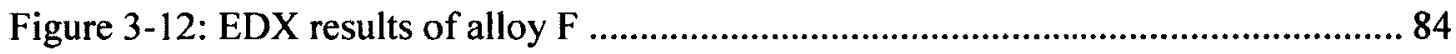

Figure 4-1: Microhardness Tester Unit, Model SMT-X7 Dual Indenter.......................... 89

Figure 4-2: An indentation made by a Vickers indenter. ............................................. 90

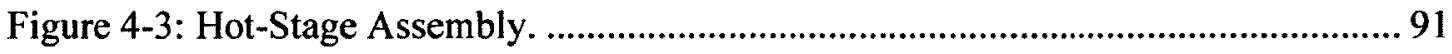

Figure 4-4: Microhardness Tester Unit equipped with a Hot-Stage Assembly ............... 91

Figure 4-5: Temperature control unit for the Hot-Stage Assembly............................... 92

Figure 4-6: Variations of hardness with temperature in heating/cooling cycle for alloy A:

(a) solid solution and (b) carbides/solution mixture. 97 
Figure 4-7: Variations of hardness with temperature in heating/cooling cycle for alloy B:

(a) solid solution and (b) carbide with minor solid solution. 98

Figure 4-8: Variations of hardness with temperature in heating/cooling cycle for alloy $\mathrm{C}$ :

(a) solid solution and (b) carbide with minor solid solution. 99

Figure 4-9: Variations of hardness with temperature in heating/cooling cycle for alloy D:

(a) solid solution and (b) carbides/solution mixture. 100

Figure 4-10: Variations of hardness with temperature in heating/cooling cycle for alloy $\mathrm{E}$ :

(a) $\mathrm{Cr}_{7} \mathrm{C}_{3}$ carbide and (b) solid solution/carbide mixture 101

Figure 4-11: Variations of hardness with temperature in heating/cooling cycle for alloy $\mathrm{F}$ :

(a) $(\mathrm{W}, \mathrm{Co})_{6} \mathrm{C}$ carbide and (b) solid solution/carbide mixture. 102

Figure 5-1: Pin-on-Disc Tribometer System. 109

Figure 5-2: Pin-on-Disc Tribometer System equipped with a heating furnace. 109

Figure 5-3: Wear tracks of alloy $A$

Figure 5-4: Wear tracks of alloy D

Figure 5-5: D150 Surface Profile Measuring System.

Figure 5-6: Schematic drawing for volume estimation of wear track.

Figure 5-7: Wear losses of Stellite alloys under the pin-on-disk wear tes 116

Figure 5-8: Comparison of wear loss variation with temperature among Stellite alloys. 118

Figure 5-9: Average friction coefficients. 120

Figure 5-10: SEM images of worn surface of alloy $A$ tested at room temperature 122

Figure 5-11: SEM images of worn surface of alloy B tested at room temperature 123

Figure 5-12: SEM images of worn surface of alloy $\mathrm{C}$ tested at room temperature 124

Figure 5-13: SEM images of worn surface of alloy D tested at room temperature 125 
Figure 5-14: SEM images of worn surface of alloy E tested at room temperature ....... 126

Figure 5-15: SEM images of worn surface of alloy $\mathrm{F}$ tested at room temperature......... 127

Figure 5-16: SEM images of worn surface of alloy $A$ tested at $250^{\circ} \mathrm{C} \ldots \ldots \ldots \ldots \ldots \ldots \ldots \ldots . . . \ldots 131$

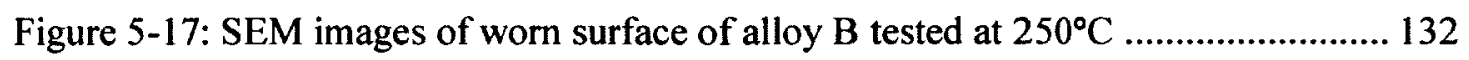

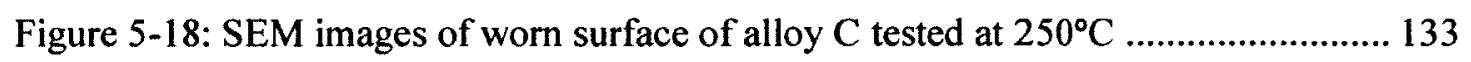

Figure 5-19: SEM images of worn surface of alloy $\mathrm{D}$ tested at $250^{\circ} \mathrm{C} \ldots \ldots \ldots \ldots \ldots \ldots \ldots \ldots . . . . . . . . . .134$

Figure 5-20: SEM images of worn surface of alloy $\mathrm{E}$ tested at $250^{\circ} \mathrm{C} \ldots \ldots \ldots \ldots \ldots \ldots \ldots \ldots . . . . . . . . . . .135$

Figure 5-21: SEM images of worn surface of alloy $\mathrm{F}$ tested at $250^{\circ} \mathrm{C} \ldots \ldots \ldots \ldots \ldots \ldots \ldots \ldots . . . . . . . . . . .136$

Figure 5-22: SEM images of worn surface of alloy A tested at $450^{\circ} \mathrm{C} \ldots \ldots \ldots \ldots \ldots \ldots \ldots . . . \ldots 138$

Figure 5-23: SEM images of worn surface of alloy $\mathrm{B}$ tested at $450^{\circ} \mathrm{C}$........................ 139

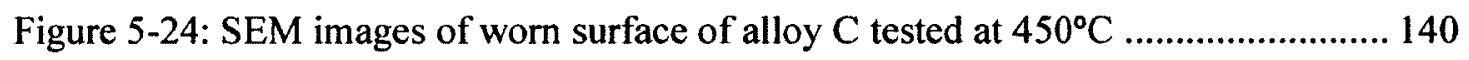

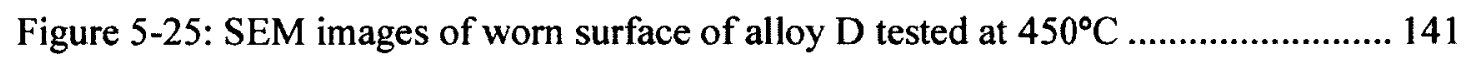

Figure 5-26: SEM images of worn surface of alloy E tested at $450^{\circ} \mathrm{C} \ldots \ldots \ldots \ldots \ldots \ldots \ldots . . . . . . . . . . . .142$

Figure 5-27: SEM images of worn surface of alloy $\mathrm{F}$ tested at $450^{\circ} \mathrm{C} \ldots \ldots \ldots \ldots \ldots \ldots \ldots \ldots . . . \ldots . \ldots . \ldots . . . .143$

Figure 6-1: Comparison of hardness between the carbides in Stellite alloys. ............... 146

Figure 6-2: Comparison of hardness between the solid solutions in Stellite alloys. ..... 147

Figure 6-3: Worn surface images showing cracks: (a) alloy $A$ and (b) alloy C. ........... 155

Figure 6-4: Cracks in the worn surface of alloy E specimen.................................... 157

Figure A-1: Microscopic images of indentation left in alloy A specimen tested at $20^{\circ} \mathrm{C}$

before heating: (a) solid solution and (b) carbides/solution mixture.......................... 162

Figure A-2: Microscopic images of indentation left in alloy A specimen tested at $250^{\circ} \mathrm{C}$

in heating cycle: (a) solid solution and (b) carbides/solution mixture......................... 162 
Figure A-3: Microscopic images of indentation left in alloy A specimen tested at $450^{\circ} \mathrm{C}$ in heating cycle: (a) solid solution and (b) carbides/solution mixture. 163

Figure A-4:Microscopic images of indentation left in alloy A specimen tested at $650^{\circ} \mathrm{C}$ in heating cycle: (a) solid solution and (b) carbides/solution mixture

Figure A-5: Microscopic images of indentation left in alloy A specimen tested at $450^{\circ} \mathrm{C}$

in cooling cycle: (a) solid solution and (b) carbides/solution mixture. 164

Figure A-6: Microscopic images of indentation left in alloy A specimen tested at $250^{\circ} \mathrm{C}$

in cooling cycle: (a) solid solution and (b) carbides/solution mixture.

Figure A-7: Microscopic images of indentation left in alloy A specimen tested at $20^{\circ} \mathrm{C}$

after heating/cooling: (a) solid solution and (b) carbides/solution mixture.

Figure A-8: Microscopic images of indentation left in alloy B specimen tested at $20^{\circ} \mathrm{C}$

before heating: (a) solid solution and (b) carbide with minor solid solution.

Figure A-9: Microscopic images of indentation left in alloy B specimen tested at $250^{\circ} \mathrm{C}$

in heating cycle: (a) solid solution and (b) carbide with minor solid solution. 166

Figure A-10: Microscopic images of indentation left in alloy B specimen tested at $450^{\circ} \mathrm{C}$

in heating cycle: (a) solid solution and (b) carbide with minor solid solution. 166

Figure A-11: Microscopic images of indentation left in alloy B specimen tested at $650^{\circ} \mathrm{C}$

in heating cycle: (a) solid solution and (b) carbide with minor solid solution.

Figure A-12: Microscopic images of indentation left in alloy B specimen tested at $450^{\circ} \mathrm{C}$

in cooling cycle: (a) solid solution and (b) carbide with minor solid solution.

Figure A-13: Microscopic images of indentation left in alloy B specimen tested at $250^{\circ} \mathrm{C}$

in cooling cycle: (a) solid solution and (b) carbide with minor solid solution. 168 
Figure A-14: Microscopic images of indentation left in alloy B specimen tested at $20^{\circ} \mathrm{C}$ after heating/cooling: (a) solid solution and (b) carbide with minor solid solution........ 168 Figure A-15: Microscopic images of indentation left in alloy $\mathrm{C}$ specimen tested at $20^{\circ} \mathrm{C}$ before heating: (a) solid solution and (b) carbide with minor solid solution. 169 Figure A-16: Microscopic images of indentation left in alloy $\mathrm{C}$ specimen tested at $250^{\circ} \mathrm{C}$ in heating cycle: (a) solid solution and (b) carbide with minor solid solution. 169 Figure A-17: Microscopic images of indentation left in alloy $\mathrm{C}$ specimen tested at $450^{\circ} \mathrm{C}$ in heating cycle: (a) solid solution and (b) carbide with minor solid solution. 170 Figure A-18: Microscopic images of indentation left in alloy $\mathrm{C}$ specimen tested at $650^{\circ} \mathrm{C}$ in heating cycle: (a) solid solution and (b) carbide with minor solid solution. 170 Figure A-19: Microscopic images of indentation left in alloy $\mathrm{C}$ specimen tested at $450^{\circ} \mathrm{C}$ in cooling cycle: (a) solid solution and (b) carbide with minor solid solution. 171 Figure A-20: Microscopic images of indentation left in alloy $\mathrm{C}$ specimen tested at $250^{\circ} \mathrm{C}$ in cooling cycle: (a) solid solution and (b) carbide with minor solid solution. 171 Figure A-21: Microscopic images of indentation left in alloy $\mathrm{C}$ specimen tested at $20^{\circ} \mathrm{C}$ after heating/cooling: (a) solid solution and (b) carbide with minor solid solution 172 Figure A-22: Microscopic images of indentation left in alloy D specimen tested at $20^{\circ} \mathrm{C}$ before heating: (a) solid solution and (b) carbides/solution mixture. 172 Figure A-23: Microscopic images of indentation left in alloy D specimen tested at $250^{\circ} \mathrm{C}$ in heating cycle: (a) solid solution and (b) carbides/solution mixture. 173 Figure A-24: Microscopic images of indentation left in alloy D specimen tested at $450^{\circ} \mathrm{C}$ in heating cycle: (a) solid solution and (b) carbides/solution mixture. 173 
Figure A-25: Microscopic images of indentation left in alloy D specimen tested at $650^{\circ} \mathrm{C}$ in heating cycle: (a) solid solution and (b) carbides/solution mixture. 174

Figure A-26: Microscopic images of indentation left in alloy D specimen tested at $450^{\circ} \mathrm{C}$ in cooling cycle: (a) solid solution and (b) carbides/solution mixture. 174

Figure A-27: Microscopic images of indentation left in alloy D specimen tested at $250^{\circ} \mathrm{C}$ in cooling cycle: (a) solid solution and (b) carbides/solution mixture. 175 Figure A-28: Microscopic images of indentation left in alloy D specimen tested at $20^{\circ} \mathrm{C}$ after heating/cooling: (a) solid solution and (b) carbides/solution mixture. 175

Figure A-29: Microscopic images of indentation left in alloy E specimen tested at $20^{\circ} \mathrm{C}$ before heating: (a) carbide and (b) solid solution/carbide mixture. 176 Figure A-30: Microscopical images of indentation left in alloy E specimen tested at $250^{\circ} \mathrm{C}$ in heating cycle: (a) carbide and (b) solid solution/carbide mixture.

Figure A-31: Microscopic images of indentation left in alloy E specimen tested at $450^{\circ} \mathrm{C}$ in heating cycle: (a) carbide and (b) solid solution/carbide mixture. 177

Figure A-32: Microscopic images of indentation left in alloy $\mathrm{E}$ specimen tested at $650^{\circ} \mathrm{C}$ in heating cycle: (a) carbide and (b) carbides/solution mixture 177 Figure A-33: Microscopic images of indentation left in alloy $\mathrm{E}$ specimen tested at $450^{\circ} \mathrm{C}$ in cooling cycle: (a) carbide and (b) solid solution/carbide mixture. 178 Figure A-34: Microscopic images of indentation left in alloy $\mathrm{E}$ specimen tested at $250^{\circ} \mathrm{C}$ in cooling cycle: (a) carbide and (b) solid solution/carbide mixture. 178 Figure A-35: Microscopic images of indentation left in alloy E specimen tested at $20^{\circ} \mathrm{C}$ after heating/cooling: (a) carbide and (b) solid solution/carbide mixture 179 
Figure A-36: Microscopic images of indentation left in alloy $\mathrm{F}$ specimen tested at $20^{\circ} \mathrm{C}$ before heating: (a) carbide and (b) solid solution/carbide mixture. 179 Figure A-37: Microscopic images of indentation left in alloy $\mathrm{F}$ specimen tested at $250^{\circ} \mathrm{C}$ in heating cycle: (a) carbide and (b) solid solution/carbide mixture. 180 Figure A-38: Microscopic images of indentation left in alloy $\mathrm{F}$ specimen tested at $450^{\circ} \mathrm{C}$ in heating cycle: (a) carbide and (b) solid solution/carbide mixture. 180 Figure A-39: Microscopic images of indentation left in alloy $\mathrm{F}$ specimen tested at $650^{\circ} \mathrm{C}$ in heating cycle: (a) carbide and (b) solid solution/carbide mixture. 181 Figure A-40: Microscopic images of indentation left in alloy $\mathrm{F}$ specimen tested at $450^{\circ} \mathrm{C}$ in cooling cycle: (a) carbide and (b) solid solution/carbide mixture. 181 Figure A-41: Microscopic images of indentation left in alloy $\mathrm{F}$ specimen tested at $250^{\circ} \mathrm{C}$ in cooling cycle: (a) carbide and (b) solid solution/carbide mixture.

Figure A-42: Microscopic images of indentation left in alloy $\mathrm{F}$ specimen tested at $20^{\circ} \mathrm{C}$ after heating/cooling: (a) carbide and (b) solid solution/carbide mixture. 182

Figure B-1: Cross section profiles of wear tracks in alloy A specimen tested.

Figure B-2: Cross section profiles of wear tracks in alloy B specimen tested

Figure B-3: Cross section profiles of wear tracks in alloy $\mathrm{C}$ specimen tested

Figure B-4: Cross section profiles of wear tracks in alloy D specimen tested 188

Figure B-5: Cross section profiles of wear tracks in alloy E specimen tested 190

Figure B-6: Cross section profiles of wear tracks in alloy F specimen tested. 191 


\section{List of Appendices}

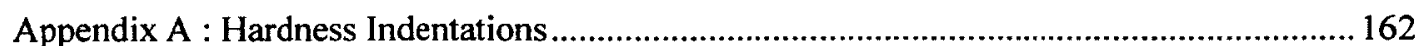

Appendix B : Wear Track Cross Section Profiles ................................................................. 183 


\section{Chapter: Introduction}

\subsection{Synopsis of Stellite Alloys}

\subsubsection{Fundamentals and features}

Stellite alloys are cobalt-based superalloys. They display a unique combination of mechanical and tribological properties such as high hardness and strength, superior adhesive and abrasive wear resistance and excellent cavitation-erosion resistance. They are designed for use in various industries, primarily for wear resistance applications involving unlubricated systems or elevated temperatures.

Stellite alloys are a range of cobalt-chromium alloys. They may also contain tungsten or molybdenum and a small ( $<3 \mathrm{wt} \%$ ) but important amount of carbon. Therefore Stellite alloys are generally strengthened by the precipitation of carbides in the cobalt solid solution matrix. Many of the properties of Stellite alloys arise from the crystallographic nature of cobalt, the solid-solution-strengthening effects of chromium, tungsten, and molybdenum, the formation of metal carbides, and the corrosion resistance imparted by chromium. The chief difference among the individual Stellite wear-resistant alloys is carbon content and, thus, carbide volume fraction in the materials. Stellite alloys can conventionally be categorized as medium-carbon alloys and high-carbon alloys designed for wear service; low-carbon alloys for high temperature service; and low-carbon alloys to combat corrosion or simultaneous corrosion and wear [1].

Chromium has a dual function in Stellite alloys. It is both the predominant carbide former, that is, most of the carbides are chromium rich, and the most important alloying element in the matrix, where it provides added strength, as a solute, and resistance to corrosion and oxidation. Tungsten and molybdenum in Stellite alloys serve to provide 
additional strength to the matrix. They do so by virtue of their large atomic size, that is, they impede dislocation flow when present as solute atoms. They also improve general corrosion resistance of the alloys. In addition, tungsten may participate in the formation of carbides when present in large quantities.

\subsubsection{Properties and applications}

The crucial characteristics of Stellite alloys include superior tribological properties; excellent mechanical strength; outstanding resistance to loading under static, fatigue, and creep conditions; good surface stability; excellent oxidation and corrosion resistance; and good phase stability at high temperatures. These properties can be controlled by processing (including heat treatment) and by adjustments in composition. In reality, Stellite alloys are either solid-solution-strengthened alloys or precipitation-hardened alloys. While the former are strengthened by solid solution hardening, the latter are strengthened by the combination of the formation of carbides, precipitation, and solid solution hardening $[1,2]$. Because of their quite high chromium content, Stellite alloys maintain good hot corrosion, sulfidation, and oxidation resistance at elevated temperatures [3]. Due to these properties, they are known to have high wear resistance, high hardness and high corrosion resistance, at both room temperature and elevated temperatures. These alloys can be used in various forms such as casting, weld overlays and powdered metallurgy (P/M). Stellite alloys are primarily used for wear resistance applications in corrosive environments and are valued for their ability to operate in a range of elevated temperatures beyond the ability of conventional materials, such as steels. 
Stellite alloys are employed in a wide range of industries, such as aerospace, nuclear, mining, oil and gas, and automotive industries [4]. Within these industries, they are utilized in harsh conditions that involve elevated temperatures, severe wear and corrosive environments or any combination of these. For instance, Stellite alloys are used in the aerospace industry within gas turbine engines [5]. A variety of degradation problems exist in aircraft gas turbine engines as a result of metal-to-metal wear, fretting, hot corrosion, and particle erosion. This degradation is accelerated due to the high-temperature conditions involved and failure of such critical equipment can be catastrophic. In this case, Stellite alloy is the best option. Another case of Stellite alloy use involves machining tools, where conventional materials would result in decreased service life compared to the Stellite alloy equivalents. Stellite alloys have proven to be beneficial in the aforementioned industries. As the use of Stellite alloys become more prominent, their applications will expand into more industries.

\subsection{Present Research}

\subsubsection{Significance and objectives}

In many applications, Stellite alloys are required to bear high stress and to combat severe corrosion and wear attack at high temperatures, such as in gas turbine engines, oil production and refining, and mechanical manufacturing, and so on. Metallic materials lose their mechanical strength at high temperatures because of increased mobility of dislocations; hence the performance and properties of a material characterized at room temperature do not represent its ability at elevated temperatures. Therefore it is necessary to characterize the high-temperature properties of Stellite alloys. Due to the limitation of 
testing facilities/methodologies and the complexity of analytical methods, the studies on high temperature behavior of Stellite alloys have not been sufficiently conducted, and few are reported in the literature. This significantly limits the applications of these materials.

Previous research, as reported in the literature regarding the high-temperature properties of Stellite alloys, did not address some of the key issues: (1) The effects of constituents in the chemical composition of Stellite alloys on their high-temperature properties are important for optimization of alloy composition for high-temperature applications, but they were not systematically investigated. (2) Hardness is considered as an important material property for Stellite alloys because it is often used to correlate with wear resistance of materials. Stellite alloys are multi-phase alloys, but the hardness of individual phases of Stellite alloys was not investigated. Without this data, material engineers cannot design the compositions of Stellite alloys with respect to the influence of alloying elements on the overall hardness of Stellite alloys. (3) Although it is well known that hardness plays an important role in wear resistance of Stellite alloys, there is not enough data to ascertain the correlation of hardness and wear resistance at high temperatures. Particularly, the temperature-dependence variations of these critical properties are not understood.

The lack of knowledge in these aspects is significantly limiting Stellite alloys' usage and application. It is more prevalent as applications in increased severe environments push engineered materials to their limits, therefore a better understanding of these relationships involving chemical composition, microstructure, hardness, wear, 
and temperature for Stellite alloys is crucially required, and hence it is the emphasis of this research.

The present research was aimed to investigate the high-temperature hardness and wear resistance of Stellite alloys, with a focus on the effects of chemical composition on their microstructures and such properties. The variations of hardness and wear resistance with temperature were determined, and the correlation between these two properties was studied for both room temperature and elevated temperatures. The research results are not only beneficial for extending the application of existing Stellite alloys but also provide the scientific guidance for designing new Stellite alloys to be used in high-temperature wear-resistance conditions.

\subsubsection{Tasks and methodologies}

A group of Stellite alloys in cast state, with a wide range of chemical compositions in its family, were selected in this study. These alloys contain various levels of carbon and hence are classified as low- $(<0.5 \mathrm{wt} \%)$, medium- $(0.5 \sim 1 \mathrm{wt} \%)$, and high-carbon $(1 \sim 3 \mathrm{wt} \%)$ Stellite alloys, respectively. They contain the main solid-solution-strengthening element, tungsten, varying from zero up to $30 \mathrm{wt} \%$, and molybdenum, varying from zero up to $5.5 \mathrm{wt} \%$. As the main agent of carbide formation, chromium varies between $22 \sim 33.5 \mathrm{wt} \%$ in these Stellite alloys.

The microstructures of these alloys were analyzed utilizing a Hitachi Model S-570 Scanning Electron Microscope (SEM) with backscatter electron imaging (BEI) and energy dispersive X-ray (EDX) spectrum, a Philips XL30S FEG scanning electron 
microscope (SEM) with an EDAX energy dispersive X-ray (EDX) spectroscopy system. Each phase in the microstructures was identified.

The hardness of individual phases (cobalt solid solution, carbides, mixture of cobalt solid solution and carbides) for each alloy at both room temperature and elevated temperatures up to $650^{\circ} \mathrm{C}$ was determined using a Microhardness Tester Unit, Model SMT-X7 Dual Indenter, which enabled the hardness measurement made on individual (single) phases of the material. A Hot-Stage Assembly was attached to the platform of the Microhardness Tester Unit to achieve the temperature capacity of $650^{\circ} \mathrm{C}$ for the hot hardness test, with a cooling system equipped to maintain the unheated platform for operation. The indentation hardness test for each specimen was conducted at room temperature, $250^{\circ} \mathrm{C}, 450^{\circ} \mathrm{C}$ and $650^{\circ} \mathrm{C}$, respectively, in a heating phase, and then for the same specimen, the indentation was continuously made at $450^{\circ} \mathrm{C}, 250^{\circ} \mathrm{C}$ and room temperature, respectively, in a cooling phase. The test through this temperature cycle could allow for exploring any impact of thermal cycle on the hardness of these materials by comparing the hardness value tested at the temperature in the heating phase with that tested at the same temperature but in the cooling phase.

The wear resistance of each alloy was evaluated at both room temperature and elevated temperatures up to $450^{\circ} \mathrm{C}$ according to the sliding wear test using a pin-on-disc tribometer with a heating furnace equipped. The friction coefficients of each alloy specimen were determined automatically during the sliding wear tests, with the assistance of a software control unit that allowed for dynamically monitoring both the normal and friction (tangential) forces thus computing the friction coefficient in real-time. The wear loss of each alloy specimen was calculated based on the cross-sectional area and the 
periphery of the wear track left in the worn surface after the wear test. The cross-sectional area of each wear track was estimated by taking the average of four measurements uniformly located along the wear track, utilizing a D150 Surface Profile Measuring System. The tribological behavior and wear mechanism of these alloys at room temperature and at elevated temperatures were studied, incorporating with the analyses of worn surfaces, with emphasis on temperature influence on their wear resistance.

Based on the experimental results, the following relationships were discussed:

(1) Microstructure versus chemical composition

(2) Hardness of cobalt solid solution versus chemical composition

(3) Hardness of cobalt solid solution versus temperature

(4) Hardness of carbides versus temperature

(5) Wear resistance versus chemical composition

(6) Friction coefficient versus chemical composition

(7) Friction coefficient versus temperature

(8) Wear resistance versus temperature

(9) Wear resistance versus hardness

(10) Temperature dependence of relationship between wear resistance and hardness

\subsection{Organization of the Thesis}

This thesis is a comprehensive report of the present research. It consists of seven chapters that cover the introduction of this research; literature review in the area related to this research; microstructural analysis, hardness and wear tests, of the selected Stellite 
alloys; discussion on the relationships between chemical composition, microstructure, hardness, wear resistance and temperature, as well the conclusions drawn from this research and the future work as expected. The details of the thesis structure are described below:

Chapter 1 is an introduction to the present research. In this chapter, the fundamentals, features, properties and applications of Stellite alloys, are briefly introduced; the significance and objectives of the present research are stated; and the tasks and methodologies of this research are described.

Chapter 2 is the literature review, which summarizes information about Stellite alloys, including chemical composition, classification, microstructure, features, and various properties, and previous research on these alloys with regards to the following aspects: mechanical properties, corrosion and erosion resistance, wear behaviour, etc.

Chapter 3 is the microstructural analysis. In this chapter, the selection of Stellite alloys for this research is explained; the detailed chemical compositions of each selected alloys are provided; the facilities and procedures for microstructural analysis of these alloys are described; and the results are discussed.

Chapter 4 is the description of the hardness investigation. The significance and objectives of this experiment are addressed. The laboratory tools of indentation test utilized for this investigation are introduced. The details of the experimental procedure and parameters are described. The obtained experimental data are analysed. The hardness variations of constituent phases of the selected alloys against temperature are studied and discussed. 
Chapter 5 is the description of the wear resistance evaluation. The experimental details of the pin-on-disc wear test are described, including the apparatus, test parameters and procedure. The method for wear loss calculation with the assistance of a surface profile measuring system is detailed. The wear resistance between the alloys at room temperature and at elevated temperatures is compared. The temperature effects on the wear resistance of the alloys are analyzed. The wear mechanisms of Stellite alloys at room temperature and at elevated temperatures are explored, incorporating with the worn surface analyses using SEM.

Chapter 6 is the discussion on the results and correlations. This chapter can be considered as an integration of all the experimental results. The correlations between chemical composition, microstructure, hardness and wear resistance, of Stellite alloys, are analyzed. Temperature dependence of these properties and their correlations are discussed.

Chapter 7 concludes the present study and proposes the future work. The experimental results of this research are summarized, the conclusions drawn from these results and the discussion are provided. The expected work that will provide further understanding of the high-temperature behaviour and performance of Stellite alloys are proposed. 


\section{Chapter: Literature Review}

\subsection{Wear of Materials}

\subsubsection{Mechanical components in wear environments}

Mechanical components often operate in wear, corrosive and high temperature environments where conventional materials would fail or cause frequent replacement. Typical application fields involving these environments include aerospace, automotive, oil production and oil refinery, chemical, nuclear, mining, and manufacturing industries. An example of mechanical components operating in such environments can be witnessed in aerospace industry, where a variety of degradation problems occur in aircraft gas turbine engines as a result of metal to metal wear, fretting, hot corrosion and particle erosion [5]. This kind of degradation is accelerated under high temperature conditions and failure of such critical equipment can be catastrophic. Another example is relevant to the automotive industry, where engines have intricate moving parts that subject these internal parts to wear and high temperatures from the combustion of fuels [6]. Failure of these parts can cause the loss of service life and reduce engine efficiencies. In the oil production and refining industry, mining and nuclear industry, the pumping of slurries and hydraulic fluids containing emulsions can wreck conventional impellers, pumps, valves, casings, etc., due to wear and corrosion attacks [7]. The failure of any of the equipment can have disastrous effects on the entire hydraulic system, and consequently can potentially impact the environment, surrounding workers, and have hefty economic loss. Finally, in the machining industry the manufacturing of products is affected by the equipment and materials used. For example, in machining operations cutting involves wear through the sliding between the cutting tool and the workpart, in particular, this 
operation also involves temperature because of friction heat, which can expedite the wear of the cutting tool. Also, in machinery, wear commonly occurs on moving parts such as bearings, gears, crankshafts, joints, brakes, etc. [8]. Of course, in some cases, for example, bearing and brake applications, materials are intentionally wear-sacrificial.

\subsubsection{Materials developed for wear resistance}

Various materials have been developed for coping with wear, in order to extend the service life of mechanical components, and to maximize the efficiencies of the machines and engines containing the mechanical components. Superalloys, owing to their unique combinations of mechanical, tribological, corrosion, and high temperatures properties, make them ideal for wear-resistant applications involving unlubricated systems or elevated temperatures. While no one material can excel in all these properties

over a wide range of temperature, particular operating ranges can be achieved by processing (including heat treatment) and by adjustments in composition of superalloys. These alloys are either solid solution strengthened alloys or precipitation hardened alloys. The former are strengthened by solid solution hardening, and the latter are strengthened by the combination of precipitates, solid solution hardening, and the presence of carbides or Laves phase [1]. Superalloys can be categorized and divided into three main classes: iron-based, nickel-based, and cobalt-based.

In many industries, to reduce life cycle/maintenance costs, the reliance on superalloys is increasing. In the manufacturing industry, cutting tools and the mechanical components operating in wear environments that are made of hardened steel traditionally can be substituted with superalloys to extend service lives while reducing maintenance 
and downtime. The development, use and reliance of superalloys, can have a major impact on any number of critical industries $[8,9]$.

\subsection{Stellite Alloys}

\subsubsection{Chemical compositions and microstructures}

Stellite alloys are a group of cobalt-based superalloys designed for wear resistance applications. It contains chromium and may also contain tungsten or molybdenum and a small amount of carbon. It was invented by Elwood Haynes in the early 1900 s and later became a trademark name of the Deloro Stellite Company. Initially, the stainless nature and high strength of the binary cobalt-chromium alloys were discovered by him. Later, he introduced the $\mathrm{Co}-\mathrm{Cr}-\mathrm{Mo}$ and $\mathrm{Co}-\mathrm{Cr}-\mathrm{W}$ ternaries as he discovered the powerful strengthening effects of molybdenum and tungsten within the cobalt-chromium system. Because of their star-like luster, the alloys were named Stellite after the Latin word, stella, for star. The name is a trademark of the Deloro Stellite Company now. During World War I, Stellite alloys were used as cutting tool materials because of their high strength at elevated temperatures. Later, from about 1922 cobaltbased alloys were promoted in weld overlay form to protect surfaces from wear. To satisfy the need for suitable high-temperature corrosion resistant application materials, cobalt-base corrosion resistant alloys were developed in the 1930s and early 1940s [1]. The biocompatible, low-carbon content cobalt-base alloys have also been used lately as dental materials and surgical implants.

There are a large number of Stellite alloys consisting of various amounts of cobalt, chromium, tungsten, molybdenum, nickel, iron, aluminum, boron, carbon, 
manganese, phosphorus, sulphur, silicon, and titanium, in various proportions, most alloys containing four to six of these elements. The main differences in Stellite alloy grades are carbon and tungsten contents, which dictate the amount and type of carbide formation in the microstructure during solidification [1]. Many of the commercial Stellite alloys today are little changed from those that were derived from the $\mathrm{Co}-\mathrm{Cr}-\mathrm{W}$ and Co-Cr-Mo combinations discovered by Elwood Haynes. Through subsequent modification and application for various uses, these materials have been found to have additional useful qualities [2]. They are corrosion resistant, heat resistant and wear resistant with optimized compositions for these specific environments.

The chemical compositions and microstructures of Stellite alloys are the basis for understanding and predicting the mechanical behaviour and tribological properties of the materials. The carbon content in Stellite alloys is responsible for the microstructure and the type of carbides formed in these materials, which are the key strengthener of Stellite alloys for wear resistance. For example, at a carbon level of $2.4 \mathrm{wt} \%$ (for Stellite 3), the carbides constitute about $30 \mathrm{wt} \%$ of the material. These carbides are of the $\mathrm{M}_{7} \mathrm{C}_{3}$ (Chromium-rich primary) and $\mathrm{M}_{6} \mathrm{C}$ (tungsten-rich eutectic) types, where $\mathrm{M}$ represents the metal components. At a carbon content of $1 \mathrm{wt} \%$ (for Stellite $6 \mathrm{~B}$ ), the carbides constitute approximately $13 \mathrm{wt} \%$ of the material; they are predominantly chromium-rich eutectic carbides of the $\mathrm{M}_{7} \mathrm{C}_{3}$ type [1]. Stellite alloys can conventionally be categorized as high-carbon (1-3 wt\%) alloys designed for wear service; low-carbon $(<0.5 \mathrm{wt} \%)$ alloys for high temperature service $\left(>500^{\circ} \mathrm{C}\right)$; and low-carbon $(<0.25 \mathrm{wt} \%)$ alloys to combat corrosion or simultaneous corrosion and wear. For carbon contents lower than $2 \mathrm{wt} \%$, these alloys are hypo-eutectic with primary face-centred cubic (fcc) cobalt dendrites 
surrounded by a network of eutectic $\mathrm{M}_{7} \mathrm{C}_{3}$ carbides, as shown in Figure 2-1. For carbon contents higher than $2.5 \mathrm{wt} \%$, they are hyper-eutectic and consist of primary $\mathrm{M}_{7} \mathrm{C}_{3}$ carbides in an interdendritic eutectic matrix with solid solution and carbides [10], as shown in Figure 2-2. Other carbides formed in hypereutectic Stellite alloys include tungsten-rich $\mathrm{M}_{6} \mathrm{C}$ and $\mathrm{MC}$, and chromium-rich $\mathrm{M}_{23} \mathrm{C}_{6}$. The alloys with very low carbon content (about $0.1 \mathrm{wt} \%$ ) are known as solid-solution strengthened alloys.

Cobalt imparts to its alloys an unstable fec crystal structure with a very low stacking fault energy (SFE). The instability arises from the fact that elemental cobalt, if cooled extremely slowly, transforms from an fcc to a hexagonal close-packed (hcp) crystal structure at $417^{\circ} \mathrm{C}$. Because of the sluggish nature of the transformation, the fcc structure of cobalt and its alloys is usually retained at room temperature, and hcp formation is triggered only by mechanical stress or time at elevated temperatures. The unstable fec structure and its associated low SFE are believed to result in high yield strength, high work-hardening rate due to the interaction between stacking faults, less susceptible to fatigue under cyclic stress due to the lack of cell walls within the plastically deformed zones, the ability to relax stress through transformation of the structure to hcp. The first three of these attributes are believed to be important in preventing material damage during sliding wear. The last two are believed to be responsible for the outstanding resistance to cavitation and erosion-corrosion of Stellite alloys $[2,3]$. While cobalt is a major source for the properties of Stellite alloys, there are additional properties gained from other alloying elements. 


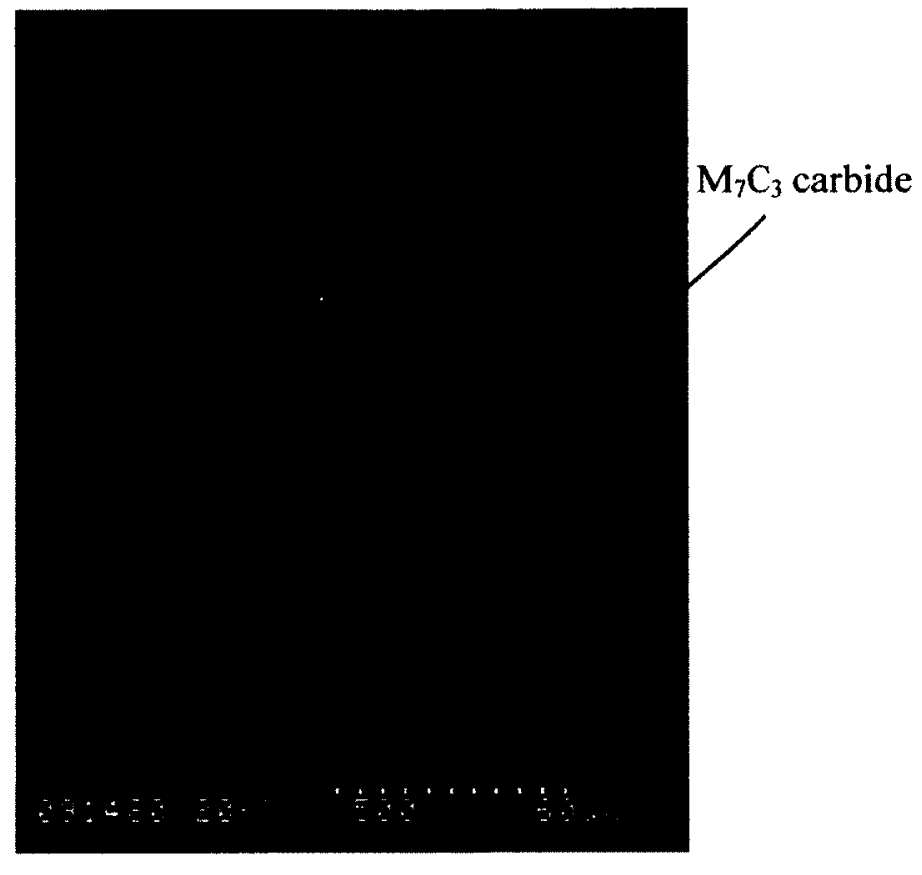

Figure 2-1: Microstructure of Stellite $6(1.2 \mathrm{wt} \% \mathrm{C})$ - a hypo-eutectic microstructure.

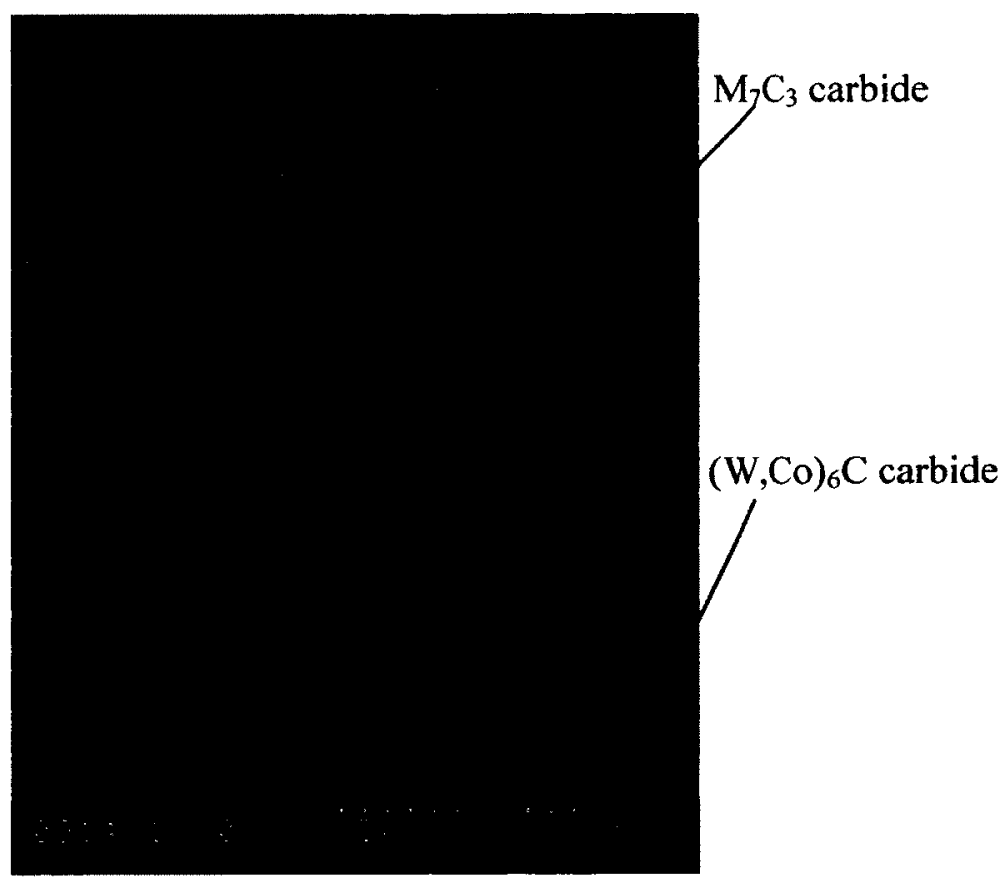

Figure 2-2: Microstructure of Stellite $3(2.4 \mathrm{wt} \% \mathrm{C})$ - a hyper-eutectic microstructure. 
Addition of Chromium, usually between $20 \sim 30 \mathrm{wt} \%$ [11], is known to be highly resistant to corrosion [12] and erosion [7]. Chromium has a dual function in Stellite alloys. It is firstly, the predominant carbide former, through the formation of Metal carbides $\mathrm{M}_{7} \mathrm{C}_{3}$ and $\mathrm{M}_{23} \mathrm{C}_{6}$ [13]. The most common carbide in Stellite alloys is of chromium-rich $\mathrm{M}_{7} \mathrm{C}_{3}$ type, although chromium-rich $\mathrm{M}_{23} \mathrm{C}_{6}$ carbides are also abundant in low-carbon alloys. Secondly, it is the most important alloying element in the matrix, where it provides added strength, as a solute, and resistance to corrosion and oxidation. Chromium imparts favourable characteristics to the alloys. The addition of chromium (about $15 \sim 30 \mathrm{wt} \%$ ) improves oxidation resistance and corrosion resistance to oxidizing solutions. Common alloying elements of Stellite alloys also include Mo and W. These elements have similar effects on Stellite alloys. The effects of Mo (up to $28 \mathrm{wt} \%$ ) and W (between $4 \sim 17 \mathrm{wt} \%$ ) are known to contribute to the solid-solution hardening [12] and also add to the strength of the material by forming primarily $\mathrm{M}_{6} \mathrm{C}$ carbides along with MC carbides and inter-metallic phases, such as $\mathrm{Co}_{3}(\mathrm{Mo}, \mathrm{W})[13,14]$, but most of the W remains in the cobalt solid solution [15]. The addition of molybdenum also significantly improves resistance to non-oxidizing acids $[1,3]$. W and Mo add strength due to their large atomic sizes which impede dislocations and slips. The effect of Mo by comparable weight percentage to $\mathrm{W}$ results in double the atomic concentration of Mo because the atomic mass of Mo $(94.94 \mathrm{~g})$ is half that of $\mathrm{W}(183.84 \mathrm{~g})$ [11]. However, it is important to note that both Mo and $\mathrm{W}$ have high coefficients of friction, and due to this, $\mathrm{W}$ and Mo are generally not suitable for sliding applications in their pure forms [3], but as alloying elements their contributions can add strength to Stellite alloys. 
There are a large number of Stellite alloys composed of various amounts of other alloying elements such as nickel, iron, aluminum, boron, carbon, manganese, phosphorus, sulphur, silicon, and titanium. These alloying elements are in various proportions, with most alloys containing four to six of these elements. For instance, additions of alloying elements of $\mathrm{Ni}, \mathrm{Cu}$ or $\mathrm{Fe}$ promote the stability of the fcc structure, however, they increase the SFE of Co-rich matrix, which is stable at high temperatures up to its melting point of $1495^{\circ} \mathrm{C}(1768 \mathrm{~K})$. On the contrary, $\mathrm{Cr}$, Mo and $\mathrm{W}$ offer stability at low-temperatures with hcp structures decreasing the SFE [14]. These two groups of elements are key in managing the SFE of Stellite alloys as an increase in the SFE results in a greater tendency for cross-slip of dislocations to occur on $\{111\}$ planes and poor erosion resistance [7].

\subsubsection{Hardness and tribological properties}

Most of Stellite alloys (low-carbon Stellite alloys excluded) possess very high hardness, between HRC $40 \sim$ HRC 63 , as they contain a high proportion of hard, wear-resistant carbides along with a hard solid-solution interface, which make them very suitable working in wear conditions. Stellite alloys retain their hardness at temperatures in excess of $760^{\circ} \mathrm{C}$.

Wear, in general, can be defined as the interaction between surfaces resulting in the removal of material. Wear can act in a number of modes, but three main types of wear include abrasive wear, adhesive wear and erosive wear which categorize the field of tribology $[16,17]$. 
Abrasive wear is encountered when hard particles, or hard projections, are forced against, and move relative to, a surface. The abrasive resistance of the Stellite alloys which contain a hard phase, generally increases as the volume fraction of the hard phase increases. Abrasion resistance is, however, strongly influenced by the size and shape of the hard phase precipitates within the microstructure, and the size and shape of the relative particle. As shown in Figure 2-3, there are three main abrasive wear mechanisms: microploughing, microcutting and microcracking. Microploughing occurs when the hard phase ploughs into the material and a fraction of the material is ploughed to the edges but not lost. Microcutting takes this a step further and the grove formed is equal to the material lost. Further, microcracking occurs when the grooved material causes cracks beneath and at the material surface in a volume larger than the affected grove. These abrasive wear mechanisms can occur simultaneously $[16,17]$.

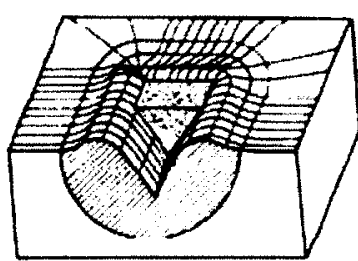

Microploughing

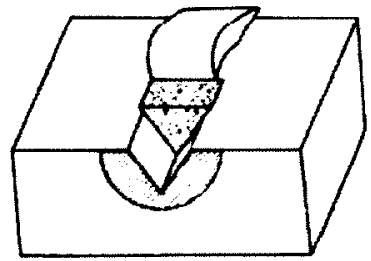

Microcutting

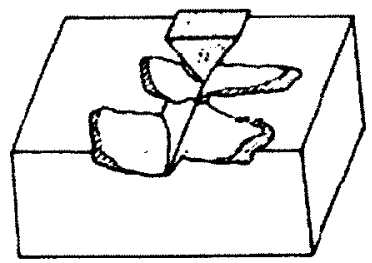

Microcracking

Figure 2-3: Mechanisms of Abrasive Wear [17]

Adhesive wear generally occurs by three mechanisms: oxide control, contact stress, subsurface deformation and fatigue. Therefore, the Stellite alloys which perform well under sliding conditions do so either by virtue of their oxidation behavior or their ability to resist deformation and fracture. Examples of the adhesive wear mechanisms are shown in Figure 2-4, depicting adhesive wear through friction of the asperities and 
deformation in the intermediate layer between the two surfaces, as well as, the formation of an oxide film $[16,17]$.
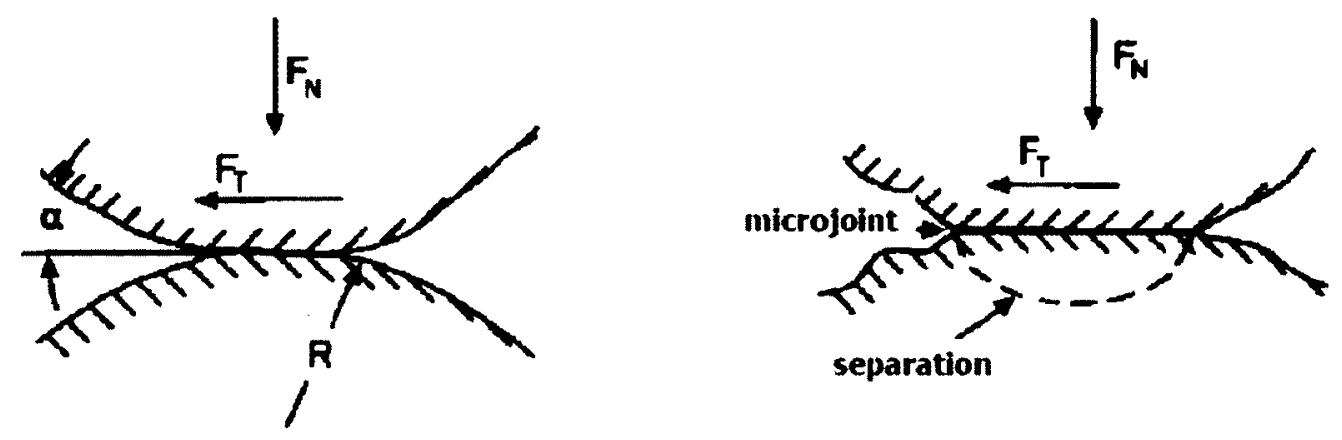

(a)

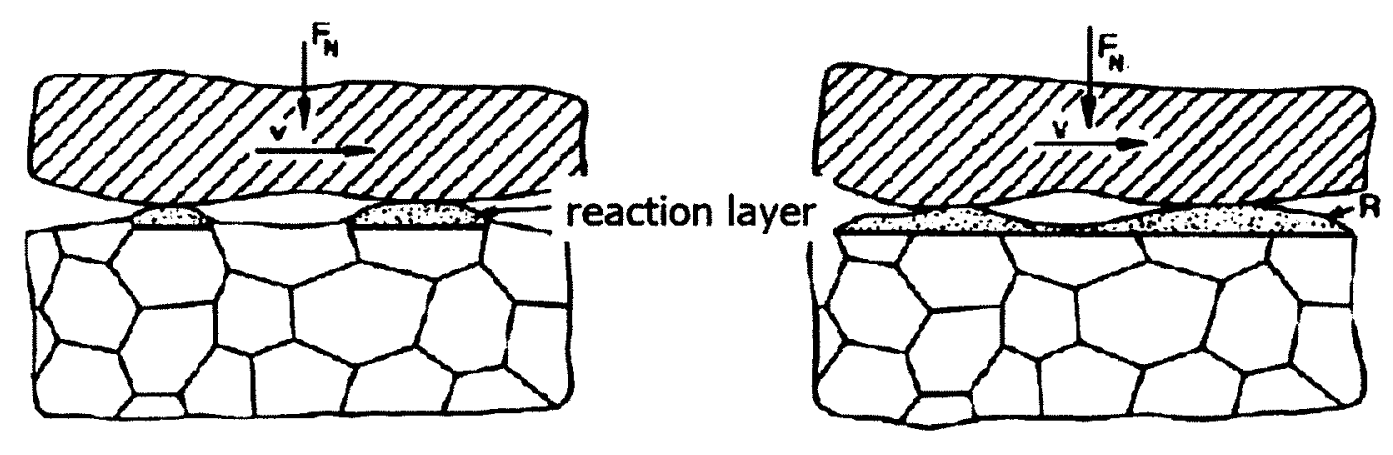

(b)

Figure 2-4: Mechanism of Adhesive Wear: (a) deformation of asperities and (b) deformation of an oxide film [17]

Erosion wear can be classified into solid-particle erosion, slurry erosion or liquid-solid particle erosion, liquid-droplet erosion and cavitation erosion. The first two types of erosion are caused by the impingement of small, solid particles against a surface. With the complex mechanisms of the erosions, however, the general abrasion mechanism 
may not be warranted. For example, in solid-particle erosion, ductility of Stellite alloys can also be a factor. As for the last two types of erosion, the performance of Stellite alloys largely depends on their ability to absorb the shock (stress) waves without, essentially, microscopic fracture. The carbide volume fraction, hence bulk hardness, has very little effect on resistance to these erosions $[16,17]$.

The importance of these wear mechanisms is that they can occur simultaneously, resulting in severe operating conditions. Stellite alloys can sustain these types of abrasion due to primarily their solid-solution or carbide hardness.

\subsubsection{Mechanical properties}

Stellite alloys possess high Young's modulus and tensile strength, but, in general, low elongation due to the nature of their microstructures. The presence of the large amount of carbides renders these alloys very brittle, but low-carbon Stellite alloys, that is, solution-strengthened Stellite alloys, have better ductility. The requirements of high mechanical strength for Stellite alloys are principally assessed by measurements of short-time tensile properties, creep deformation or stress-rupture properties - the material is subjected to a steadily maintained stress at a constant temperature, and the rate of deformation is monitored continuously over periods of thousands of hours, or the time to fracture determined. The strengthening of Stellite alloys is provided in part by solid-solution strengthening of the matrix, and in part by precipitation of carbides. The morphology and location of the carbide precipitates influence the strengthening effect and, for the optimum improvement, precipitation both at grain boundaries and within the grains is required. At the grain boundaries the precipitates prevent gross sliding and 
migration of the boundaries, and when present in sufficient quantities may form a skeletal network which can, to an extent, support some of the imposed stress. Intragranular precipitation strengthens the matrix by providing obstacles to the movement of dislocations and thus inhibiting crystallographic slip [1]. The distribution of the carbides is determined in any alloy initially by the solidification conditions - the pouring temperature of the melt and the cooling rate both during and after solidification.

The short-time tensile properties of Stellite alloys can be relevant to the manufacturing operations involved in producing components - the ductility in particular controls the amount of hot or cold working that can be imposed. The properties depend to a large extent on the form and thermal history of the material, as shown for Stellite 21 in Figure 2-5 [2]. In the as-cast condition the tensile elongation is about $8 \%$ at room temperature and rises fairly steadily with increasing the temperature. After the alloy was aged for 50 hours at $732^{\circ} \mathrm{C}$, however, hardening by carbide precipitation reduced the room-temperature elongation to $1 \sim 2 \%$, and recovery of the ductility only occurred at temperatures above the aging temperature. Wrought alloys generally have much higher tensile elongation than cast alloys. The high ductility makes them particularly suitable for the manufacturing of sheet metal components by either hot or cold forming.

Stellite alloys exhibit rapid hardening with respect to cold work when their compositions are not fully stabilized relative to fcc $\rightarrow$ hcp transformation [18]. This behaviour is illustrated for the solid-solution strengthened alloys (low-carbon Stellite alloys) - Stellite $25(0.1 \% \mathrm{C}$ and $10 \% \mathrm{Ni}$ in weight $)$ and Stellite $188(0.1 \% \mathrm{C}$ and $22 \% \mathrm{Ni}$ in weight) in Figure 2-6, which includes the data for nickel-based alloy Nistelle 625 $(0.1 \% \mathrm{C}, 21.5 \% \mathrm{Cr}, 9 \% \mathrm{Mo})$ for comparison. In contrast, the hardening characteristics of 
Stellite 188 , which is fully stabilized due to the high Ni content, are very similar to those of nickel-based Nistelle 625. As one would expect, the hardening response are reflected in the corresponding yield strength values obtained, as shown in Figure 2-7. Surprisingly, however, the residual levels of ductility observed for the Stellite alloys tended to be higher than those of the nickel-based alloy, as illustrated in Figure 2-8. These data clearly indicate that metastable cobalt-based compositions require higher levels of force during forming operations. Stable compositions, on the other hand, should have forming characteristics similar to nickel-based alloys. Stellite 6 exhibited better thermal fatigue properties than hot work tool steel X32CrMoV33 [19]. It was found to be much more resistant to oxidation and temper softening, as shown in Figure 2-9 and Figure 2-10, respectively, providing a superior resistance to thermal fatigue cracking with few and relatively shallow cracks after as many as $\mathbf{5 0 0 0}$ thermal cycles.

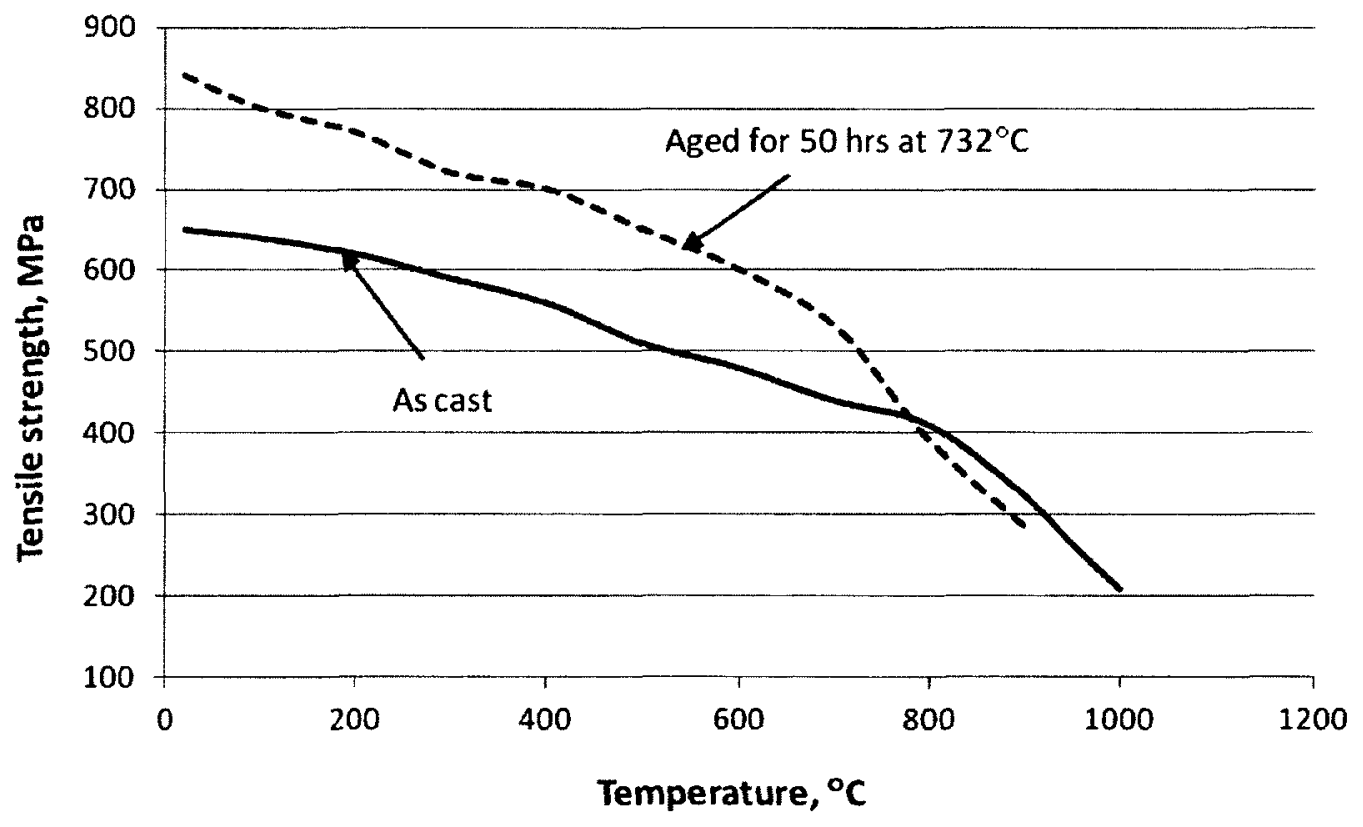

(a) 


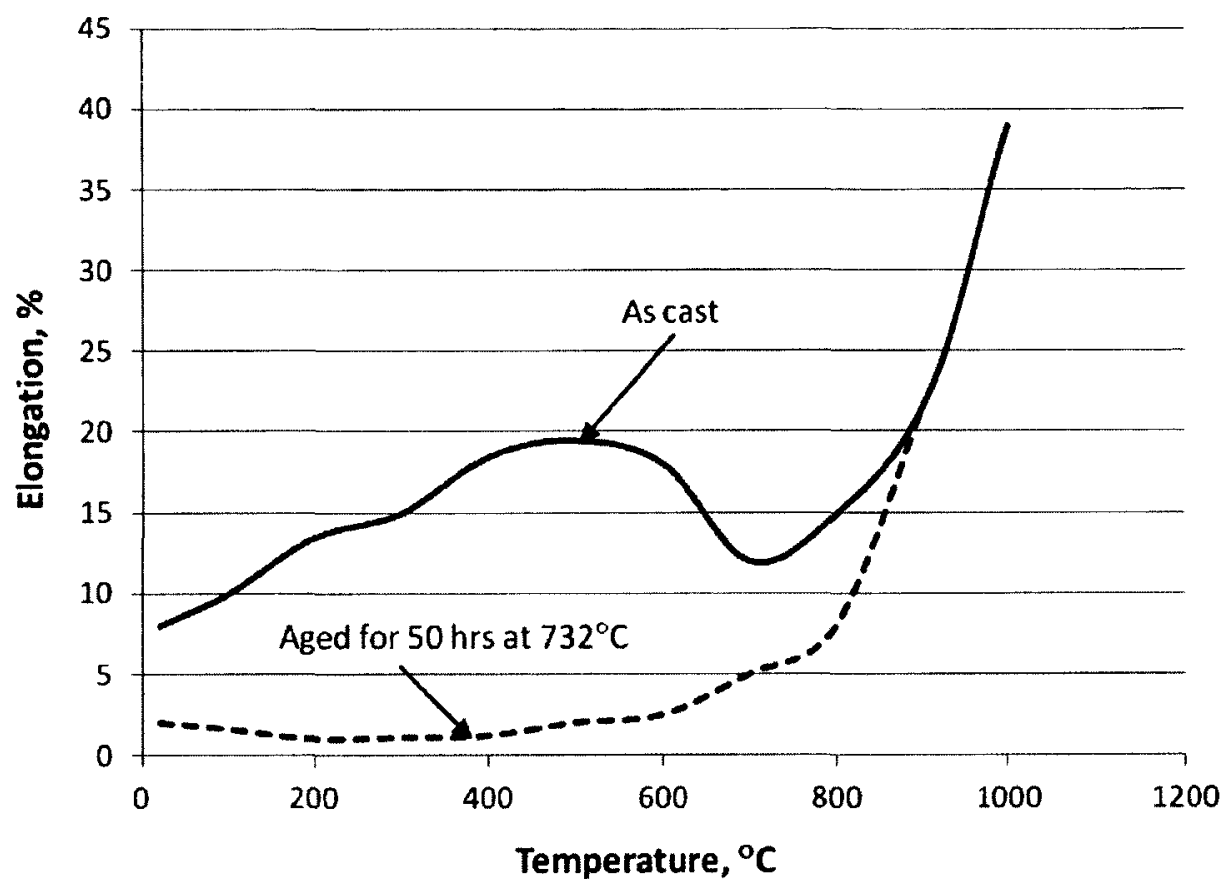

(b)

Figure 2-5: Tensile properties of Stellite 21: (a) tensile strength and (b) elongation [2].

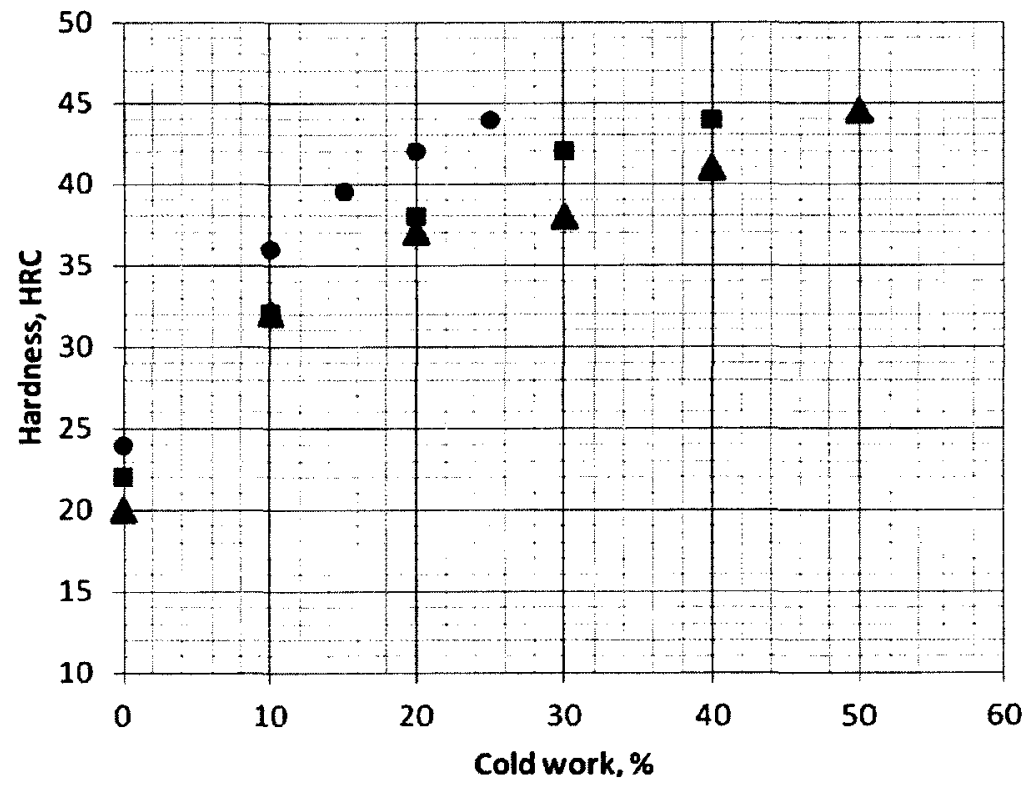

- Stellite 25

- Stellite 188

A Nistelle 625

Figure 2-6: Work hardening behaviour of Stellite alloys and nickel-based alloy [18]. 


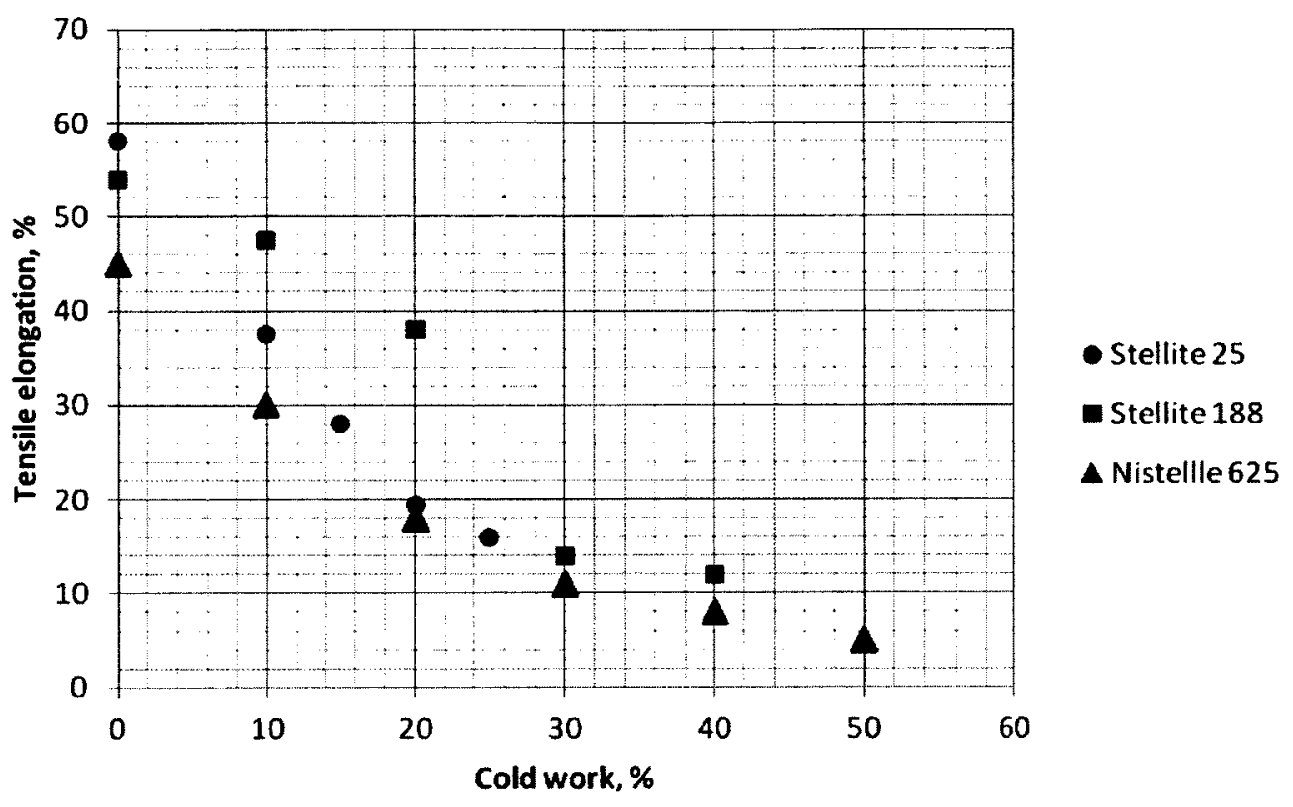

Figure 2-7: Room-temperature $0.2 \%$ yield strength versus percent cold work of Stellite alloys and nickel-based alloy [18].

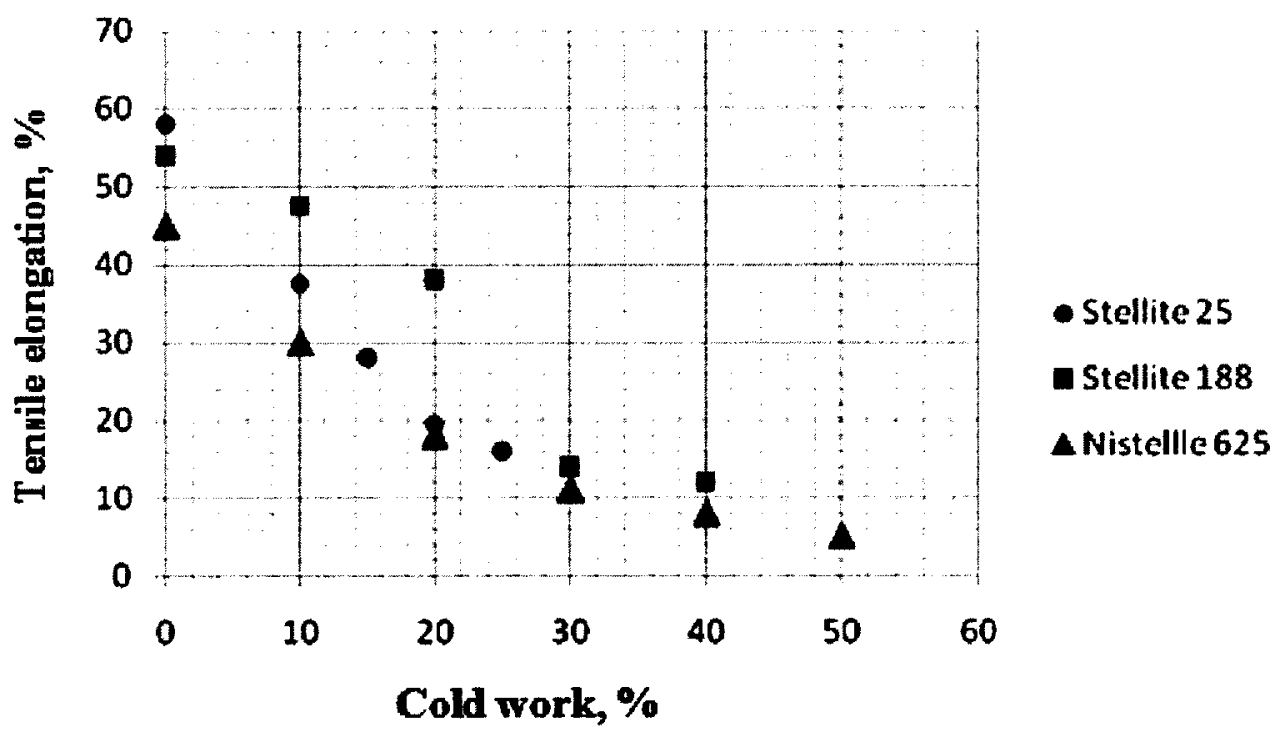

Figure 2-8: Room-temperature tensile elongation versus percent cold work of Stellite alloys and nickel-based alloy [18]. 


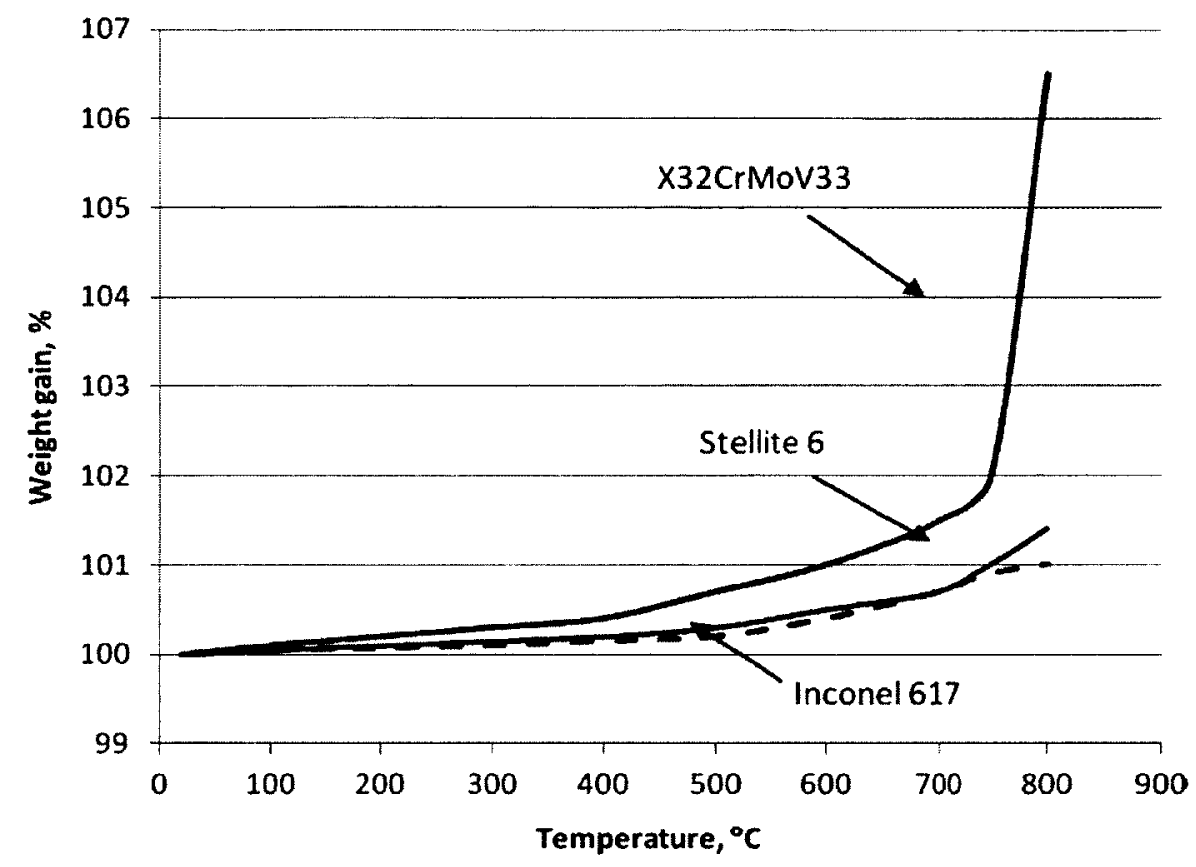

Figure 2-9: Weight gain in thermal gravimetric analysis (TGA) of tested materials as a function of temperature [19].

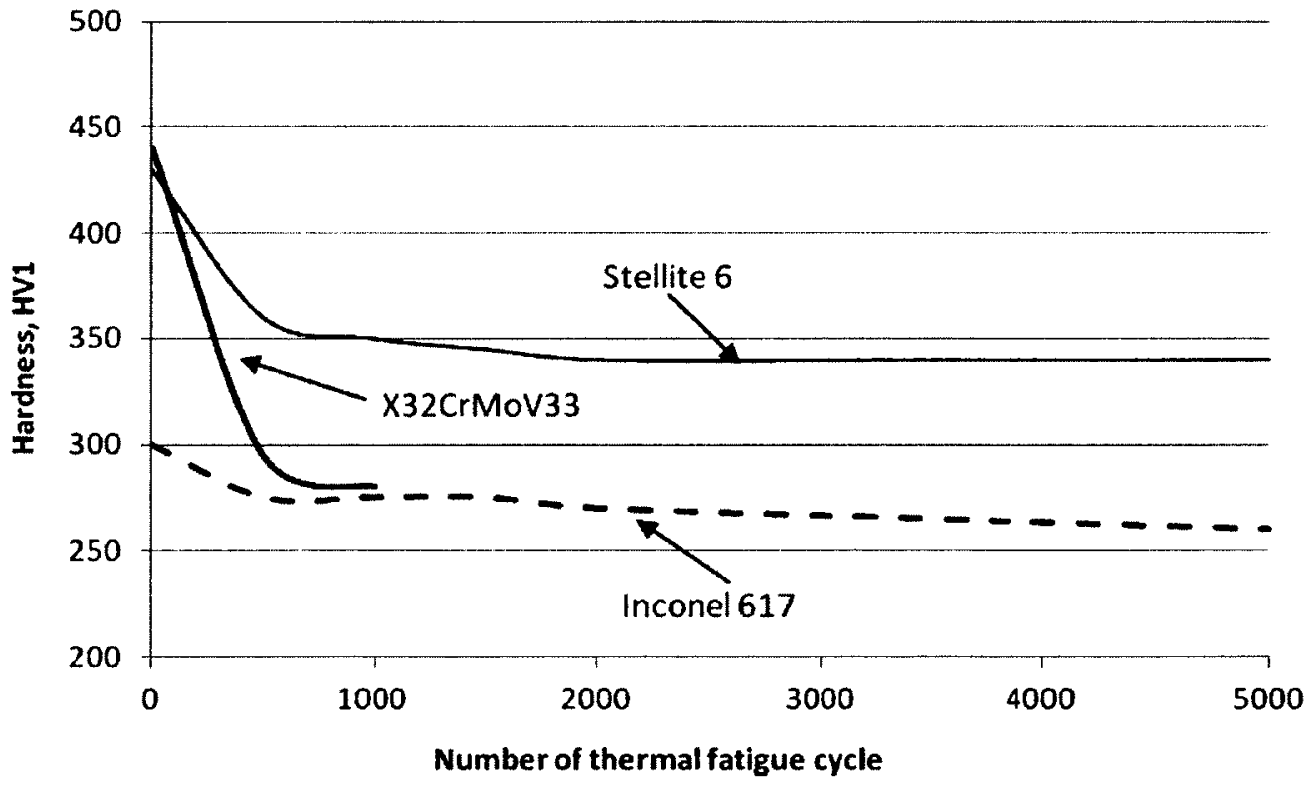

Figure 2-10: Change in hardness of tested materials with increasing number of thermal fatigue cycle [19]. 


\subsubsection{Corrosion properties}

Stellite alloys, in general, are resistant to various corrosive media and oxidation, owing to the high $\mathrm{Cr}$ content. Single-phase alloys are more resistant to corrosion than multi-phase alloys due to the lack of interfaces between phases. Therefore from a corrosion standpoint, Stellite alloys can be broadly classified into two categories. The alloys containing low levels of carbon (about $0.025 \sim 0.15 \mathrm{wt} \%$ ) are intended for use in severely corrosive environments, at high temperatures, or where ductility is an important consideration, due to less interfaces in their microstructures, while the alloys having high carbon contents ( 1 to $>3 \%$ ) exhibit high hardness, and provide resistance to low-stress abrasion, in addition to other forms of wear, but they exhibit low ductility [1]. Although the high-carbon content Stellite alloys possess some resistance to aqueous corrosion, they are limited by grain boundary carbide precipitation, the lack of vital alloying elements in the matrix materials, and by chemical segregation in the microstructures. Examples of these alloys are Stellite 1, Stellite 6, Stellite 12 and Stellite 21. Regarding the role of various alloying elements, $\mathrm{Cr}$, Mo, and $\mathrm{W}$, are highly soluble in both the fcc and hcp atomic forms of cobalt. Chromium is added to Stellite alloys to provide passivity over a wide range of potentials and resistance to oxidation. Molybdenum and tungsten enhance resistance to corrosion within the active regime. Nickel serves to stabilize the fcc structure with a view toward improved ductility during service and also improves resistance to mineral acids and stress-corrosion cracking [3].

Corrosive media, acids, can be either oxidizing or reducing in nature. Some metals are resistant to oxidizing acids such as nitric while others are resistant to reducing acids such as hydrochloric and sulfuric. The studies on the corrosion resistance of a 
number of Stellite alloys, such as Stellite 21 , Stellite 25 , Stellite $6 \mathrm{~B}$ and so on, in sulphuric acid $\left(\mathrm{H}_{2} \mathrm{SO}_{4}\right)$ and hydrochloric acid $(\mathrm{HCl})$, reported that regardless of their $\mathrm{Cr}$ and Mo contents these alloys exhibited similar corrosion resistance in dilute $\mathrm{H}_{2} \mathrm{SO}_{4}$. In $\mathrm{H}_{2} \mathrm{SO}_{4}$ and $\mathrm{HCl}$, the $\mathrm{Co}$ content governs the behaviour of Stellite alloys as long as minimum amounts of $\mathrm{Cr}$ and Mo or $\mathrm{W}$ are present [15]. The corrosion resistance of Stellite alloys to diluted nitric acid $\left(\mathrm{HNO}_{3}\right)$ is very good due to appreciable amounts of $\mathrm{Cr}$ present. However, in concentrated $\mathrm{HNO}_{3}$ medium Stellite $6 \mathrm{~B}$, which has high $\mathrm{Cr}$ content, exhibited high corrosion rate, while Stellite 25 , which contains lower $\mathrm{Cr}$ content, showed low corrosion rate. This could be a consequence of the high carbon content of Stellite $6 \mathrm{~B}$. High $\mathrm{C}$ and $\mathrm{Cr}$ are present intentionally in this alloy to form chromium carbides for abrasive resistance, but concentrated $\mathrm{HNO}_{3}$ is known to attack high-Cr phases such as $\sigma$-phase and Cr-rich carbides.

The resistance to localized corrosion (pitting and crevice corrosion) of Stellite alloys is generally determined by the $\mathrm{Cr}$, Mo and $\mathrm{W}$ contents, which is measured by immersion tests in oxidizing chloride solutions or by electro-chemical tests in chloride solutions. The experimental results of Stellite 21 , Stellite 25 , Stellite $6 \mathrm{~B}$ in an oxidizing chloride-containing solution demonstrated that Stellite 25 exhibited the highest resistance to corrosion and Stellite $6 \mathrm{~B}$ exhibited a high corrosion rate. The alloys with high levels of W, for example, Stellite 25, and high Cr plus Mo, for example, Stellite 21, showed lower corrosion rates [15].

Stellite alloys can be used to combat hydrogen embrittlement where steels fail by this mechanism. Susceptibility to hydrogen embrittlement is closely related to yield strength. Since Stellite alloys can be processed to achieve much higher yield and tensile 
strengths than most of nickel-based alloys, the potential for hydrogen embrittlement in Stellite alloys may be higher. Annealed Stellite alloys do not show significant susceptibility to hydrogen embrittlement, even in the most severe hydrogen-charging conditions. Stellite alloys also exhibit excellent resistance to high-temperature corrosive attack including oxidation, sulfidation and carburization [20].

Corrosion and oxidation behaviour of Stellite alloys can be influenced by addition elements such as $\mathrm{Ni}, \mathrm{Cu}$ or Mo [20]. Six alloys that have close contents of $\mathrm{C}, \mathrm{Cr}$ and $\mathrm{W}$ but different contents of $\mathrm{Ni}, \mathrm{Cu}$ and $\mathrm{Mo}$, as shown in Table 2-1, were tested for corrosion resistance in $10 \% \mathrm{H}_{2} \mathrm{SO}_{4}$ and in an aqueous solution containing the following chemicals $28 \% \mathrm{P}_{2} \mathrm{O}_{4}+13 \% \mathrm{H}_{2} \mathrm{SO}_{4}+2 \% \mathrm{HF}$, respectively, at room temperature for 192 hours, and at $60^{\circ} \mathrm{C}$ in $28 \% \mathrm{P}_{2} \mathrm{O}_{4}+13 \% \mathrm{H}_{2} \mathrm{SO}_{4}+2 \% \mathrm{HF}$ for 140 hours.

Table 2-1: Compositions (wt\%, Co in balance) of Stellite alloys for corrosion tests

\begin{tabular}{|c|c|c|c|c|c|c|}
\hline Alloy & $\mathrm{C}$ & $\mathrm{Cr}$ & $\mathrm{W}$ & $\mathrm{Ni}$ & $\mathrm{Cu}$ & Mo \\
\hline Specimen 1 & 2.1 & 31 & 12.3 & & & \\
\hline Specimen 2 & 2.1 & 32.2 & 12.5 & 19.5 & & \\
\hline Specimen 3 & 2.2 & 32.2 & 13.9 & 18.8 & & 8.9 \\
\hline Specimen 4 & 2.3 & 32 & 14 & & & 9.4 \\
\hline Specimen 5 & 2.1 & 32.2 & 13.1 & 17.6 & 4.3 & \\
\hline Specimen 6 & 2.2 & 31 & 15.2 & 18.2 & 4 & 8.7 \\
\hline
\end{tabular}

The experimental results plotted in Figure 2-11 show that the weight losses in both solutions are fairly similar. The alloy with additions of $\mathrm{Ni}$ and $\mathrm{Cu}$ remained passive 
throughout the test. Relatively high weight losses were recorded only for the alloy with additions of $\mathrm{Ni}, \mathrm{Cu}$ and $\mathrm{Mo}$. This can be ascribed to the precipitation of copper particles within the alloy matrix. The temperature has a significant effect on the corrosion attack to the alloys. Molybdenum can greatly improve the corrosion resistance of the alloy at elevated temperatures. Additions of $\mathrm{Cu}$ and $\mathrm{Ni}$ also have a favourable effect. This effect seems to be additive for both binary and ternary combinations of these three elements.

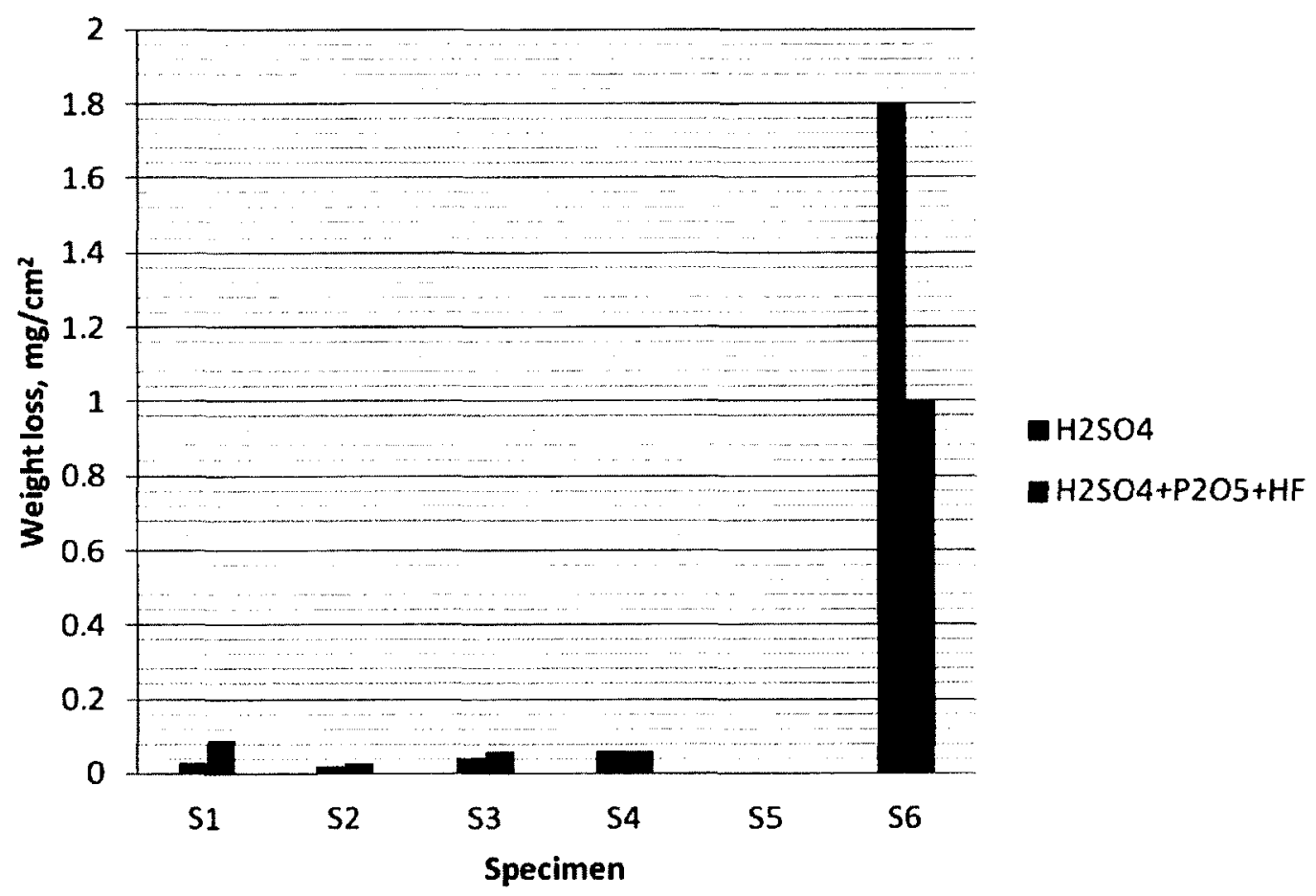

(a) 


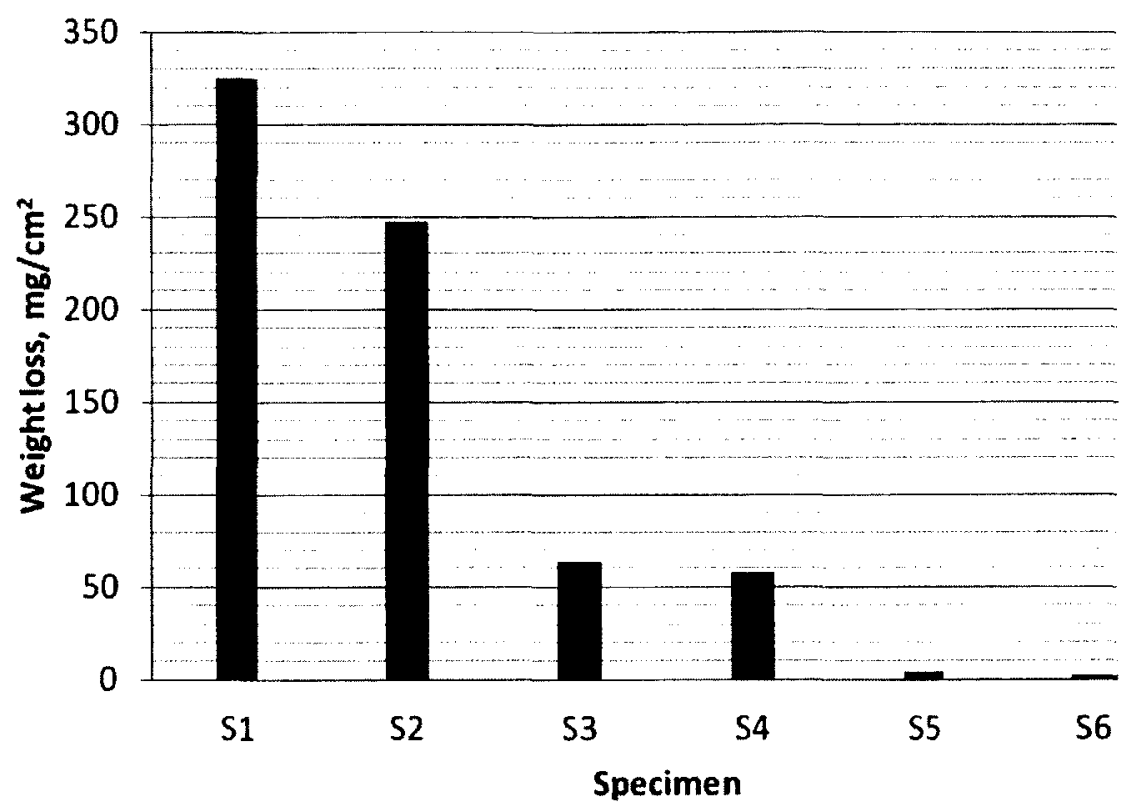

(b)

Figure 2-11: Corrosion resistance of Stellite alloys with varying $\mathrm{Ni}, \mathrm{Cu}$ and $\mathrm{Mo}$ contents:

(a) at room temperature and (b) at $60^{\circ}$ in $28 \% \mathrm{P} 2 \mathrm{O} 4+13 \% \mathrm{H} 2 \mathrm{SO} 4+2 \% \mathrm{HF}$ [20].

In regard of oxidation resistance, Stellite alloys are not as good as nickel-based alloys because of the difficulty in overcoming non-protective $\mathrm{CoO}$ scales through addition of $\mathrm{Cr}$ [21]. This problem was largely overcome in the development of Stellite alloy 188 through the use of small addition of lanthanum $(0.03 w t \%)$ [22]. Hot corrosion is a complex phenomenon involving attack by oxidation and sulfidation when $\mathrm{Na}_{2} \mathrm{SO}_{4}$ deposits form on an alloy surface [18]. The $\mathrm{Na}_{2} \mathrm{SO}_{4}$ is produced when sulphur in the fuel reacts with $\mathrm{NaCl}$ in the air stream as might occur in marine environments. This type of corrosion attack is particularly severe in the $870^{\circ} \mathrm{C}$ to $950^{\circ} \mathrm{C}$ temperature range. It is generally held that Stellite alloys offer better resistance to hot corrosion than nickel-based 
alloys. Stellite 188 has superior hot corrosion to Stellite 25, as illustrated in Figure 2-12, which could be attributed to the superior oxidation resistance of Stellite 188 [23].

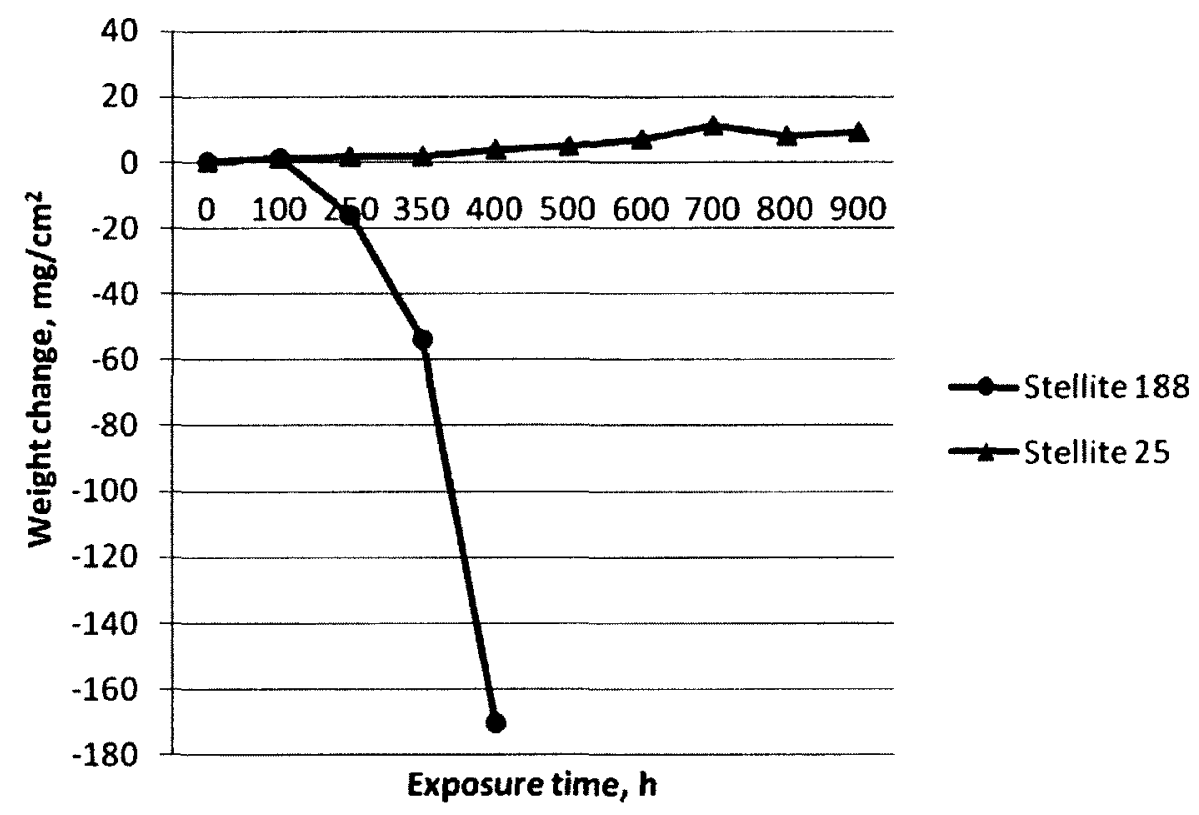

Figure 2-12: Hot corrosion of Stellite alloys in $50 \mathrm{ppm}$ salt $/ 0.4 \%$ sulphur fuel medium at $900^{\circ} \mathrm{C}[23]$.

Stellite 21 was reported to have better resistance to stress corrosion cracking in the Ringer's solution at $37^{\circ} \mathrm{C}$ than in boiling $30 \% \mathrm{MgCl}_{2}$ [24], and also the cast specimen exhibited better resistance to stress corrosion cracking than wrought and the $\mathrm{P} / \mathrm{M}$ specimens. The metallographic examination revealed that in $\mathrm{MgCl}_{2}$ solution all specimens suffered stress corrosion cracking except the cast product when the test duration was short (9 hours). However, for longer test duration of about 14 hours, stress corrosion cracking was incurred on the cast product. No stress corrosion cracking was detected in the Ringer's solution. 


\subsection{Research in Wear Behaviour of Stellite Alloys}

\subsubsection{Room-temperature wear}

Tribological properties of Stellite alloys have been investigated extensively in various research activities. Frenk and Wagnière [10] conducted a dry-sliding wear test on Stellite 6 , using a pin-on-disc ( $90 \% \mathrm{WC}-10 \% \mathrm{Co}$ in weight) tribometer apparatus that controlled the compressive load and sliding speed to provide a measure of wear rate. The resulting map is shown in Figure 2-13. The results demonstrated that the dry-sliding wear of Stellite 6 against a hard metal counterface could result from at least two mechanisms. Mild wear occurred at low loads or low sliding velocities, leading to the formation of oxide debris. Under such an oxidative regime, the wear rate was essentially controlled by the kinetics of oxide formation as well as by the mechanical or thermo-mechanical properties of the oxide formed and its attachment to the surface. The microstructure is not of prime importance under these conditions. With higher loads or elevated sliding velocities, a transition to a severe metallic wear regime occurred, causing nucleation and propagation of cracks, thus leading to localized fracture and forming wear debris. Frenk and Kurz [12] investigated the influence of microstructure on the wear properties of Stellite 6. Dry-sliding wear test was conducted on Stellite 6 specimens with different microstructures using a pin-on-disc type of machine. The microstructure of Stellite 6 could be modified by the processing conditions. The hardness of the alloy was strongly dependent on the microstructure and in particular on the size of the phases. However, the drying-sliding wear test against a much harder mating material $(90 \% \mathrm{WC}-10 \% \mathrm{Co}$ in weight) showed that in the severe metallic wear regime, the wear rate was independent of the microstructure (size and volume fraction of the phases). Therefore, in this case, no 
direct relationship existed between the initial hardness of the material and its wear resistance, because the structure in the subsurface was completely destroyed by the resulting stress cycles. The high hardness of Stellite alloys is dependent on the microstructure and particularly the size of the dendrites and carbide particles. In addition, the hardness is dependent on the chemical composition of the matrix, and in particular the elements modifying the SFE due to the slip of dislocations within the material lattice.

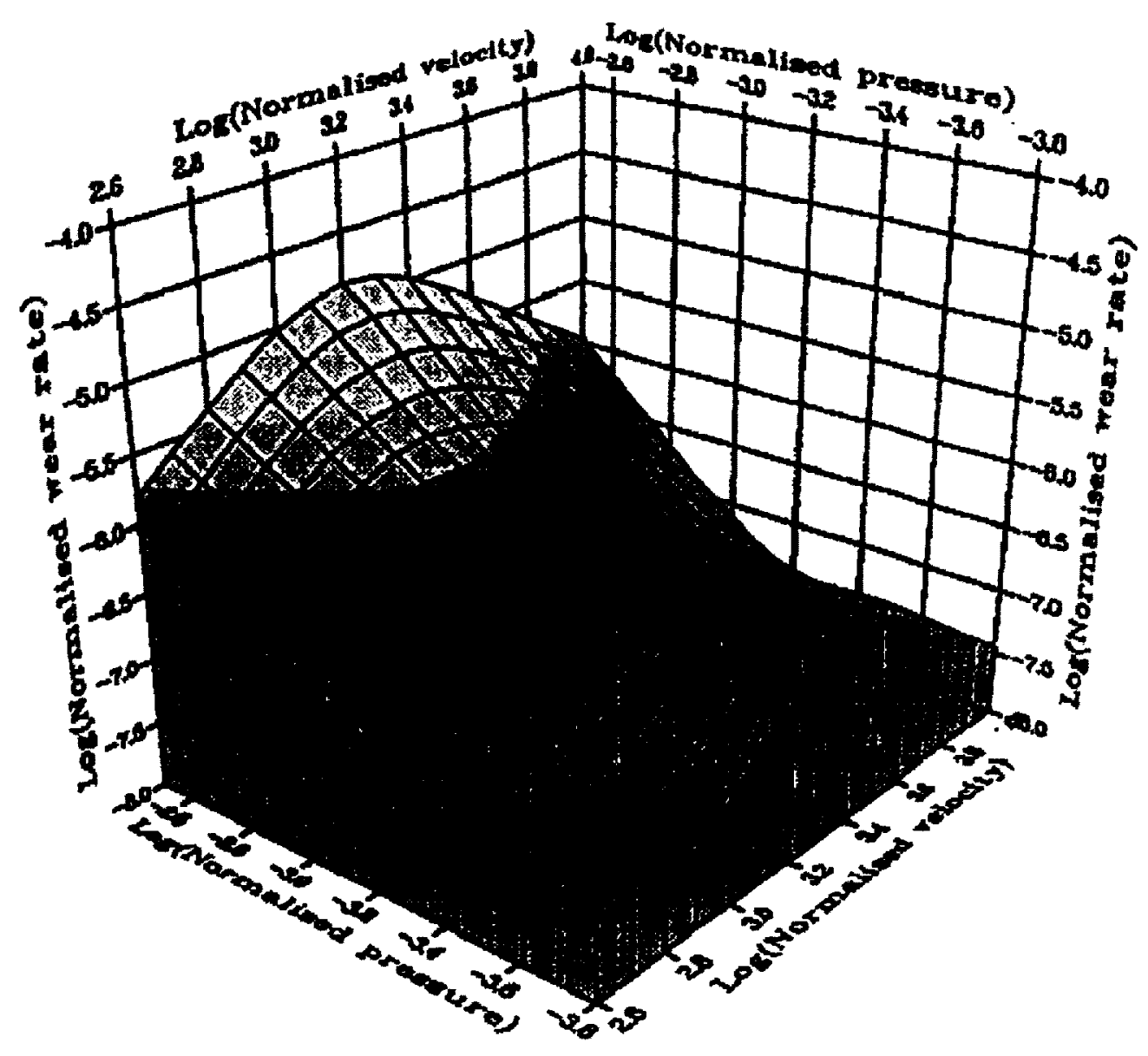

Figure 2-13: Dry sliding wear map for Stellite 6 against a WC-Co 90/10 disc [12] 
This is important as pointed out by Shin et al. [13] that the volume fraction and particle size of the $\mathrm{M}_{6} \mathrm{C}$ carbide increase rapidly with increasing Mo content from zero to $6 \mathrm{wt} \%$, as well as, the $\mathrm{Cr}$-rich carbides decrease in size but increase in volume fraction slightly with increasing Mo content over the same range. Yao et al. [15] arrived at a similar conclusion that $\mathrm{Mo}$ in replace of $\mathrm{W}$ in Stellite alloys results in an increased volume fraction of carbides as compared with $\mathrm{W}$ containing alloys. They suggested that the hardness and wear resistance of Stellite alloys would be dependent on the size and volume fraction of the carbides present [15].

Overall, hyper-eutectic Stellite alloys are generally used for severe abrasion conditions and the more ductile hypo-eutectic alloys are used in application subject to cavitation [7]. It was also shown that adding Mo singularly or in combination with $\mathrm{Ni}$ and/or $\mathrm{Cu}$ enhanced the corrosion and abrasion resistance of high carbon Stellite cast alloys. Cavitation erosion behavior of Stellite 3, Stellite 6 and Stellite 20 was studied by Heathcock et al. [7]. A steady source of vibratory cavitation was produced by means of a modified industrial ultrasonic drilling system operated at a frequency of $20 \mathrm{kHz}$. It was shown in Figure 2-14 that Stellite 3 has the highest resistance to erosion; Stellite 6 has the lowest and Stellite 20 has the similar erosion resistance to Stellite 6.

Stellite 3 and Stellite 20 have similar compositions and both have high macro hardness (530 HV and $610 \mathrm{HV}$ respectively). However, Stellite 20 has much lower erosion resistance than Stellite 3 . This difference is considered to be a consequence of the microstructures. In Stellite 3 carbides $\mathrm{Cr}_{7} \mathrm{C}_{3}$ and $\mathrm{W}_{6} \mathrm{C}$ form a fine interdendritic network in a Co-rich matrix. However, Stellite 20, owing to higher $\mathrm{Cr}$ and $\mathrm{W}$ contents, has acicular $\mathrm{Cr}_{7} \mathrm{C}_{3}$ and islands of Co-rich solid solution which are embedded in a complex 
carbide eutectic. Moreover, the acicular carbides in Stellite 20 are much harder than those in Stellite 3. Based upon microstructure, Stellite 6 is a coarse version of Stellite 3. Compared with Stellite 3, Stellite 6 contains less W and C, which results in less volume fraction of carbides.

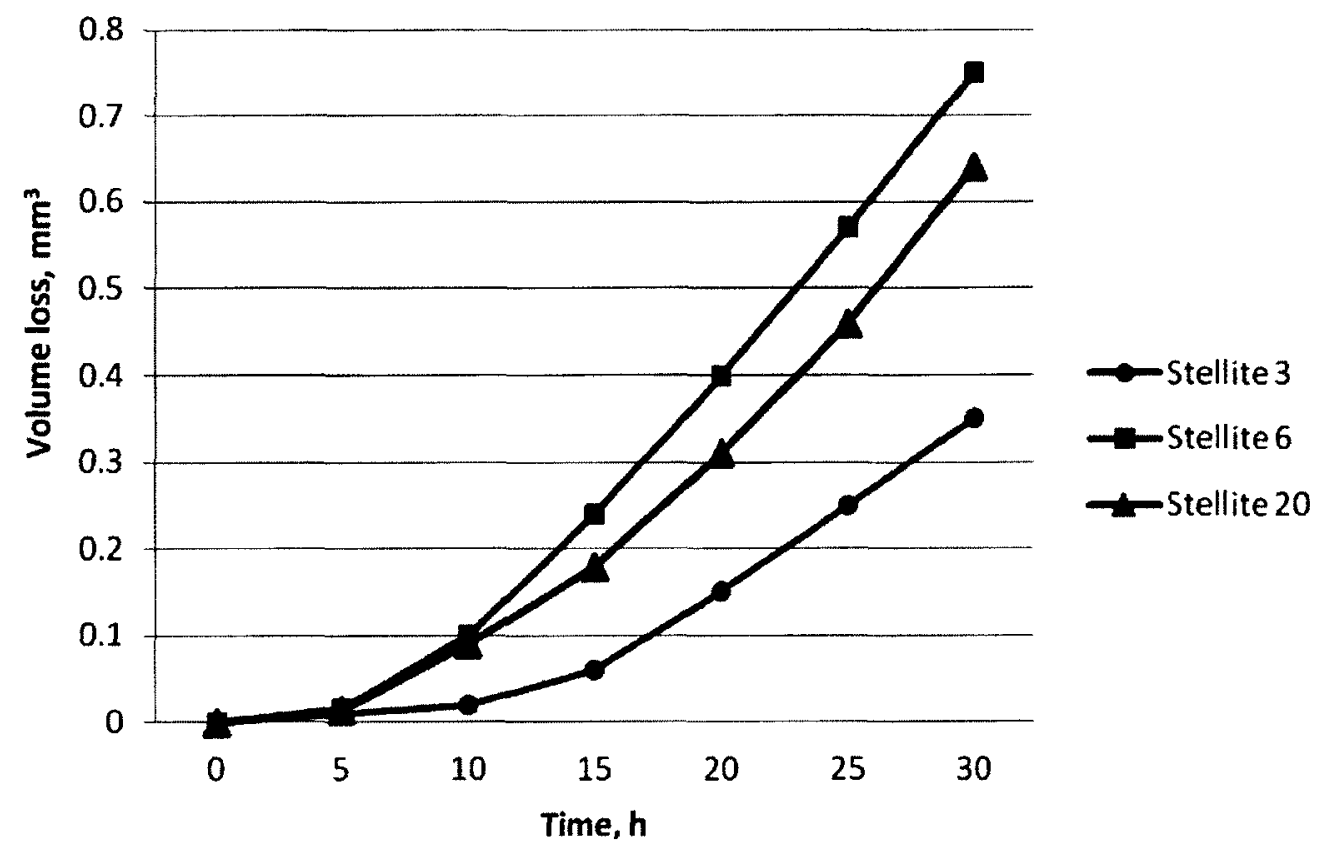

Figure 2-14: Erosion test curves of Stellite alloys [7].

The SEM analysis investigated the mechanisms of erosion of these alloys $[7,11$, 15]. For Stellite 3 and Stellite 20, it was demonstrated that the carbides were selectively eroded while the carbide-matrix interface acted as an initiating site for erosion. Also material was lost, to a less extent, from twin intersections in the Co-rich matrix phase of these alloys. The lower erosion resistance of Stellite 20 is due, in part, to a higher rate of removal of the massive, harder, more brittle carbides and also, in part, to the greater matrix-carbide interface area. Regarding Stellite 6, it contains less C than Stellite 3 and 
Stellite 20 , consequently less volume fraction of carbides. In this alloy, erosion occurred predominantly by the loss of material from twin boundary intersections within the Co matrix. Owing to the prime importance of the Co-rich solid solution in determining the erosion resistance of this alloy, Stellite 6 is less resistant to erosion than Stellite 3 and Stellite 20.

Malayoglu and Neville performed erosion-corrosion tests under liquid-solid erosion conditions in $3.5 \% \mathrm{NaCl}$ liquid medium [11]. This research was focused on comparing the erosion-corrosion behaviour of Stellite alloy 706 that contains $5 \mathrm{wt} \%$ molybdenum with Stellite alloy 6 that contains $4.8 \mathrm{wt} \%$ tungsten, both in cast and hot isostatically pressed (HIPed) form. They investigated their electrochemical corrosion characteristics, resistance to mechanical degradation and relationship between microstructure and degradation mechanisms. It was found that both cast and HIPed Stellite 706 exhibited better erosion and erosion-corrosion resistance than Stellite 6 counterparts under a wide range of conditions. The microstructure and specifically the type of carbides the erosion-corrosion affected the performance of the alloys significantly. In these multiphase alloys there was no direct relationship between the hardness and erosion-corrosion resistance. They also suggested that the strength of the matrix of Stellite alloys was an important factor, referring to a case of abrasion wear, stating that the support of the matrix can prevent the pulling out of the harder carbides. This was demonstrated with showing the effect of material matrix strength on the wear rate, using a normalised alloying content (NAC) measure, defined as the sum of the weight percentages of nickel, vanadium and tungsten - which are the elements as solid-solution strengtheners. It was shown that the material with a higher NAC had a 
lower weight loss in an erosion-corrosion test. There was a linear relationship between the NAC measure and the weight loss, which was explained by the strain hardening of the matrix, associated to the SFE. With the relation to erosion-corrosion, the low SFE tended to cause materials to strain-harden more rapidly and enhance erosion resistance [11]. This is addressing the important concept as well known Mo and $\mathrm{W}$ are strain-hardeners in relation to the composition and microstructure of Stellite alloys.

\subsubsection{Elevated-temperature wear}

Several researchers investigated the effect of the oxide scale or glaze layer formed between sliding materials at high temperatures. It was found that the oxide scale or glaze layer that adhered to the base material had a beneficial effect to reduce friction and wear at elevated temperatures $[25,26]$. It is a protective layer against wear that formed in an oxygen containing atmosphere. The sliding action generates oxide debris that is compacted against one or both sliding surfaces. The importance of such a glaze layer is that when it is formed; it inhibits further wear as this layer prevents direct contact between the sliding surfaces. Both Mo and $\mathrm{W}$ contribute to the formation of the glaze layer with Mo producing a more stable and adhesive film than W [3]. It was found that patches of glaze formed on Stellite 6 around the temperature $400^{\circ} \mathrm{C}$ to $500^{\circ} \mathrm{C}$ at a wear

speed of $0.314 \mathrm{~m} / \mathrm{s}$ [5]. This glaze layer became more consistent at temperatures exceeding approximately $600^{\circ} \mathrm{C}$ at the same speed.

Extensive research has been conducted to improve the adhesion of the oxide scale and understand its benefit effect at elevated temperatures. For instance, the addition of yttrium to Stellite alloys $[26,27,14,25]$ was studied for its effects on improving the 
oxide scale adhesion. It was also found that yttrium additive in Stellite 6 can improve the wear resistance and hardness of the alloy through refining the microstructure. The experimental results in Figure 2-15 show that Stellite 6 with 2 wt\% Y has the lowest wear loss but $5 \mathrm{wt} \% \mathrm{Y}$ has less beneficial effect than $2 \mathrm{wt} \% \mathrm{Y}$ on the alloy for wear resistance. The beneficial effect of $\mathrm{Y}$ can be attributed to the finer microstructure and the $\mathrm{CO}_{2} \mathrm{Y}$ phase by the presence of $\mathrm{Y}$ in the alloy. These modifications strengthen the alloy. On the other hand, excessive level of $\mathrm{Y}$ promotes formation of rhombohedral $\mathrm{CO}_{17} \mathrm{Y}_{2}$ intermetallic compound which is brittle and breaks easily under wear [25].

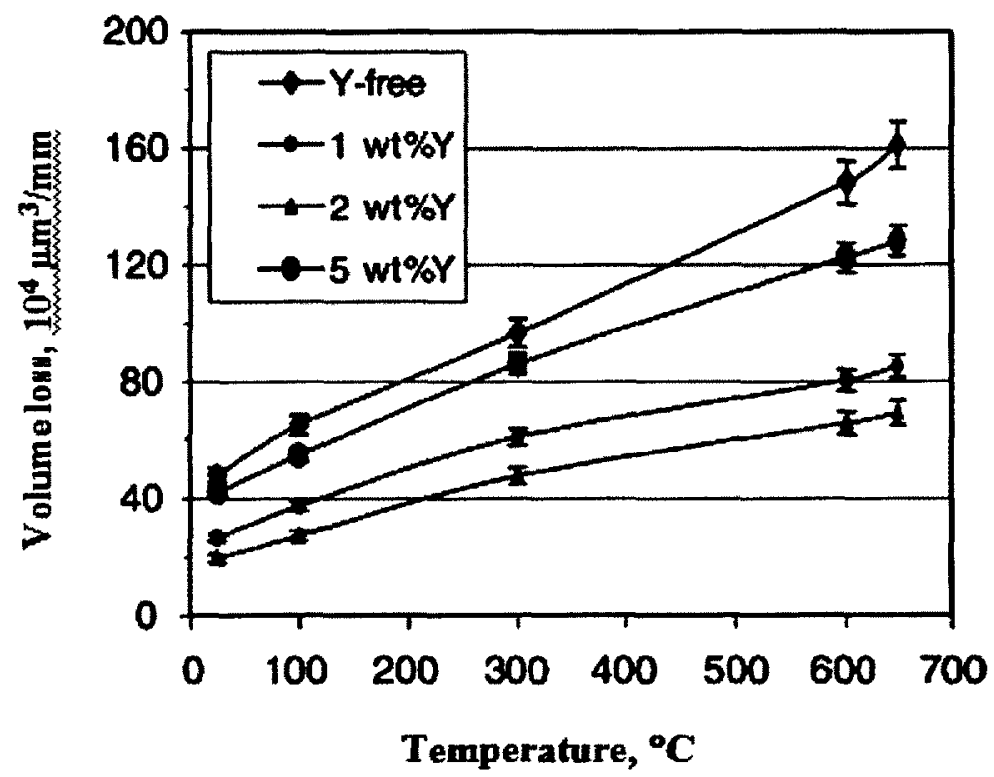

Figure 2-15: Influence of yttrium additive on wear behavior of Stellite 6 at elevated temperatures [25].

Similar tests were conducted on Stellite $21[14,26]$ and Stellite $712[27]$ with yttrium additive and it was demonstrated that addition of yttrium did not increase the hardness of Stellite 21 but largely affected the oxide scale. The oxide scale was enhanced 
and it improved resistance and adherence in air, however; the oxide layer became less protective as the wearing force was increased. Under high loads, this oxide scale could be destroyed easier, and the removal of the oxide debris could result in more wear or accelerated wear. The mechanical properties of Stellite 712 were not affected by the addition of yttrium, and that small amount of yttrium $(<1 \mathrm{wt} \%)$ enhanced the mechanical properties of the oxide scale and its adherence, which benefitted the wear performance of Stellite 712 . However, exceeding $1 \mathrm{wt} \%$ yttrium negatively affected the wear resistance of the alloy, and the addition of $0.5 \mathrm{wt} \%$ yttrium performed the best at elevated temperatures.

The effect of silicon addition to Stellite 6 on its hardness and wear resistance at elevated temperatures was studied by Celik and Kaplan [28]. They found that the hardness of Stellite 6 was enhanced by the addition of Si and the wear resistance of Stellite 6 increased with silicon addition at low temperatures (below $100^{\circ} \mathrm{C}$ ) but decreased at high temperatures, as shown in Figure 2-16. It is also observed that the wear resistance of the material decreases with the increase of the temperature. The beneficial effect of Si on the wear resistance of Stellite 6 at room temperature is ascribed to the increased hardness. 


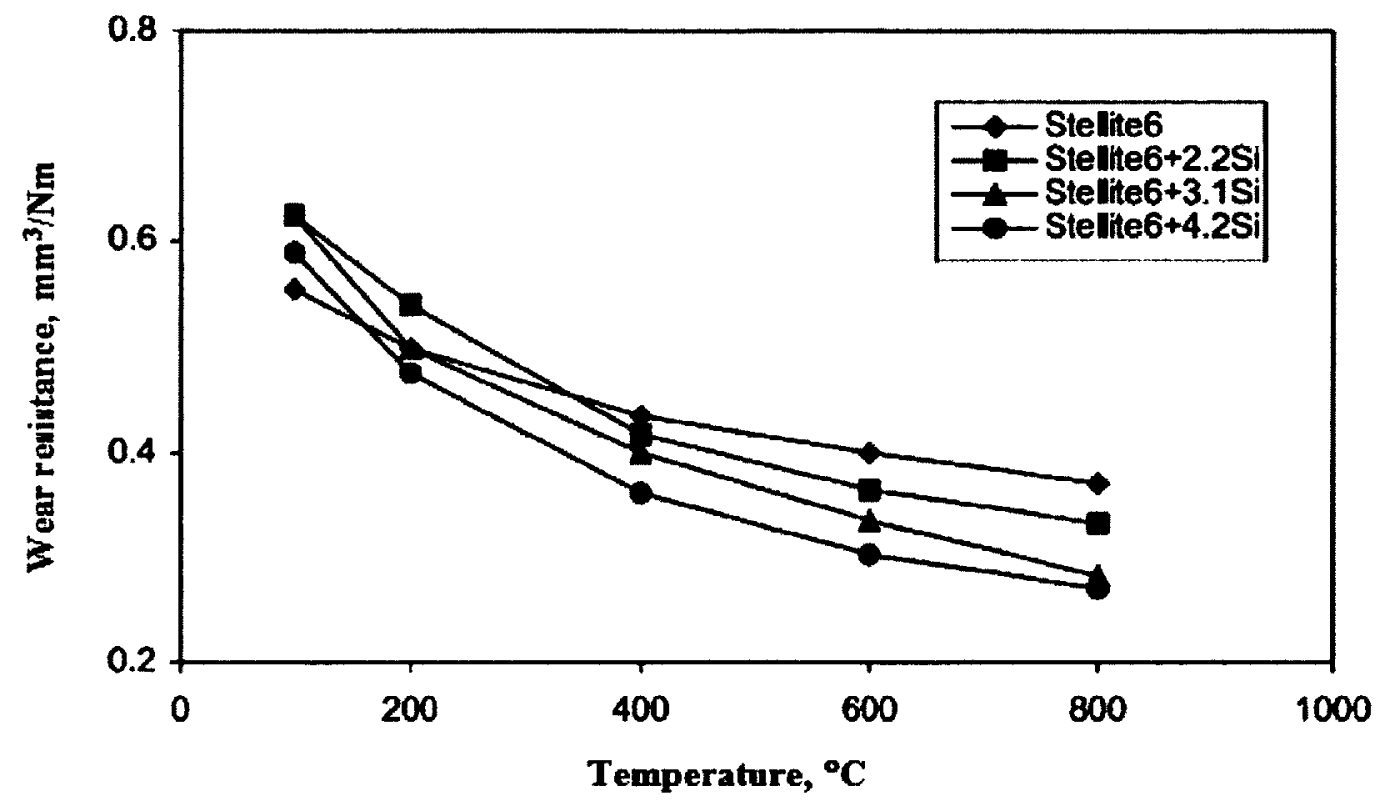

Figure 2-16: Effects of silicon additive on wear resistance of Stellite 6 at elevated temperatures [28].

\subsection{Summary}

Wear is a complex surface failure which is affected by many factors. The various research activities summarized in this chapter investigated the microstructure, hardness and various forms of wear on Stellite alloys in order to better understand the beneficial properties of these alloys.

In the literature, the investigation on a handful of Stellite alloys was reported. Only two articles presented the research on a range of Stellite alloys, including one investigating the cavitation-erosion of Stellite alloys [7] and the other investigating the cracking resistance [15] of Mo and $\mathrm{W}$ containing Stellite alloys. Of the remaining articles, the erosion/corrosion resistance of Stellite 6 and 706 [11] was investigated, the scuffing behaviour of Stellite 3 [6] was studied, but no information on the wear 
characteristics of the Stellite alloy was reported. The beneficial effect of yttrium on the adhesion of oxide film or scale, which could improve high-temperature wear resistance, was studied on Stellite 6, Stellite 21 and Stellite 712 [14, 25, 26, 27]. Also as additives, the beneficial effects of Silicon [28] and Mo [13] on improving the high-temperature wear resistance of Stellite 6 were studied. Among Stellite alloys, Stellite 6 attracted more attention of researchers than the others. The room-temperature sliding wear behavior [12] and high-temperature wear behavior [5] of Stellite 6 were all investigated.

Although many efforts have been made in obtaining the data of various properties of Stellite alloys, the available information is still very limited; in particular, the high-temperature hardness and wear resistance of these alloys were not studied systematically. The reported research examined only one or two Stellite alloys in their analyses. Differently, the present research was aimed to further understand the wear behaviour of Stellite alloys, by studying a group Stellite alloys that cover a wide range of chemical compositions, with the emphasis on the role of chemical composition in controlling their wear resistance and the influence of temperature on their wear performance. The sliding wear test, utilizing a pin-on-disc tribometer, is a standard test that can be used to compare materials relative to one another, and also it is available in our research group. Therefore, the present wear test was performed in the sliding wear mode. The focus of this research was on analyzing the effects of carbon and other alloying elements on the high-temperature wear resistance of Stellite alloys thus providing the scientific basis for designing new high-temperature wear-resistant alloys. 


\section{Chapter: Microstructural Characterization}

\subsection{Test Specimens}

\subsubsection{Alloy selection}

As mentioned previously, Stellite alloys can conventionally be categorized as high-carbon alloys designed for wear service; low-carbon alloys for high temperature service; and low-carbon alloys to combat corrosion or simultaneous corrosion and wear. Therefore, the alloys studied in this research were carefully selected to broadly cover these categories. Six Stellite alloys were selected purposefully in consideration of chemical composition. Understanding the elements involved in Stellite alloys is an important or fundamental step to understand the basis of material properties. Carbon, in steel and other metal alloys, increases hardness while increasing brittleness. Carbon increases hardness by forming carbides which, through dispersion and solid solution strengthening, prevent slipping in the atomic crystal lattice. Three important elements that need to be specifically described are molybdenum, tungsten and chromium as their contents vary among Stellite alloys and these elements play important roles in controlling the material properties. Molybdenum has half the atomic mass of tungsten, so for the same weight percentage, there will be an excessive atomic concentration of molybdenum compared to tungsten. Because of this the tendency for molybdenum-rich carbides to form is higher. As discussed previously, the main role of both tungsten and molybdenum in Stellite alloys is in solid-solution strengthening. Chromium improves the resistance to corrosion and oxidation and is the main carbide former. As hardness and wear resistance are major considerations for the Stellite alloys being studied in this research, these elements were certainly important concern in the alloy selection. 
Firstly, considering the main strengthening agent, carbon, the content which controls the carbide volume fraction in Stellite alloys, these alloys contain different levels of carbon and are identified as low-, medium-, and high-carbon Stellite alloy, respectively. Secondly, considering the main strengthening element of solid solution, tungsten, these alloys were selected to contain varying levels of tungsten, from zero up to a maximum $>30 \mathrm{wt} \%$. Thirdly, considering another strengthening element of solid solution, molybdenum, these alloys may not contain molybdenum or contain a small to medium amount of molybdenum. Finally, as the main agent of carbide formation, chromium, usually takes $20 \sim 30 \mathrm{wt} \%$ in Stellite alloys. Other elements such as nickel, iron, boron, and so on were also taken into account. From these considerations of chemical composition, the effects of main constituents of Stellite alloys on the hardness and wear resistance of these alloys would be investigated in this research, in particular, on the hardness and wear resistance of Stellite alloys at elevated temperatures.

\subsubsection{Chemical compositions}

The selected six alloys were designated as alloy A, alloy B, alloy C, alloy D, alloy E and alloy F, respectively. The chemical compositions (wt\%) of these alloys are detailed in Table 3-1. They have a carbon content varying between $0.25 \sim 2.4 \%$, chromium content between $22 \sim 33.5 \%$, tungsten content between $4.5 \sim 32 \%$ except alloy D which contains no tungsten. Instead this alloy contains $5.5 \%$ molybdenum and a very low content of carbon $(0.25 \%)$. These alloys also contain a small amount of nickel between $1.5 \sim 3.5 \%$ and iron between $3 \sim 5 \%$ except alloy $\mathrm{E}$ and alloy $\mathrm{F}$. With respect to the amount of carbon, Alloy A contains the highest amount of carbon, followed by alloy $\mathrm{E}$. 
Alloy $\mathrm{B}$, alloy $\mathrm{C}$ and alloy $\mathrm{F}$ have a medium amount of carbon. Alloy $\mathrm{B}$ also contains a small amount of molybdenum in addition to tungsten and alloy E contains a small amount of boron.

Table 3-1: Chemical compositions (wt\%, Co in balance) of Stellite alloys

\begin{tabular}{|c|c|c|c|c|c|c|c|c|c|}
\hline $\begin{array}{c}\text { Element } \\
\text { Specimen }\end{array}$ & Cr & W & Mo & Ni & Fe & C & B & Si & Mn \\
\hline Alloy A & 30.5 & 12.5 & 0 & 3.5 & 5 & 2.4 & & 2 & 2 \\
\hline Alloy B & 29 & 4.5 & 1.5 & 3 & 3 & 1.2 & & 0.75 & 0.5 \\
\hline Alloy C & 30 & 8.3 & 0 & 1.5 & 3 & 1.4 & & 0.7 & 2.5 \\
\hline Alloy D & 27 & 0 & 5.5 & 2.75 & 3 & 0.25 & & 1 & 1 \\
\hline Alloy E & 33.5 & 19 & 0 & 0 & 0 & 1.9 & 1 & 0 & 0 \\
\hline Alloy F & 22 & 32 & 0 & 0 & 0 & 1.5 & & 0 & 0 \\
\hline
\end{tabular}

Among these alloys, the first four are conventional Stellite alloys, known as Stellite 3 , Stellite 6 , Stellite 12 and Stellite 21 , respectively, which have been widely applied in various industries involving wear and corrosion environments, in particular, the wear and corrosion environments combined with high temperatures. The last two alloys were newly developed, named Stellite 80 and Stellite 300 , respectively, by Deloro Stellite Group. Alloy E was designed for P/M products; addition of boron was to reduce the melting temperature of the alloy, because borides have a lower melting point [29]. The reduction in melting temperature of an alloy for $\mathrm{P} / \mathrm{M}$ products has two advantages; one is reducing the furnace temperature; the other is allowing diffusion of liquidus phase into solidus phase thus improve the density of the products. 


\subsection{Microstructural Analysis}

\subsubsection{Specimen preparation}

To study the hardness and wear resistance of Stellite alloys, especially, the effects of their chemical compositions on these properties, it is necessary to understand their microstructures first, because chemical composition determines the microstructure of a material (certainly the fabrication process is also another critical factor in controlling the microstructure) and the microstructure affects the final properties of the material or product. Therefore, the microstructures of the six alloys being studied were investigated prior to hardness and wear tests.

The tested alloys were fabricated using a centrifugal casting technique at Deloro Stellite Group. The preparation of the specimens for microstructural analysis followed the steps below:

(1) Cut the metallographic specimens from the main body of the cast materials to approximately $45 \sim 60 \mathrm{~mm}$ in length and $5 \mathrm{~mm}$ in thickness using a cutting machine with an $\mathrm{Al}_{2} \mathrm{O}_{3}$ abrasive cut-off blade. Care was taken to minimize excessive heating by following the usual precautions such as proper cooling conditions to avoid any microstructure alteration. The specimens were mounted by encapsulating into a compression mounting compound. The compound was the phenolic plastic. The hot mounting press of Struers Co. (laboPress-3), shown in Figure 3-1, with adjustable pressing parameters such as heating temperature, heating time, cooling time, and force, was used to provide heat $\left(150^{\circ} \mathrm{C} \sim 180^{\circ} \mathrm{C}\right)$ and force $(0 \sim 50 \mathrm{MPa})$ for mounting. 


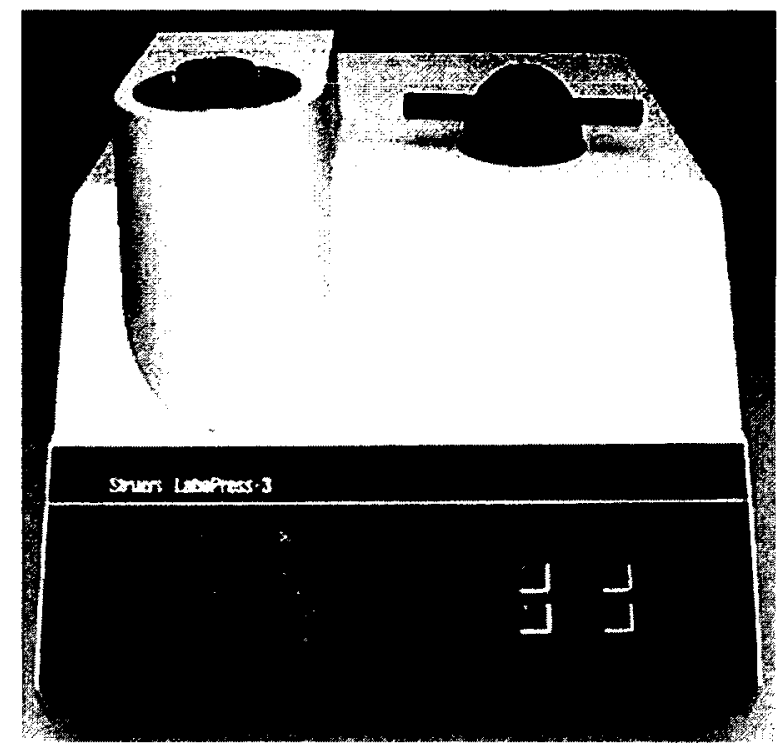

Figure 3-1: LaboPress-3 mounting press (Courtesy of Struers Co.).

(2) Grind the surfaces of the specimens. The operations were performed automatically by a Buehler Ecomet-4 semiautomatic grinder, shown in Figure 3-2. The specimen holder of the machine is a fixed frame in which the pressure is applied on the specimens via the central column of the holder. Therefore, it is necessary to place the specimens symmetrically in order to obtain flat surfaces after grinding operation. Grinding operation was required to remove the surface layer of the cast products and also reduce the surface damage caused by cutting. A 320 standard grit size of silicon carbide ( $\mathrm{SiC})$ abrasive paper was used with the operation parameters: a contact load of $27 \mathrm{~N}$ and a spindle speed of $250 \mathrm{rpm}$. The selection of these parameters depended on the hardness of materials. Water was used as the coolant to reduce the generated friction heat during grinding. 


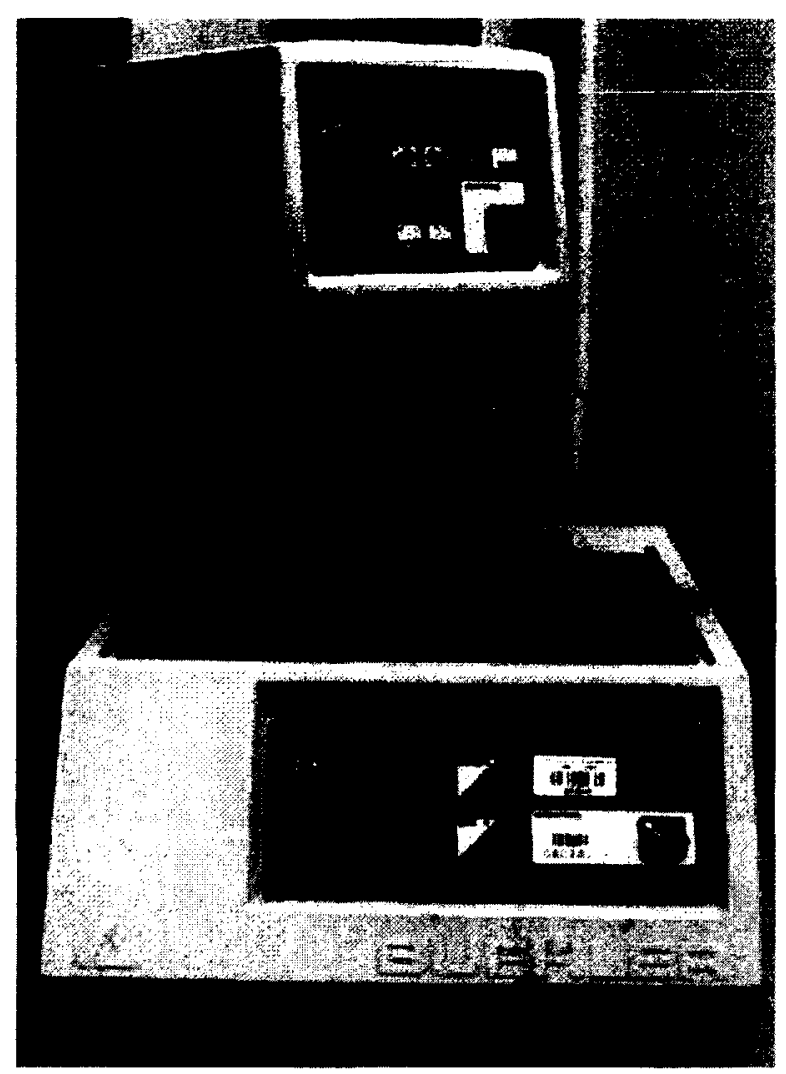

Figure 3-2: Buehler Ecomet-4 semiautomatic grinder polisher.

(3) Polish the surfaces of the specimens. The purpose of polishing operation was to produce a specularly reflecting or bright mirrorlike surface. The polishing operation included rough and final polishing steps. Rough polishing was performed to remove the damage produced during planar grinding. The specimens were roughly polished with sequentially decreasing abrasive paper grit sizes. Final polishing was just performed to eliminate surface damage. Thus the specimen surfaces were lightly polished with $1 \mu \mathrm{m}$ diamond suspension and $0.05 \mu \mathrm{m}$ alumina suspension on two specific polishing pads. The specimens were thoroughly cleaned in an ultrasonic bath, prior and after each step of the final polishing since surface quality could be degraded by abrasion from the debris produced during polishing. 
(4) Etch the specimen surfaces. After polished, the specimen surfaces were subjected to electrolytic and immersion etching with the solution mixture of $15 \mathrm{ml} \mathrm{HNO}_{3}, 15 \mathrm{ml}$ acetic acid, $60 \mathrm{ml} \mathrm{HCl}$ and $15 \mathrm{ml} \mathrm{H} 2 \mathrm{O}$.

\subsubsection{Microstructure examination}

The microstructure analysis of the alloy specimens at room temperature was performed on a Hitachi Model S-570 Scanning Electron Microscope (SEM) with backscatter electron imaging (BEI) and energy dispersive X-ray (EDX) spectrum, shown in Figure 3-3, and on a Philips XL30S FEG Scanning Electron microscope (SEM) with an EDAX energy dispersive X-ray (EDX) spectroscopy system, shown in Figure 3-4. These two SEM systems are similar, but the latter is able to identify nonmetallic elements such as carbon, silicon, boron, etc. in the EDX analysis, providing more accurate analysis for phases present in a microstructure. Among the alloys being studied, alloy A, alloy B, alloy $\mathrm{C}$ and alloy D are conventional Stellite alloys with Trade Mark Stellite 3, Stellite 6, Stellite 12 and Stellite 21, respectively; the phases in their microstructures are generally well known. The SEM images of microstructure for these alloys presented below were obtained from the former system. However, alloy $\mathrm{E}$ and alloy $\mathrm{F}$ were newly developed and their microstructures had not been well studied. To investigate the phases present and their distributions in these alloys, the microstructures of these alloys were examined using the latter SEM system. Each phase present in their microstructures was identified utilizing the EDX technique. 


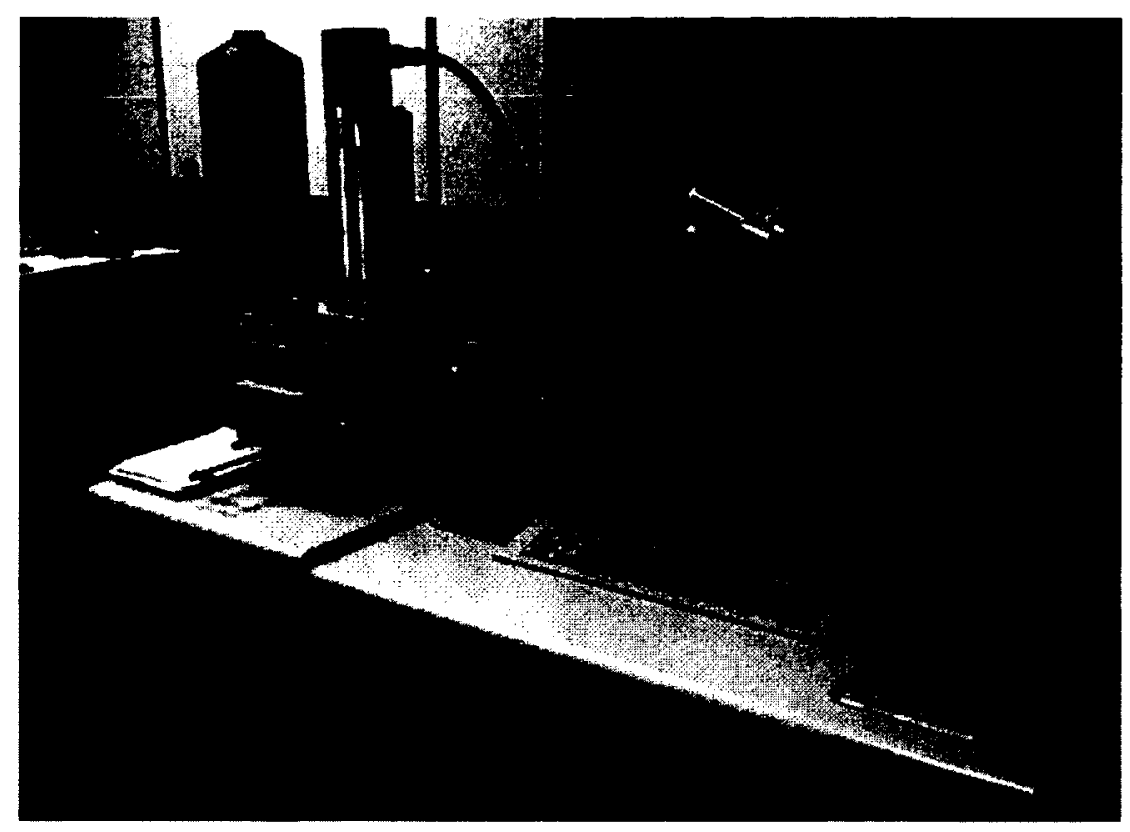

Figure 3-3: Hitachi Model S-570 Scanning Electron Microscope (SEM) with energy dispersive X-ray (EDX) spectrum.

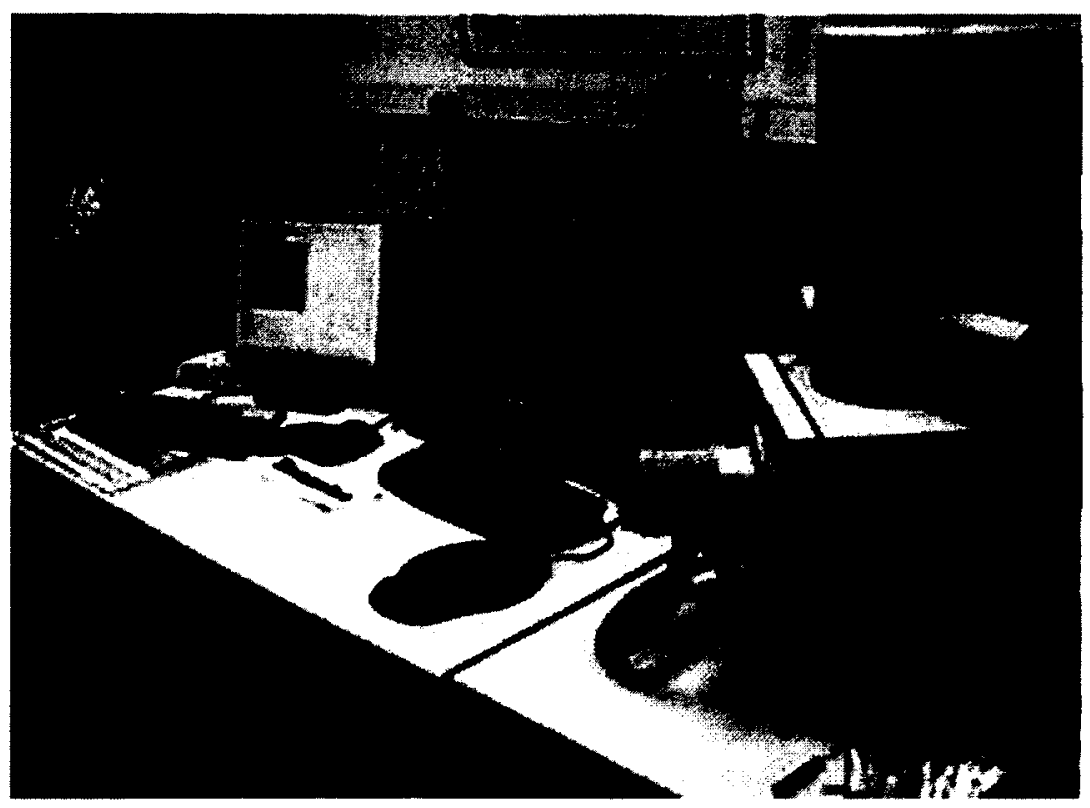

Figure 3-4: Philips XL30S FEG Scanning Electron microscope (SEM) with an EDAX energy dispersive X-ray (EDX) spectroscopy system. 


\subsubsection{SEM images of microstructure}

The SEM images of microstructure for alloy $\mathrm{A}$, alloy $\mathrm{B}$, alloy $\mathrm{C}$ and alloy $\mathrm{D}$ at low and high magnifications are presented in Figure 3-5 to Figure 3-8. Stellite alloys have a microstructure typically consisting of complex wear-resistant carbides (mostly chromium-rich carbides) dispersed in a tougher and more ductile cobalt solid solution matrix mainly containing chromium and tungsten or chromium and molybdenum. The volume fraction of carbides in the microstructure of a Stellite alloy is proportional to its carbon content. The alloy may have a hypo-eutectic microstructure or a hyper-eutectic microstructure, depending mostly on its carbon content but also on the contents of other elements, for example, tungsten. The type of carbides in the microstructure is controlled by the alloying elements in the solution matrix and their contents. The microstructures of each alloy are discussed in detail as follows.

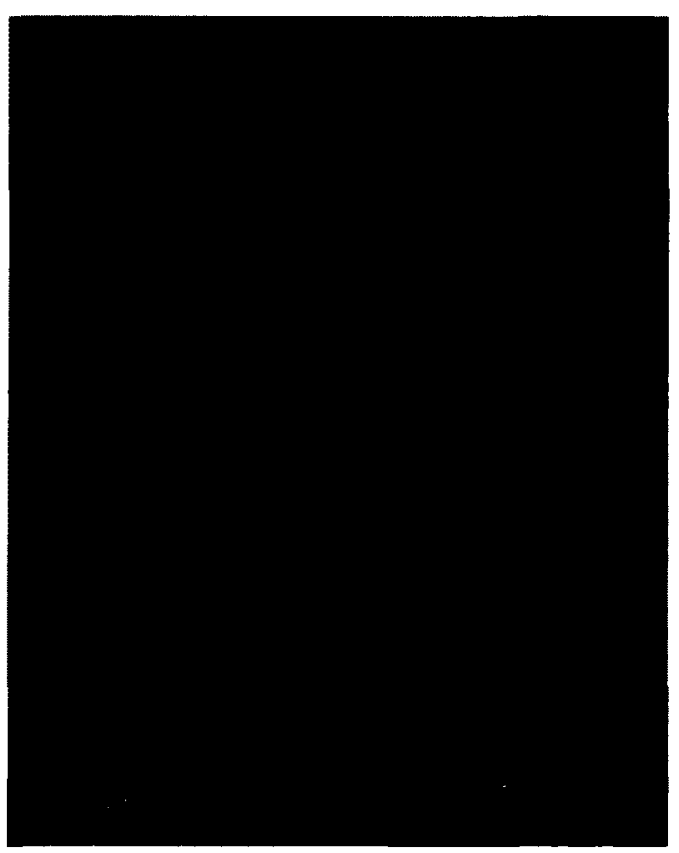

(a) 


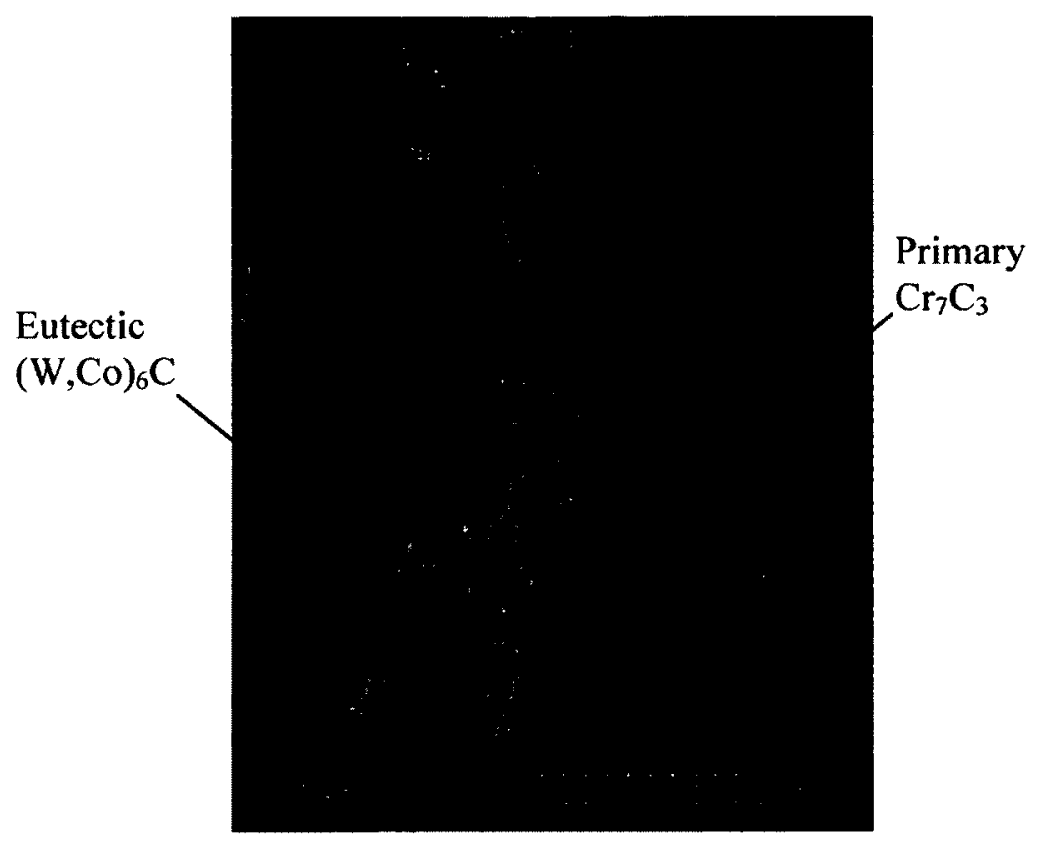

(b)

Figure 3-5: SEM microstructure of alloy A: (a) at low magnification and (b) at high magnification.

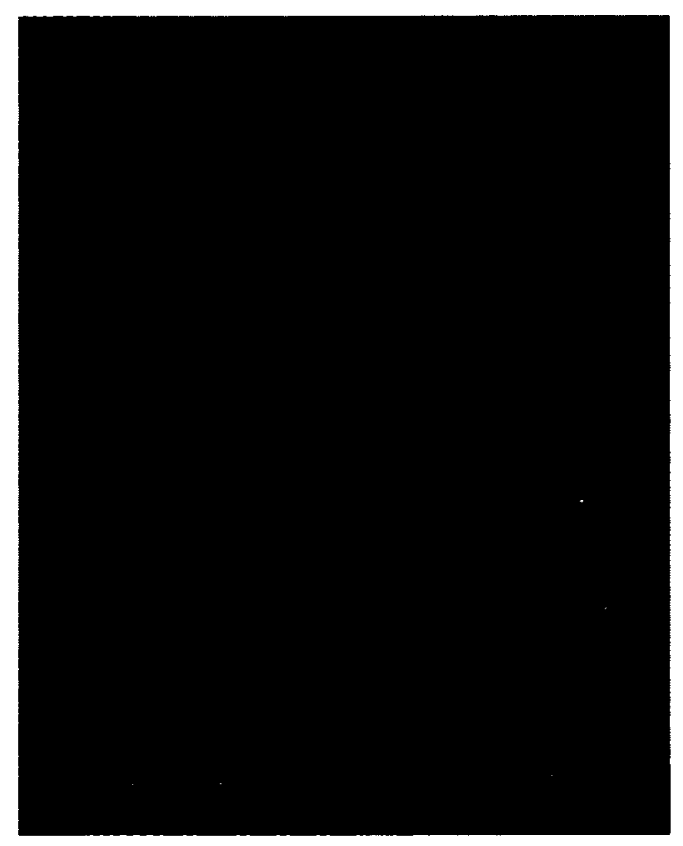

(a) 


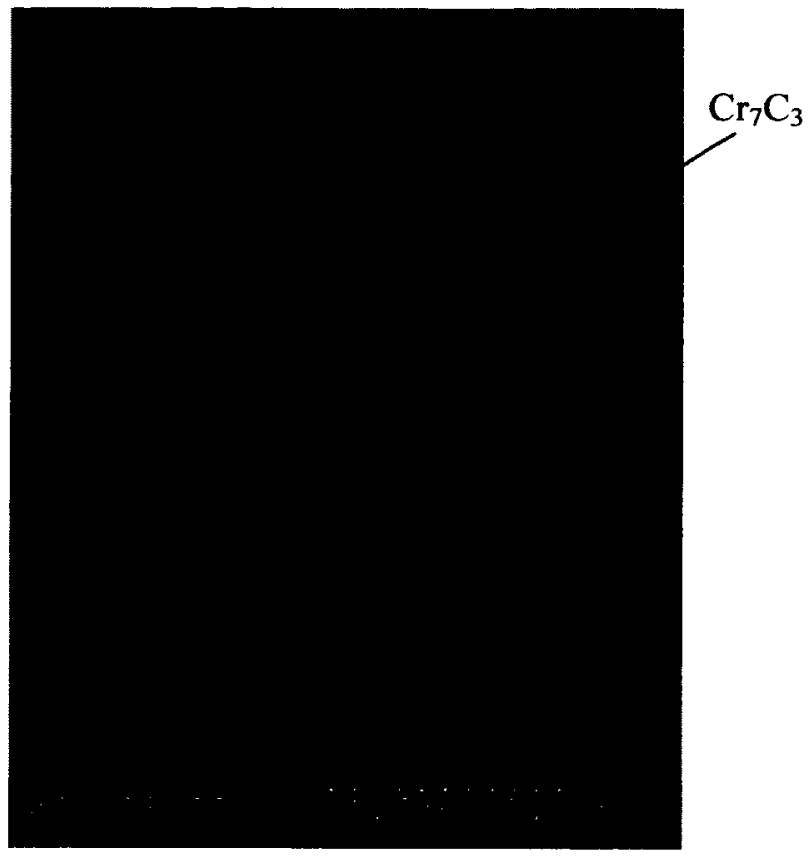

(b)

Figure 3-6: SEM microstructure of alloy B: (a) at low magnification and (b) at high magnification.

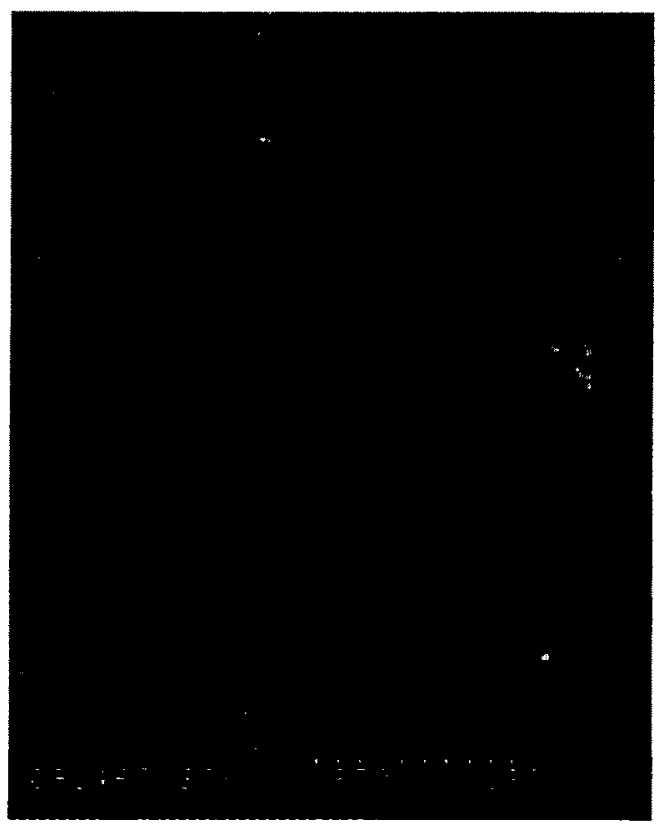

(a) 


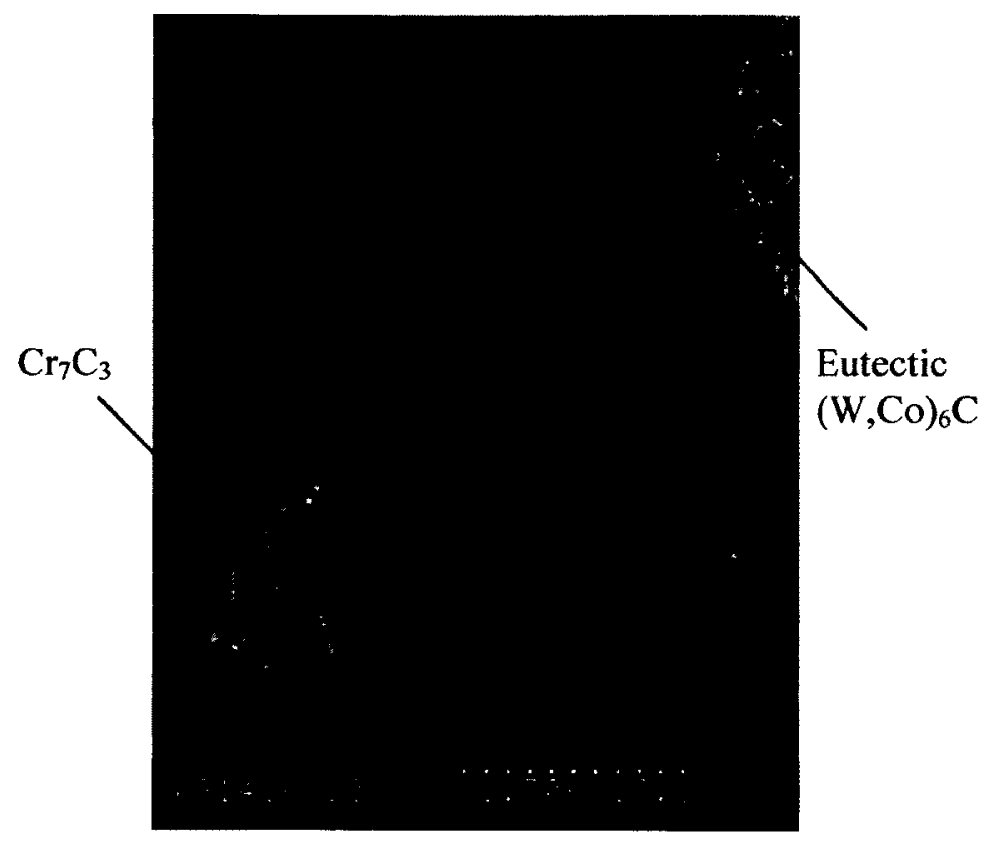

(b)

Figure 3-7: SEM microstructure of alloy $\mathrm{C}$ : (a) at low magnification and (b) at high magnification.

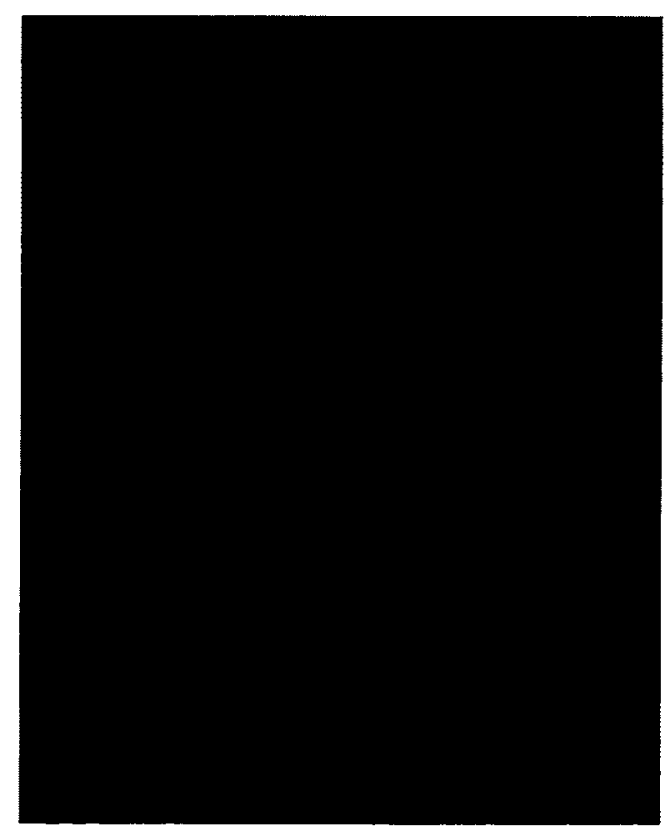

(a) 


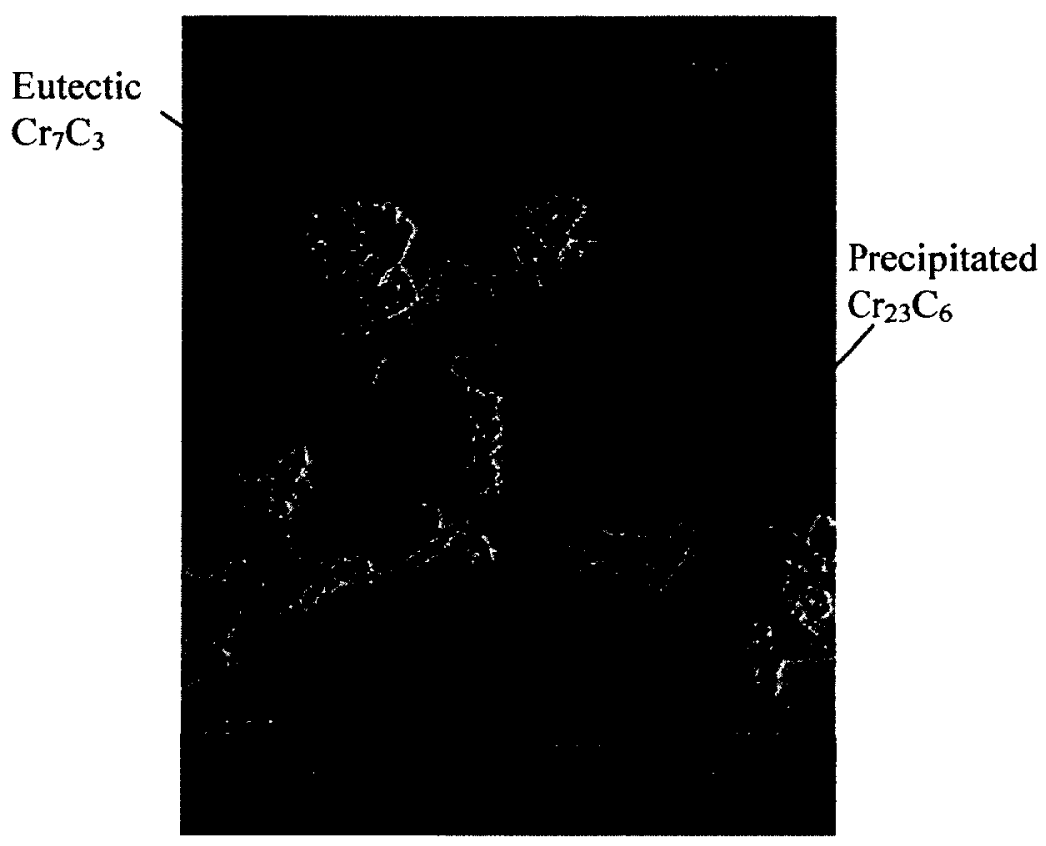

(b)

Figure 3-8: SEM microstructure of alloy D: (a) at low magnification and (b) at high magnification.

\begin{abstract}
Alloy A
It consists of a high carbon content that increases the volume fraction of carbides. The high carbide phase $\mathrm{Cr}_{7} \mathrm{C}_{3}$ (dark) is dispersed in a Co solid solution matrix (grey), with the lighter spots representing eutectic tungsten carbides, $(\mathrm{W}, \mathrm{Co})_{6} \mathrm{C}$ (in light), see Figure 3-5, when the tungsten is not present in the matrix solution. Tungsten in Stellite alloys serves mainly to provide additional strength to the matrix, but when present in large quantities, it participates in the formation of carbides during alloy solidification and promotes the precipitation of $(\mathrm{W}, \mathrm{Co})_{6} \mathrm{C}$. This microstructure is a hyper-eutectic structure.
\end{abstract}




\begin{abstract}
Alloy B
Its microstructure has a less volume fraction of carbides as this alloy has half of the carbon content of Alloy $\mathrm{A} . \mathrm{Cr}_{7} \mathrm{C}_{3}$ (dark) carbides having a laminar shape are dispersed in a similar CoCr alloy matrix, see Figure 3-6. This alloy contains Mo which, as discussed previously, may explain the larger carbide size. The alloy is hypo-eutectic with primary cobalt dendrites surrounded by a network of eutectic $\mathrm{Cr}_{7} \mathrm{C}_{3}$ carbides.
\end{abstract}

\title{
Alloy C
}

This alloy can be considered as a combination of alloy A and alloy B. It is similar to Alloy B with respect to carbon but does not contain Mo. This alloy has the average of the tungsten content and half of the nickel content of these two alloys. Its microstructure is similar to that of Alloy B, hypo-eutectic, consisting of primary cobalt solid solution with longitudinal eutectic $\mathrm{Cr}_{7} \mathrm{C}_{3}$ carbides, see Figure 3-7. However, due to the higher tungsten content, this alloy is also similar to alloy A, containing a small amount of eutectic $(\mathrm{W}, \mathrm{Co})_{6} \mathrm{C}$, as seen in Figure 3-7.

\section{Alloy D}

This alloy appears different from the other alloys being studied. It contains a very low level of carbon so that it has a very small volume fraction of carbides. Therefore, this alloy is a solution-strengthened alloy rather than a carbide-strengthened alloy. Its microstructure contains almost entire solid solution, see Figure 3-8(a); at higher magnification in Figure 3-8(b), one may observe two types of carbides present in the microstructure, eutectic $\mathrm{Cr}_{7} \mathrm{C}_{3}$ and precipitate $\mathrm{Cr}_{23} \mathrm{C}_{6}$. 


\section{Alloy E}

The SEM images of microstructure for alloy $E$ are presented in Figure 3-9. This alloy contains a high level of carbon so that it has a hyper-eutectic microstructure. The areas (locations) detected, representing different phases, are labeled in Figure 3-10(a), and the EDX spectra along with the corresponding element contents for each location are presented in Figure 3-10(b) to Figure 3-10(e). According to the SEM images, this alloy has a microstructure consisting of four phases, as labeled in Figure 3-10(a). From the EDX spectra and the associated constituent content tables, location 1 (in black) is primary $\mathrm{Cr}_{7} \mathrm{C}_{3}$ carbide, because this area has a high concentration of $\mathrm{Cr}$; location 2 (in grey) is $\mathrm{Co}$ solid solution, because of the high concentrations of $\mathrm{Co}$ and $\mathrm{Cr}$; location 3 (in white) must be $(\mathrm{W}, \mathrm{Co})_{6} \mathrm{C}$ carbide, since this area is W-rich; location 4 (in diverse colors) is the eutectic containing a mixture of Co solid solution, both $\mathrm{Cr}_{7} \mathrm{C}_{3}$ and $(\mathrm{W}, \mathrm{Co})_{6} \mathrm{C}$ carbides, as demonstrated by its EDX spectrum, this area is rich in $\mathrm{Co}, \mathrm{Cr}$ and $\mathrm{W}$.

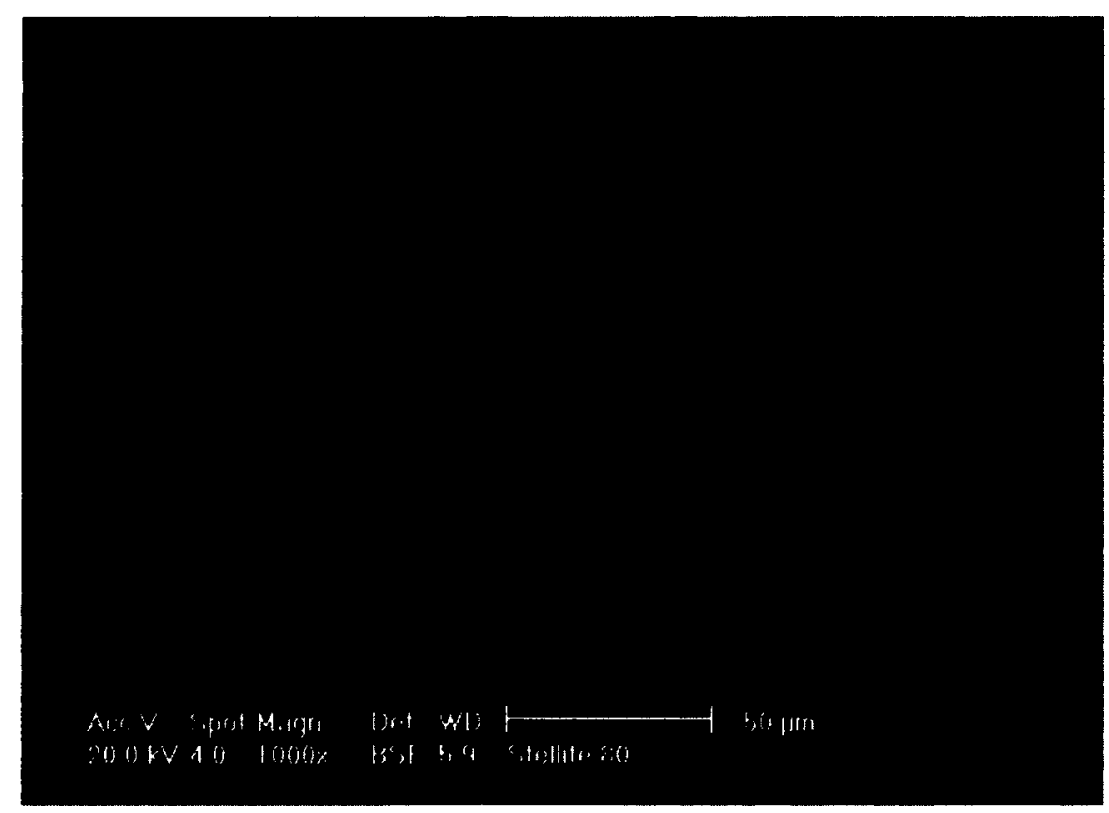

(a) 


\section{(b)}

Figure 3-9: SEM images of microstructure of alloy E used for EDX analysis: (a) at lower magnification and (b) at higher magnification.

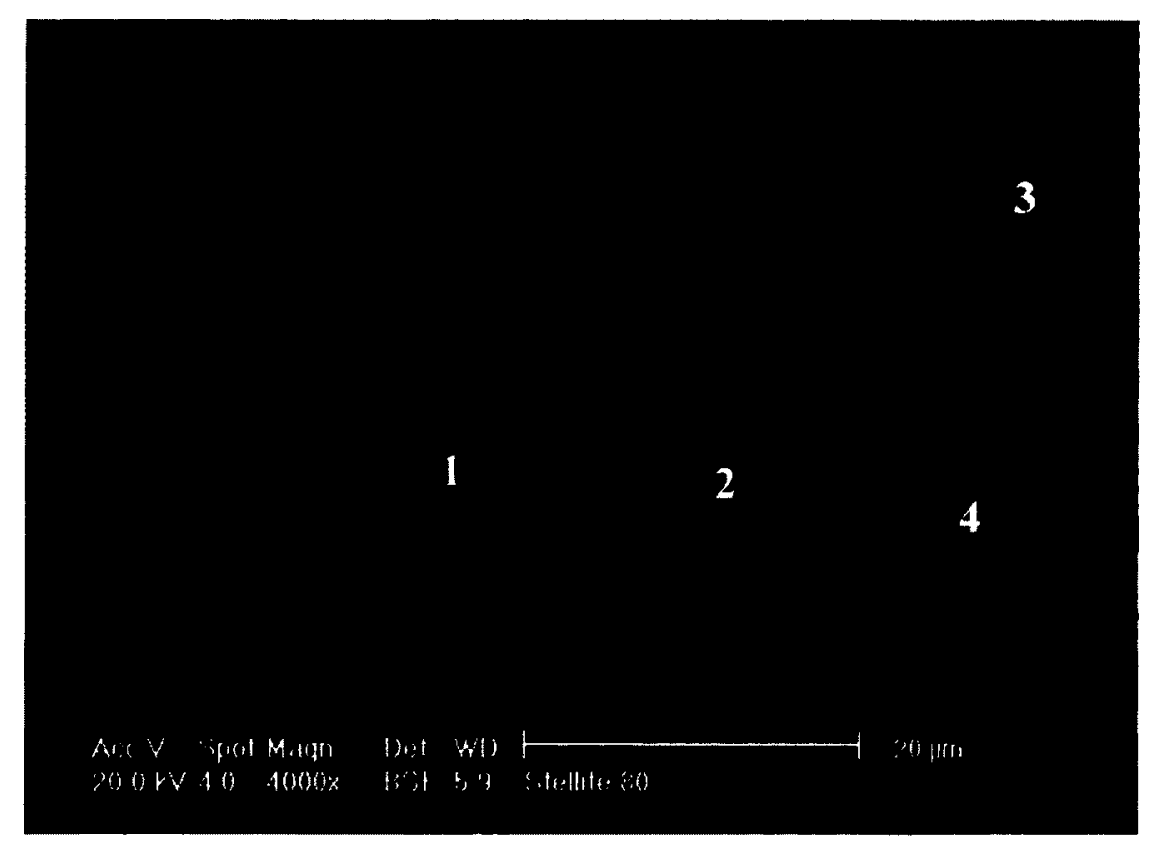

(a) 


\section{C:|x|\}USRIYang|Stellite $80 \_1 . s p c$}

Label A: Stellite 80 _1

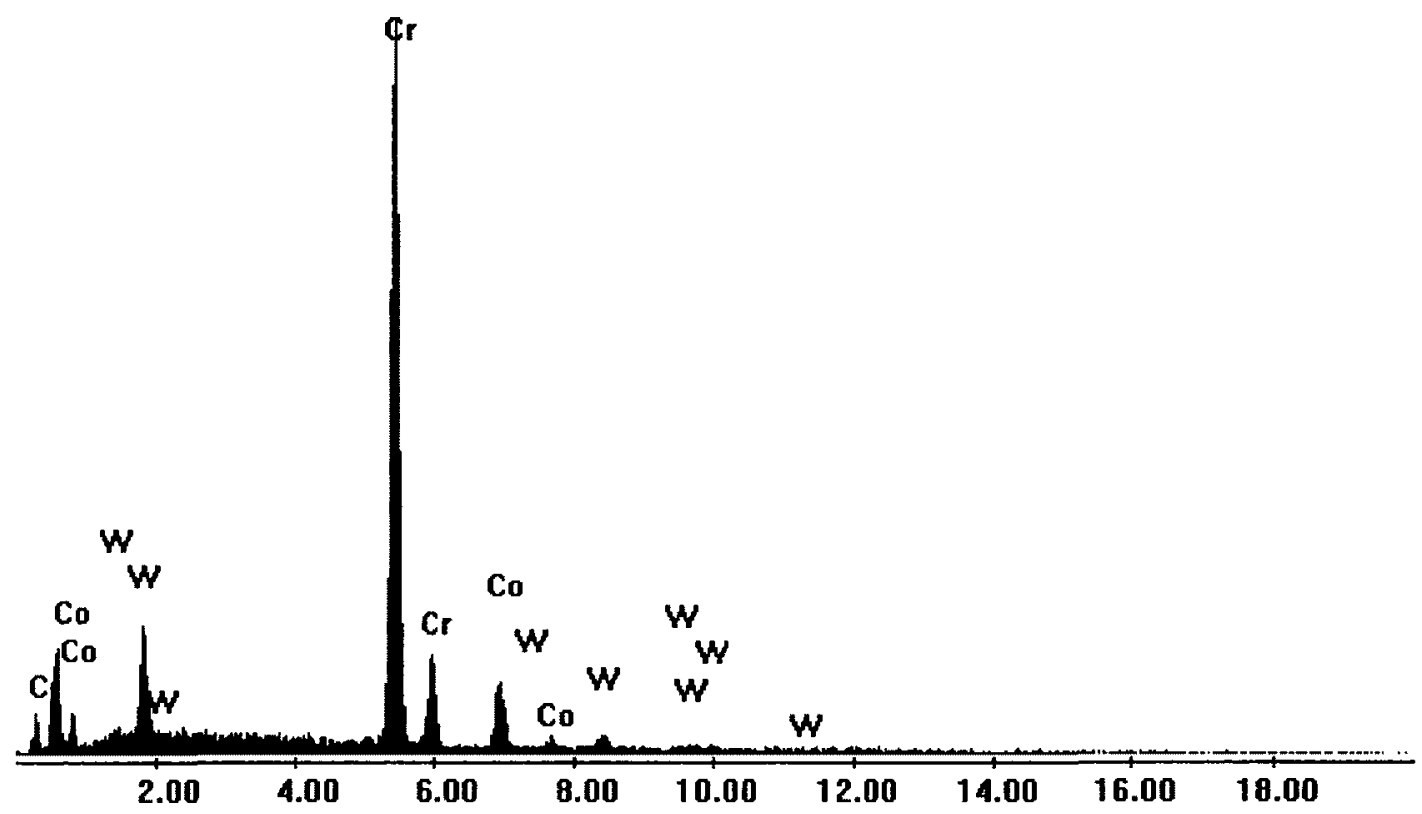

\begin{tabular}{|c|c|c|}
\hline Element & Wt \% & At \% \\
\hline C K & 8.59 & 31.1 \\
\hline CrK & 68.07 & 56.93 \\
\hline CoK & 12.85 & 9.48 \\
\hline W L & 10.49 & 2.48 \\
\hline Total & 100 & 100 \\
\hline
\end{tabular}

(b) 


\section{C:|xl\}USAYYang|Stellite $60 \_2 . s p c$}

Label A: Stellite 80 _2

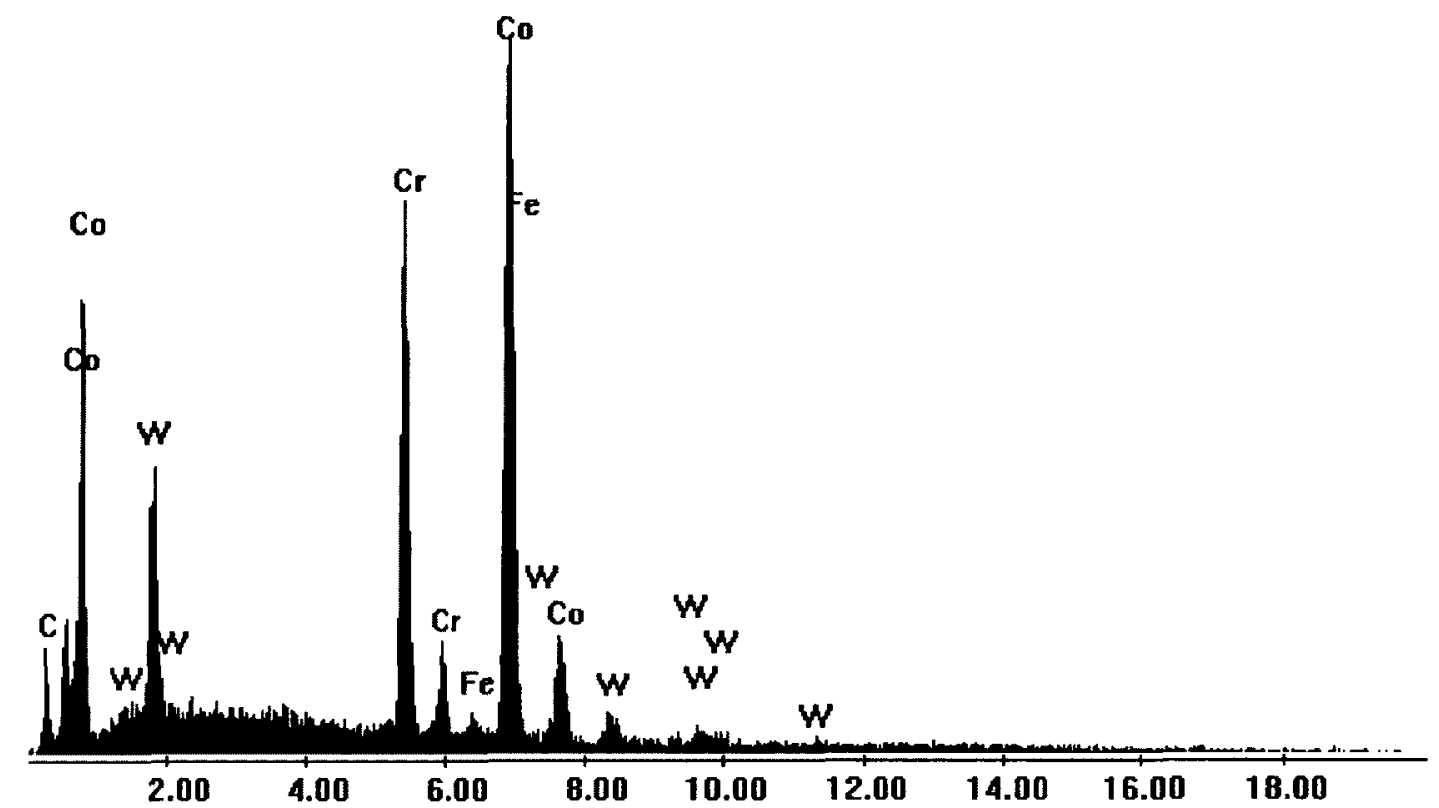

\begin{tabular}{|c|c|c|}
\hline Element & Wt \% & At \% \\
\hline C K & 11.11 & 39.5 \\
\hline CrK & 20.46 & 16.8 \\
\hline FeK & 1.05 & 0.8 \\
\hline CoK & 55.35 & 40.1 \\
\hline W L & 12.03 & 2.79 \\
\hline Total & 100 & 100 \\
\hline
\end{tabular}

(c) 


\section{C:|x|\}USR|Yang|Stellite 80 _3.spc}

Label A: Stellite 80 _3

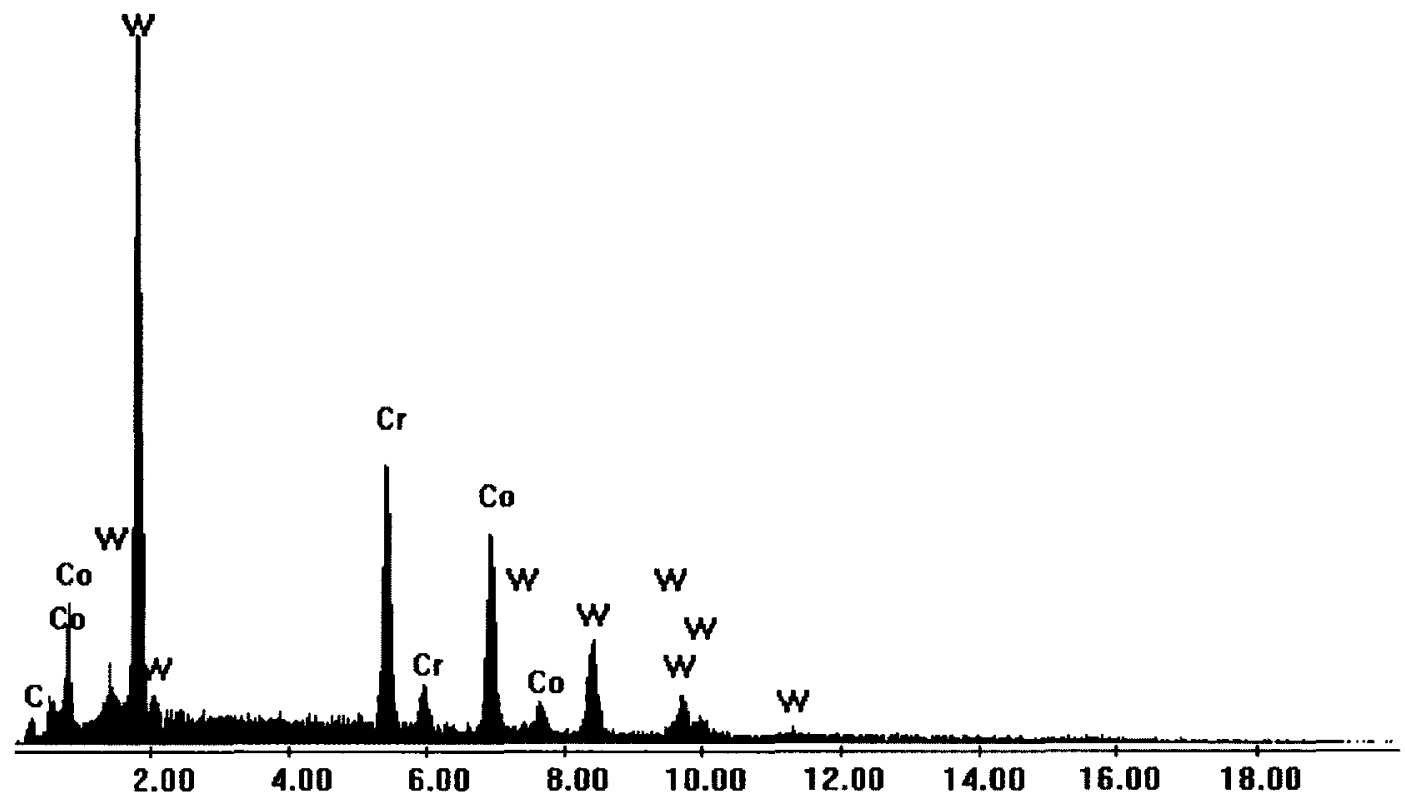

\begin{tabular}{|c|c|c|}
\hline Element & Wt \% & At \% \\
\hline C K & 4.39 & 25.66 \\
\hline CrK & 19.4 & 26.19 \\
\hline CoK & 23.54 & 28.04 \\
\hline W L & 52.66 & 20.11 \\
\hline Total & 100 & 100 \\
\hline
\end{tabular}

(d) 
Label A: Stellite 80 _

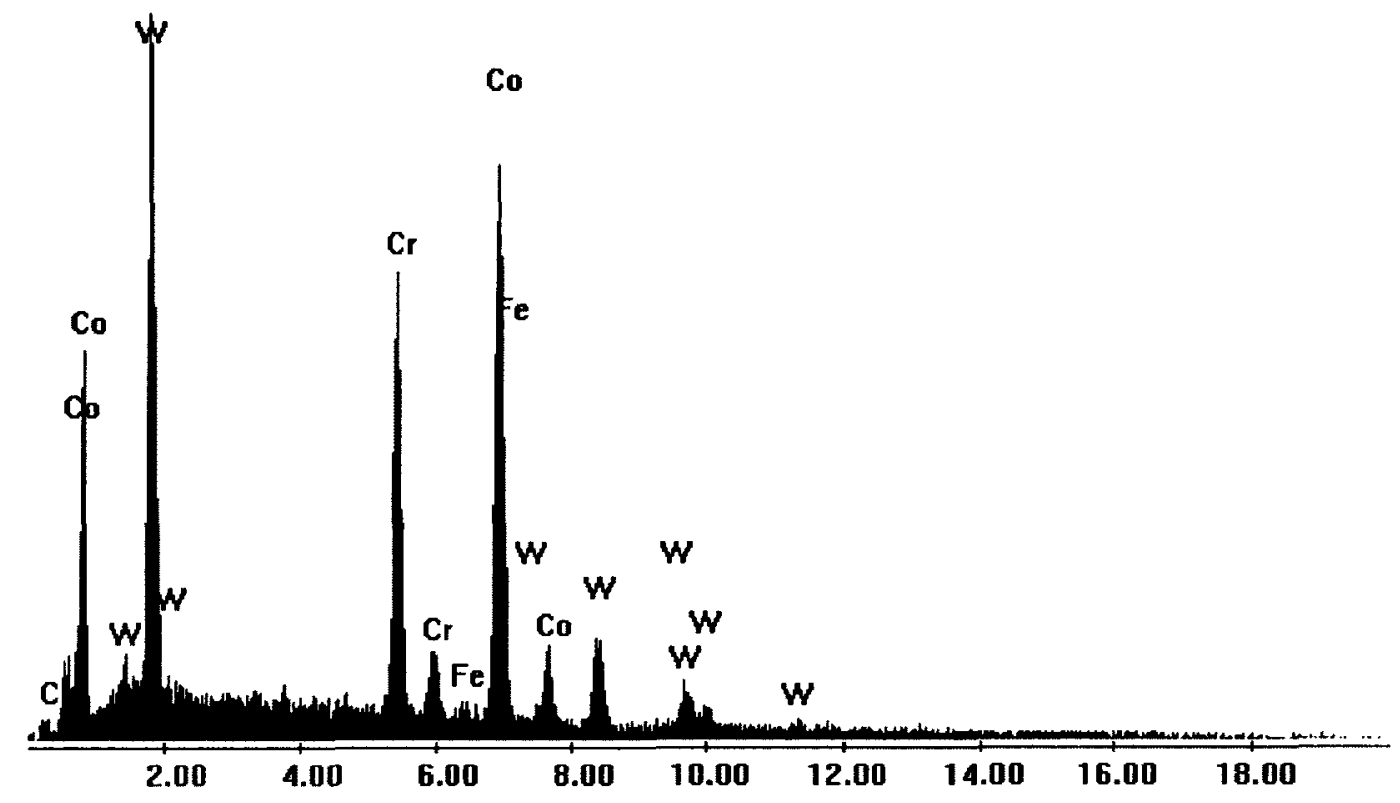

\begin{tabular}{|c|c|c|}
\hline Element & Wt \% & At \% \\
\hline C K & 2.24 & 12.57 \\
\hline CrK & 18.9 & 24.46 \\
\hline FeK & 0.87 & 1.04 \\
\hline CoK & 43.02 & 49.13 \\
\hline W L & 34.97 & 12.8 \\
\hline Total & 100 & 100 \\
\hline
\end{tabular}

(e)

Figure 3-10: EDX results of alloy E: (a) phases detected, (b) EDX spectrum of location 1 (c) EDX spectrum of location 2, (d) EDX spectrum of location 3 and (e) EDX spectrum of location 4. 
The presence of boron can form $\mathrm{Cr}$-rich borides in alloy $\mathrm{E}$, which was proved by previous research [30], but the boron peak cannot be identified and presented in the EDX spectrum since its amount is very small. The minor amount of eutectic $\mathrm{Cr}$-rich boride was formed at a lower temperature (around $95^{\circ} \mathrm{C} \sim 100^{\circ} \mathrm{C}$ ). It is also observed that as the primary $\mathrm{Cr}_{7} \mathrm{C}_{3}$ carbide has a larger size and takes a large volume fraction of this alloy; see Figure 3-9, because of both the high $\mathrm{Cr}$ content and the high carbon content in this alloy. Tungsten exists mainly in the solid solution for matrix strengthening, but owing to the high content, it also forms eutectic $(\mathrm{W}, \mathrm{Co})_{6} \mathrm{C}$ in this alloy. However, the amount of (W, Co) $)_{6} \mathrm{C}$ is much less than that of $\mathrm{Cr}_{7} \mathrm{C}_{3}$ in this alloy, as shown in Figure 3-9. Similar to but also different from tungsten, chromium is the predominant carbide former in Stellite alloys so that it exists largely in the carbides, for example, in $\mathrm{Cr}_{7} \mathrm{C}_{3}$ of alloy $\mathrm{E}$, but it is also the most important alloying element of the matrix, providing added strength, as a solute, and resistance to corrosion and oxidation.

\section{Alloy F}

Alloy $\mathrm{F}$ contains a very high level of $\mathrm{W}$ and a medium level of $\mathrm{C}$. The SEM images of microstructure for this alloy are presented in Figure 3-11. Due to the very high level of $\mathrm{W}$, this alloy also has a hyper-eutectic microstructure, with $(\mathrm{W}, \mathrm{Co})_{6} \mathrm{C}$ carbide as the primary phase. The primary $(\mathrm{W}, \mathrm{Co})_{6} \mathrm{C}$ (in light) has a larger size and takes a large volume fraction. The eutectic consists of a mixture of solid solution, $\mathrm{Cr}_{7} \mathrm{C}_{3}$ carbide and (W,Co) ${ }_{6} \mathrm{C}$ carbide as well. The areas (locations) identified, representing different phases, are labeled in Figure 3-12(a); the EDX spectra and the associated element content tables for each location (phase) are shown in Figure 3-12(b) to Figure 3-12(e). 
(a)

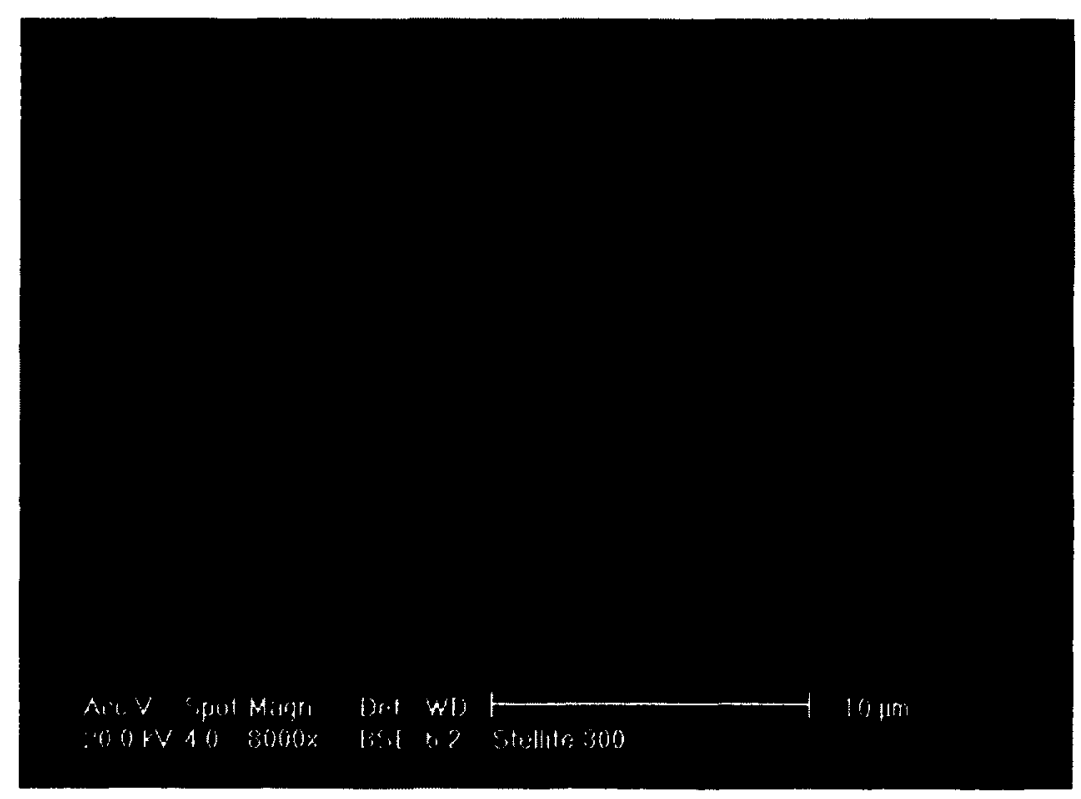

(b)

Figure 3-11: SEM images of microstructure of alloy F used for EDX analysis: (a) at lower magnification and (b) at higher magnification. 


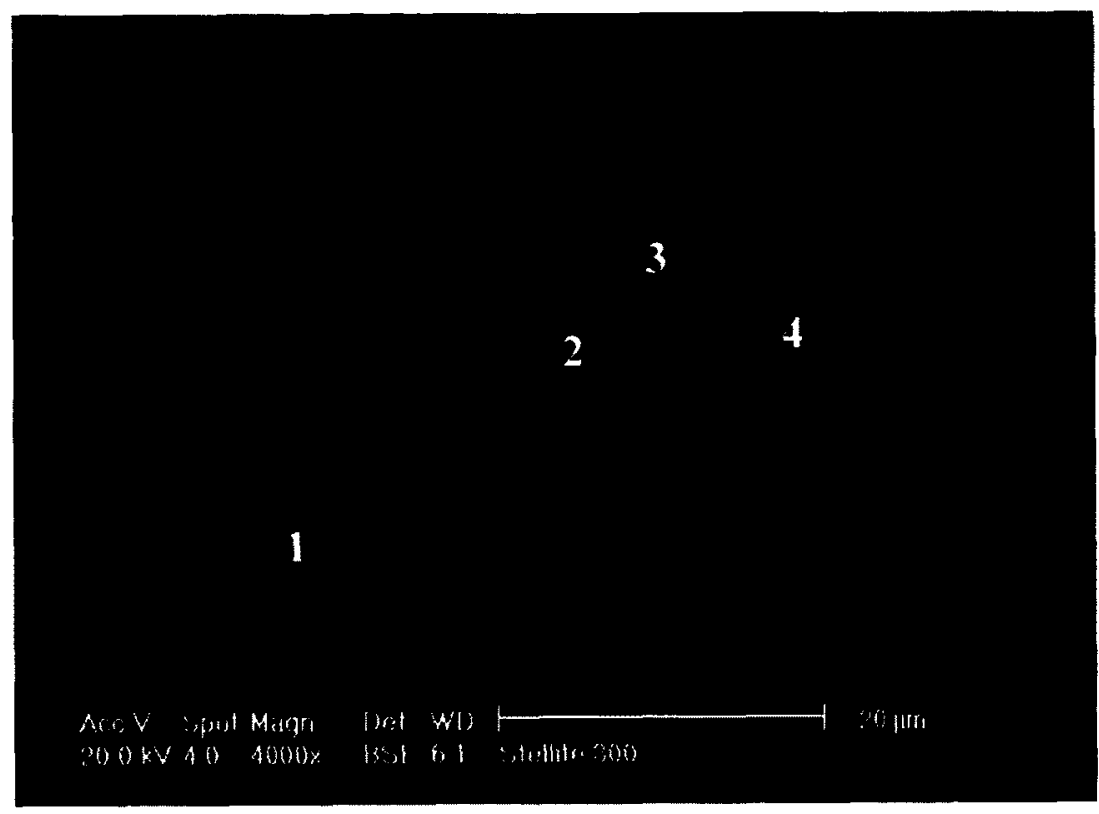

(a)

C:XXI\}USA|YangłStellite-300_1.spc

Label A: Stellite 300 _

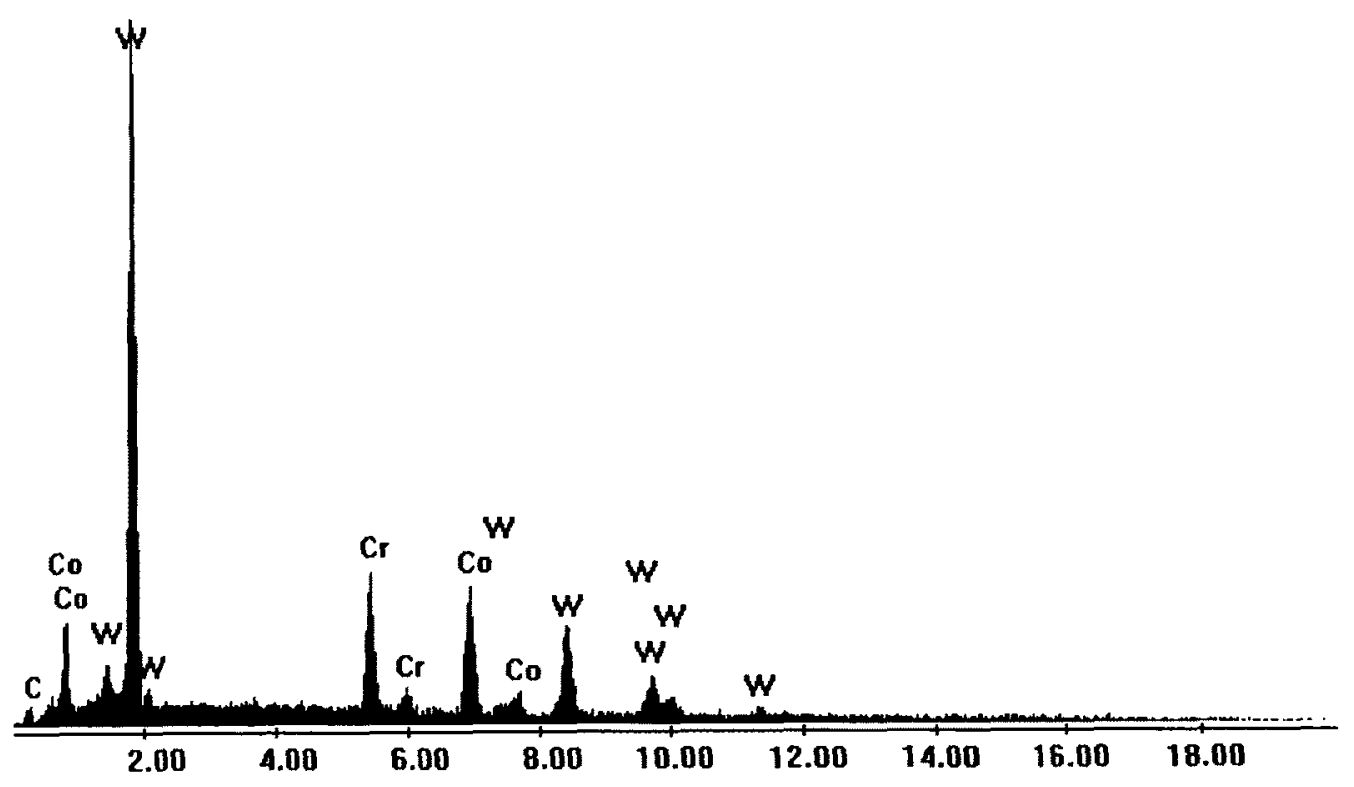




\begin{tabular}{|l|l|l|}
\hline Element & Wt \% & At \% \\
\hline C K & 3.44 & 23.99 \\
\hline CrK & 12.15 & 19.58 \\
\hline CoK & 18.57 & 26.42 \\
\hline W L & 65.84 & 30.02 \\
\hline Total & 100 & 100 \\
\hline
\end{tabular}

(b)

C:Ix|yUSP|Yang|Stellite 300 _2.spc

Label A: Stellite $300 \_2$

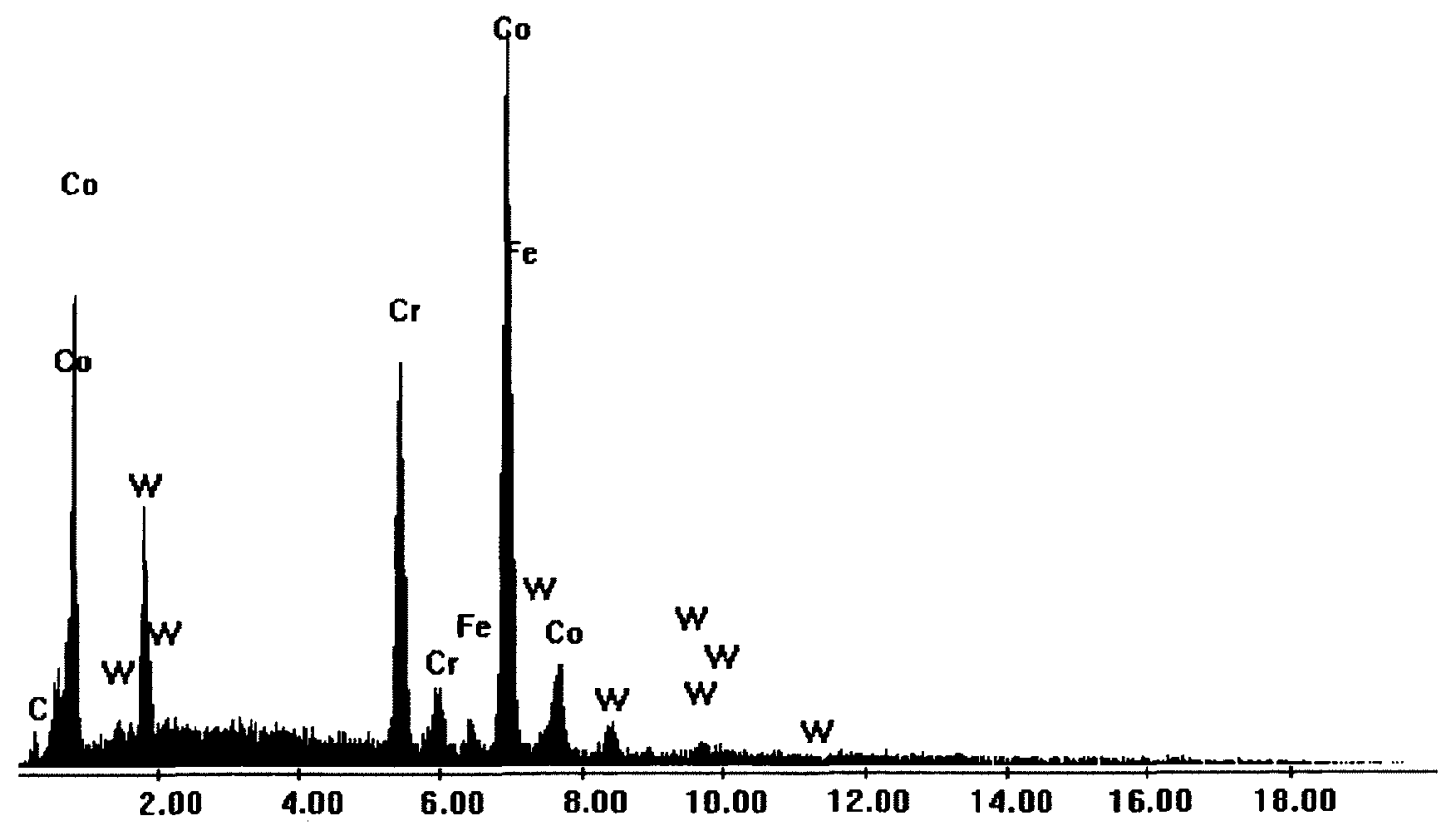




\begin{tabular}{|l|l|l|}
\hline Element & Wt \% & At \% \\
\hline C K & 3.91 & 17.62 \\
\hline CrK & 18.56 & 19.3 \\
\hline FeK & 2.29 & 2.22 \\
\hline CoK & 62.13 & 57.01 \\
\hline W L & 13.1 & 3.85 \\
\hline Total & 100 & 100 \\
\hline
\end{tabular}

(c)

C:|x|\}USRIYang|Stellite $300 \_3 . s p c$

Label A: Stellite $300 \_3$

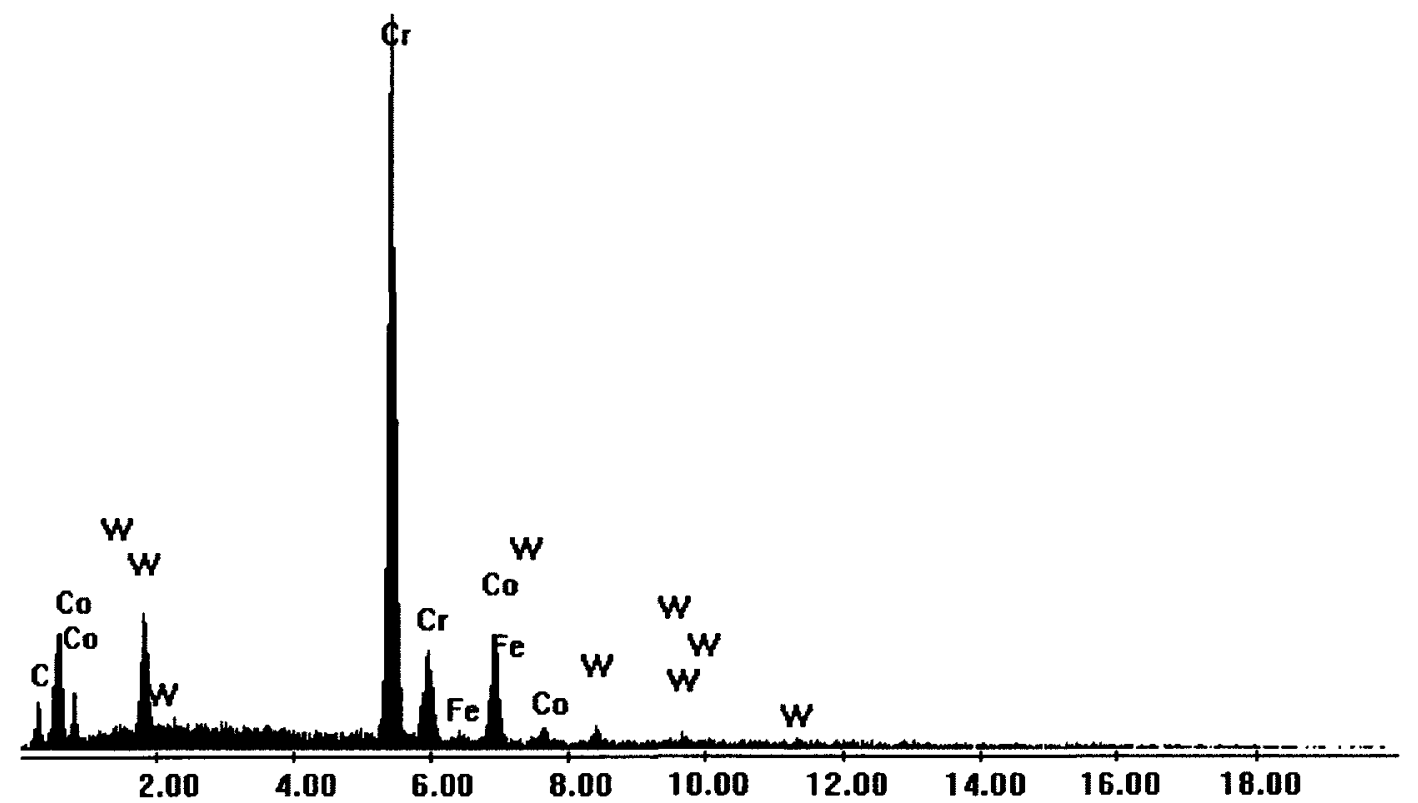




\begin{tabular}{|l|l|l|}
\hline Element & Wt \% & At \% \\
\hline C K & 9.99 & 35.02 \\
\hline CrK & 61.12 & 49.48 \\
\hline FeK & 0.98 & 0.74 \\
\hline CoK & 17.25 & 12.32 \\
\hline W L & 10.66 & 2.44 \\
\hline Total & 100 & 100 \\
\hline
\end{tabular}

(d)

C:|X|\}USA|Yang|Stellite 300 _4.spc

Label A: Stellite 300 _4

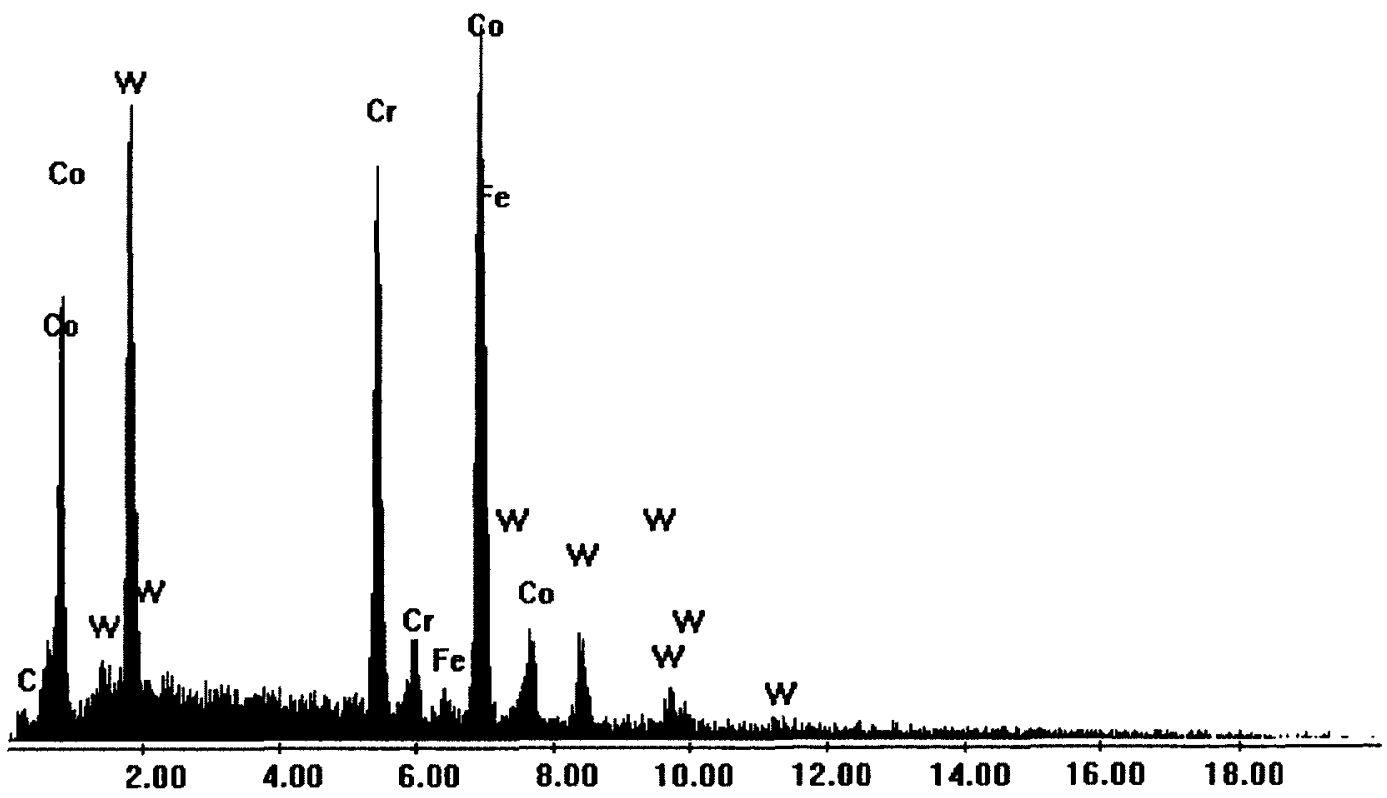




\begin{tabular}{|l|l|l|}
\hline Element & Wt \% & At \% \\
\hline C K & 3.16 & 16.18 \\
\hline CrK & 20.19 & 23.85 \\
\hline FeK & 1.21 & 1.33 \\
\hline CoK & 47.19 & 49.2 \\
\hline W L & 28.25 & 9.44 \\
\hline Total & 100 & 100 \\
\hline
\end{tabular}

(e)

Figure 3-12: EDX results of alloy F: (a) phases detected, (b) EDX spectrum of location 1 (c) EDX spectrum of location 2, (d) EDX spectrum of location 3 and (e) EDX spectrum of location 4 .

According to the SEM images in Figure 3-11, this alloy has a microstructure consisting of four phases, as indicated in Figure 3-12(a). Based on the information in the EDX spectra and the associated element content tables, location 1 (in white) is primary $(\mathrm{W}, \mathrm{Co})_{6} \mathrm{C}$ carbide, as this area has a high concentration of $\mathrm{W}$; location 2 (in grey) is Co solid solution, because of the high concentrations of $\mathrm{Co}$ and $\mathrm{Cr}$; location 3 (in black) must be eutectic $\mathrm{Cr}_{7} \mathrm{C}_{3}$ carbide, since this area has a high content of $\mathrm{Cr}$; location 4 (in diverse colors) is the eutectic containing a mixture of $\mathrm{Co}$ solid solution, both $\mathrm{Cr}_{7} \mathrm{C}_{3}$ and $(\mathrm{W}, \mathrm{Co})_{6} \mathrm{C}$ carbides, as demonstrated by its EDX spectrum, this area contains high contents of $\mathrm{Co}, \mathrm{Cr}$ and $\mathrm{W}$.

Compared with alloy $\mathrm{E}$, the amount of $\mathrm{Cr}_{7} \mathrm{C}_{3}$ in alloy $\mathrm{F}$ is reduced significantly. This may be attributed to both the reduced $\mathrm{C}$ content and the increased $\mathrm{W}$ content. On the 
other hand, the amount of $(\mathrm{W}, \mathrm{Co})_{6} \mathrm{C}$ in alloy $\mathrm{F}$ increases greatly. This can be explained as most of $\mathrm{C}$ is to form $(\mathrm{W}, \mathrm{Co})_{6} \mathrm{C}$ thus resulting in reduction of $\mathrm{Cr}_{7} \mathrm{C}_{3}$. According to the microstructure, less amount of $(\mathrm{W}, \mathrm{Co})_{6} \mathrm{C}$ is in the eutectic (with small size) and more is the primary (with large size). Tungsten also exists in the solid solution for matrix strengthening. Chromium in alloy $\mathrm{F}$ is to form $\mathrm{Cr}_{7} \mathrm{C}_{3}$, but it also exists in the solid solution to provide additional strength, as a solute, and resistance to corrosion and oxidation. As the primary phase, Co solid solution of alloy $\mathrm{F}$ takes more volume fraction than that of alloy $\mathrm{E}$ as one of constituents of the eutectic.

\subsubsection{Estimation of carbide volume fraction}

In order to facilitate the consequent analyses of wear behaviour of these alloys, it was necessary to quantify the carbide phases in the alloys. Based on the carbon contents of each alloy and the literature data, the weight percentages of carbides in the alloys can be estimated. As reported, at a carbon level of $2.4 \mathrm{wt} \%$ (Stellite 3), the carbides constitute about $30 \mathrm{wt} \%$ of the material; and at $1 \mathrm{wt} \%$ carbon (Stellite $6 \mathrm{~B}$ ), the carbides constitute approximately $13 \mathrm{wt} \%$ of the material [1]. The amount of carbides in a Stellite alloy is proportional to its carbon content. Utilizing the interpolation method, one may estimate the weight percentage of carbides in each alloy; the values are given in Table 3-2. Consequently, using the density values of carbides and cobalt solid solution, one may convert the weight percentages to the volume fractions. For the density of carbides, the density of chromium carbide, $6.97 \mathrm{~g} / \mathrm{cm}^{3}$, was used in this calculation, while the density of $(\mathrm{W}, \mathrm{Co})_{6} \mathrm{C}$ was not considered separately, which may lead to some error in the values reported in Table 3-2. However, since the difference in density between $\mathrm{Cr}_{7} \mathrm{C}_{3}$ carbide 
and $(\mathrm{W}, \mathrm{Co})_{6} \mathrm{C}$ carbide is not much, the accuracy of the data from this calculation is sufficient for the wear resistance analyses of the alloys. To obtained the density of Co solid solution, Stellite 25 was selected to measure its density, because this alloy contains a very low carbon content $(0.1 \mathrm{wt} \%)$, thus minimal carbide amount; it is a solution-strengthened alloy. As an approximation, the density of Stellite 25, which was measured to be $8.82 \mathrm{~g} / \mathrm{cm}^{3}$, was used as the density of Co solid solution in this calculation. The detailed procedure of the conversion is described below.

Let $W_{s}$ represents the weight of solid solution and $W_{c}$ carbides, $\rho_{s}$ represents the density of solid solution and $\rho_{c}$ carbides, then $V_{s}=\frac{W_{s}}{\rho_{s}}$ and $V_{c}=\frac{W_{c}}{\rho_{c}}, W_{s}+W_{c}=W$ and $V_{s}+V_{c}=V, \frac{W}{V}=\rho$, where $V_{s}$ and $V_{c}$ are the volumes of solid solution and carbides, respectively; $W, V$ and $\rho$ are the weight, volume and density of the alloy, respectively.

Let $a$ and $b$ are the weight percentages of solid solution and carbides, respectively, then $\frac{W_{s}}{W}=a$ and $\frac{W_{c}}{W}=b, a+b=1$

Using the above relations, the following may be derived,

$$
\frac{a W}{\rho_{s}}+\frac{b W}{\rho_{c}}=\frac{W}{\rho}, \frac{a}{\rho_{s}}+\frac{b}{\rho_{c}}=\frac{1}{\rho}, \rho=\frac{\rho_{s} \rho_{c}}{a \rho_{c}+b \rho_{s}}
$$

Let $x$ and $y$ are the volume percentages of solid solution and carbides, respectively, then

$$
x+y=1, x=\frac{V_{s}}{V} \text { and } y=\frac{V_{c}}{V}=\frac{\frac{W_{c}}{\rho_{c}}}{\frac{W}{\rho}}=\frac{\rho W_{c}}{\rho_{c} W}=\frac{\rho b W}{\rho_{c} W}=\frac{\rho b}{\rho_{c}}=\frac{b \rho_{s} \rho_{c}}{\rho_{c}\left(a \rho_{c}+b \rho_{s}\right)}
$$


Using $y=\frac{b \rho_{s} \rho_{c}}{\rho_{c}\left(a \rho_{c}+b \rho_{s}\right)}$, the volume fraction of carbides for each alloy can be calculated, and the data are provided in Table 3-2.

Table 3-2: Calculated Quantities of Carbides in Stellite Alloys

\begin{tabular}{|l|c|c|c|}
\hline Specimen & $\begin{array}{c}\text { Carbon content } \\
(\mathrm{wt} \%)\end{array}$ & $\begin{array}{c}\text { Carbide weight percentage } \\
(\mathbf{w t} \%)\end{array}$ & $\begin{array}{c}\text { Carbide volume fraction } \\
(\text { vol\%) }\end{array}$ \\
\hline Alloy A & 2.4 & 30 & 35.16 \\
\hline Alloy B & 1.2 & 15.43 & 18.76 \\
\hline Alloy C & 1.4 & 17.86 & 21.56 \\
\hline Alloy D & 0.25 & 3.25 & 28.31 \\
\hline Alloy E & 1.9 & 23.93 & 22.97 \\
\hline Alloy F & 1.5 & 19.07 & \\
\hline
\end{tabular}




\section{Chapter: Hardness Investigation}

\subsection{Indentation Test}

\subsubsection{Test apparatus}

Hardness is one of the important factors in the characterization of a material. It is the measure of how resistant a solid material is to a permanent shape change when a force is applied. It is an important characteristic in material selection as many material properties such as ductility, elasticity, strain, toughness and strength are related to this value. In particular, the hardness property is often used in the field of wear resistance as a qualitative indicator for judging alloys, coatings, hardfacings and overlays. It is generally accepted that the harder the material, the greater the wear resistance, for most of materials. The hardness of metallic materials usually decreases with temperature, especially when the temperature reaches a critical level, the hardness drops steeply, depending on individual materials. For wear resistance application of Stellite alloys at elevated temperatures, therefore it is necessary to understand the variations of hardness over a range of operating temperatures.

In this research, a Microhardness Tester Unit, Model SMT-X7 Dual Indenter, shown in Figure 4-1, was employed to investigate the hardness of each individual phase in the microstructures of the six alloys being studied, at both room and elevated temperatures. This model of microhardness tester unit is fully-automated with a computer-controlled motorized turret, and compatible with both Vickers indenter and Knoop indenter standards. It has a software interfaced dial, from $1 \mathrm{gf}$ to a maximum load capacity of 2000 gf. The loading duration can vary between $5 \sim 60 \mathrm{~s}$. With a microscope equipped, each individual phase in a microstructure can be identified and selected to be 
measured. The apparatus applies a constant force to the sharp indenter making a permanent indent on the specimen material. The hardness value is automatically computed by a built-in software package based upon the area of the indentation left in the specimen and the force applied. For Vickers hardness, the value is calculated based on the measurement of the diagonals of the indentation (

Figure 4-2) made under a set load.

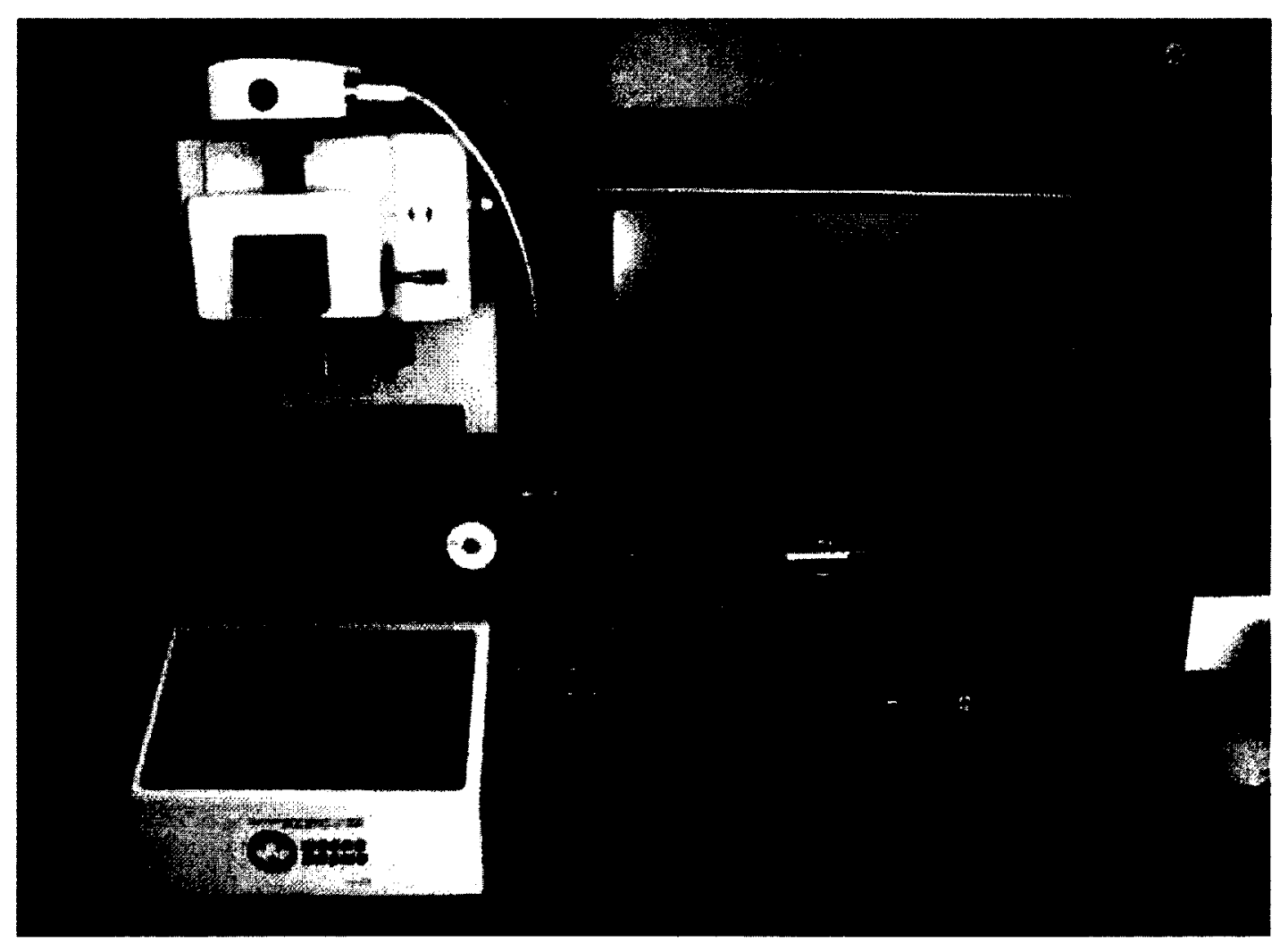

Figure 4-1: Microhardness Tester Unit, Model SMT-X7 Dual Indenter. 


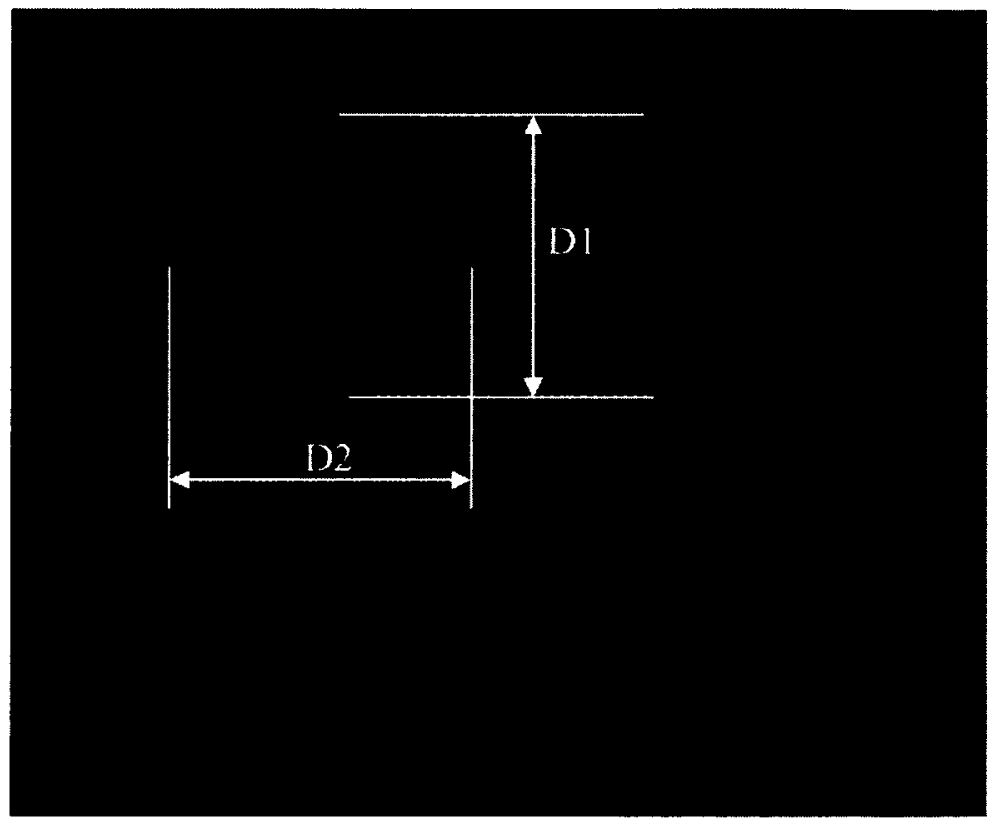

Figure 4-2: An indentation made by a Vickers indenter.

To achieve the temperature capacity of $700^{\circ} \mathrm{C}$, a Hot-Stage Assembly, shown in Figure 4-3, is attached to the platform of the Microhardness Tester Unit when the hardness test is performed at elevated temperatures. A cooling system is also available to maintain the platform unheated for operation, see Figure 4-4. The heating and cooling rates can be selected and automatically controlled by a control unit shown in Figure 4-5. However, since the entire system is exposed to air, that is, the test specimen is not in a vacuum environment, the oxidation of the specimen surface at high temperatures is inevitable, which may affect the accuracy of the hardness result. On the other hand, hardness is only associated with plastic deformation of a material, while oxide films are generally brittle or fragile, with this viewpoint, the effect of surface oxidation in this test may be neglected. 


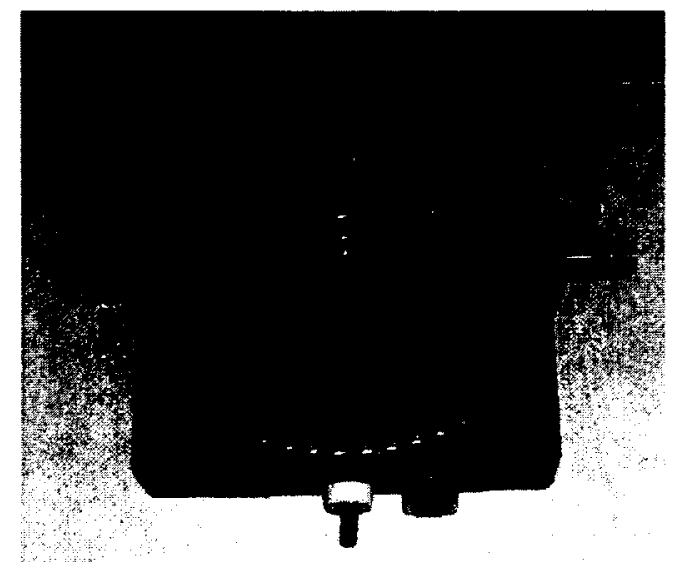

Figure 4-3: Hot-Stage Assembly.

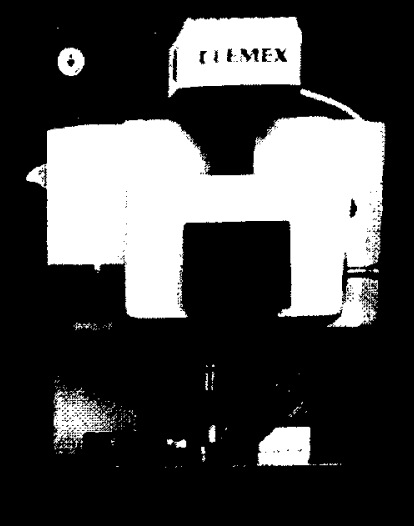

$\hat{*}$
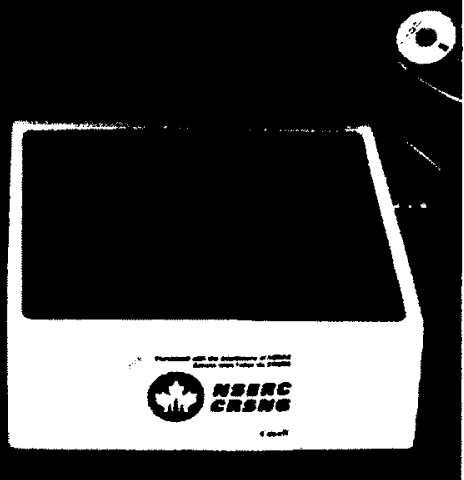

Figure 4-4: Microhardness Tester Unit equipped with a Hot-Stage Assembly and cooling system. 


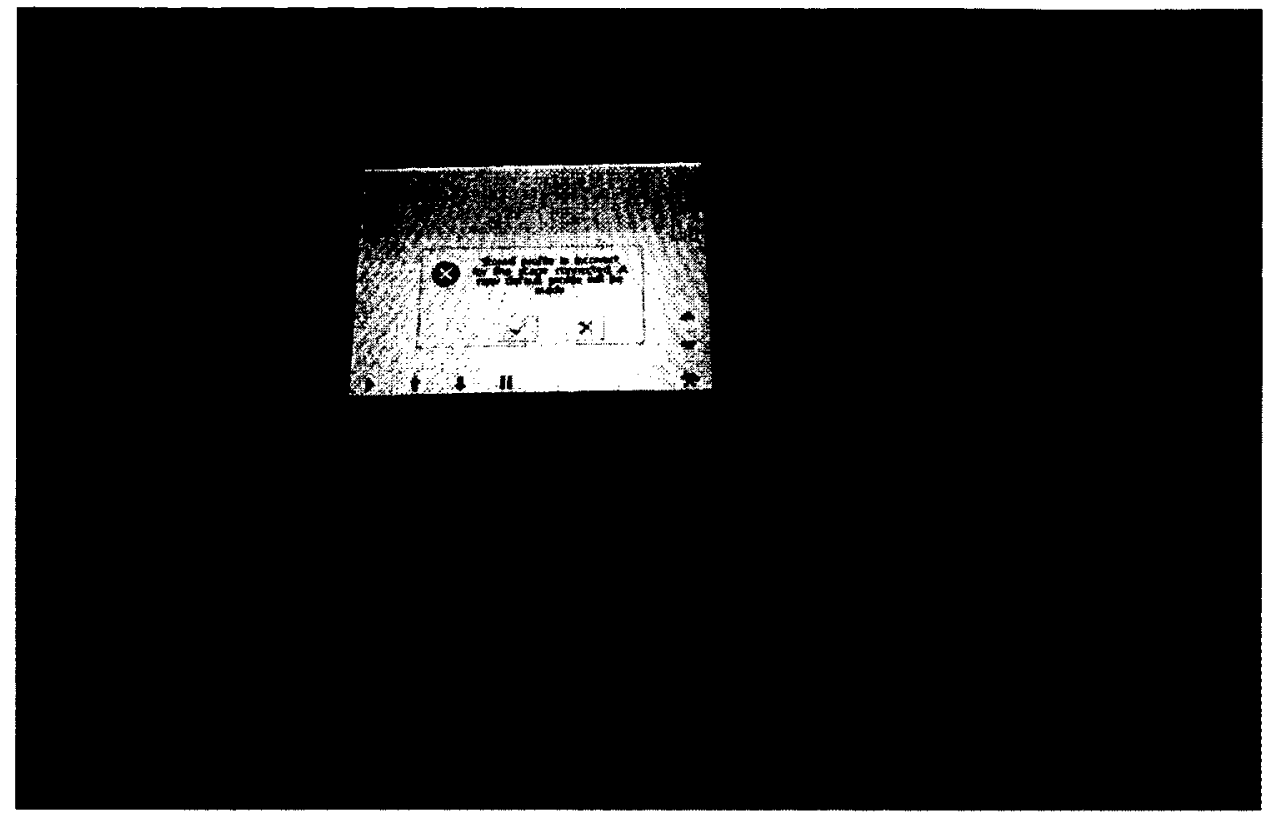

Figure 4-5: Temperature control unit for the Hot-Stage Assembly.

\subsubsection{Experiment details}

The specimens for high-temperature microhardness test must have a dimension of $6.5 \mathrm{~mm}$ in diameter and $1.5 \sim 2 \mathrm{~mm}$ in thickness that fit into the hot-stage furnace, but for room temperature test, the specimen can have any dimension. However, since a specimen can be used for a test cycle, that is, from room temperature up to $650^{\circ} \mathrm{C}$ and then down to room temperature, the specimens used for this test were all made to the dimension for the hot-stage furnace. The specimen surfaces for testing were ground with grit papers from $\# 180$ to $\# 600$ and polished with abrasive cloth plus $1 \mu \mathrm{m}$ alumina powders. A low indentation load of $100 \mathrm{gf}$ was selected, which allowed the indentation to be made on a selected phase, because if the load was too high, the indentation may cover an area with other phases involved. The indentation test for each specimen was conducted at room temperature, $250^{\circ} \mathrm{C}, 450^{\circ} \mathrm{C}$ and $650^{\circ} \mathrm{C}$, respectively, in a heating process, and then for the 
same specimen, the indentation was successively made at $450^{\circ} \mathrm{C}, 250^{\circ} \mathrm{C}$ and room temperature, respectively, in a cooling process. The purpose of doing this reciprocal cycle test was to explore any thermal effects on the hardness of these materials by comparing the hardness value tested at the temperature in heating process with that tested at the same temperature but in cooling process. The apparatus with the control unit is capable of climbing temperatures at a set rate and also allows holding each temperature for a certain period of time prior to indentation to ensure a uniformly heated surface. During indentation, a constant force is applied to a sharp indenter and held for a very short period of time that generates permanent deformation in the material under testing. The test parameters used in this research are summarized in Table 4-1.

Table 4-1: Summary of micro hardness test specifications

\begin{tabular}{|l|l|}
\hline Temperature profile & $\begin{array}{l}\text { Heating: } 20^{\circ} \mathrm{C}, 250^{\circ} \mathrm{C}, 450^{\circ} \mathrm{C}, 650^{\circ} \mathrm{C} \\
\text { Cooling: } 650^{\circ} \mathrm{C}, 450^{\circ} \mathrm{C}, 250^{\circ} \mathrm{C}, 20^{\circ} \mathrm{C}\end{array}$ \\
\hline Temperature holding time & $3 \mathrm{~min}$ \\
\hline Heating rate & $50^{\circ} \mathrm{C} / \mathrm{min}$ \\
\hline Indentation force & $100 \mathrm{gf}$ \\
\hline Indenter dwell time & $15 \mathrm{sec}$ \\
\hline
\end{tabular}

Five indentations were made at each temperature for each specimen and two specimens were tested for each alloy being studied. The hardness value for each test case was an average of the ten test results. In order to avoid the influence of material pre-deformation under previous indentations on the hardness result, there should be a space between two indentations at least larger than three indentation diagonal lengths. 


\subsection{Hardness Values}

\subsubsection{Experimental results}

Since Stellite alloys are multi-phase alloys which contain at least two phases, known as cobalt solid solution and carbides, and each phase may exhibit different features including hardness, the micro hardness test was conducted on each phase of the alloys being studied at the temperature cycle. The following summarizes the test results. The microscopic images of indentations left in the tested specimens, shown below, were all taken at a magnification of $400 \mathrm{X}$.

\section{Alloy A}

From its microstructure in Figure 3-5, this alloy consists of two types of carbides, $\mathrm{M}_{7} \mathrm{C}_{3}$ and $(\mathrm{W}, \mathrm{Co})_{6} \mathrm{C}$, dispersed in the cobalt solid solution matrix. Attempts were made to conduct the indentation on these three phases respectively. For the solution matrix, it was possible to make the indentation on single solid solution phase, as shown in Figure 0-1(a) to Figure 0-7(a) within Appendix A. However, for the carbides, due to their small sizes, especially, for the carbide (W,Co $)_{6} \mathrm{C}$, it was impossible for the indenter to cover a single phase, because the area under the indenter is a mixture of $\mathrm{M}_{7} \mathrm{C}_{3},(\mathrm{~W}, \mathrm{Co})_{6} \mathrm{C}$ and solid solution, as shown in Figure $0-1(\mathrm{~b})$ to Figure $0-7(\mathrm{~b})$. The average hardness values from the indentation tests for alloy A are plotted again temperature in Figure 4-6.

\section{Alloy B}

As shown in Figure 3-6, the microstructure of this alloy consists of $\mathrm{M}_{7} \mathrm{C}_{3}$ carbides dispersed in the cobalt solid solution matrix. The carbides have a laminar shape. The indentation test was conducted on the carbide phase and the solution, respectively. For 
the solution matrix, it was possible to make the indentation on single solid solution phase, as shown in Figure 0-8(a) to Figure 0-14(a), however, for the carbide phase, due to the laminar structure, the area covered by the indenter may contain minor solution phase, as shown in the images in Figure 0-8(b) to Figure 0-14(b). The average hardness values from the indentation tests for alloy B are plotted again temperature in Figure 4-7.

\section{Alloy C}

This alloy has a similar microstructure to Alloy B, consisting of primary solid solution with longitudinal eutectic $\mathrm{Cr}_{7} \mathrm{C}_{3}$ carbides, as shown in Figure 3-7. In addition, due to the higher tungsten content, this alloy is also similar to alloy $\mathrm{A}$, containing a small amount of eutectic $(\mathrm{W}, \mathrm{Co})_{6} \mathrm{C}$ as seem in Figure $3-7$. It was possible to make the indentation on single solid solution phase, as shown in Figure 0-15(a) to Figure 0-21(a), but similar to alloy $\mathrm{B}$, for the indentation test on $\mathrm{Cr}_{7} \mathrm{C}_{3}$ carbide, the area covered by the indenter also contained minor solid solution phase, as shown in Figure 0-15(b) to Figure $0-21$ (b). Also, the indentation could not be made on the $(\mathrm{W}, \mathrm{Co})_{6} \mathrm{C}$ phase because the sizes of the carbides are too small. The average hardness values from the indentation tests for alloy $\mathrm{C}$ are plotted again temperature in Figure 4-8.

\section{Alloy D}

This alloy contains a very low level of carbon so that a very small volume fraction of carbides are formed in the alloy. As shown in Figure 3-8, its microstructure appears almost entire solid solution. Since the carbides are very small and very rare, the indentation made on the carbides had to cover certain amounts of the solid solution. From 
the observation, more than half of the area under the indenter was the solid solution. The microscopic images of indentations left in the tested specimens of alloy $D$ are provided in Figure $0-22$ to Figure $0-28$. The average hardness values from the indentation tests for this alloy are plotted again temperature in Figure 4-9.

\begin{abstract}
Alloy E
This alloy has a hyper-eutectic microstructure, consisting of primary $\mathrm{Cr}_{7} \mathrm{C}_{3}$ carbide and eutectic $(\mathrm{W}, \mathrm{Co})_{6} \mathrm{C}$ dispersed in a solid solution matrix, see Figure 3-9. It was possible to make the indentation on the entire $\mathrm{Cr}_{7} \mathrm{C}_{3}$ carbide phase because of its large size of the carbides. However, the solid solution is mixed with $(\mathrm{W}, \mathrm{Co})_{6} \mathrm{C}$ and minor $\mathrm{Cr}_{7} \mathrm{C}_{3}$ so that the indentation could only be made on the eutectic of (W,Co) 6 C, $\mathrm{Cr}_{7} \mathrm{C}_{3}$ and solid solution. The microscopic images of indentations left in the tested specimens of alloy $\mathrm{E}$ are provided in Figure $0-29$ to Figure $0-35$. The average hardness values from the indentation tests for this alloy are plotted again temperature in Figure 4-10.
\end{abstract}

\title{
Alloy F
}

This alloy has a hyper-eutectic microstructure, consisting of primary $(\mathrm{W}, \mathrm{Co})_{6} \mathrm{C}$ and the eutectic containing solid solution, $\mathrm{Cr}_{7} \mathrm{C}_{3}$ and $(\mathrm{W}, \mathrm{Co})_{6} \mathrm{C}$, owing to the very high $\mathrm{W}$ content, as shown in Figure $3-11$. The $(\mathrm{W}, \mathrm{Co})_{6} \mathrm{C}$ carbide is large enough to allow the indentation to be made on single (W,Co) 6 C carbide phase, as shown in Figure $0-36$ (a) to Figure $0-42$ (a). However, the amounts of solid solution and $\mathrm{Cr}_{7} \mathrm{C}_{3}$ are small and are all mixed with $(\mathrm{W}, \mathrm{Co})_{6} \mathrm{C}$ so that the indentation could only be made on the mixture rather than the entire solid solution phase, as seen in Figure 0-36(b) to Figure 0-42(b). The 
average hardness values from the indentation tests for alloy $F$ are plotted again temperature in Figure 4-11.

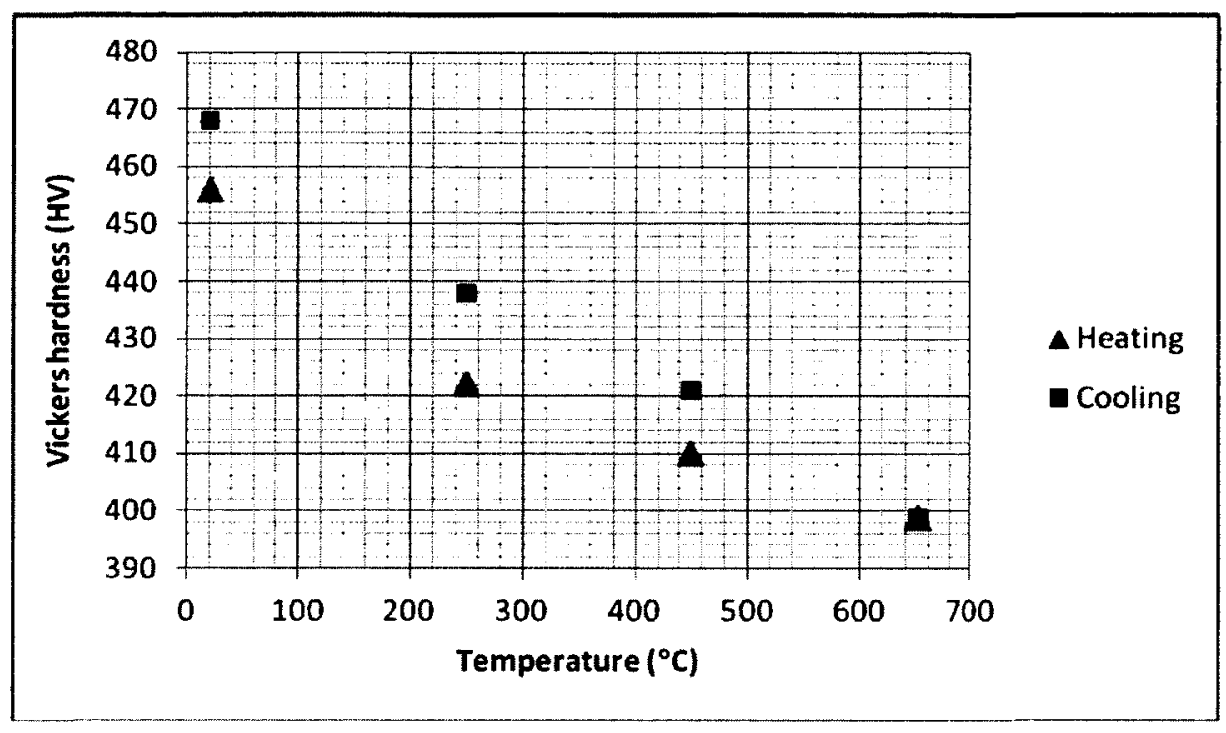

(a)

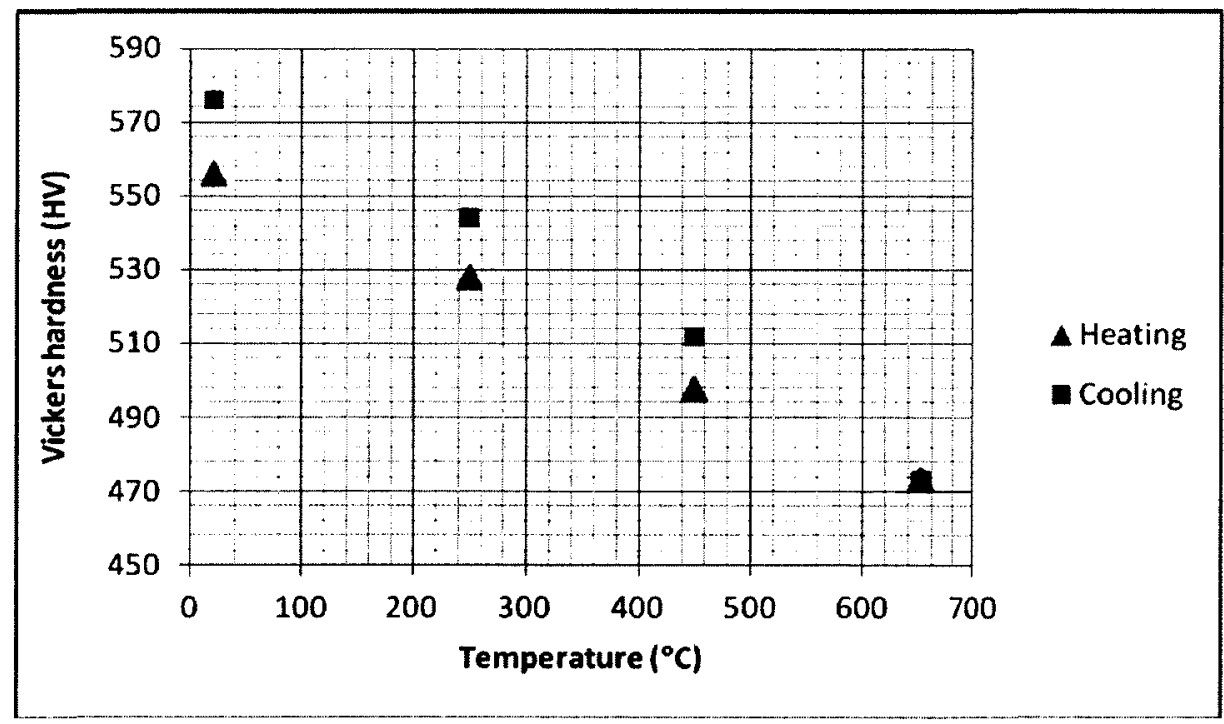

(b)

Figure 4-6: Variations of hardness with temperature in heating/cooling cycle for alloy $\mathrm{A}$ :

(a) solid solution and (b) carbides/solution mixture. 


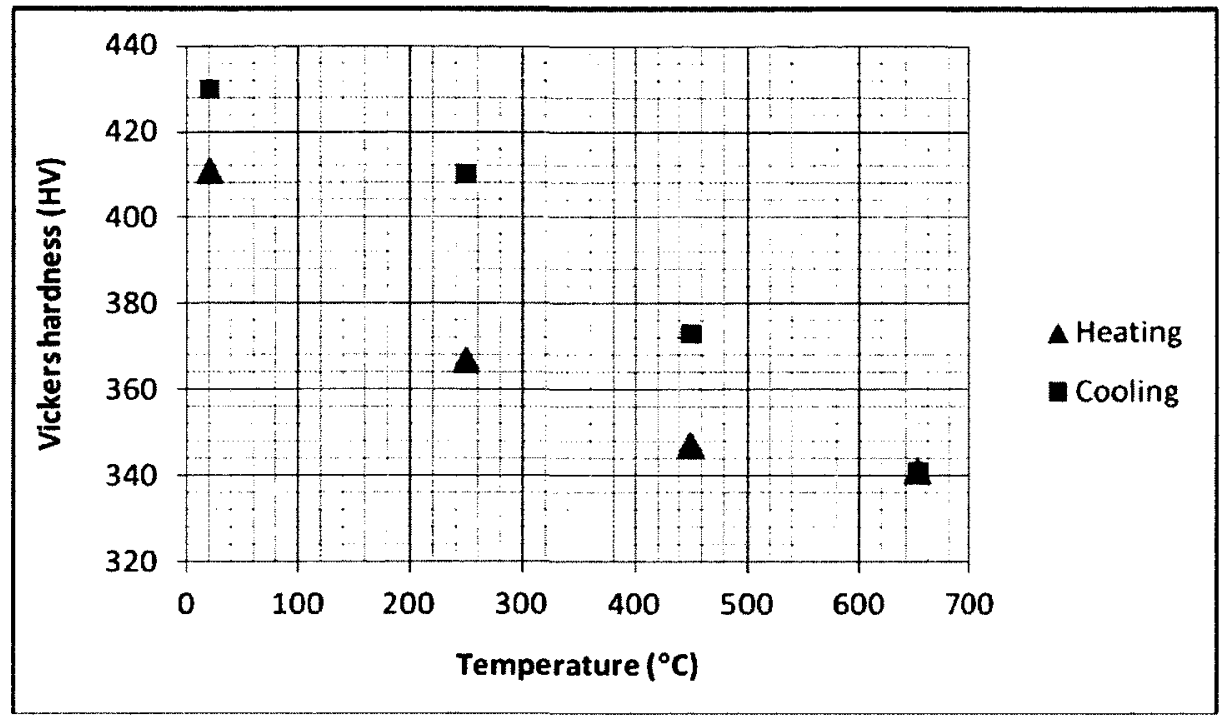

(a)

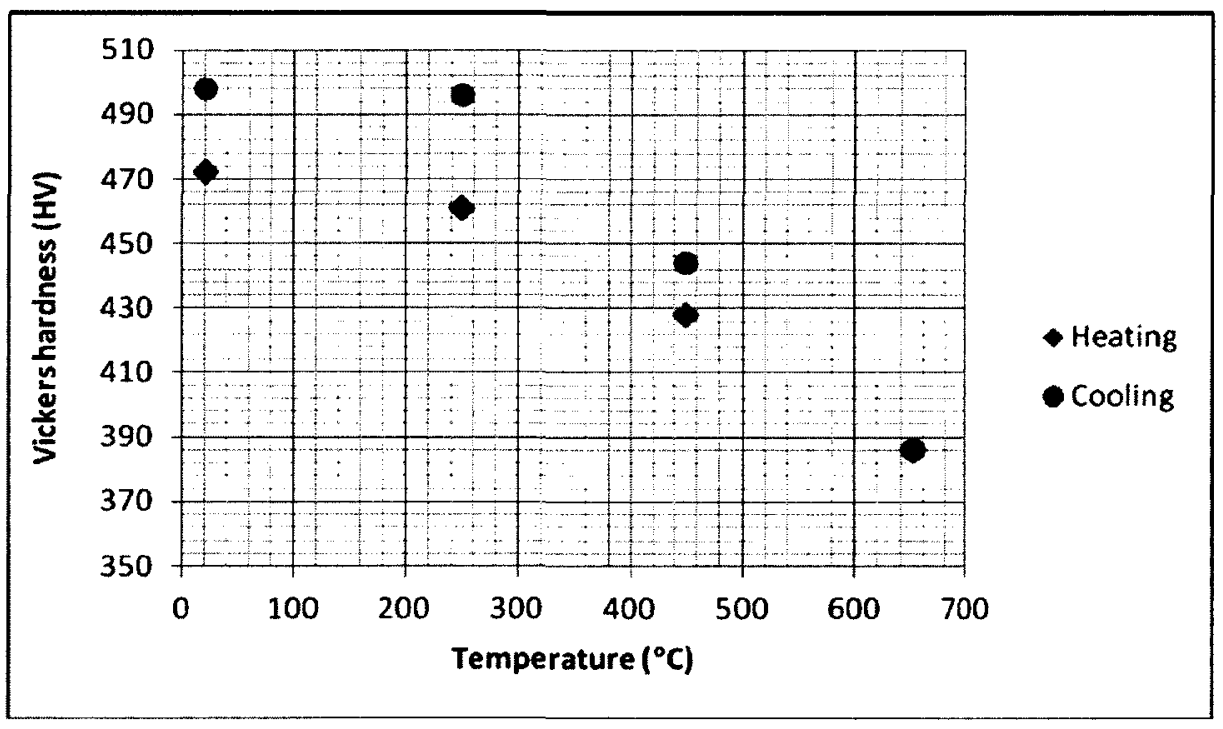

(b)

Figure 4-7: Variations of hardness with temperature in heating/cooling cycle for alloy B:

(a) solid solution and (b) carbide with minor solid solution. 


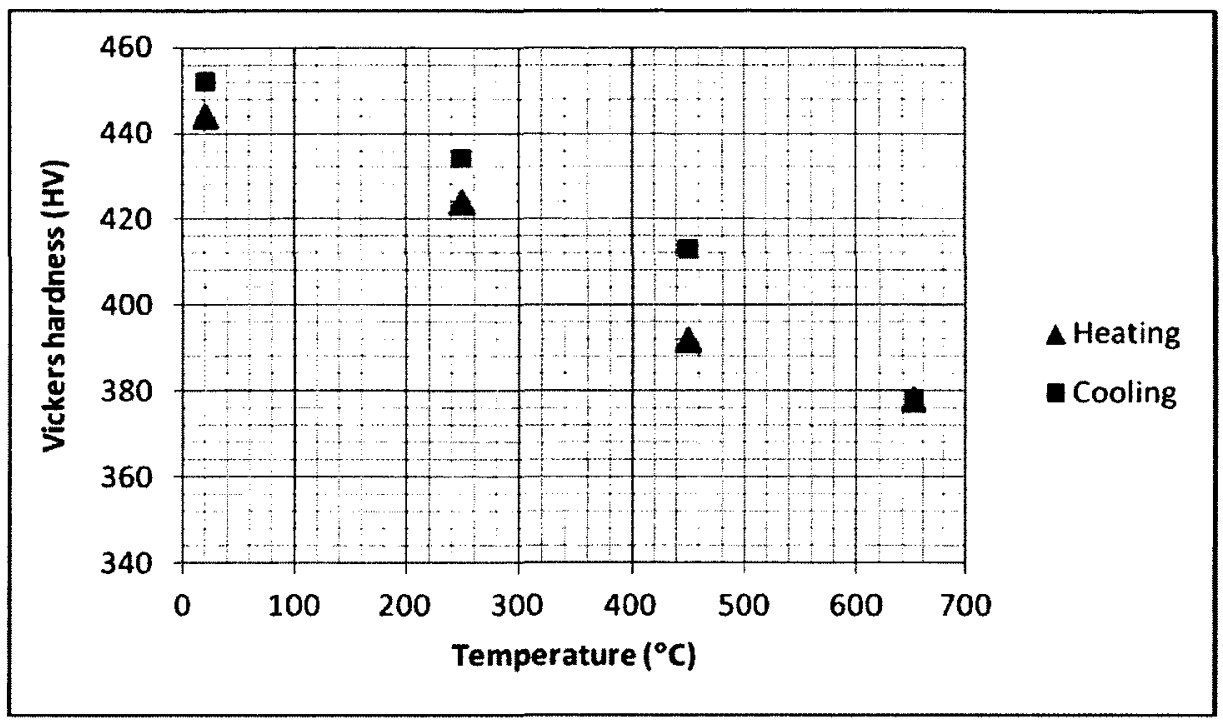

(a)

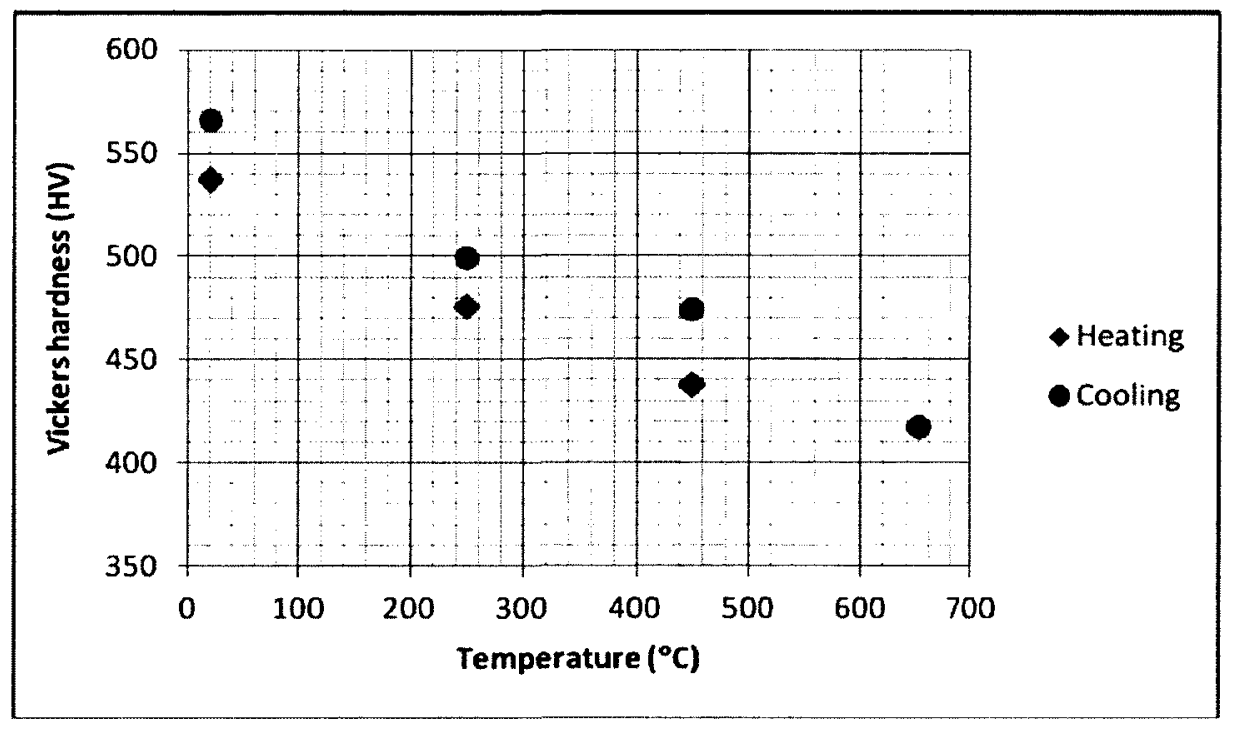

(b)

Figure 4-8: Variations of hardness with temperature in heating/cooling cycle for alloy $\mathrm{C}$ :

(a) solid solution and (b) carbide with minor solid solution. 


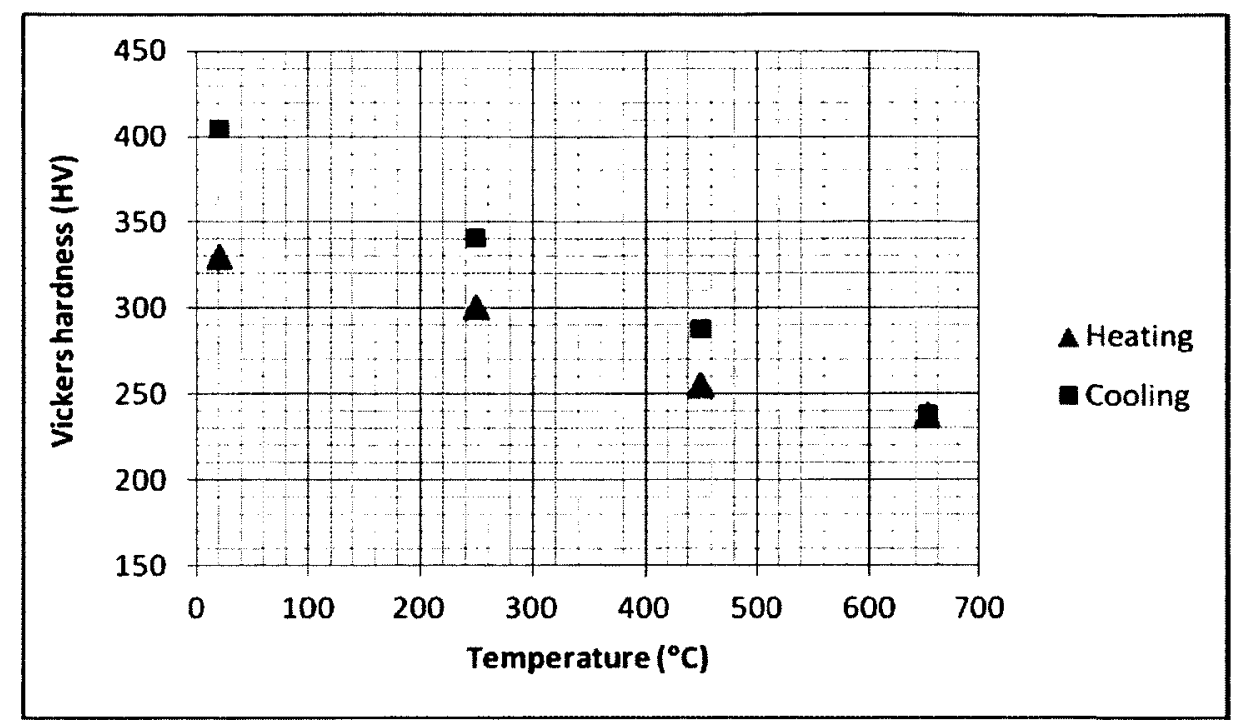

(a)

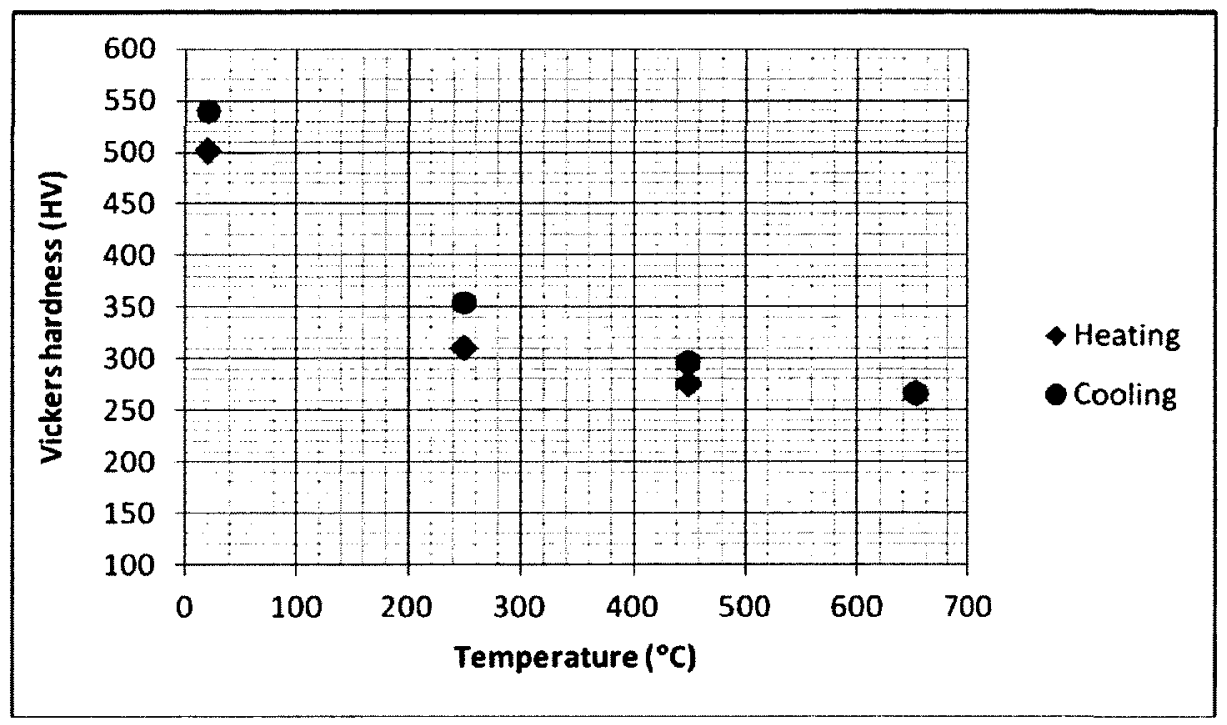

(b)

Figure 4-9: Variations of hardness with temperature in heating/cooling cycle for alloy D:

(a) solid solution and (b) carbides/solution mixture. 


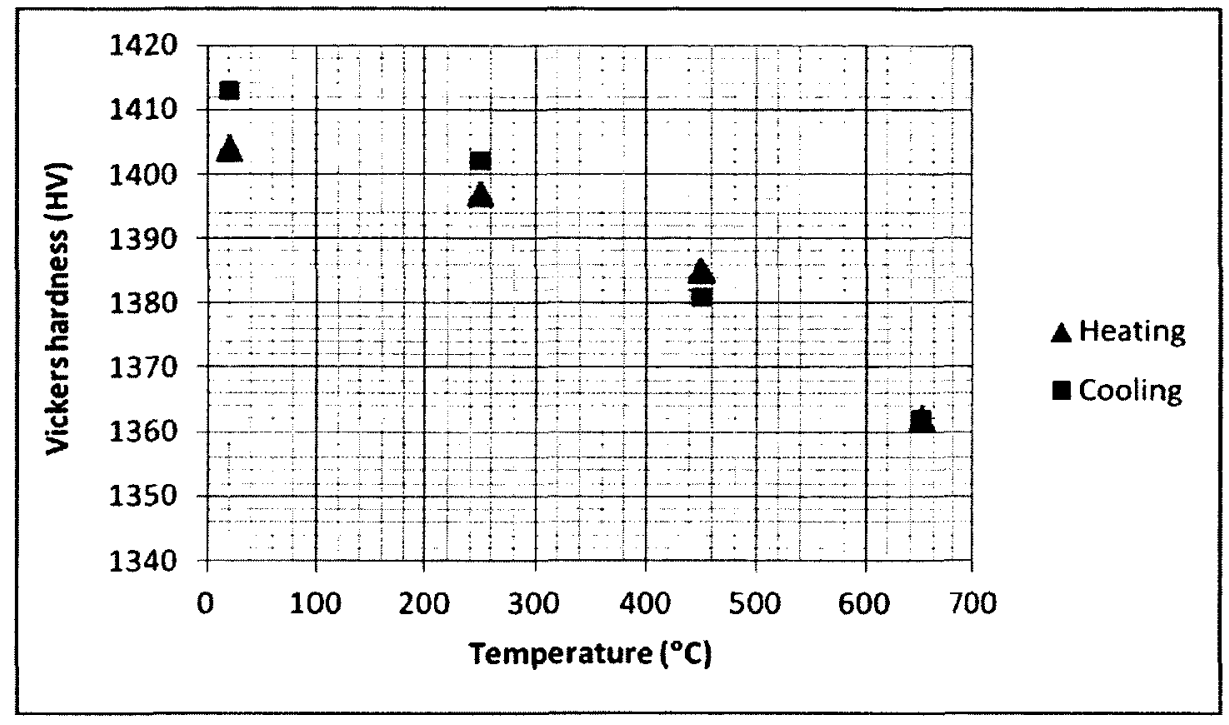

(a)

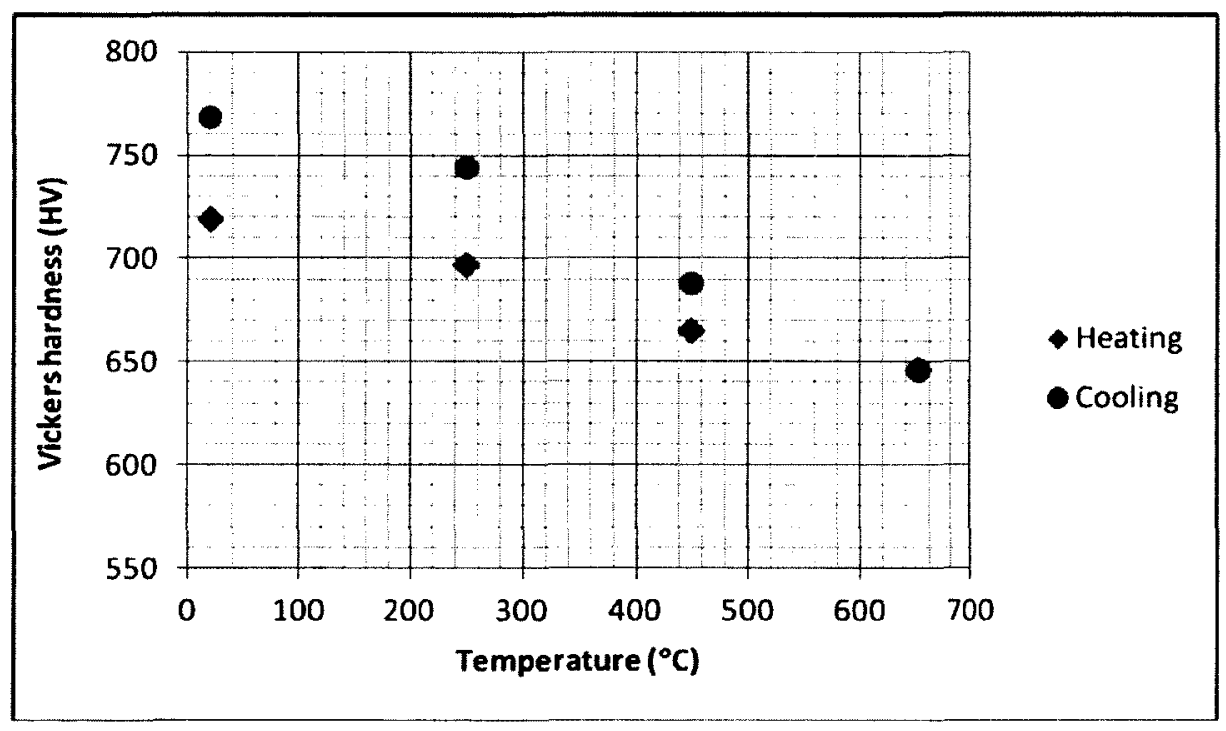

(b)

Figure 4-10: Variations of hardness with temperature in heating/cooling cycle for alloy E:

(a) $\mathrm{Cr}_{7} \mathrm{C}_{3}$ carbide and (b) solid solution/carbide mixture. 


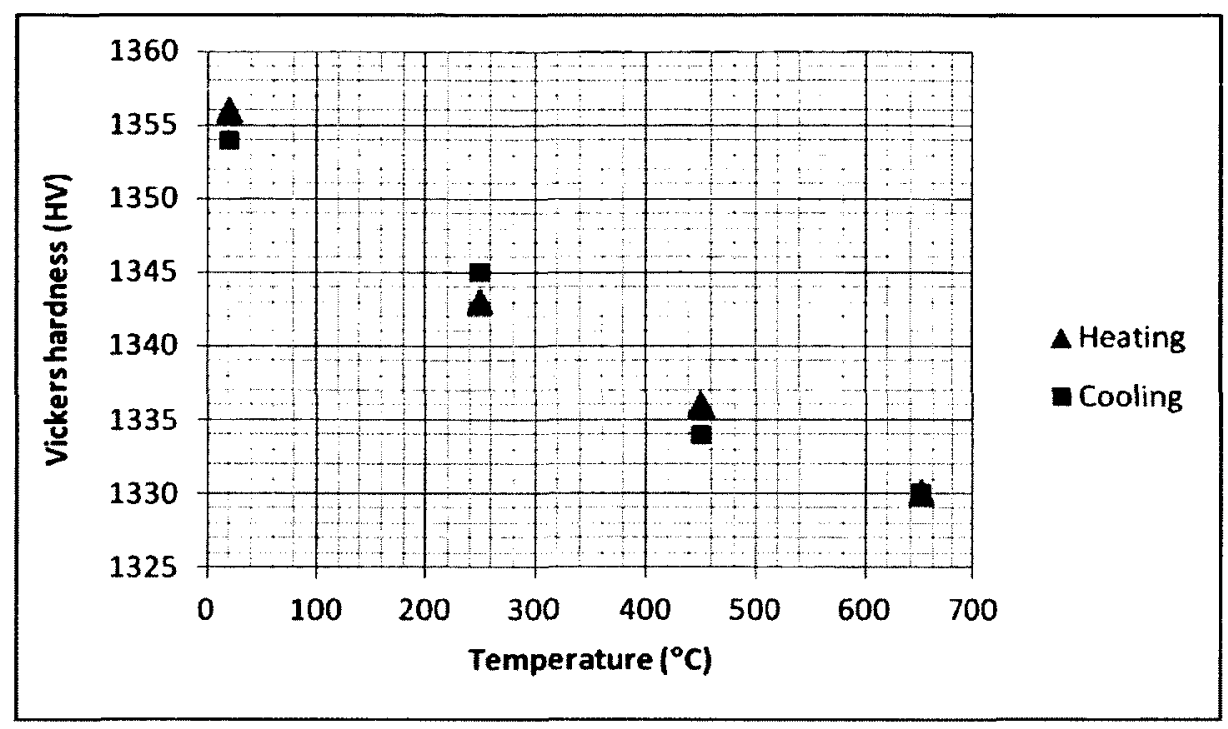

(a) .

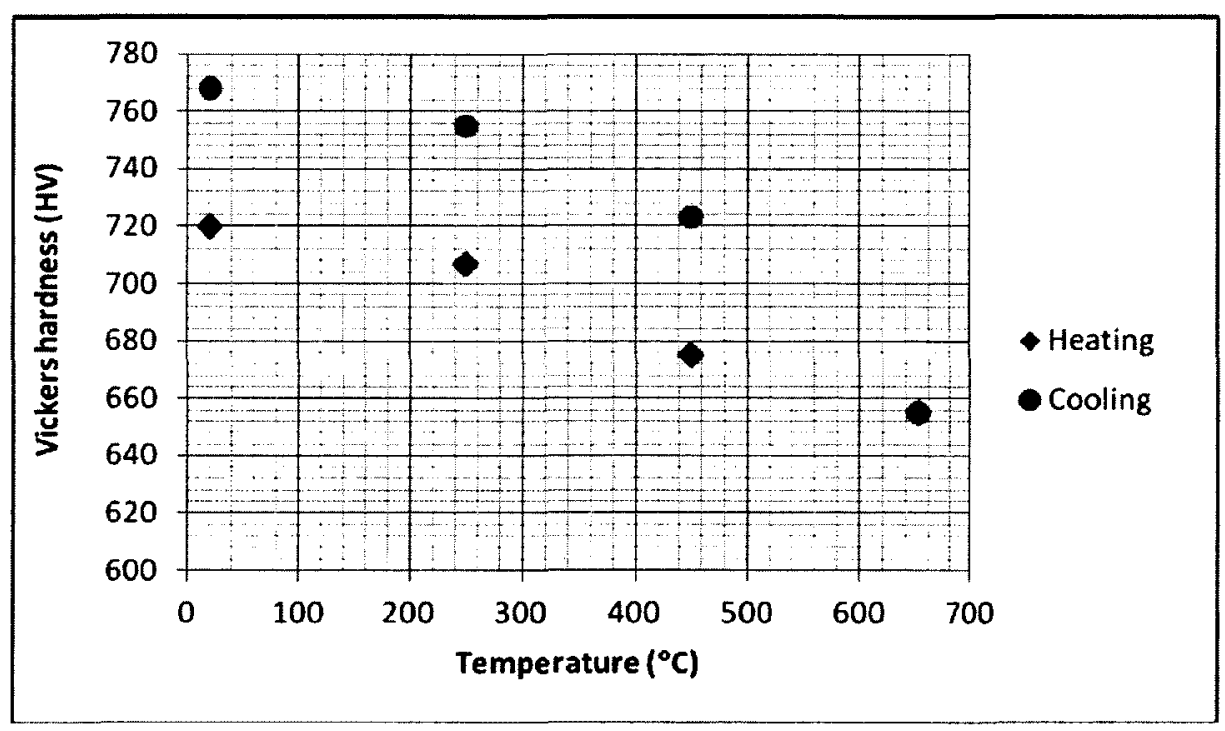

(b)

Figure 4-11: Variations of hardness with temperature in heating/cooling cycle for alloy $\mathrm{F}$ :

(a) $(\mathrm{W}, \mathrm{Co})_{6} \mathrm{C}$ carbide and (b) solid solution/carbide mixture. 


\subsubsection{Analysis and discussion}

To facilitate the following analysis, the average hardness values of solid solution, carbides and mixtures for each alloy are summarized in Table 4-2 and Table 4-3; the maximum error percentages for each average value are provided in brackets. As explained previous, for alloy A, alloy B, alloy C and alloy D, only solid solution phase has a large size to enable the indentation made on its entire phase, but the $M_{7} C_{3}$ and $(\mathrm{W}, \mathrm{Co})_{6} \mathrm{C}$ phases are all too small to do so, and they are mixed with solid solution. On the contrary, for alloy $\mathrm{E}$, only $\mathrm{M}_{7} \mathrm{C}_{3}$ phase, and for alloy $\mathrm{F}$, only $(\mathrm{W}, \mathrm{Co})_{6} \mathrm{C}$ phase, are large enough in size for the indentation to make on their entire phases, respectively, while the solid solution phases are all too small to do so, and they are mixed with carbides.

Table 4-2: Average hardness values (HV) of solid solution and carbides

\begin{tabular}{|l|c|c|c|c|c|c|c|}
\hline Temperature & $\begin{array}{c}\text { Heating } \\
20^{\circ} \mathrm{C}\end{array}$ & $\begin{array}{c}\text { Heating } \\
250^{\circ} \mathrm{C}\end{array}$ & $\begin{array}{c}\text { Heating } \\
450^{\circ} \mathrm{C}\end{array}$ & $\begin{array}{c}\text { Heating } \\
\text { Cooling } \\
650^{\circ} \mathrm{C}\end{array}$ & $\begin{array}{c}\text { Cooling } \\
450^{\circ} \mathrm{C}\end{array}$ & $\begin{array}{c}\text { Cooling } \\
250^{\circ} \mathrm{C}\end{array}$ & $\begin{array}{c}\text { Cooling } \\
20^{\circ} \mathrm{C}\end{array}$ \\
\hline Alloy A & 456 & 422 & 410 & 399 & 421 & 438 & 468 \\
$(1.12 \%)$ & $(1.23 \%)$ & $(1.32 \%)$ & $(1.20 \%)$ & $(1.34 \%)$ & $(1.02 \%)$ & $(1.41 \%)$ \\
\hline Alloy B & 411 & 367 & 347 & 341 & 373 & 410 & 430 \\
Solution & $(1.12 \%)$ & $(1.16 \%)$ & $(1.11 \%)$ & $(1.42 \%)$ & $(1.35 \%)$ & $(1.25 \%)$ & $(1.43 \%)$ \\
\hline Alloy C & 444 & 424 & 392 & 378 & 413 & 434 & 452 \\
Solution & $(1.30 \%)$ & $(1.28 \%)$ & $(1.15 \%)$ & $(1.12 \%)$ & $(1.33 \%)$ & $(1.22 \%)$ & $(1.45 \%)$ \\
\hline Alloy D & 330 & 301 & 255 & 238 & 288 & 341 & 405 \\
Solution & $(1.32 \%)$ & $(1.32 \%)$ & $(1.01 \%)$ & $(1.33 \%)$ & $(1.07 \%)$ & $(1.20 \%)$ & $(1.28 \%)$ \\
\hline Alloy E & 1404 & 1397 & 1385 & 1362 & 1381 & 1402 & 1413 \\
Cr7 $\mathrm{C}_{3}$ & $(1.32 \%)$ & $(1.14 \%)$ & $(1.06 \%)$ & $(1.41 \%)$ & $(1.16 \%)$ & $(1.27 \%)$ & $(1.20 \%)$ \\
\hline Alloy F & 1356 & 1343 & 1336 & 1330 & 1334 & 1345 & 1354 \\
$($ W,Co) 6 & $(1.52 \%)$ & $(1.04 \%)$ & $(1.11 \%)$ & $(1.42 \%)$ & $(1.33 \%)$ & $(1.12 \%)$ & $(1.32 \%)$ \\
\hline
\end{tabular}


Table 4-3: Average hardness values (HV) of mixtures

\begin{tabular}{|l|c|c|c|c|c|c|c|}
\hline Temperature & $\begin{array}{c}\text { Heating } \\
20^{\circ} \mathrm{C}\end{array}$ & $\begin{array}{c}\text { Heating } \\
250^{\circ} \mathrm{C}\end{array}$ & $\begin{array}{c}\text { Heating } \\
450^{\circ} \mathrm{C}\end{array}$ & $\begin{array}{c}\text { Heating } \\
\text { Cooling } \\
650^{\circ} \mathrm{C}\end{array}$ & $\begin{array}{c}\text { Cooling } \\
450^{\circ} \mathrm{C}\end{array}$ & $\begin{array}{c}\text { Cooling } \\
250^{\circ} \mathrm{C}\end{array}$ & $\begin{array}{c}\text { Cooling } \\
20^{\circ} \mathrm{C}\end{array}$ \\
\hline Alloy A & $\begin{array}{c}556 \\
(1.22 \%)\end{array}$ & $\begin{array}{c}528 \\
(2.54 \%)\end{array}$ & $\begin{array}{c}498 \\
(4.38 \%)\end{array}$ & $\begin{array}{c}473 \\
(3.12 \%)\end{array}$ & $\begin{array}{c}512 \\
(3.88 \%)\end{array}$ & $\begin{array}{c}544 \\
(4.27 \%)\end{array}$ & $\begin{array}{c}576 \\
(3.52 \%)\end{array}$ \\
\hline Alloy B & 472 & 461 & 428 & 386 & 444 & 496 & 498 \\
& $(2.52 \%)$ & $(4.12 \%)$ & $(2.89 \%)$ & $(4.32 \%)$ & $(3.11 \%)$ & $(3.72 \%)$ & $(4.12 \%)$ \\
\hline Alloy C & 537 & 476 & 438 & 417 & 474 & 499 & 566 \\
& $(2.65 \%)$ & $(2.44 \%)$ & $(3.52 \%)$ & $(3.54 \%)$ & $(2.98 \%)$ & $(2.21 \%)$ & $(4.02 \%)$ \\
\hline Alloy D & 502 & 310 & 275 & 266 & 297 & 355 & 539 \\
& $(3.54 \%)$ & $(4.12 \%)$ & $(5.12 \%)$ & $(4.32 \%)$ & $(3.98 \%)$ & $(3.09 \%)$ & $(4.10 \%)$ \\
\hline Alloy F & 719 & 697 & 665 & 646 & 688 & 744 & 768 \\
& $(3.52 \%)$ & $(2.92 \%)$ & $(3.60 \%)$ & $(3.09 \%)$ & $(3.26 \%)$ & $(4.52 \%)$ & $(4.76 \%)$ \\
\hline & $(2.11 \%)$ & $(2.52 \%)$ & $(3.76 \%)$ & $(3.1 .2 \%)$ & $(2.52 \%)$ & $(2.57 \%)$ & $(3.87 \%)$ \\
\hline
\end{tabular}

As summarized in Table 4-2 and Table 4-3, the carbides are much harder than the solid solutions. Accordingly, the hardness values of the mixture for each alloy are between the hard values of solid solution and carbides. This is because the mixtures consist of both carbides and solid solution. Since the amounts of each constituent in the mixture present in the area covered by the indenter would vary in each test; the obtained hardness values on the mixture cannot accurately predict the effects of individual phases on the overall hardness of the mixture. Therefore, the following analysis will be focused on the single phases but not on the mixtures. 
From Table 4-2, the hardness values of both solid solution and carbides decrease with temperature, which means that the solid solution and carbides of Stellite alloys can be softened by temperature. The reductions in hardness of solid solution and carbides at $650^{\circ} \mathrm{C}$ were calculated and the values are presented in Table 4-4. It is also noted that the hardness values of solid solution and carbides are different at the temperatures in the heating process and in the cooling process, which indicates that the heating/cooling cycle has effects on the hardness of the solid solution and carbides of Stellite alloys. The changes in hardness of solid solution and carbides at room temperature before and after the heating/cooling cycle were calculated and the results are reported in Table 4-4. According to the data in Table 4-4, both $\mathrm{Cr}_{7} \mathrm{C}_{3}$ carbide and (W,Co) 6 C carbide are insensitive to temperature; the small amounts of reduction and change in hardness of the carbides can be considered as the errors of the tests, that is, the carbides were almost not affected by the temperature up to $650^{\circ} \mathrm{C}$. For the solid solutions, the one of alloy $\mathrm{D}$ seems the most sensitive to temperature, while alloy A exhibited the best temperature insensitivity. If comparing the chemical composition of this alloy with those of the other three alloys in Table 3-1, one may find that alloy D is the only alloy that does not contain tungsten. The element, tungsten, is well known for high-temperature properties [1], so that it plays a critical role in maintaining the properties of the alloys at elevated temperatures when present in the alloys. Among the three alloys containing tungsten, alloy $\mathrm{A}$, with the highest content of tungsten (Table 3-1), exhibited the least variation of hardness with temperature, and alloy $\mathrm{B}$, with the lowest content of tungsten (Table 3-1) exhibited the most. Therefore, it may be concluded that tungsten content is the main factor that affects the temperature dependence of properties of Stellite alloys. 
Table 4-4: Temperature-dependences of hardness for solid solution and carbides

\begin{tabular}{|c|c|c|}
\hline $\begin{array}{c}\text { Temperature } \\
\text { condition } \\
\text { Phase }\end{array}$ & $\begin{array}{c}\text { Reduction of hardness at } \\
650^{\circ} \mathrm{C}\end{array}$ & $\begin{array}{c}\text { Hardness change at room } \\
\text { temperature after } \\
\text { heating/cooling cycle }\end{array}$ \\
\hline Alloy A Solution & $12.5 \%$ & $2.63 \%$ \\
\hline Alloy B Solution & $17 \%$ & $4.62 \%$ \\
\hline Alloy C Solution & $14.9 \%$ & $22.7 \%$ \\
\hline Alloy D Solution & $27.9 \%$ & $0.64 \%$ \\
\hline Alloy E Cr7 $\mathrm{C}_{3}$ & $3 \%$ & $0.15 \%$ \\
\hline Alloy F (W,Co) 6 & $1.9 \%$ & \\
\hline
\end{tabular}

Regarding the hardness variations of mixture in these alloys, since the carbides are insensitive to temperature, the temperature-dependent variations in hardness of the mixtures are attributed to the hardness variations of the solid solutions. As discussed earlier, it is impossible to estimate how much contribution each constituent made to the hardness value of the mixture. However, on the other hand, the tests on these mixtures provided the hardness values which are useful to correlate the wear resistance of these alloys.

\subsubsection{High temperature oxidation}

It was observed that alloy $\mathrm{A}$, alloy $\mathrm{E}$ and alloy $\mathrm{F}$ were all oxidized severely at $650^{\circ} \mathrm{C}$, which was characterized by the change in color of each phase, see Figure $0-4$, Figure 0-32 and Figure 0-39. The oxides remained on the specimen surfaces until the specimen was cooled down to room temperature. If relating this behaviour to their microstructures, these alloys all have a hyper-eutectic microstructure, with carbides as the 
primary phase. The first two alloys contain a large amount of $\mathrm{Cr}_{7} \mathrm{C}_{3}$ carbide, which depletes $\mathrm{Cr}$ of the solution matrix thus resulting in severe oxidation of the alloys. The last alloy contains the lowest $\mathrm{Cr}$ among the alloys being studied. It contains a large amount of $(\mathrm{W}, \mathrm{Co})_{6} \mathrm{C}$ carbide, which is free of $\mathrm{Cr}$, so that it was oxidized significantly at high temperatures, as seen in Figure 0-39. In the meanwhile, the solution matrix of this alloy was also oxidized badly due to the less amount of $\mathrm{Cr}$ in the alloy. On the contrary, alloy $\mathrm{B}$ and alloy $\mathrm{C}$ exhibited better oxidation resistance at high temperatures. This is because these two alloys have a hypo-eutectic microstructure, with the solid solution as the primary phase that contains a high level of Cr. Alloy D is different from the other alloys; it contains a very small amount of carbides and also due to the high level of $\mathrm{Cr}$, it was expected to be oxidation-resistant. However, surface oxidation was observed in this alloy when heated to $650^{\circ} \mathrm{C}$, see Figure $0-25$. Nevertheless, compared with alloy A, alloy $\mathrm{E}$ and alloy $\mathrm{F}$ specimens, the oxide film formed on the alloy D specimen surface looks thinner, which indicates less oxidation. Further investigation into the oxidation behaviour of Stellite alloys has been planned for future work of this project. 


\section{Chapter: Wear Resistance Evaluation}

\subsection{Pin-on-Disc Test}

\subsubsection{Testing facilities}

The wear resistance of the six alloys being studied was evaluated using a Pin-on-Disc Tribometer, according to the testing procedure outlined in ASTM Designation G 99 - 95A Standard Test Method for Wear Testing with a Pin-on-Disc Apparatus. This test method involves a ball shaped upper specimen that slides against a rotating disk as a lower specimen under a prescribed set of conditions. The load is applied vertically downward with a motor driven carriage that uses the force/load sensor for feedback to maintain a constant load. A software control unit allows for monitoring during the test the actual dynamic normal load and friction force thus computing friction coefficient in real-time. A pin-on-disc tribometer consists of a stationary "pin" under an applied load in contact with a rotating disc. The pin used in this research was a spherical tip having a radius of $2.5 \mathrm{~mm}$ and was made of $94 \% \mathrm{WC}$ and $6 \%$ Co with the hardness of HV 1534. The disk with the specimen mounted was a plate $(\sim 5 \mathrm{~mm}$ thick) having a flat surface. The entire pin-on-disc tribometer system is shown in Figure 5-1. For elevated temperature tests the pin-on-disc tribometer has a small furnace surrounding the disk, as shown in Figure 5-2, which allows the pin to go through a top cover where it makes contact with the disk in an almost enclosed environment. This environment is capable of heating the specimen to a maximum temperature of $450^{\circ} \mathrm{C}$. Again, this enclosure is not oxidation-protective, therefore, oxidation of materials definitely occurs on the surface of the specimen under wear at high temperatures, resulting in formation of oxides. 


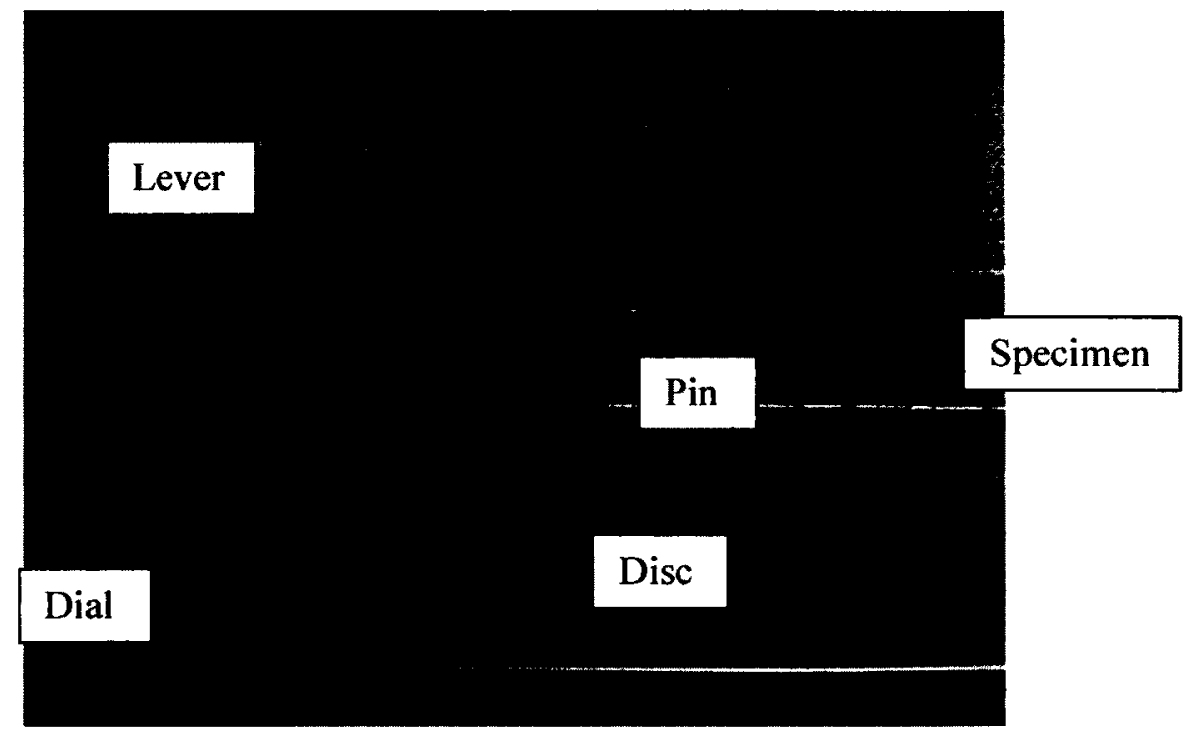

Figure 5-1: Pin-on-Disc Tribometer System.

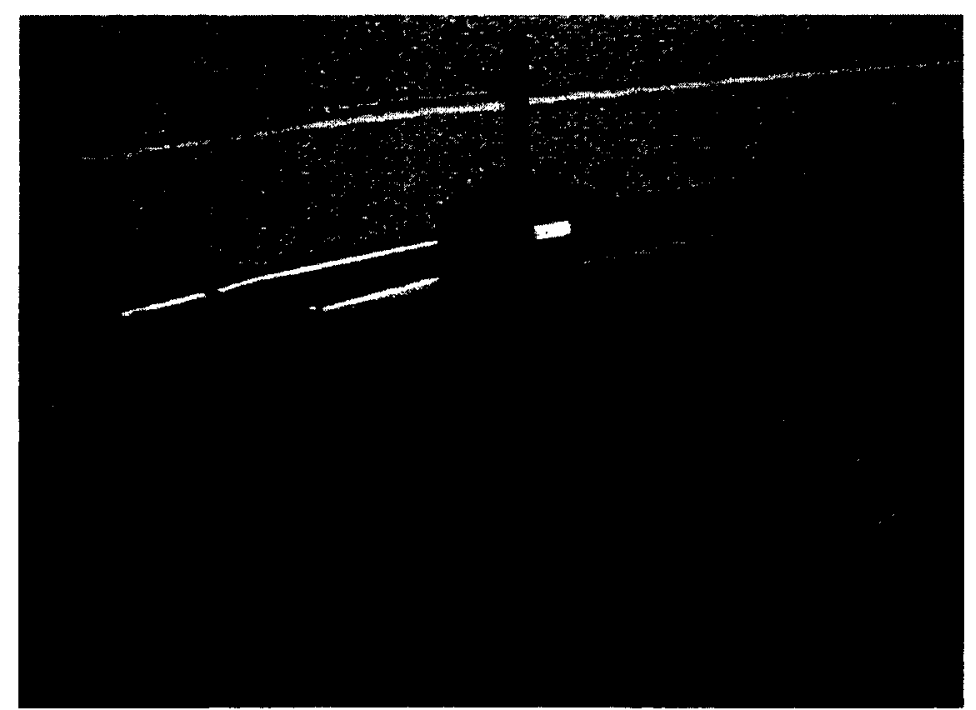

Figure 5-2: Pin-on-Disc Tribometer System equipped with a heating furnace. 


\subsubsection{Test parameters}

For wear test, the surface of each specimen was prepared by planar grinding with grit papers from coarse \#180 to fine $\# 600$ in order to flatten the specimen surfaces. During the wear test the pin (ball) was pressed under a compressive force on the specimen without lubrication; the latter was spinning at a constant rotational speed. As the result of friction/wear, a wear track or pit was generated on the specimen surface, as shown in Figure 5-3 for high-carbon alloy $\mathrm{A}$ and Figure 5-4 for low-carbon alloy D, as examples. The wear loss was evaluated by calculating the volume of the wear track after the specimen surface was worn for a period of time. The test parameters used for this research are given in Table 5-1. The computation of wear track volume resorted to a D150 Surface Profile Measuring System, shown in Figure 5-5, which allows simulating the cross-section profiles of a wear track and computing the cross-sectional areas directly. Three tests were conducted on each alloy at each temperature.

Table 5-1: Pin-on-disc wear test parameters

\begin{tabular}{|l|l|}
\hline Load (normal force) & $10 \mathrm{~N}$ \\
\hline Rotational speed of disc & $350 \mathrm{rpm}$ \\
\hline Test duration & $2.5 \mathrm{hr}$ \\
\hline Test environment & $20^{\circ} \mathrm{C}, 250^{\circ} \mathrm{C}, 450^{\circ} \mathrm{C}$ \\
\hline Diameter of wear track & $6 \mathrm{~mm}$ \\
\hline Sliding distance & $1000 \mathrm{~m}$ \\
\hline
\end{tabular}




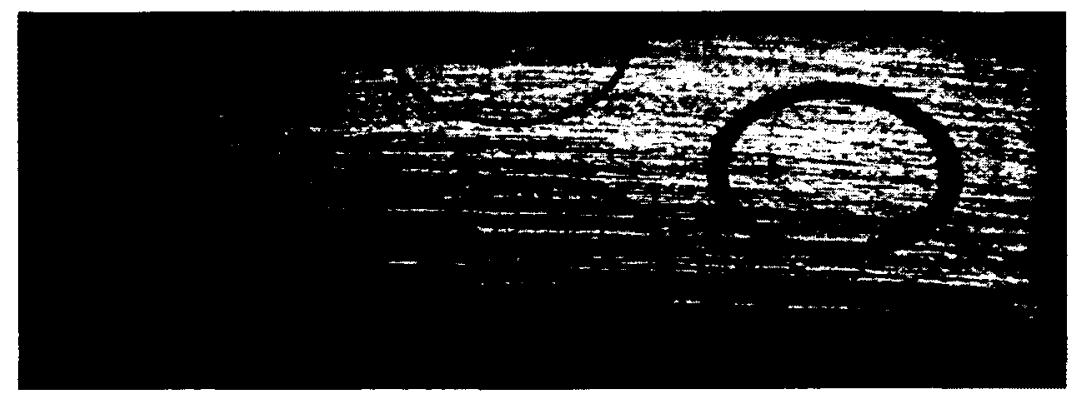

(a)

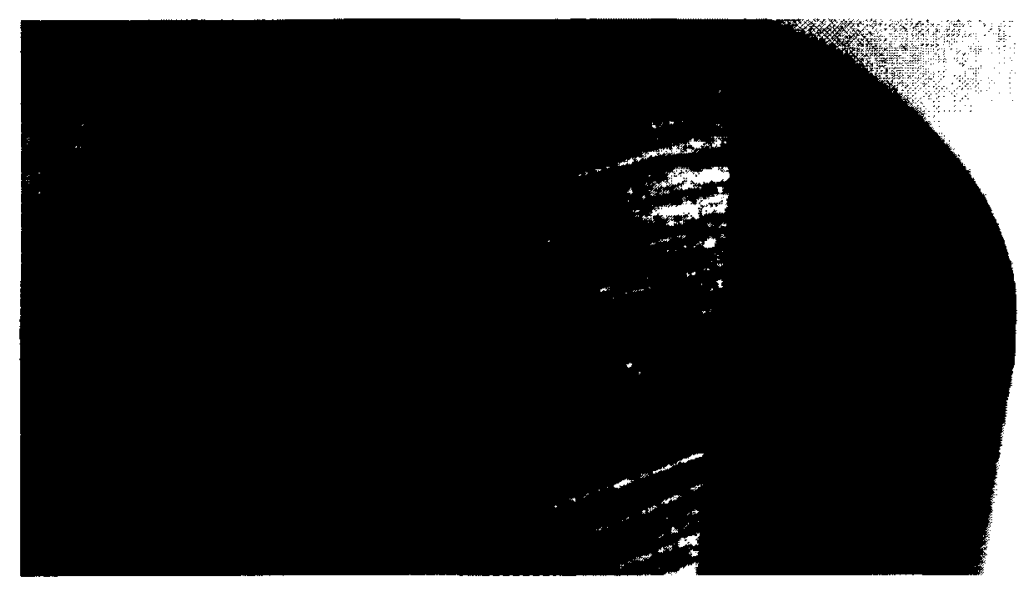

(b)

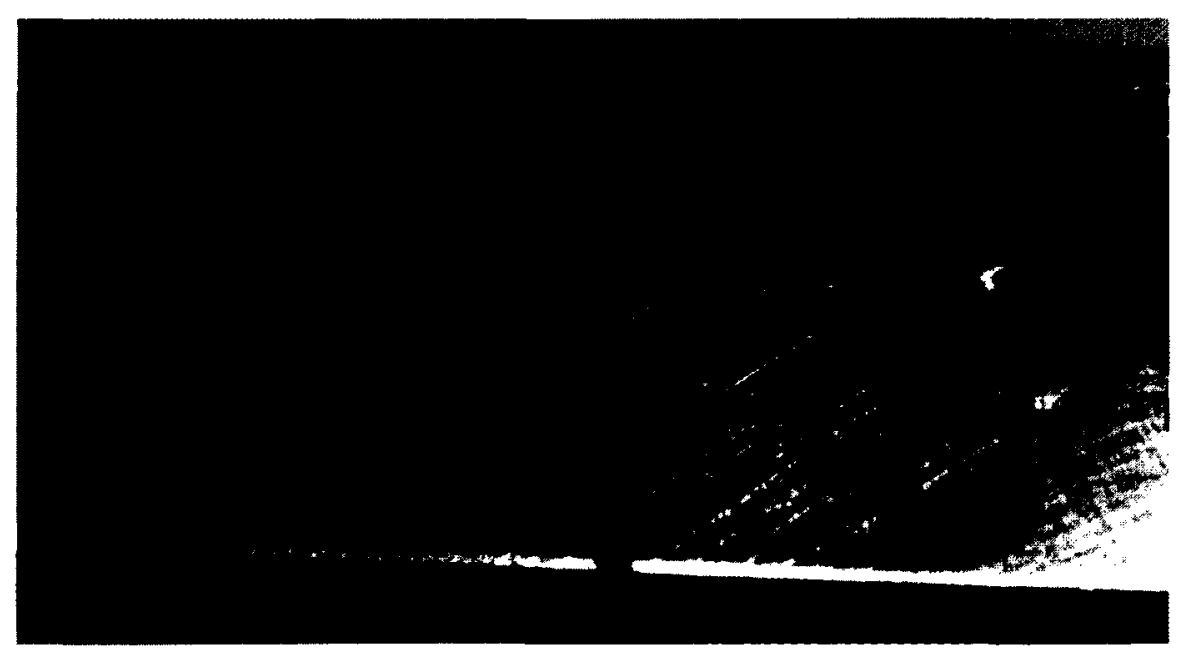

(c)

Figure 5-3: Wear tracks of alloy A: (a) at room temperature, (b) at $250^{\circ} \mathrm{C}$ and (c) at $450^{\circ} \mathrm{C}$. 


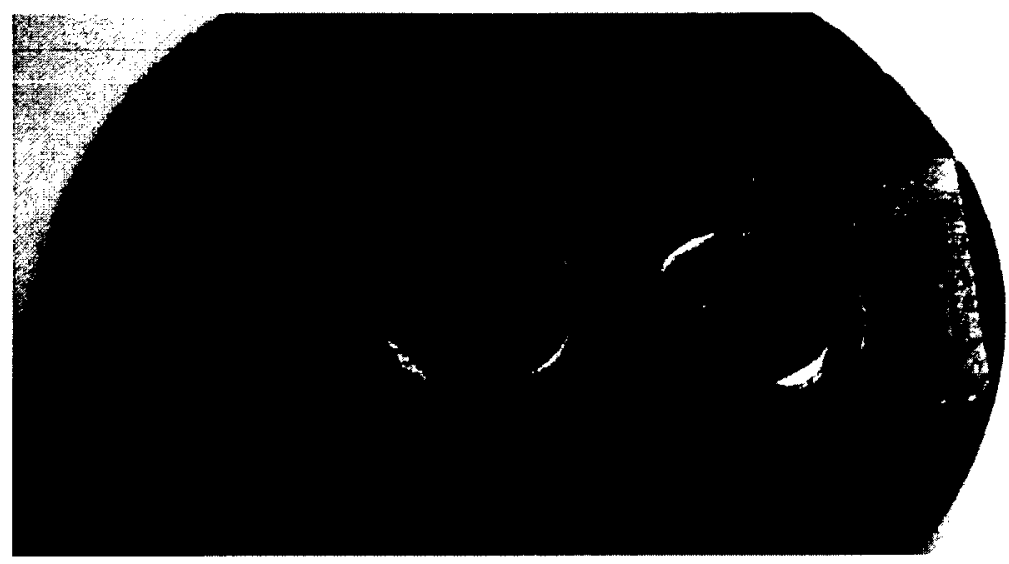

(a)

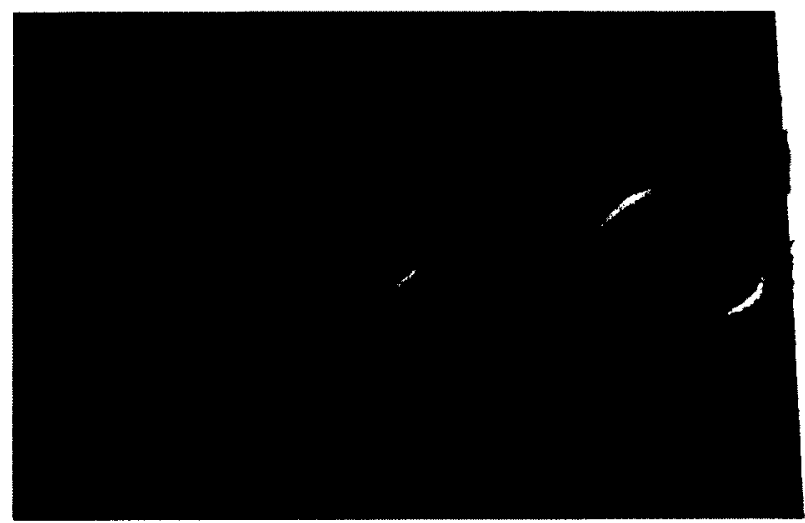

(b)

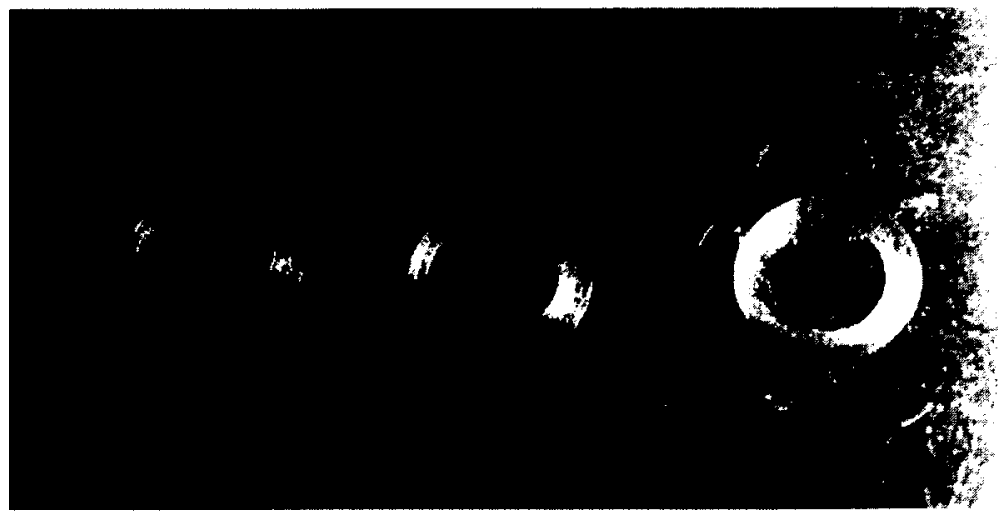

(c)

Figure 5-4: Wear tracks of alloy D: (a) at room temperature, (b) at $250^{\circ} \mathrm{C}$ and

(c) at $450^{\circ} \mathrm{C}$. 


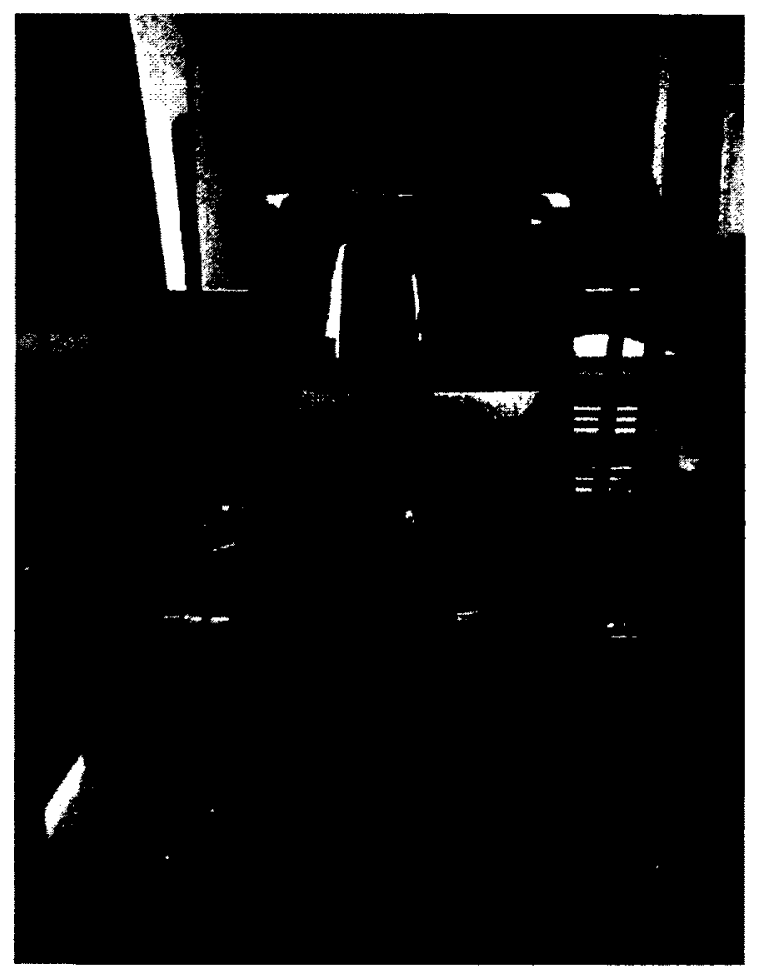

Figure 5-5: D150 Surface Profile Measuring System.

\subsection{Wear Loss}

\subsubsection{Wear track analysis}

The wear resistance of each tested alloy specimen is estimated by the volume loss of the specimen material, which is equal to the volume of the wear track. For each wear track four locations were selected uniformly along the wear track to calculate the cross-sectional area, and the average value was taken to be multiplied by the periphery length of the wear track to obtain the volume of the wear track. The cross section profiles of the wear tracks that represent the medium wear losses of each alloy are presented in Figure B-1 to Figure B-6 for room temperature test, $250^{\circ} \mathrm{C}$ test and $450^{\circ} \mathrm{C}$ test respectively. 


\subsubsection{Wear resistence}

The cross-sectional areas of the selected locations along each wear track were calculated automatically based on the corresponding cross section profiles by the software associated with the D150 Surface Profile Measuring System. The volume of each wear track was then calculated as the average cross-sectional area multiplied by $\pi D$ ( $D=6 \mathrm{~mm})$, which is the periphery length of the wear track, as schematically shown in Figure 5-6. It should be mentioned that since the wear track analysis in this research was implemented using a surface profile measuring system, not a volume measuring system, the obtained volume values of the wear tracks in this way are only approximate, not exact. However, to minimize the error, four locations were selected uniformly along each wear track to obtain the cross sectional area. From the viewpoint of statistics, the average of the four cross-sectional areas would fairly represent the overall cross-sectional area of the wear track. The average wear losses (volumes of the wear tracks) of each alloy at room temperature and at elevated temperatures are illustrated in Figure 5-7.

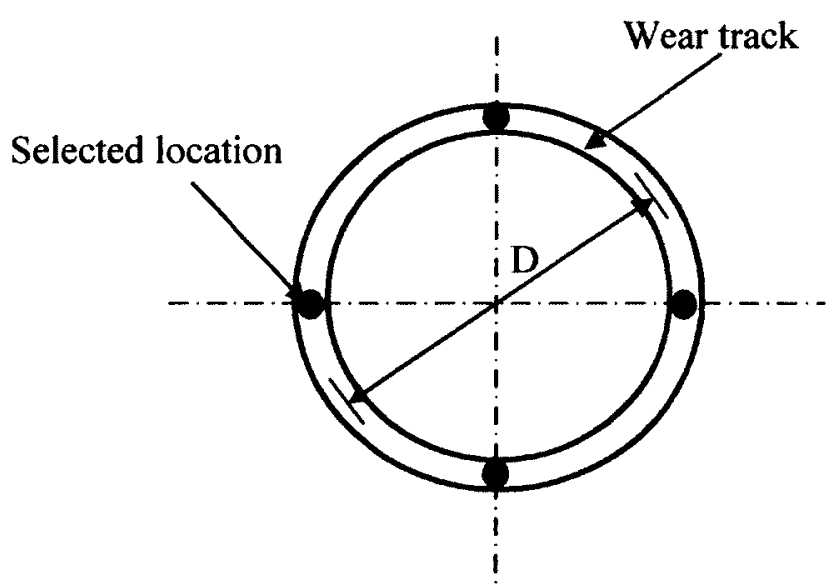

Figure 5-6: Schematic drawing for volume estimation of wear track. 


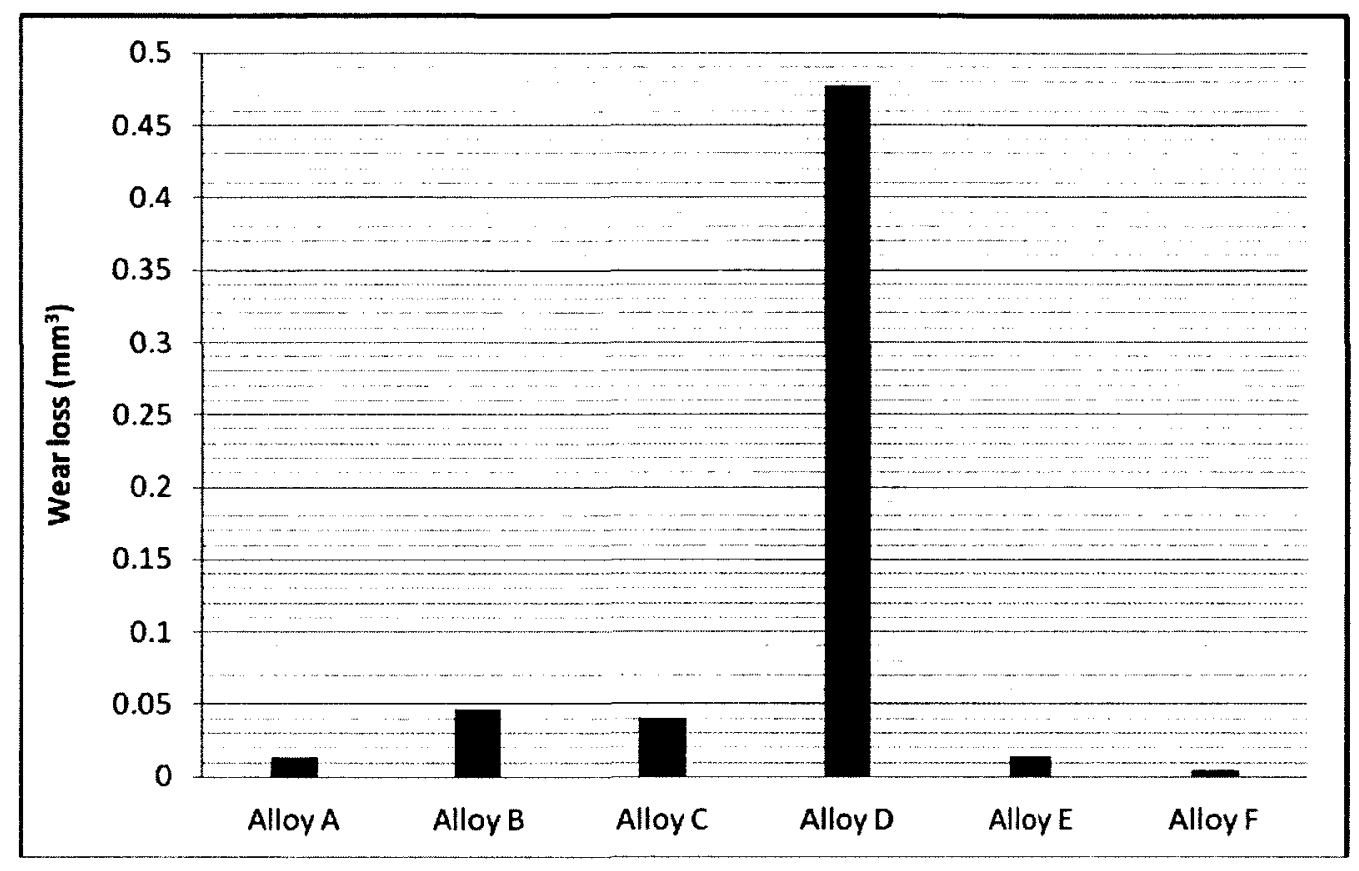

(a)

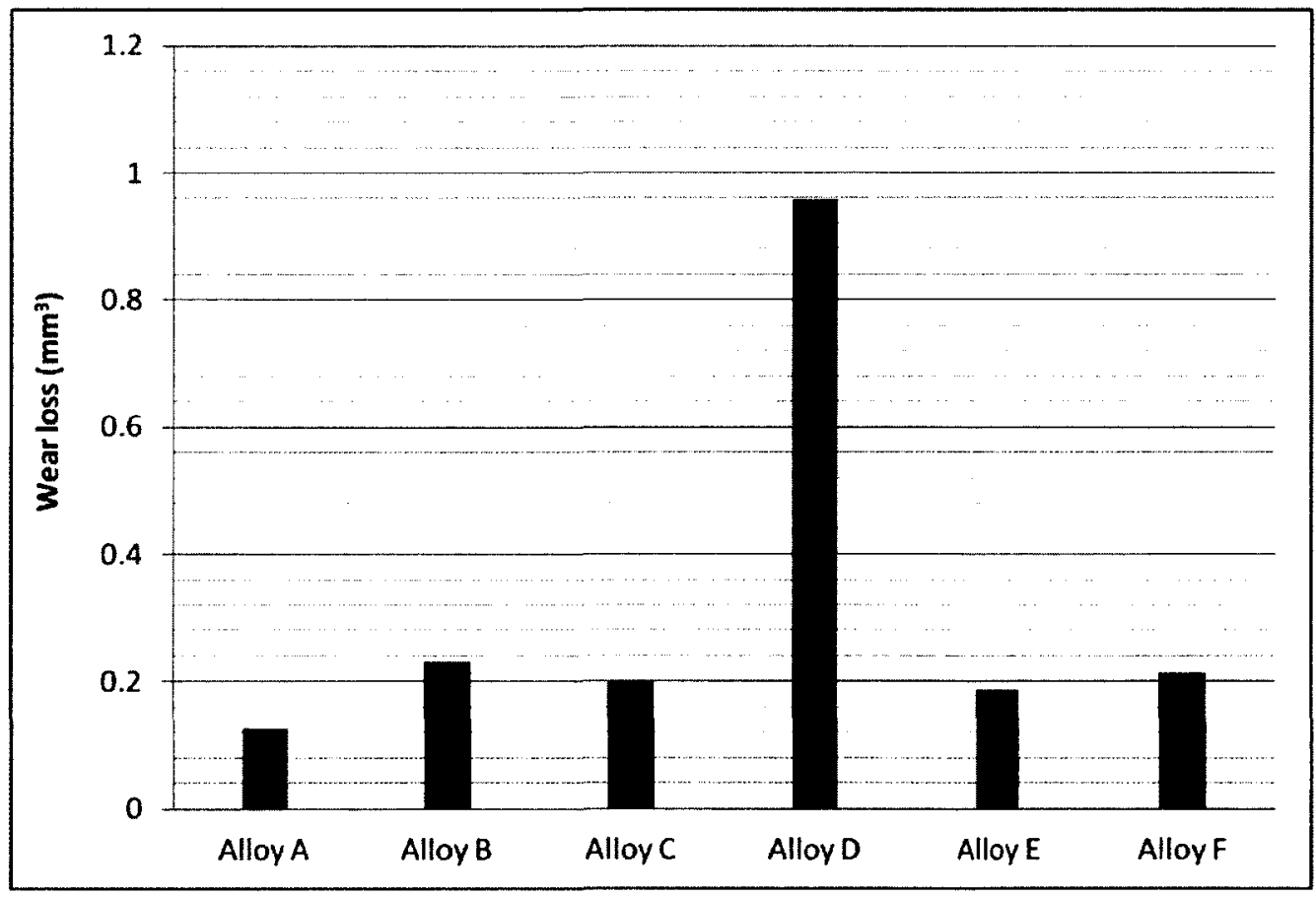

(b) 


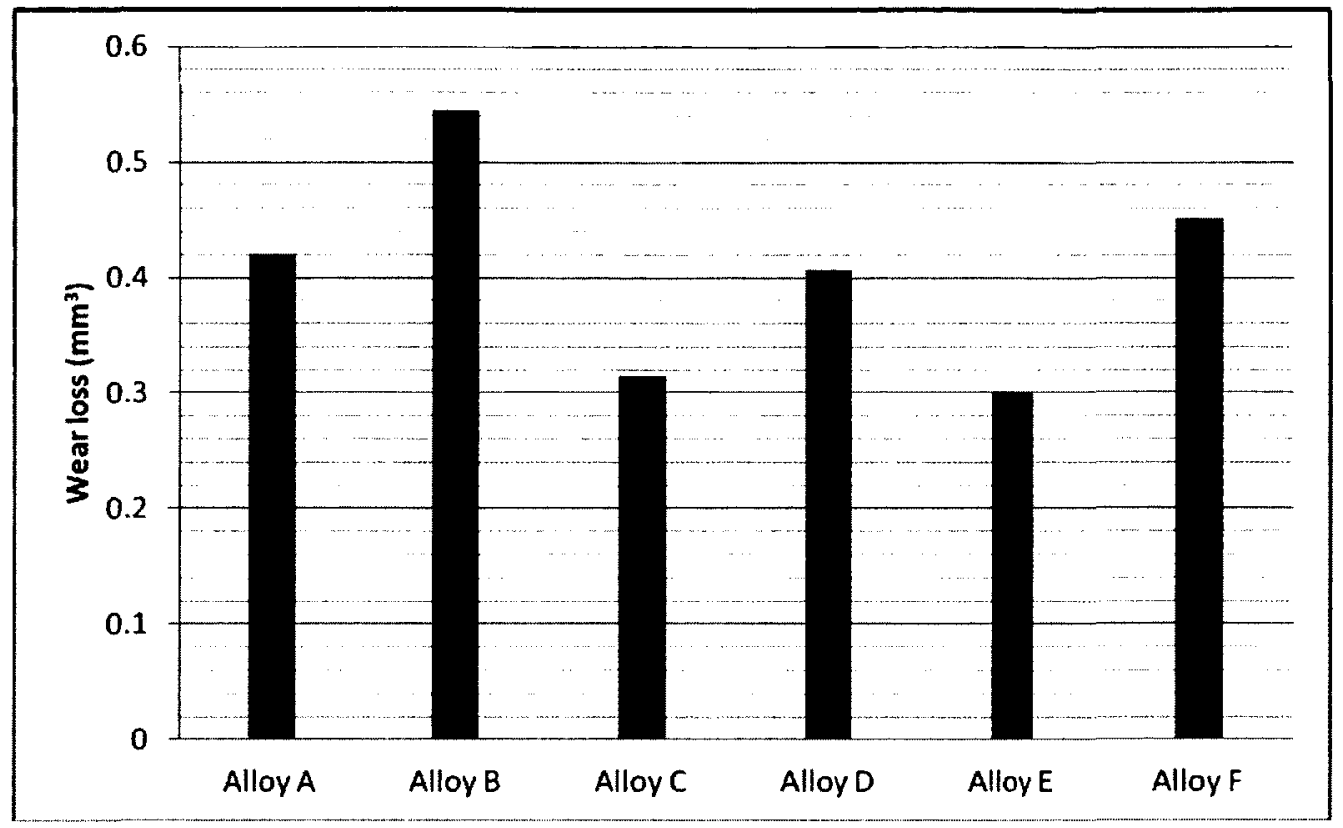

(c)

Figure 5-7: Wear losses of Stellite alloys under the pin-on-disk wear test: (a) at room temperature, (b) at $250^{\circ} \mathrm{C}$ and (c) at $450^{\circ} \mathrm{C}$.

At room temperature, in general, the wear resistance of Stellite alloys is controlled by the carbon content in the alloy. As demonstrated in Figure 5-7(a), alloy D, containing very low $\mathrm{C}(0.25 \mathrm{wt} \%)$, has the worst wear resistance. However, alloying elements such as $\mathrm{W}, \mathrm{Mo}$ and $\mathrm{Ni}$ also play an important role. For example, alloy $\mathrm{F}$ has the best wear resistance, but this alloy contains less $\mathrm{C}$ than alloy $\mathrm{A}$. The excellent wear resistance of alloy $\mathrm{F}$ may be attributed to both high $\mathrm{C}$ and high $\mathrm{W}$. Alloy $\mathrm{A}$, containing the highest $\mathrm{C}$ among the alloys being studied and also containing high $\mathrm{W}$, has better wear resistance than the others except alloy F. Alloy $\mathrm{E}$, containing higher $\mathrm{W}$ but lower $\mathrm{C}$ than alloy $\mathrm{A}$, has slightly lower wear resistance. Between alloy B and alloy $\mathrm{C}$, the latter has better resistance to wear due to its both higher $\mathrm{C}$ and higher $\mathrm{W}$. 
With the increase in the temperature of the specimen to $250^{\circ} \mathrm{C}$, the wear resistance of all the alloys decreased, as demonstrated by comparing the wear loss data in Figure 5-7(a) with those in Figure 5-7(b). The wear resistance of alloy $\mathrm{F}$ deteriorated significantly at elevated temperatures; it was worse than alloy $\mathrm{A}$, alloy $\mathrm{C}$ and alloy $\mathrm{E}$ at $250^{\circ} \mathrm{C}$. Alloy A exhibited the best wear resistance among the alloys being studied, followed by alloy $\mathrm{E}$, at this temperature. Alloy $\mathrm{C}$ was still better than alloy $\mathrm{B}$ at $250^{\circ} \mathrm{C}$. Similar to the test at room temperature, the low-carbon alloy D still exhibited the worst wear resistance at $250^{\circ} \mathrm{C}$ among the alloys being studied.

When further increasing the temperature of the specimen up to $450^{\circ} \mathrm{C}$, these alloys continuously lost wear resistance except alloy D which exhibited an abnormal behaviour - an increase in wear resistance at this higher temperature, as illustrated in Figure $5-7(\mathrm{c})$. This is more evident in the presentation of temperature dependence on wear resistance of each alloy as provided in Figure 5-8. The predominant role of carbon content in the wear resistance of Stellite alloys was lessened by temperature effect. For instance, the low-carbon alloy D exhibited higher wear resistance than the high-carbon alloy $\mathrm{A}$ and medium-carbon alloy $\mathrm{B}$ and alloy $\mathrm{F}$. In addition, it is noted that at room temperature the difference in wear resistance between Stellite alloys is much larger than that at elevated temperatures, for example, alloy $F$ has more than two-orders of magnitude better wear resistance than alloy $D$, which is the largest difference in wear resistance between the Stellite alloys being studied at room temperature, while alloy $\mathrm{E}$ has only less than one-order of magnitude higher wear resistance than alloy $\mathrm{B}$, which is the largest difference in wear resistance between the alloys at $450^{\circ} \mathrm{C}$. In other words, the wear resistance of Stellite alloys varies dramatically with composition at room 
temperature but this variation becomes less pronounced with increase in the specimen temperature.

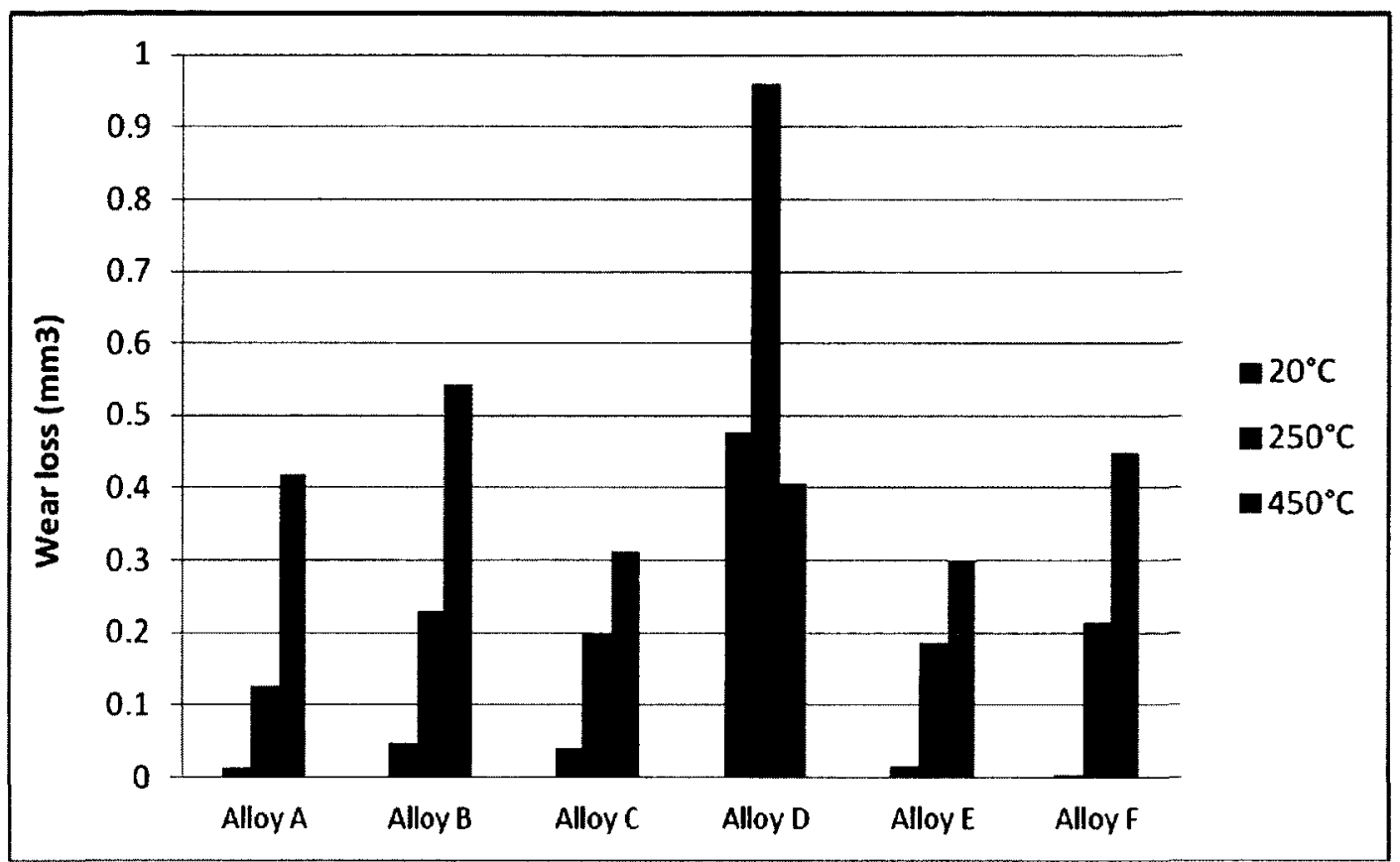

Figure 5-8: Comparison of wear loss variation with temperature among Stellite alloys.

\subsection{Friction Coefficient}

\subsubsection{Data collection}

Friction is generally one of the factors that explain the wear of a material. The common sense approach is to reduce friction in order to reduce wear. Therefore, friction is usually concerned when wear of a material is studied. In the present research, friction forces were recorded automatically with time increase during the wear test and the corresponding friction coefficients in real time were obtained by calculating the ratio of the friction force to the applied load (the normal force of $10 \mathrm{~N}$ ). It was observed that the 
friction coefficient was not constant within the wear duration for every specimen; it always increased with time initially and became stable after about $1 / 5$ of duration time or sliding distance. An example of friction versus time of Stellite alloys, as recorded in this test, is shown in Figure 5-9(a). The friction coefficients at stable state for each specimen were taken as the final values. For each alloy at each temperature, the friction coefficients from three tests were averaged and the average friction coefficients are illustrated in Figure 5-9(b).

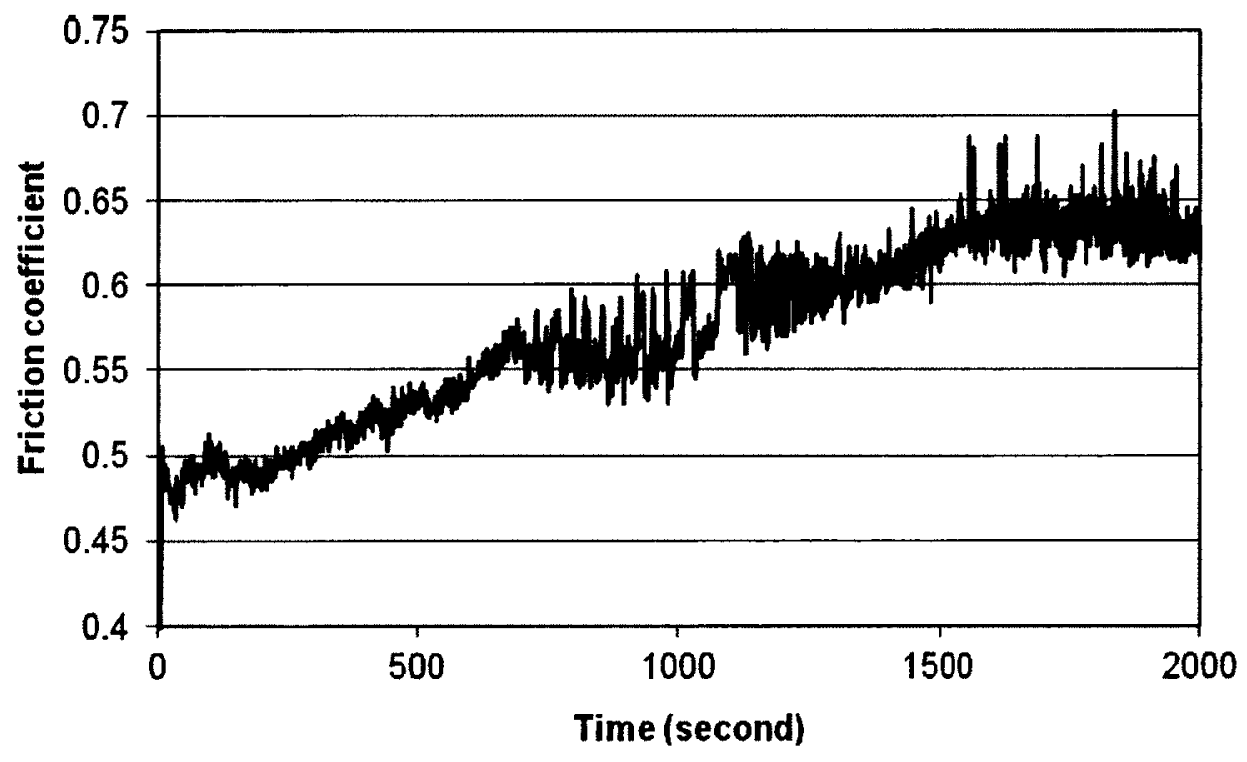

(a) 


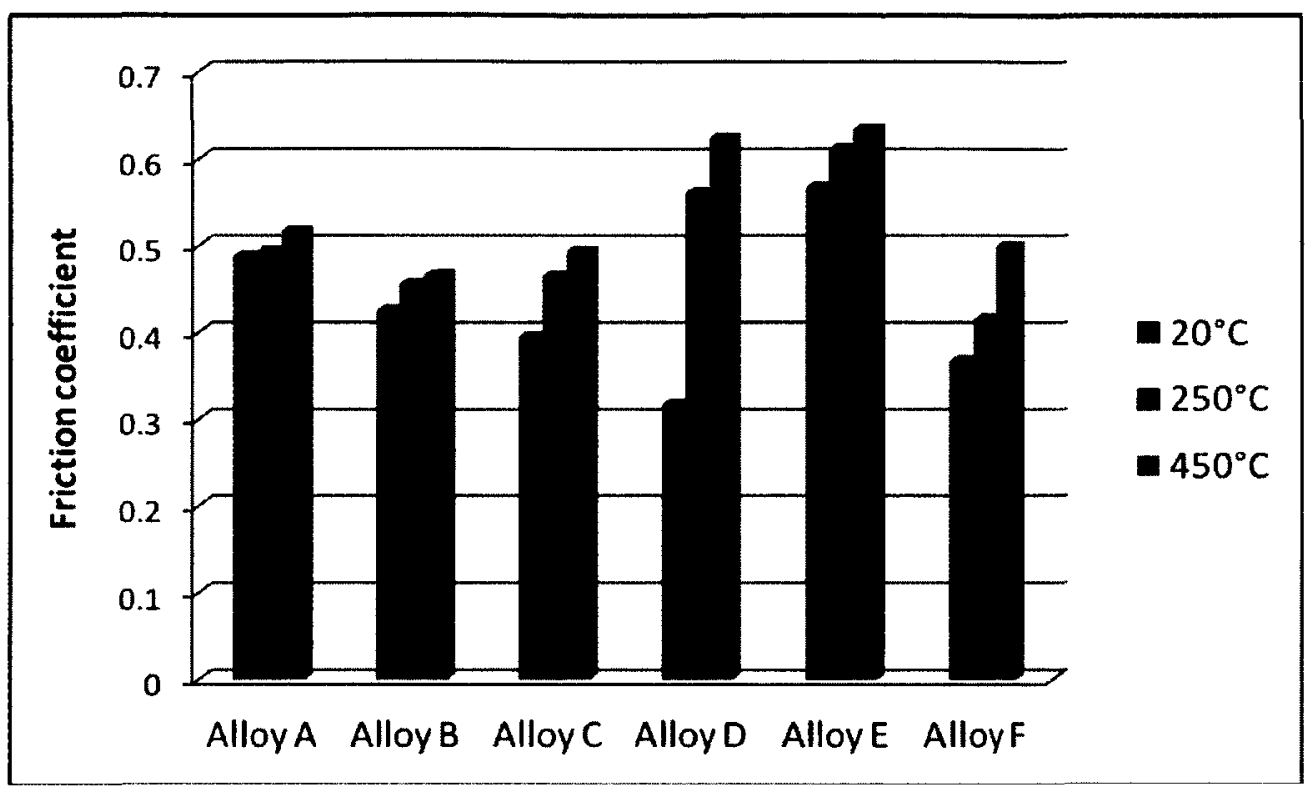

(b)

Figure 5-9: Average friction coefficients: (a) variation with time for alloy $D$ tested at $450^{\circ} \mathrm{C}$ and (b) comparison among Stellite alloys.

\subsubsection{Results and analysis}

From the diagrams in Figure 5-9(b), friction coefficient increased with the specimen temperature for all the alloys being studied. This may be understood as with increasing the specimen temperature adhesion of the contact surfaces under wear was more prone to occur, which resulted in the increase of the friction coefficient. However, it hardly relates the friction coefficients directly to the wear loss results, because the friction may be affected by many factors during the wear test such as defects in the specimen material, wear debris, vibration of the testing system, and so on. In addition to these, the friction coefficient is also associated with multiple features of the material under wear test. Therefore, there is no such simple relation that the larger the friction coefficient, the 
more the wear is caused. For example, the wear results show that at room temperature alloy D has the worst wear resistance but the friction coefficient of this alloy measured at the room temperature is the least among the alloys tested. As known from above analyses, alloy D contains a very small volume fraction of carbides so that the wear resistance of this alloy is controlled by its solution matrix. Compared with the other alloys, alloy D is nearly one-phase alloy. The alloys with carbides may encounter with cracking/fracture of carbides under the wear attack; the spallation of carbide debris from the material may consequently act as the third body between the contact surfaces, which would increase the friction in the successive wear. Without carbides, on the other hand, the debris from the alloy D surface was only chips and it may not influence the reaction between the contact surfaces very much. In general, the more smooth the contact surfaces, the less the friction is. Based on this premise, the lower friction coefficient of alloy $\mathrm{D}$ at room temperature can be explained.

\subsection{Worn Surface Analysis}

\subsubsection{Specimens tested at room temperature}

In order to better understand the wear test results and explore the wear mechanisms of Stellite alloys, the worn surfaces of the tested specimens were examined using the Hitachi Model S-570 Scanning Electron Microscope. The images of worn surface morphologies of each specimen from the room temperature test are provided in Figure 5-10 to Figure 5-15. 


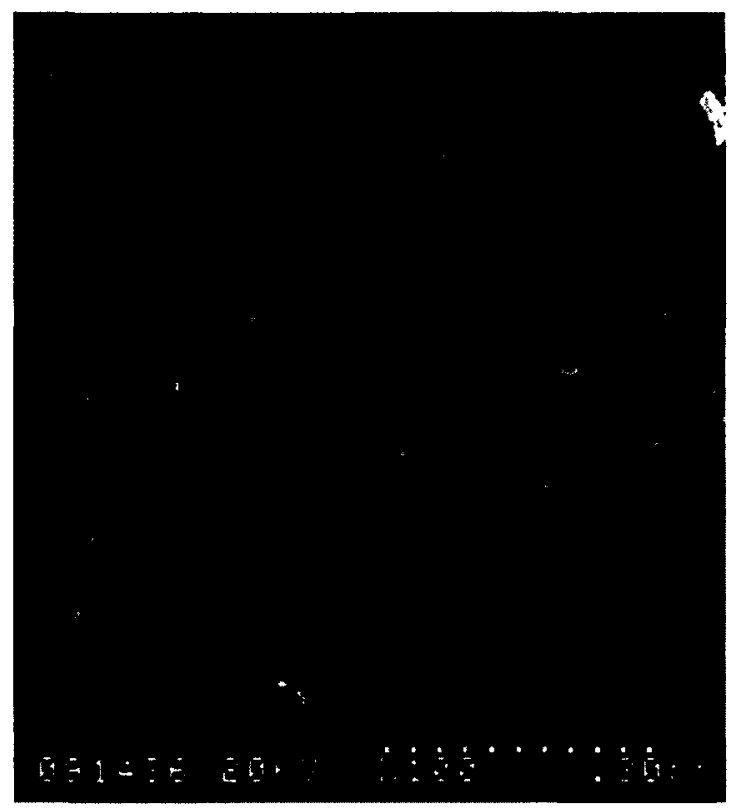

(a)

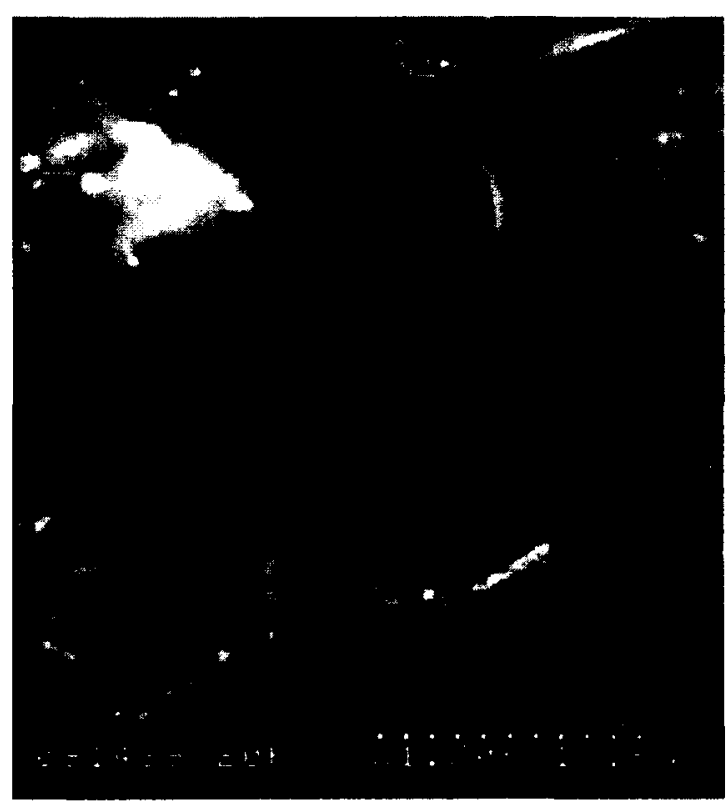

(b)

Figure 5-10: SEM images of worn surface of alloy $A$ tested at room temperature:

(a) at low magnification and (b) at high magnification. 


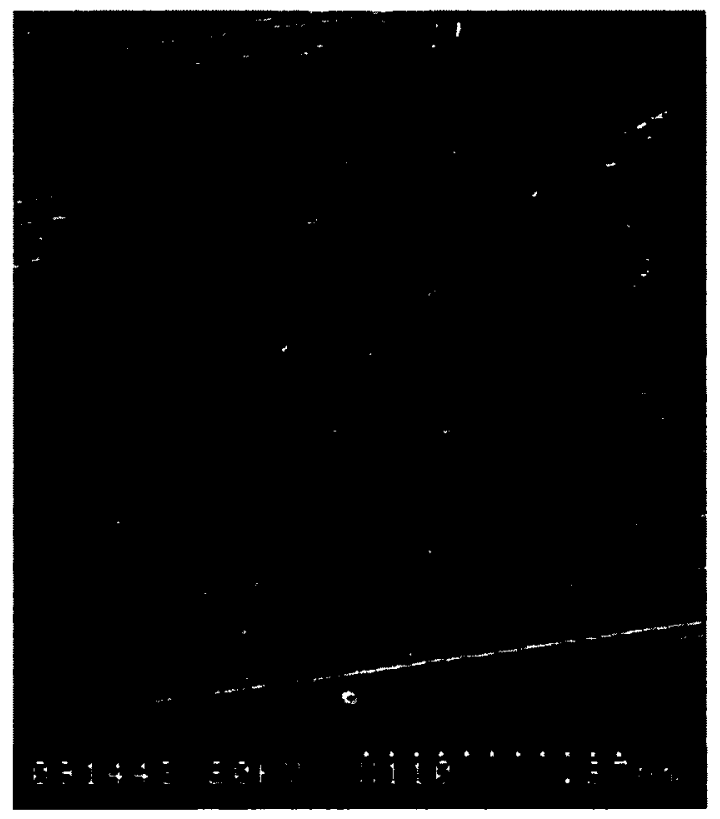

(a)

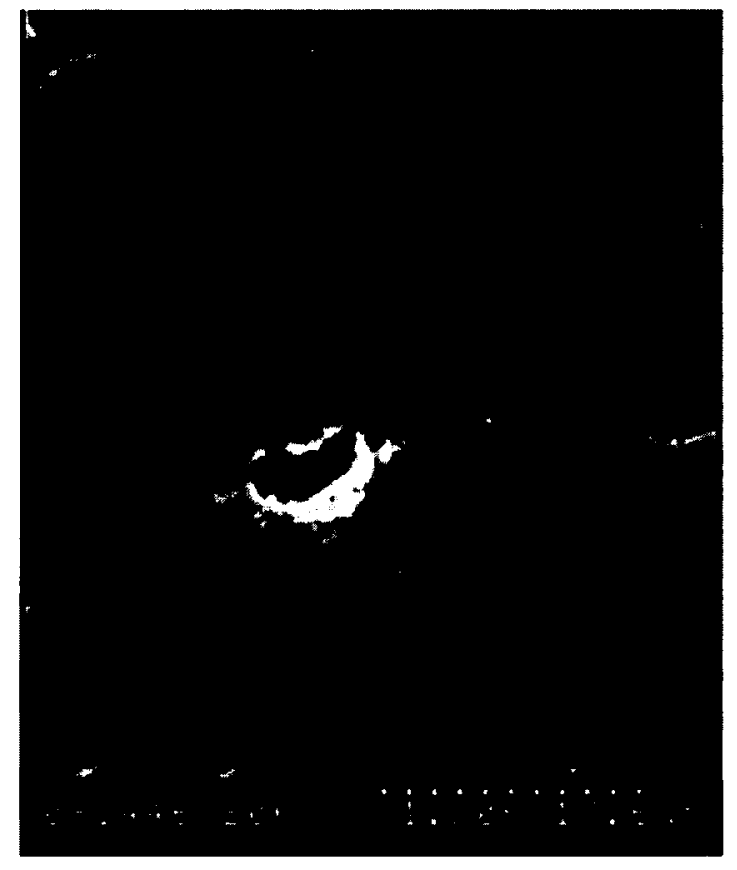

(b)

Figure 5-11: SEM images of worn surface of alloy B tested at room temperature:

(a) at low magnification and (b) at high magnification. 


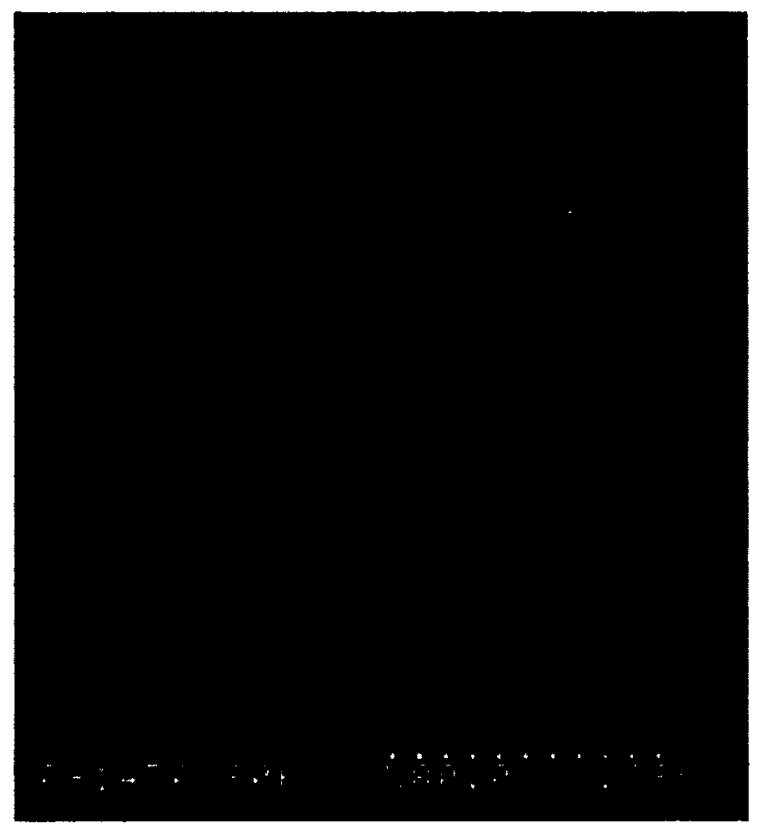

(a)

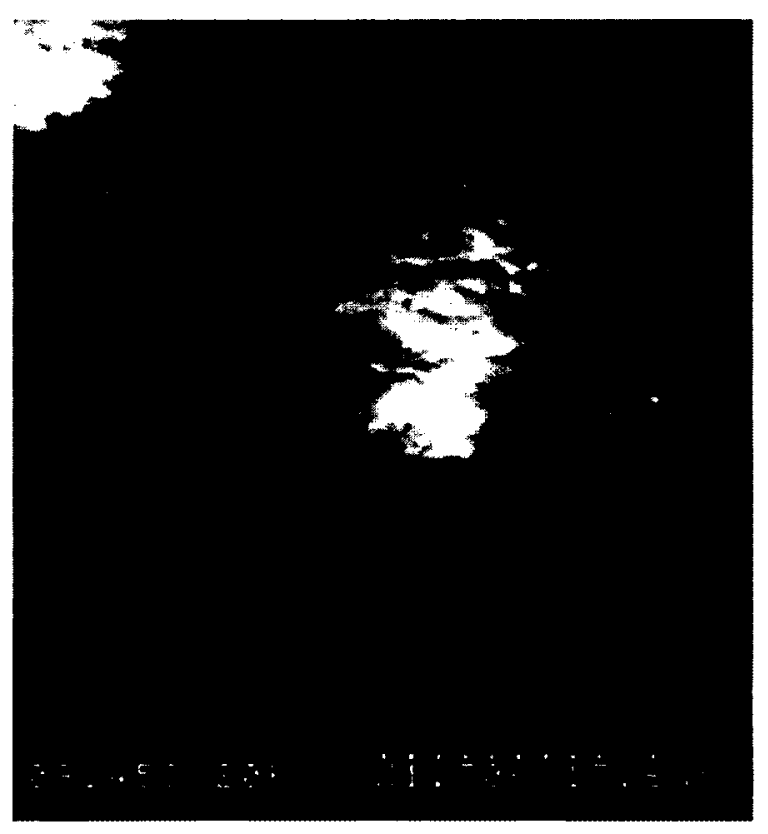

(b)

Figure 5-12: SEM images of worn surface of alloy $\mathrm{C}$ tested at room temperature:

(a) at low magnification and (b) at high magnification. 


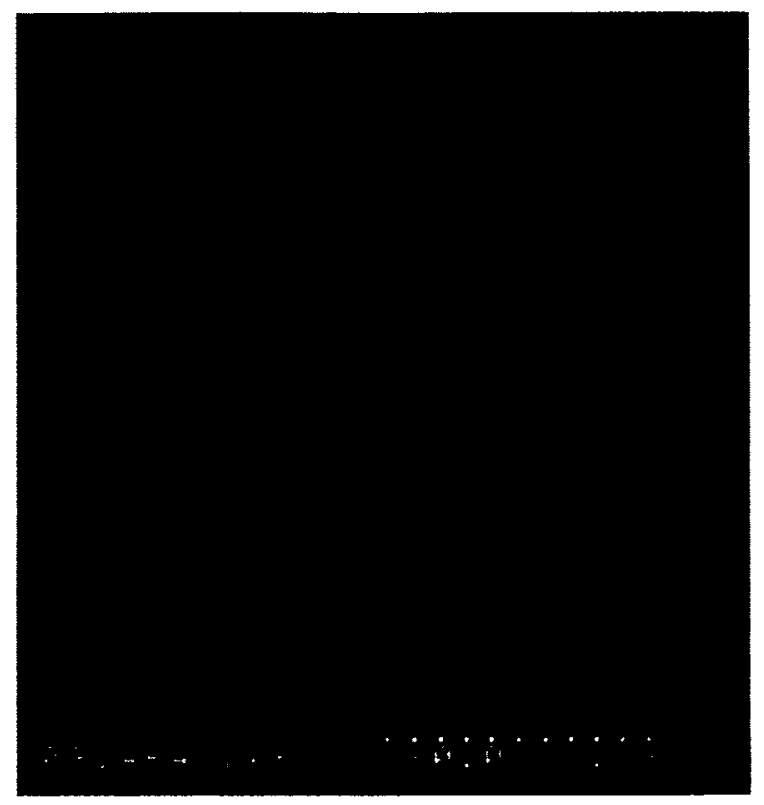

(a)

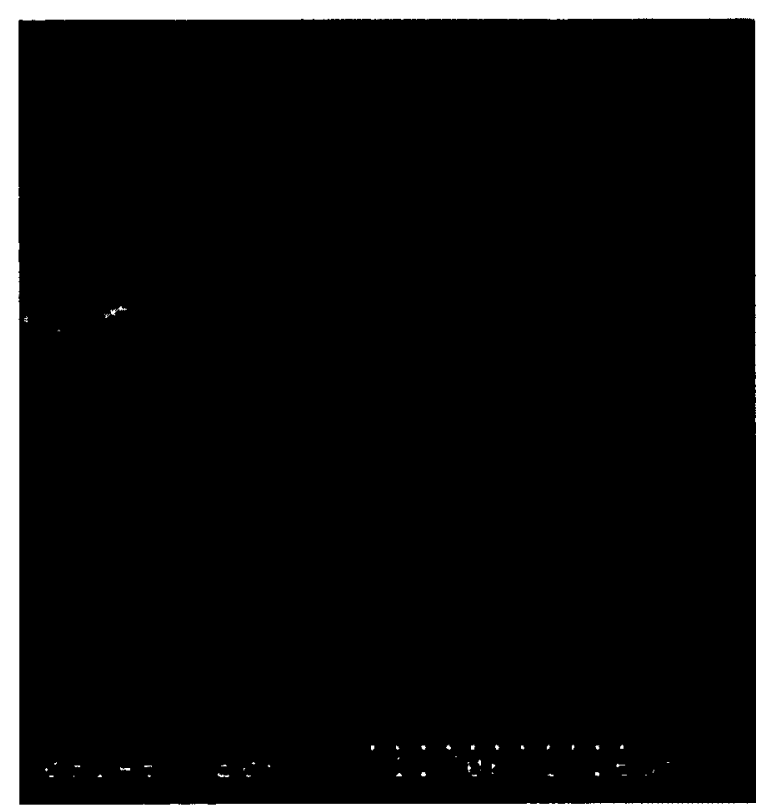

(b)

Figure 5-13: SEM images of worn surface of alloy D tested at room temperature:

(a) at low magnification and (b) at high magnification. 


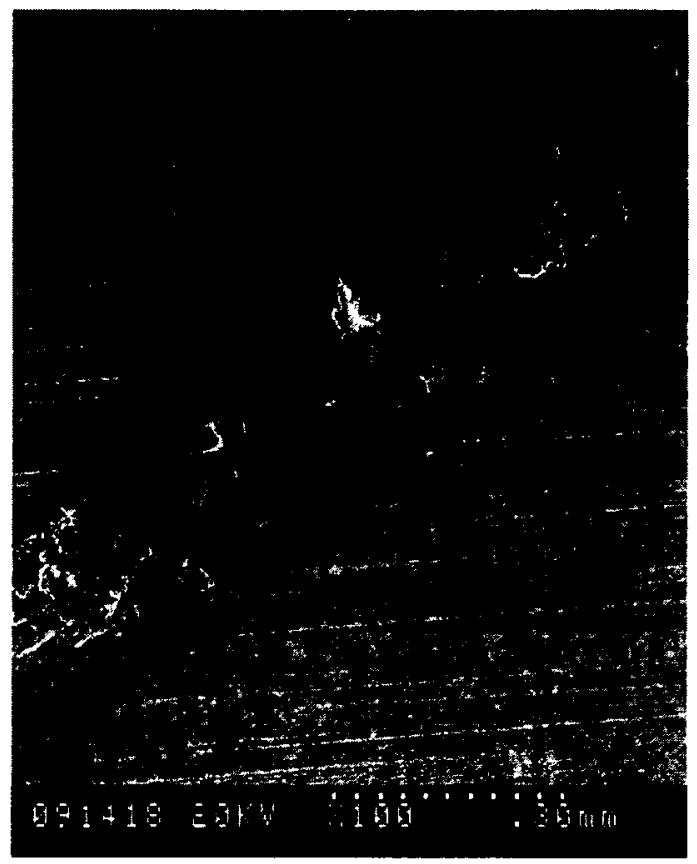

(a)

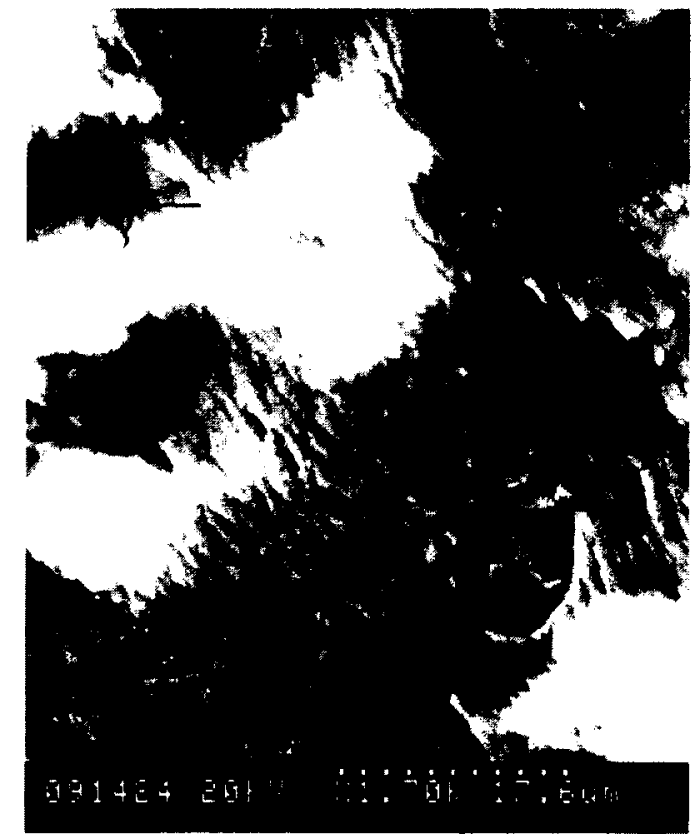

(b)

Figure 5-14: SEM images of worn surface of alloy $\mathrm{E}$ tested at room temperature:

(a) at low magnification and (b) at high magnification. 


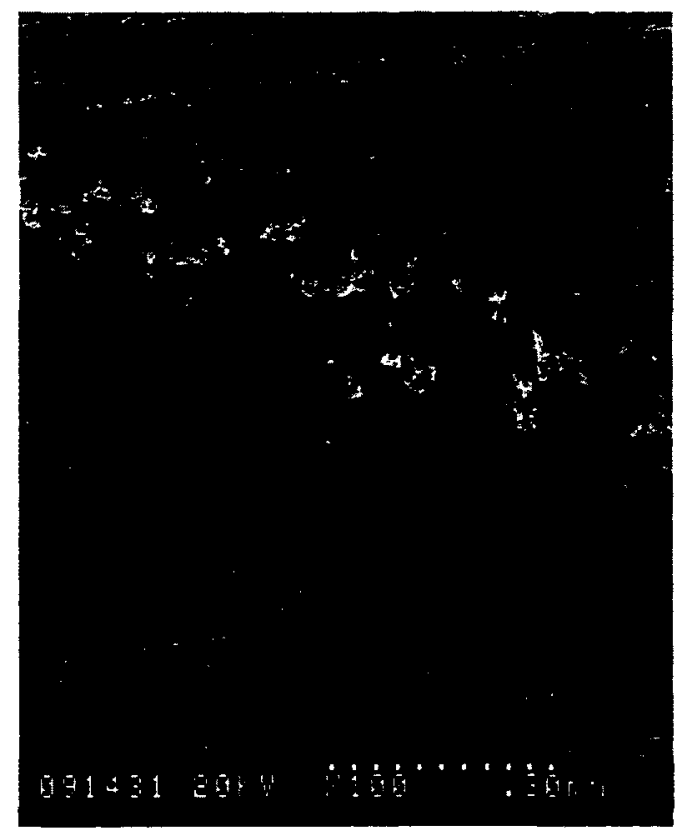

(a)

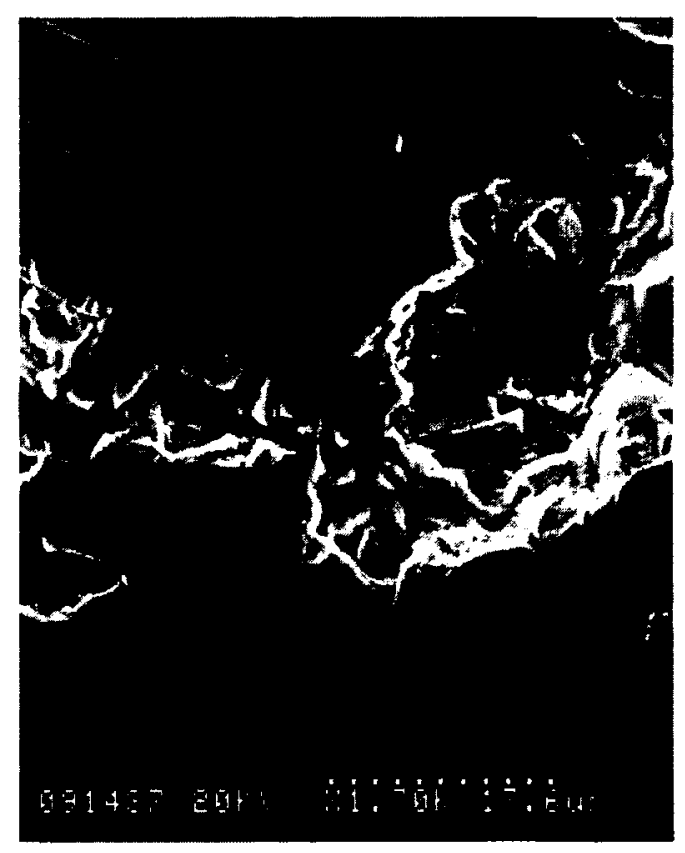

(b)

Figure 5-15: SEM images of worn surface of alloy $\mathrm{F}$ tested at room temperature:

(a) at low magnification and (b) at high magnification. 
Sliding wear generally occurs by three mechanisms: oxide control, contact stress, resistance to deformation and subsurface fatigue. For Stellite alloys, oxidation resistance is mainly determined by their $\mathrm{Cr}$ content; contact stress and deformation resistance are affected by their hardness, which is associated with the carbides content in the alloys; subsurface fatigue is controlled by the toughness of their solution matrices.

For the worn surface of alloy $F$ in Figure 5-15, the wear track is apparently shallow and narrow, compared with the other alloys, which confirms that this alloy has the least wear loss and best wear resistance among the alloys being studied. The worn surface of this alloy also looks fairly smooth, but in the high magnification image, one may observe that the solution matrix (in grey) is ploughed and the carbides (in white) are crushed. For alloy D, due to the low carbon content or small volume fraction of carbides, the wear loss of this alloy is mainly caused by material removal of the solid solution matrix, which can be clearly seen in the high magnification image in Figure 5-13(b). Significant cracking and fracture of the solution matrix are observed in the worn surface of this alloy, which have caused material removal in bulk in the surface, leading to the large wear loss of this alloy. In contrast, alloy A has a large volume fraction of carbides due to the high content of carbon, and therefore its worn surface is less cracked and damaged, as seen in Figure 5-10. Alloy $\mathrm{C}$ and alloy $\mathrm{E}$ have a similar morphology of worn surface, as shown in Figure 5-12 and Figure 5-14. Their matrices show accumulated plastic deformation resulting from cyclic mechanical attack during the wearing process, which is characterized by a staircasing profile. It is also observed that in some local areas carbides were crushed during the wear process. Alloy B appears differently from the others. As seen in Figure 5-11, plastic deformation of the matrix is less but particle 
spallation from the matrix can be observed obviously in this alloy surface, which may be the main reason for larger wear loss than the other alloys except alloy D.

\subsubsection{Specimens tested at elevated temperatures}

As the specimen temperature increased to $250^{\circ} \mathrm{C}$, the wear resistance of all the alloys decreased. This may be theoretically explained due to softening of the alloys at elevated temperatures, which resulted in loss of the strengths. In addition, high temperature oxidation may be another cause of increase in wear loss, because in the room-temperature wear test oxidation may occur only at the contact surfaces where friction heat is generated due to rubbing of wearing surfaces. However, in high-temperature wear, the whole specimen is heated, which generates oxidation of its surface. In the meanwhile, under mechanical attack in the wear process the oxide film breaks down, adding to the material loss.

The images in Figure 5-16 show obvious oxidation and oxide film breakdown in the worn surface of alloy A specimen. This corresponds to the observation of high-temperature hardness test. This alloy was seriously oxidized at $650^{\circ} \mathrm{C}$ in the hardness test. In the wear test, although the specimen temperature was $250^{\circ} \mathrm{C}$, the real temperature of the material at the wearing (contacting) surface would be much higher than $250^{\circ} \mathrm{C}$ because of friction heat. At this temperature the alloy A material could be oxidized. Compared to alloy A, much less oxidation is observed in the worn surfaces of alloy B specimen and alloy $\mathrm{C}$ specimen, see Figure 5-17 and Figure 5-18. This is also consistent with the observation in the high-temperature hardness test. As known from the previous chapter, alloy B and alloy $\mathrm{C}$ were not oxidized obviously at $650^{\circ} \mathrm{C}$. For alloy $\mathrm{D}$, tested at $250^{\circ} \mathrm{C}$, it still 
exhibited the worst wear resistance among the alloys tested. Similar wear mechanisms at room temperature can occur in this alloy tested at $250^{\circ} \mathrm{C}$. Local oxidation occurred in this alloy surface, characterized by white spots in the image in Figure 5-19(a). In the high magnification image, Figure 5-19(b), one may also see oxides (in white) in the large plastic deformation regions. Different from the room temperature test, at $250^{\circ} \mathrm{C}$ alloy $\mathrm{E}$ exhibited better wear resistance than alloy $F$. The main reason for the decrease in wear resistance of alloy $\mathrm{F}$ at elevated temperatures may be surface oxidation. Comparing the image in Figure 5-20 with that in Figure 5-21; the oxidation debris in the worn surface of alloy $\mathrm{F}$ is apparently more and larger. Its lower chromium content may be responsible for the lower oxidation resistance of this alloy. The high-temperature hardness test also showed that alloy $\mathrm{E}$ and alloy $\mathrm{F}$ were oxidized at $650^{\circ} \mathrm{C} ;(\mathrm{W}, \mathrm{Co})_{6} \mathrm{C}$ carbide phase was oxidized more severely than other phases since it does not contain chromium.

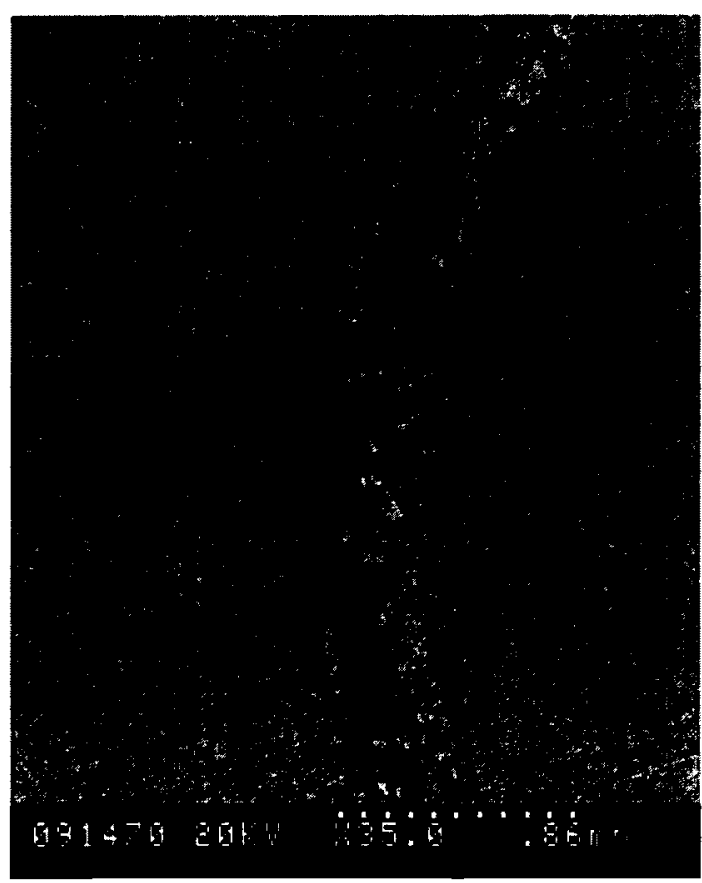

(a) 


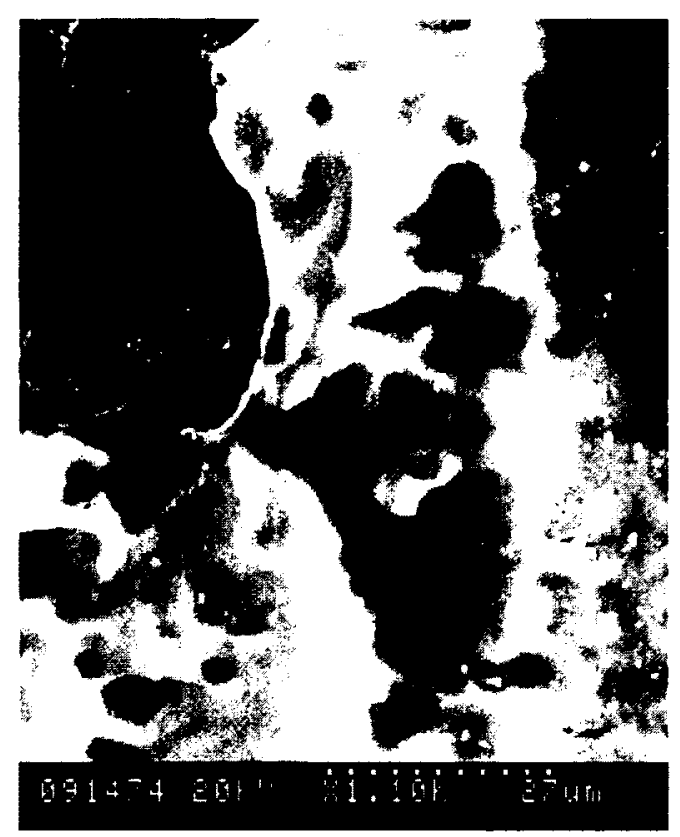

(b)

Figure 5-16: SEM images of worn surface of alloy A tested at $250^{\circ} \mathrm{C}$ :

(a) at low magnification and (b) at high magnification.

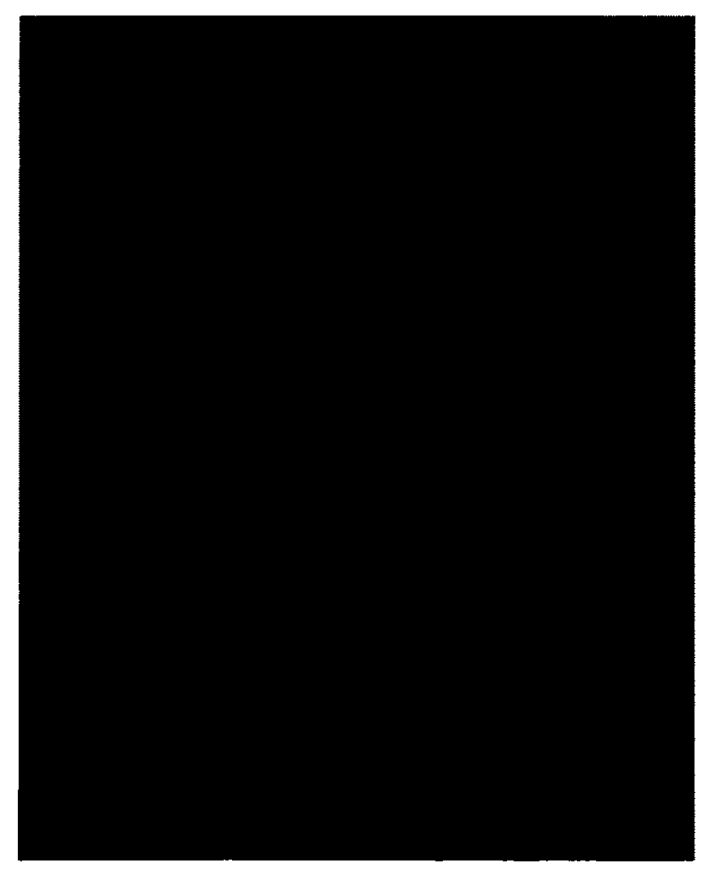

(a) 


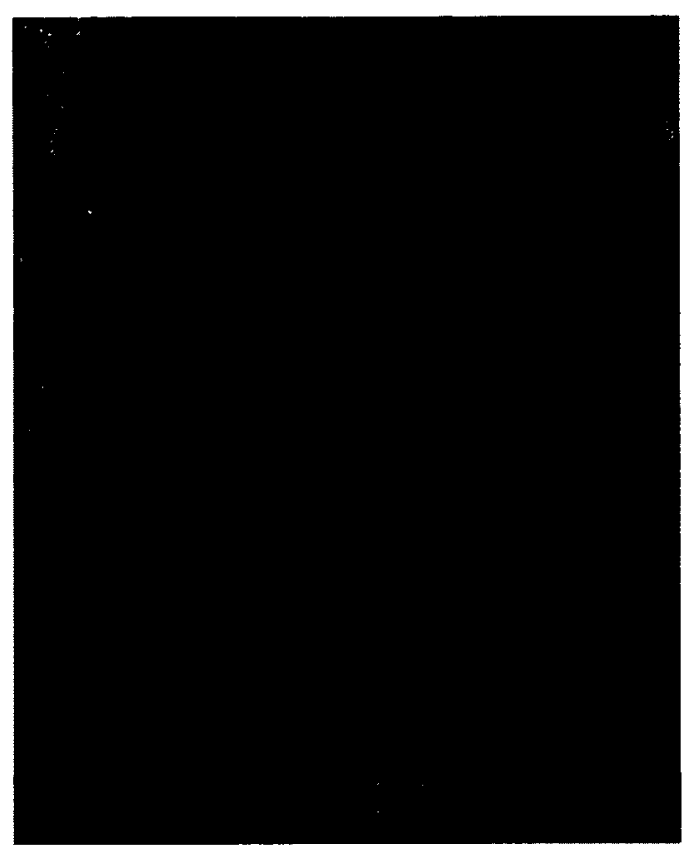

(b)

Figure 5-17: SEM images of worn surface of alloy B tested at $250^{\circ} \mathrm{C}$ :

(a) at low magnification and (b) at high magnification.

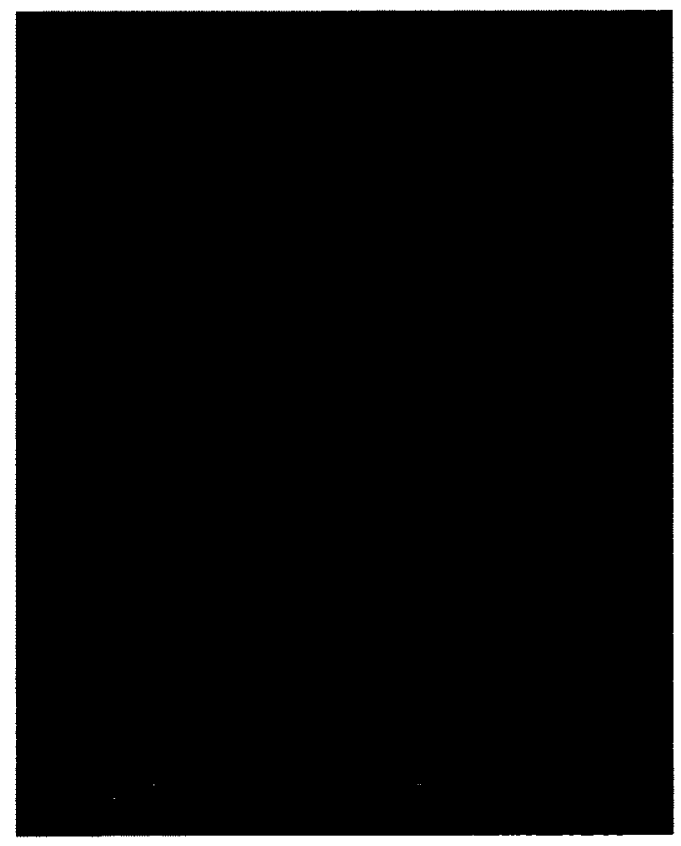

(a) 


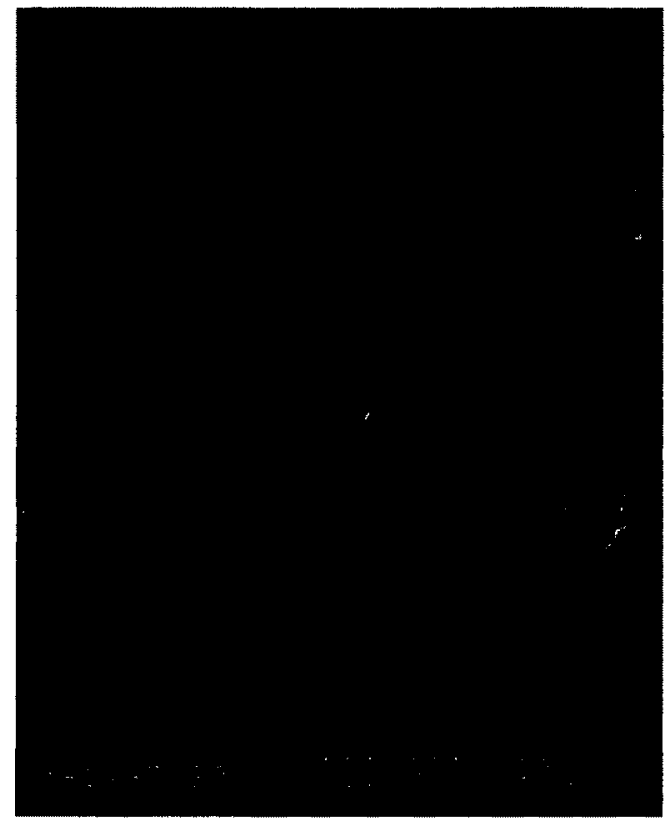

(b)

Figure 5-18: SEM images of worn surface of alloy $\mathrm{C}$ tested at $250^{\circ} \mathrm{C}$ :

(a) at low magnification and (b) at high magnification.

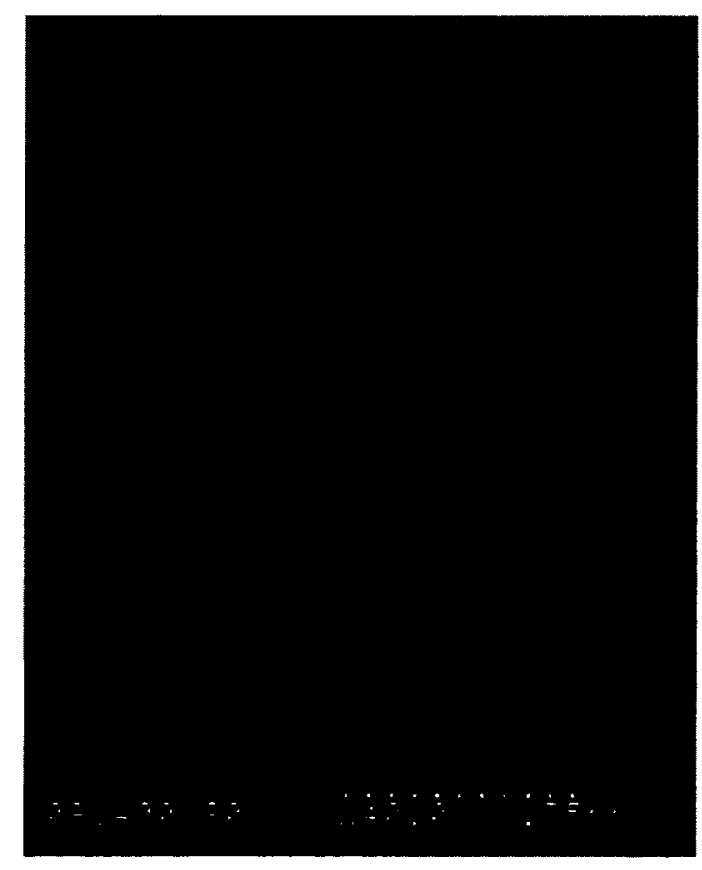

(a) 


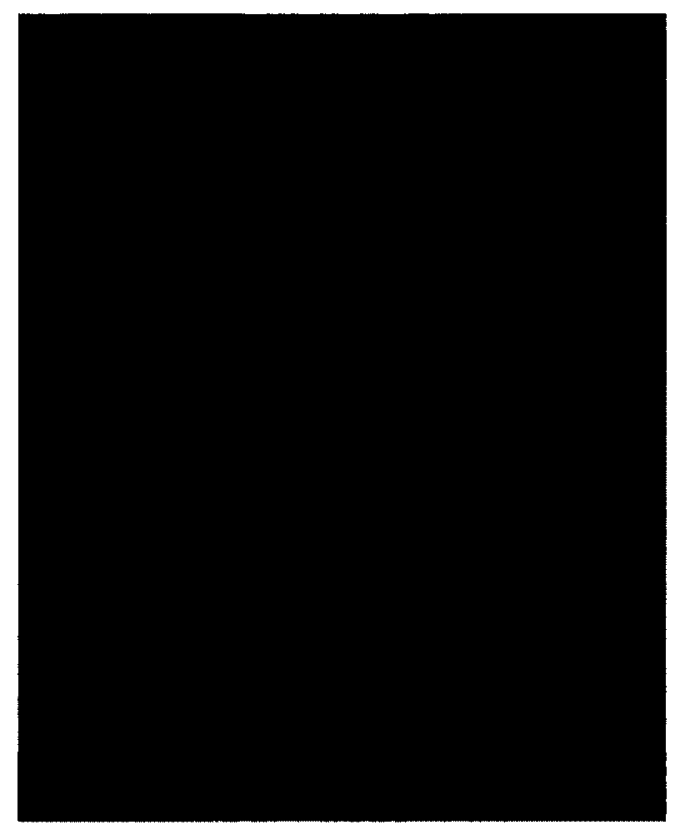

(b)

Figure 5-19: SEM images of worn surface of alloy D tested at $250^{\circ} \mathrm{C}$ :

(a) at low magnification and (b) at high magnification.

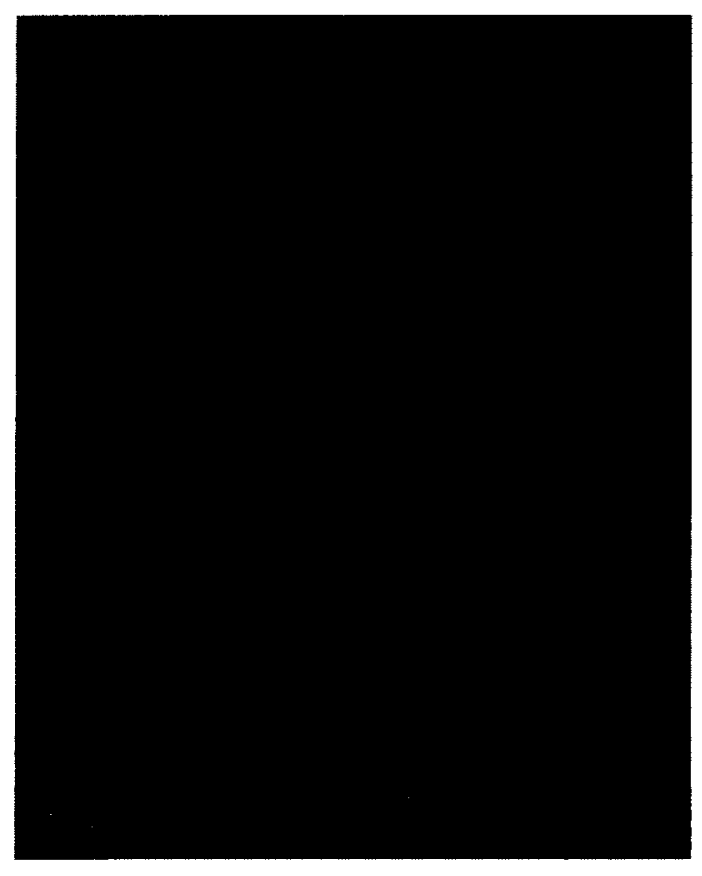

(a) 


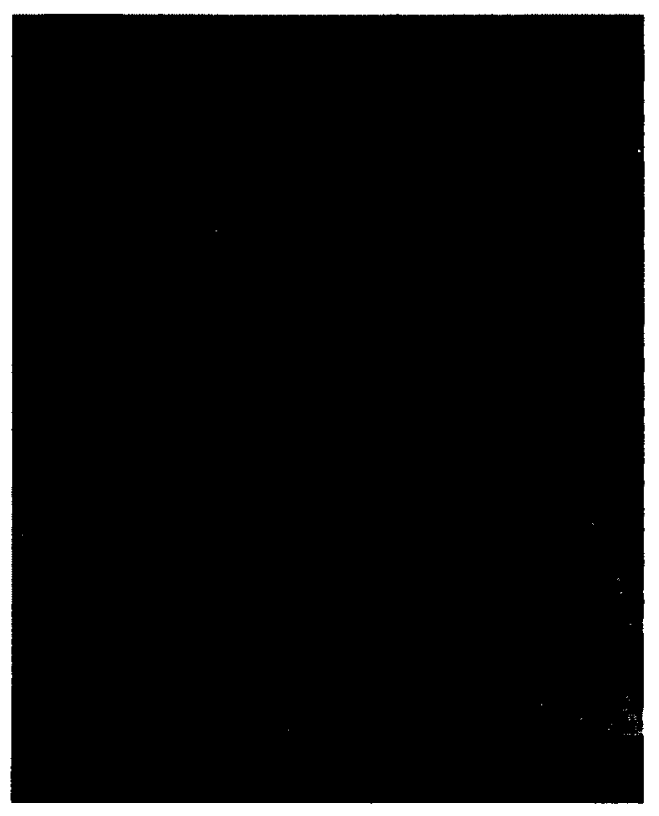

(b)

Figure 5-20: SEM images of worn surface of alloy E tested at $250^{\circ} \mathrm{C}$ :

(a) at low magnification and (b) at high magnification.

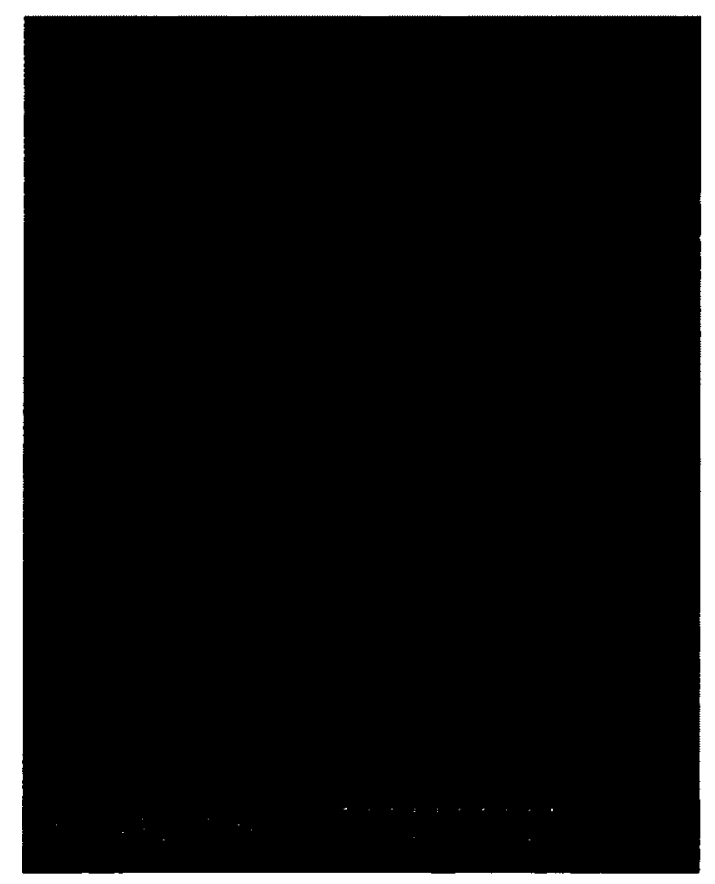

(a) 


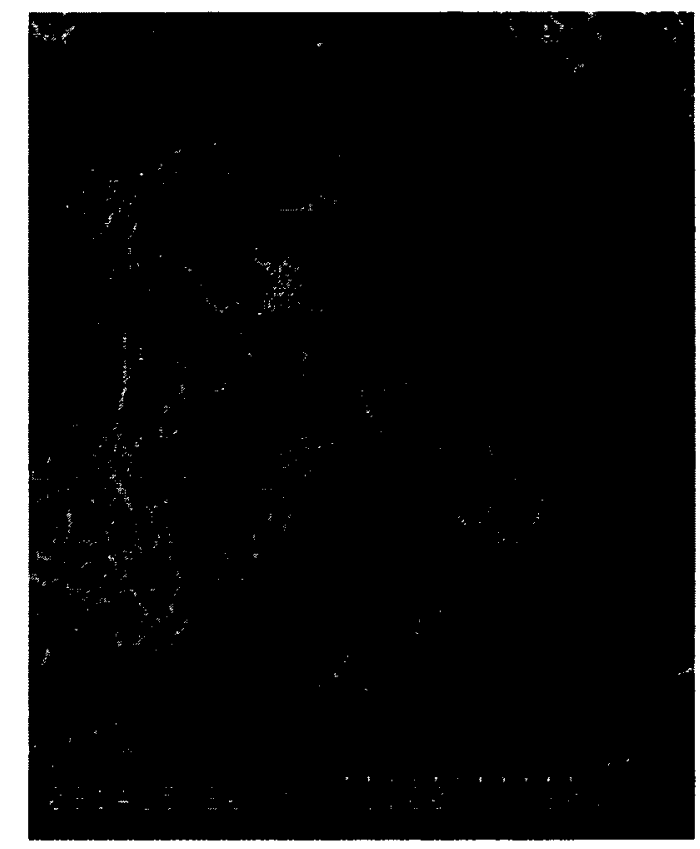

(b)

Figure 5-21: SEM images of worn surface of alloy $\mathrm{F}$ tested at $250^{\circ} \mathrm{C}$ :

(a) at low magnification and (b) at high magnification.

Further analyzing the worn surfaces of the specimens tested at $450^{\circ} \mathrm{C}$, it is found that all the specimens exhibited obvious oxidation at this temperature, but alloy B and alloy $\mathrm{C}$ were still better than the others, as shown in Figure 5-22 to Figure 5-27. Alloy $\mathrm{B}$ exhibited the worst wear resistance at $450^{\circ} \mathrm{C}$ and alloy $\mathrm{E}$ exhibited relatively good wear resistance at high temperatures. There are two possible reasons for alloy $\mathrm{E}$ being more wear-resistant at high temperatures; one is that this alloy has the highest chromium content among the alloys being studied, which enhanced its resistance to oxidation; the other is that this alloy also exhibited good resistance to wear at room temperature, owing to the presence of a large amount of $(\mathrm{W}, \mathrm{Co})_{6} \mathrm{C}$ and $\mathrm{M}_{7} \mathrm{C}_{3}$ carbides. Regarding alloy $\mathrm{B}$, it contains the least carbon among the alloys except alloy $\mathbf{D}$ that a low-carbon Stellite alloy. 
This may be the main reason for the lowest wear resistance of this alloy at both room temperature and at high temperatures. Alloy B also suffered from high-temperature oxidation, but together with alloy $C$ it was less oxidized, compared to the others. The oxide debris and the fresh surfaces exposed after the oxide films were broken down can be found in its worn surface, see Figure 5-23. Comparing alloy $\mathrm{C}$ with alloy $\mathrm{A}$, the former was worse in wear resistance at room temperature but better at high temperatures. The better oxidation resistance of alloy $\mathrm{C}$ may be beneficial for the less wear loss at high temperatures.

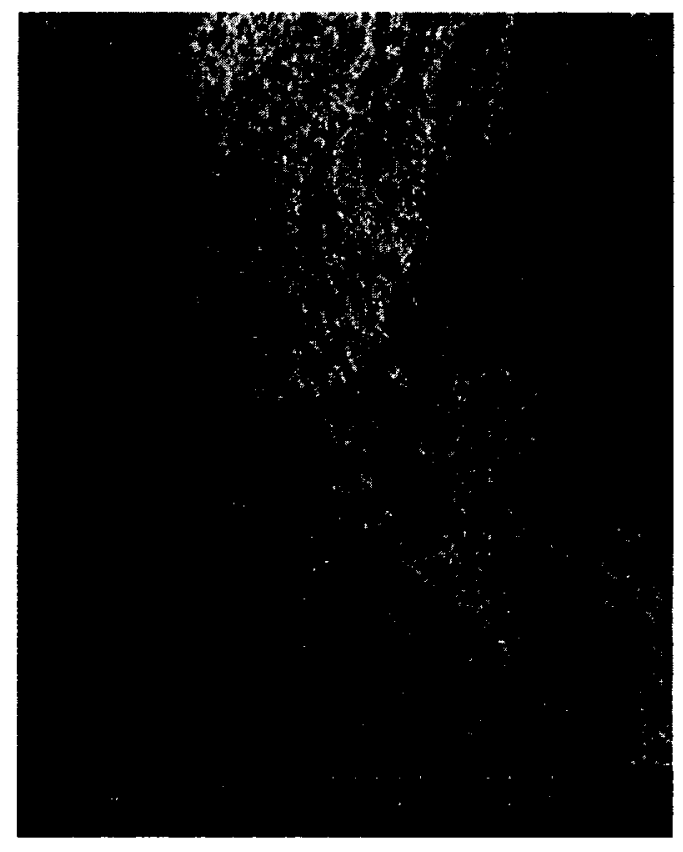

(a) 


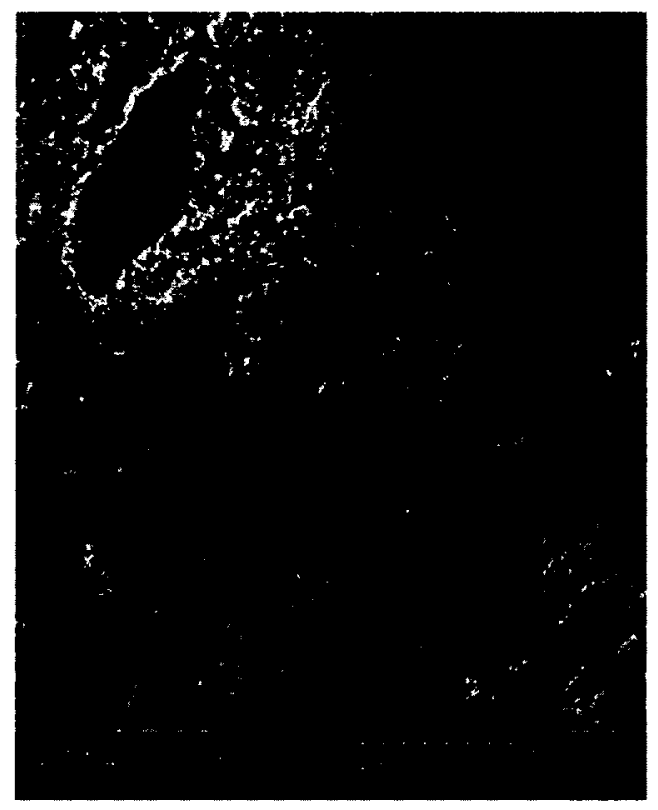

(b)

Figure 5-22: SEM images of worn surface of alloy A tested at $450^{\circ} \mathrm{C}$ :

(a) at low magnification and (b) at high magnification.

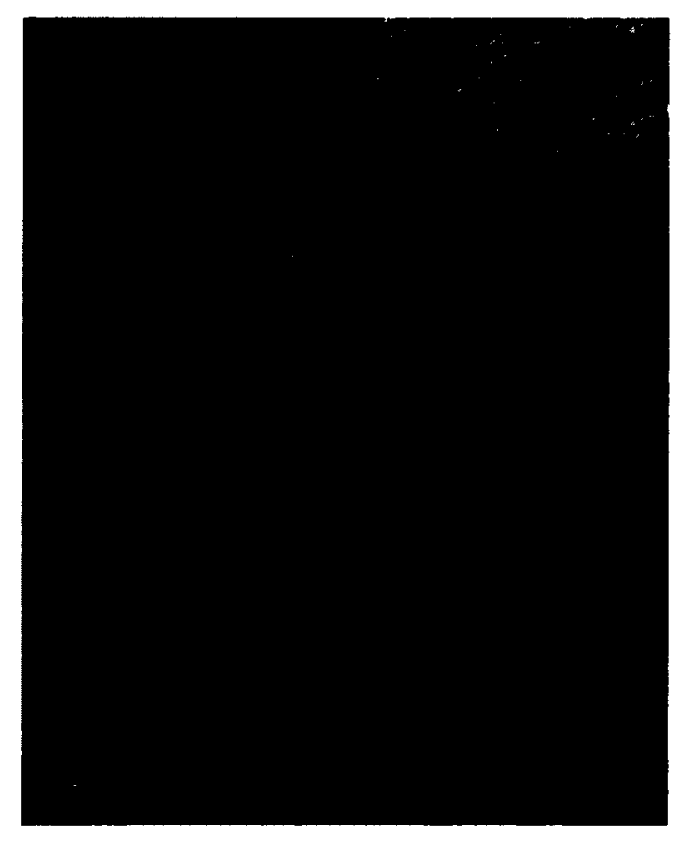

(a) 


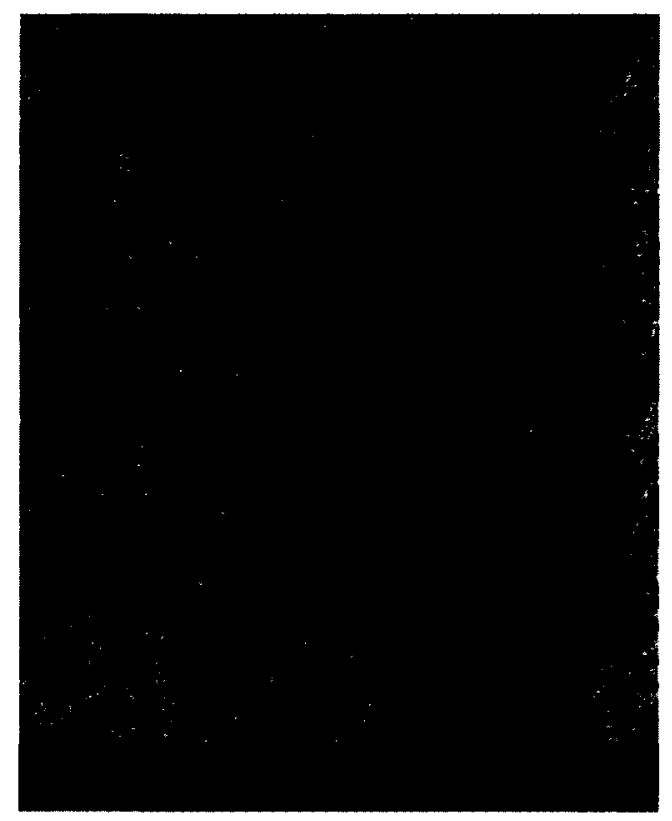

(b)

Figure 5-23: SEM images of worn surface of alloy $\mathrm{B}$ tested at $450^{\circ} \mathrm{C}$ :

(a) at low magnification and (b) at high magnification.

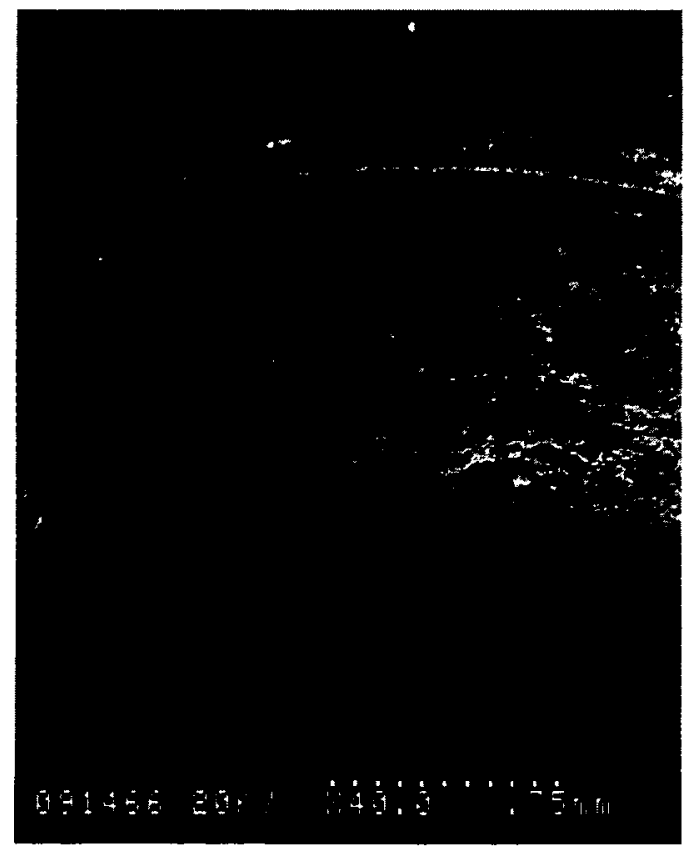

(a) 


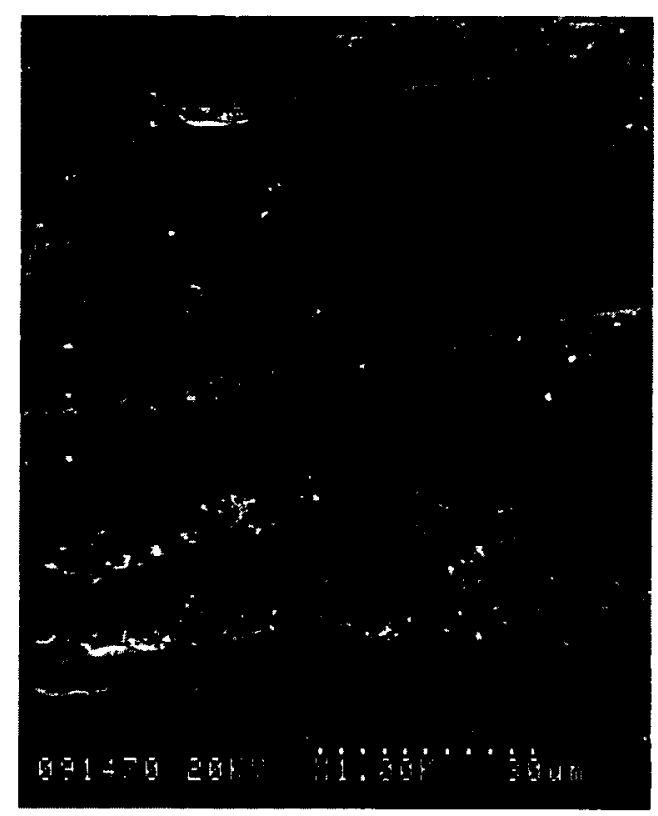

(b)

Figure 5-24: SEM images of worn surface of alloy $\mathrm{C}$ tested at $450^{\circ} \mathrm{C}$ :

(a) at low magnification and (b) at high magnification.

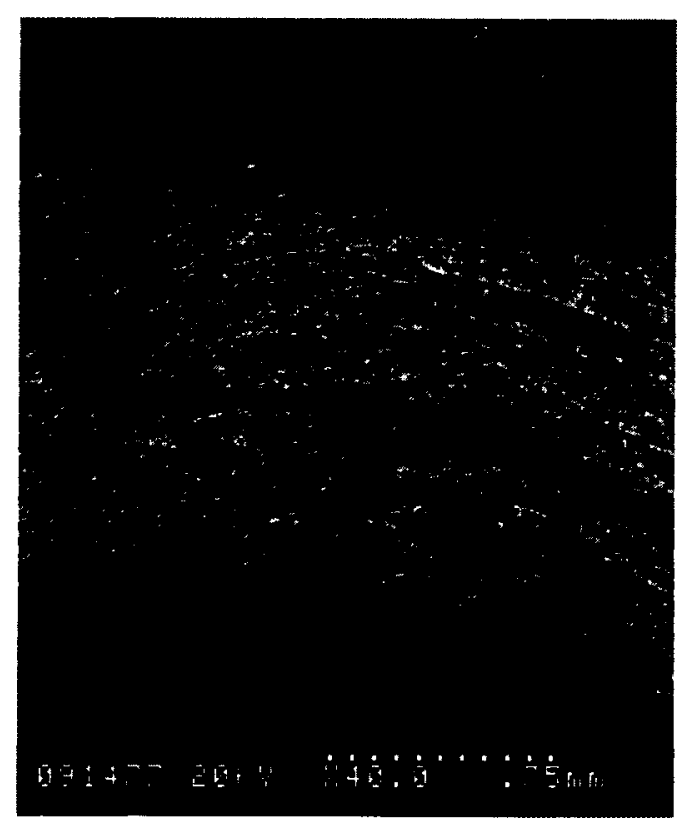

(a) 


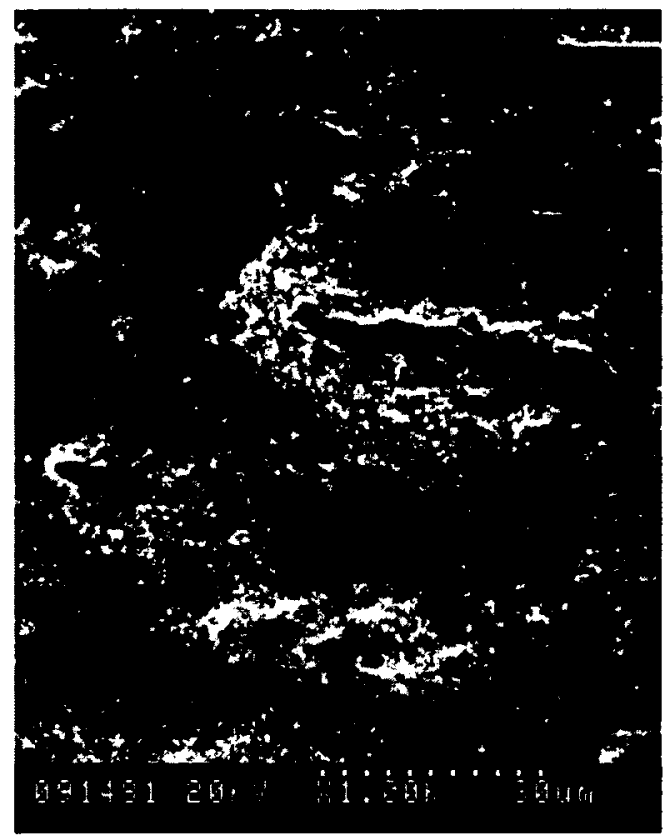

(b)

Figure 5-25: SEM images of worn surface of alloy D tested at $450^{\circ} \mathrm{C}$ :

(a) at low magnification and (b) at high magnification.

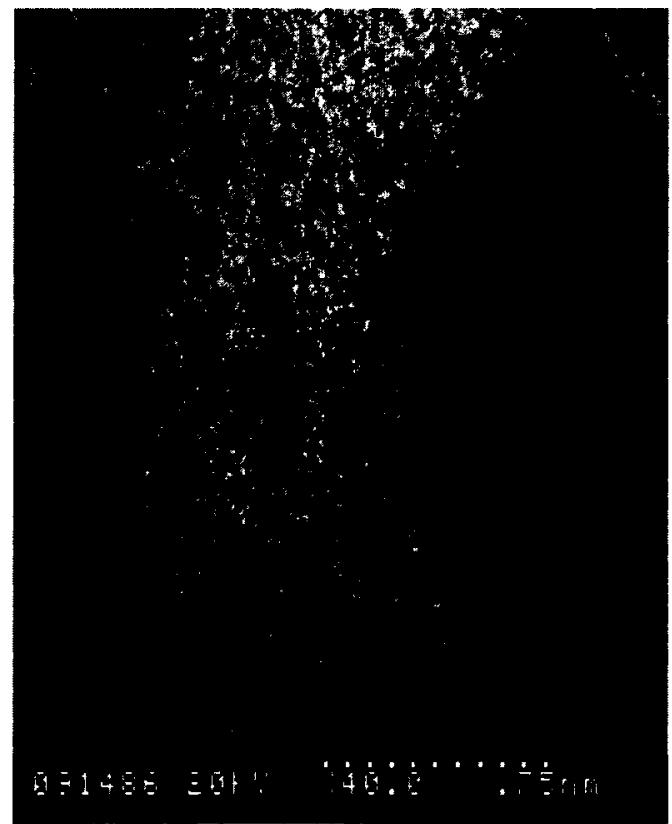

(a) 


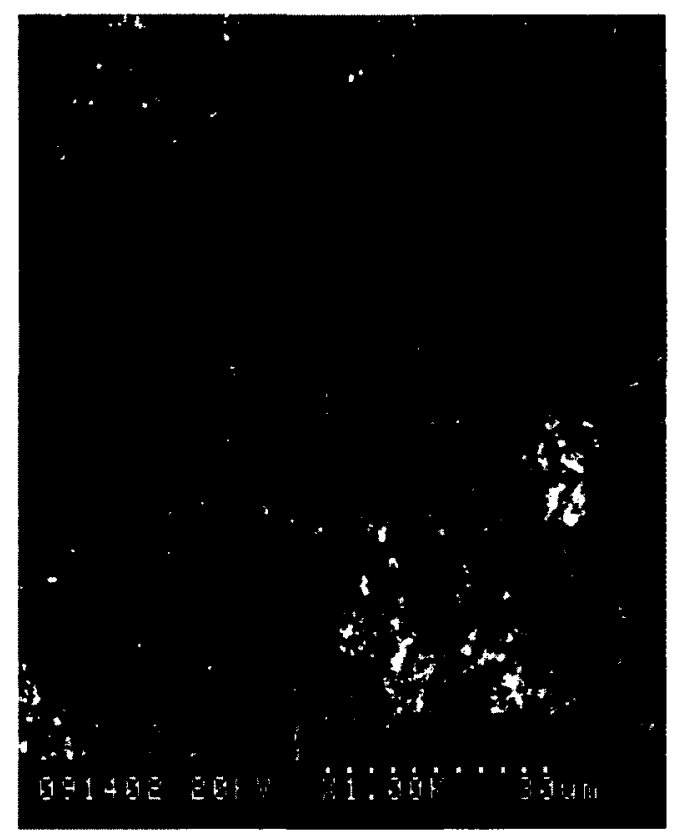

(b)

Figure 5-26: SEM images of worn surface of alloy E tested at $450^{\circ} \mathrm{C}$ :

(a) at low magnification and (b) at high magnification.

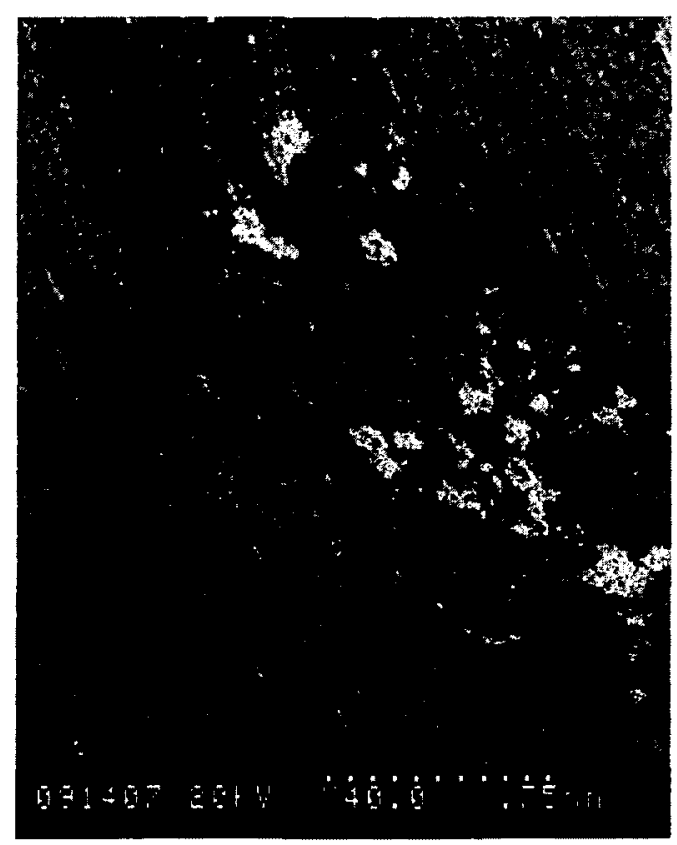

(a) 


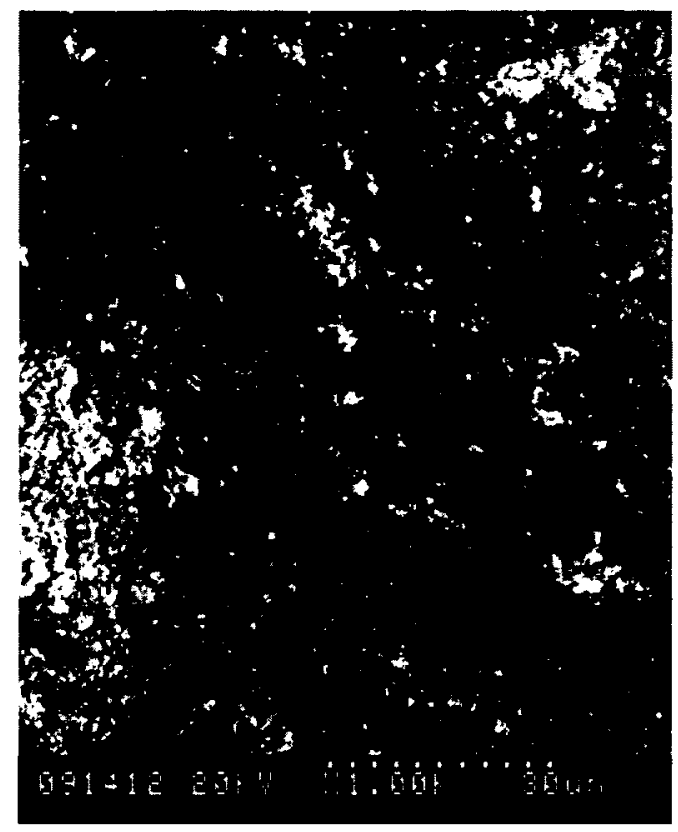

(b)

Figure 5-27: SEM images of worn surface of alloy $\mathrm{F}$ tested at $450^{\circ} \mathrm{C}$ : at low magnification and (b) at high magnification.

The wear loss results show all the alloys lost wear resistance at the temperature of $650^{\circ} \mathrm{C}$ except alloy $\mathrm{D}$ that had an increase in wear resistance. The abnormal behaviour of alloy D at high temperatures is possibly attributed to surface hardening which was caused by strain hardening and the "glazing" effect [31]. The morphology of the worn surface in Figure 5-25 shows large plastic deformation flow in the alloy D specimen surface. Since this alloy contains a very small amount of carbides, the plastic flow occurring in the solution matrix of this alloy appears continuous, as seen in Figure 5-25(b), which is the most significant difference in worn surface features of alloy $D$ from the other alloys. 


\section{Chapter: Discussion on Results and Correlations}

\subsection{Chemical Composition}

\subsubsection{Effects on microstructure}

Chemical composition, fabrication process, heat treatment, cold and hot work, altogether determine the microstructure of a material, and hence control the physical/mechanical properties of its products. The most important element addition in Stellite alloys is carbon, which determines the amount of carbides in the alloys. The volume fraction of carbides in Stellite alloys controls the hardness and wear resistance of these alloys. Among the six alloys studied in this research, alloy D contains considerably less carbon, so that it is a solution-strengthened alloy. In its microstructure, as shown in Figure 3-8, there is a very small amount of carbides. On the contrary, alloy A contains a very high content of carbon, thus a large amount of carbides, in the forms of both primary $\mathrm{Cr}_{7} \mathrm{C}_{3}$ and eutectic $(\mathrm{W}, \mathrm{Co})_{6} \mathrm{C}$, as seen in its microstructure in Figure 3-5. This alloy has a hyper-eutectic microstructure. In addition to carbon, other alloying elements such as $\mathrm{Cr}$, $\mathrm{W}$ and Mo also play an important role in the microstructures of Stellite alloys. For example, tungsten mostly serves to provide additional strength to the solid solution matrix, but when present in large quantities, it participates in the formation of carbides during alloy solidification and promotes the precipitation of $(\mathrm{W}, \mathrm{Co})_{6} \mathrm{C}$, as demonstrated in the microstructures of alloy A, alloy C, alloy E and alloy F in Figure 3-5, Figure 3-7, Figure 3-9 and Figure 3-11. Molybdenum in alloy B and alloy D also serves to provide additional strength to the matrix; it also enhances corrosion resistance. Chromium is the indispensable element in Stellite alloys. The six alloys under investigation all contain a large amount of chromium $(22 \sim 33.5 \mathrm{wt} \%)$ which provides corrosion and oxidation 
resistance and also forms chromium carbides for wear resistance. Nickel in alloy A, alloy B, alloy $C$ and alloy D stabilizes fcc form of the matrix at room temperature, which increases machinability of the alloys. Boron in alloy $\mathrm{E}$ provides strengthening by effects on grain boundaries and by precipitate formation. But the main effect of boron in this alloy is for the purpose of powder metallurgy. As discussed previously, addition of boron can reduce the melting temperature of the alloy, which favours microstructural homogenization of the part in $\mathrm{P} / \mathrm{M}$ process [29]. On the other hand, owing to the feature of low melting point the presence of boron can enhance the mobility of the alloy during the hardfacing welding process [32].

\subsubsection{Relationship between microstructure and hardness}

The hardness test was performed on individual phases of the microstructure for each alloy being studied in this research. As demonstrated in the indentation test, The solid solutions of Stellite alloys are much softer than carbides, whether $\mathrm{Cr}_{7} \mathrm{C}_{3}$ or $(\mathrm{W}, \mathrm{Co})_{6} \mathrm{C}$. Therefore, the overall hardness of each alloy is controlled by the volume fraction of carbides in its microstructure. Definitely, the more carbides in the microstructure, the harder the alloy is. For example, alloy $A$, alloy $E$ and alloy $F$ have a hyper-eutectic microstructure because of the high carbon and tungsten contents in their chemical compositions, containing a large amount of $\mathrm{Cr}_{7} \mathrm{C}_{3}$ and $(\mathrm{W}, \mathrm{Co})_{6} \mathrm{C}$ carbides, whereas alloy D is a solution-strengthened alloy, containing a very small fraction of carbides due to the very low carbon content. Thus alloy $A$, alloy $E$ and alloy $F$ must be much harder than alloy $\mathrm{D}$, which was confirmed by previous research and reported in literature [1]. In addition, the indentation test results show that $\mathrm{Cr}_{7} \mathrm{C}_{3}$ is harder than 
$(\mathrm{W}, \mathrm{Co})_{6} \mathrm{C}$, as illustrated in Figure 6-1, therefore, with the same amount of carbides the alloy that contains more $\mathrm{Cr}_{7} \mathrm{C}_{3}$ will have higher overall hardness than the alloy that contains more $(\mathrm{W}, \mathrm{Co})_{6} \mathrm{C}$. For the solid solution phase, owing to the different constituents, the solid solutions of each alloy vary in hardness, as illustrated in Figure 6-2. The solid solution of alloy $\mathrm{A}$ is the hardest among the other alloys and that of alloy $\mathrm{D}$ is the softest. The solid solution of alloy $\mathrm{C}$ has comparable hardness to that of alloy $\mathrm{A}$. The higher hardness of solid solutions of alloy $\mathrm{A}$ and alloy $\mathrm{C}$ are attributed to the high tungsten contents. Although the hardness values of solid solutions of alloy $\mathrm{E}$ and alloy $\mathrm{F}$ are not available, as explained earlier, it can be deducted that the solid solutions of these two alloys are hard and may be harder than those of alloy $\mathrm{A}$ and alloy $\mathrm{C}$ because of the very high tungsten contents in their compositions.

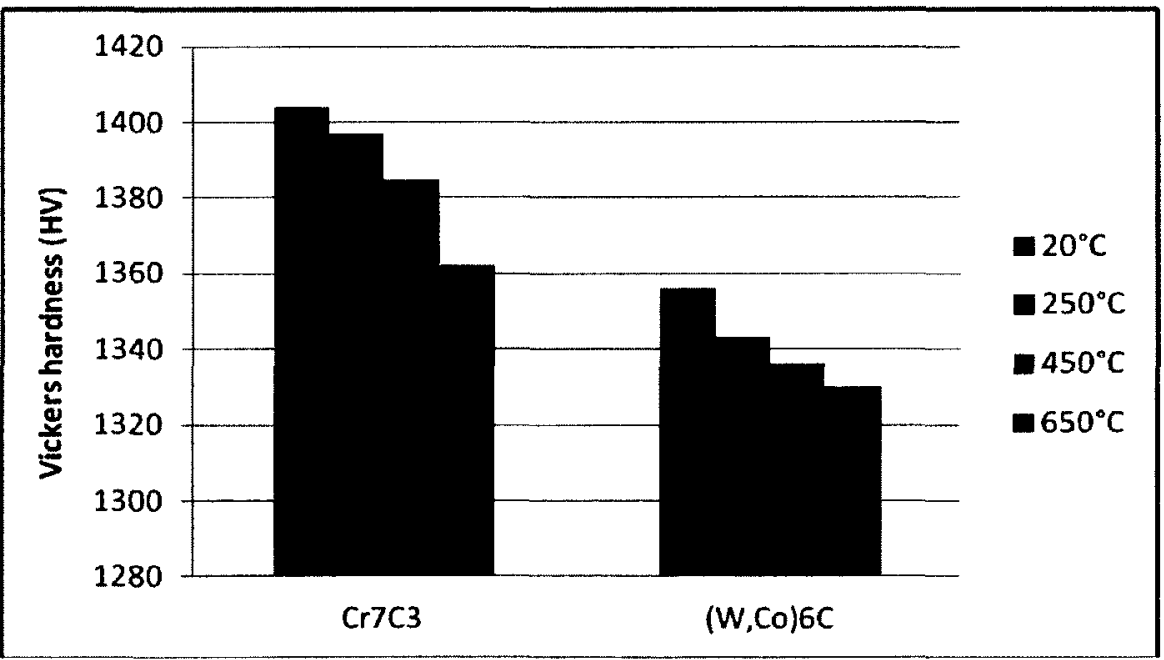

Figure 6-1: Comparison of hardness between the carbides in Stellite alloys. 


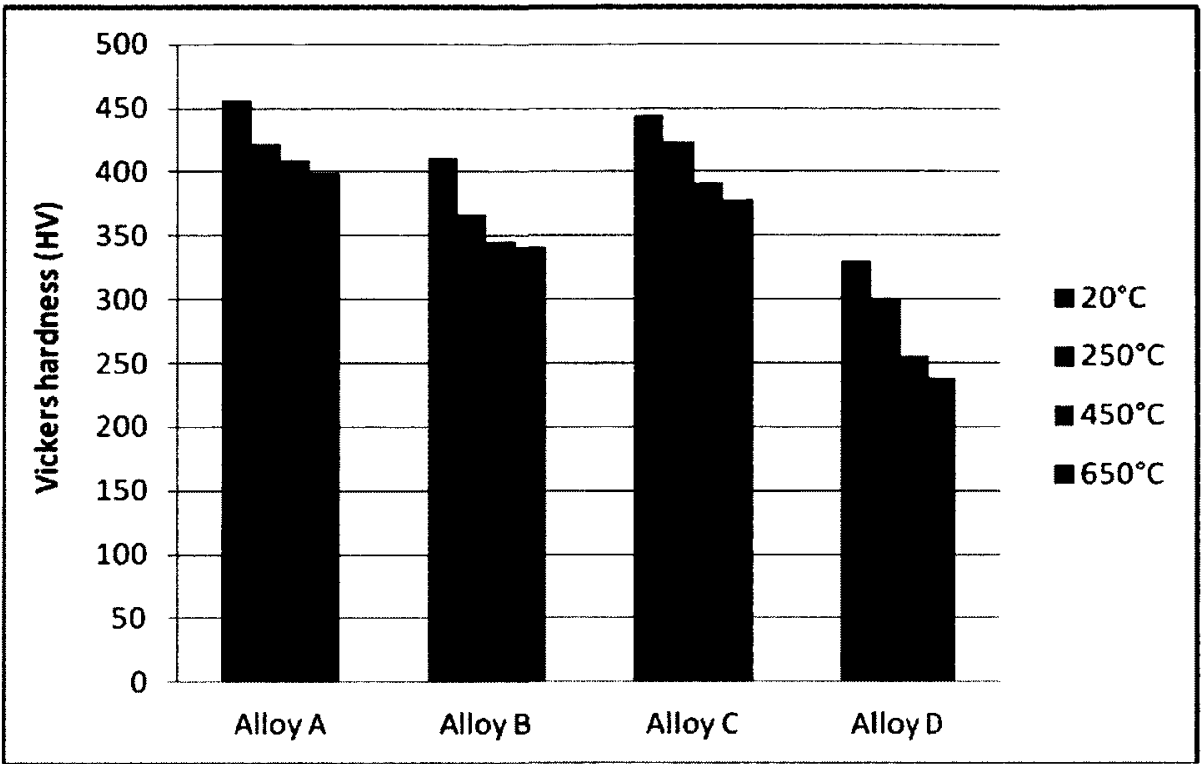

Figure 6-2: Comparison of hardness between the solid solutions in Stellite alloys.

\subsubsection{Relationship between microstructure and wear resistance}

Similar to the discussion on hardness, the volume fraction of carbides in a Stellite alloy determines its wear resistance. As demonstrated by the pin-on-disc wear test, the wear resistance of Stellite alloys at room temperature is directly related to their carbon contents. This is because carbides are much more resistant to wear than solid solution. Of course, other alloying elements also play an important role in wear resistance of Stellite alloys, for example, tungsten. As shown in Figure 5-7(a), alloy A exhibited excellent wear resistance at room temperature; this is because it has a hyper-eutectic microstructure, containing a large volume fraction of carbides. However, although alloy $\mathrm{F}$ contains less volume fraction of carbides than alloy $A$, it exhibited higher wear resistance, as shown in Figure 5-7(a). This can be attributed to the high content of tungsten in alloy $\mathrm{F}$, which not only promoted the formation of a large amount of 
wear-resistant $(\mathrm{W}, \mathrm{Co})_{6} \mathrm{C}$ but also enhanced the wear resistance of the solution matrix as a solute. Also, alloy $\mathrm{E}$ has a hyper-eutectic microstructure, but the volume fraction of carbides in this alloy is apparently less than that in alloy $\mathrm{A}$ due to the reduced carbon content. As a result, alloy $\mathrm{E}$ exhibited lower wear resistance than alloy $\mathrm{A}$ at room temperature, as seen in Figure 5-7(a). On the contrary, alloy $\mathrm{B}$ and alloy $\mathrm{C}$ all have a hypo-eutectic microstructure, containing much less volume fraction of carbides compared with alloy $\mathrm{A}$ and alloy $\mathrm{E}$, accordingly, these alloys exhibited worse wear resistance at room temperature, as seen in Figure 5-7(a). Between alloy B and alloy C, the latter is better in wear resistance owing to its larger volume fraction of carbides compared with the former, especially the presence of wear-resistant $(\mathrm{W}, \mathrm{Co})_{6} \mathrm{C}$. Finally, the low-carbon Stellite alloy, alloy D, contains a very small amount of carbides, so that it exhibited the worst wear resistance at room temperature amount the alloys being studied.

\subsubsection{Relationship between hardness and wear resistance}

As discussed earlier, hardness is commonly related to wear resistance, because it is generally accepted that the harder the material, the higher the wear resistance. This hypothesis is based on the fact that hardness is a measure of a solid material to resist permanent deformation. According to the fundamentals of abrasive wear, this type of wear is related to interactions between surfaces and more specifically related to the removal and deformation of material on a surface as a result of mechanical action of the opposite surface [33]. During a wear process, the relative motion between two contact surfaces results in impingement of asperities due to mechanical attack, which generates plastic deformation at the sub-layer beneath the contact surface. Plastic deformation is 
accumulated with the reciprocal impingement of asperities in the wear process until the resulting strain at the sub-layer reaches the failure limit of the surface material; fracture then occurs in the contact surface, which leads to the removal of material from the surface at the sub-layer $[34,35]$. Since hardness of a material measures its ability to resist permanent deformation, while wear of a material is directly caused by accumulated permanent deformation at the sub-layer of the wearing surface, the hardness level of a material can represent its capability of resisting wear in certain extent. However, not in all cases and not for all materials, the premise that the harder the material, the greater the wear resistance, applies. As extensively studied and reported in literature, wear is a complicated process involving multiple factors such as the properties of the material under wear, counterpart material, surface condition, environment, etc., these may all affect the wear of a material.

From the hardness test results, both $\mathrm{Cr}_{7} \mathrm{C}_{3}$ and $(\mathrm{W}, \mathrm{Co})_{6} \mathrm{C}$ carbides are much harder than the solid solutions of Stellite alloys. Accordingly, the alloys containing more carbides are more resistant to wear than those containing less carbides, as demonstrated by the pin-on-disc wear test. Certainly, as discussed above, in addition to carbides, other alloying elements such as tungsten and molybdenum also influence the wear resistance of Stellite alloys. As shown in Figure 6-2, the solid solutions of alloy $\mathrm{A}$ and alloy $\mathrm{C}$ are harder than those of alloy B and alloy D. If correlating the hardness of these solid solutions with chemical compositions of their corresponding alloys, one may find that the higher tungsten content may be the main contribution to the hardness increase of alloy $\mathrm{A}$ and alloy $\mathrm{C}$, and the increased hardness consequently enhanced the wear resistance of these alloys, as seen in Figure 5-7(a), alloy $\mathrm{A}$ and alloy $\mathrm{C}$ are more resistant to wear than 
alloy $\mathrm{B}$ and alloy $\mathrm{D}$. It can be deduced that the high wear resistance of alloy $\mathrm{F}$ is attributed to both enhanced hardness of the solid solution matrix and formation of large volume fraction of hard $(\mathrm{W}, \mathrm{Co})_{6} \mathrm{C}$ carbide due to the high tungsten content.

\subsection{Temperature Effects}

\subsubsection{Effects on hardness}

The hardness tests at elevated temperatures revealed that both the solid solution phase and carbide phases of Stellite alloys were affected by temperature, but the temperature effect on carbides was trivial and can be neglected. The solid solutions were softened at elevated temperatures; this may be due to the promoted atomic motion and relief of stress. The better high-temperature performance of carbides may be attributed to their higher melting points. Chromium carbides have a high melting point between $1250^{\circ} \mathrm{C} \sim 1895^{\circ} \mathrm{C}$ and tungsten carbides can be as high as $2870^{\circ} \mathrm{C}$. The solid solutions of Stellite alloy mostly melt at the temperatures between $1000^{\circ} \mathrm{C} \sim 1200^{\circ} \mathrm{C}$. The main reasons that caused softening of solid solutions at the temperatures $\left(250^{\circ} \mathrm{C}, 450^{\circ} \mathrm{C}\right.$ and $650^{\circ} \mathrm{C}$ ) can be the so-called stress relief anneal. This heat treatment is usually used to reduce residual stresses in large castings, welded parts and cold-formed parts. Such parts tend to have stresses due to thermal cycling or work hardening. At these temperatures any dislocations and residual stresses induced in the specimen material during the material processing and the specimen manufacturing may be released. It was also found that after the heating/cooling cycle performed in the indentation test the solid solutions were hardened. This can be explained as the structures of the solid solutions were homogenized by the heating/cooling cycle as a heat treatment process, which increased 
the overall strength of the solid solutions and thus the local resistance to deformation in the indentation test. As carbides have good high-temperature properties, they were almost not softened at the temperatures up to $650^{\circ} \mathrm{C}$, that is, the microstructures of the carbides remained nearly unchanged at this high temperature. Therefore, the hardness of the carbides was not altered by the heating/cooling cycle. In addition, comparing the temperature dependence data of hardness of the solid solutions in Table 4-4, it is found that the solid solutions containing tungsten have lower variation sensitivity. The higher the tungsten content, the lower the variation sensitivity. The beneficial effect of tungsten on the high-temperature properties of Stellite alloys is owing to its high melting point and excellent high-temperature performance.

\subsubsection{Effects on wear resistance}

The wear behaviour of Stellite alloys at elevated temperatures is much complex than that at room temperature, because the temperature effect may induce many changes in the factors that are involved in the wear process, for example, the material surface may be oxidized, the synergic effect of temperature and mechanical attack may result in different wear mechanisms.

It was demonstrated by the wear test that when the specimen temperature was increased, the wear resistance of all the alloys decreased. This was due to softening of the alloys at elevated temperatures, resulting in loss of their strength. Also, high temperature oxidation was another cause of increase in wear loss, because in room temperature wear oxidation occurred only at the contact surfaces where friction heat was generated due to rubbing of wearing surfaces. However, in high temperature wear the whole specimen was 
heated, which resulted in oxidation of the specimen surface; under mechanical attack during the wear process the oxide films were broken down, thus increasing the material loss. The oxidation behaviour of Stellite alloys in high temperature wear can be found in the worn surfaces of the alloy specimens, shown in Figure 5-16 to Figure 5-27, the white areas are the debris of oxidation.

The significant reduction in wear resistance of alloy $F$ at elevated temperatures may be caused by the lowered chromium content in this alloy, which compromised its oxidation resistance. In its worn surface in Figure 5-21 and Figure 5-27 oxide debris can be largely found, in particular, in Figure 5-27 (b) one may see large areas of fresh surface due to breakdown and removal of oxide films.

The abnormal behaviour of alloy $\mathrm{D}$ worn at $450^{\circ} \mathrm{C}$ was possibly attributed to surface hardening, which may be caused by two aspects. In one aspect, alloy D contains very low carbon thus a very small amount of carbides so that the properties of this alloy are dominated by the cobalt solid solution. Cobalt solid solution is much softer than the tougher carbides, as demonstrated by the hardness test. At high temperatures the dislocations occurring in the solid solution due to mechanical attack of wear was aggravated because of enhanced atom motion, which rendered the wearing surface strain-hardened. In the meanwhile, both the high temperature and induced stress promoted the fcc $\rightarrow$ hep transformation of the solid solution, which also contributed to the surface hardening [36]. This behaviour can be further confirmed by the morphology of its worn surface in Figure 5-25; large plastic deformation flow can be observed. In the other aspect, during the wear process the material was removed from the surface as fine particles. These hard and tough particles may be pressed into the solution matrix under 
the wear load at high temperatures when it got softened. This physical change of the surface hardness enhanced its wear resistance, which is so-called "glazing" effect [31]. It should be indicated that the surface hardening of this alloy only occurred in the worn area and the overall surface may still be softened at high temperatures, as demonstrated by the indentation test.

Alloy B exhibited the worst wear resistance at both room temperature and elevated temperatures among the studied alloys except alloy D. In particular, the wear resistance of alloy $\mathrm{B}$ decreased quickly with temperature. One possible reason for its worse wear resistance is the lower tungsten and carbon contents of this alloy, which renders its solid solution relatively less strengthened, compared with the other four alloys (alloy D excluded). Another possible reason may be the nickel content, which suppressed the fcc $\rightarrow$ hcp transformation of the solution matrix. Nickel has the similar function to molybdenum and tungsten as a solution strengthening element but it can also stabilize the fcc phase at low temperatures [37]. The wear resistance of alloy $A$ also dropped significantly with temperature. Surface oxidation was the main contribution to the largely increased wear loss of this alloy at elevated temperatures. As seen in its worn surfaces, at the lower temperature $250^{\circ} \mathrm{C}$ about half of the worn surface was covered by oxide debris; see Figure $5-17(\mathrm{a})$, but at the higher temperature $450^{\circ} \mathrm{C}$ almost the entire worn surface was covered by oxide debris; see Figure 5-25(a). Furthermore, in the images at high magnification in Figure 5-22(b) and Figure 5-27(b), one may see broken oxide films left in the worn surface and the fresh surfaces after the breakdown and removal of the oxide films. In addition to oxidation, another feature of the worn surfaces is also noticeable. By closely examining the worn surfaces of alloy $\mathrm{A}$ and alloy $\mathrm{C}$ specimens tested at $450^{\circ} \mathrm{C}$, 
one may find largely cracking of carbides in alloy A but less cracking in alloy $\mathrm{C}$, see Figure 6-3. Alloy A contains a very high content of carbon thus a large volume fraction of carbides in its microstructure. Carbides are much more brittle than the cobalt solid solution and therefore they were much easier to crack/fracture by mechanical attack in the wear process. At high temperatures, the interface bonding between the solid solution and the carbides would be weakened due to the softening of the solution matrices, which definitely increased the occurrence probability of cracking and spalling-off of the carbides. The spallation of the carbides from the specimen surface added to the material loss. Since alloy A has much more carbides than alloy $\mathrm{C}$, it had more chances for carbides cracking and spalling-off in the wear process. The fractured carbides that spalled sequentially from the surface due to the successive wear attacks resulted in the large wear loss of the alloy material.

In consistence with the observations in the indentation test, the worn surfaces of alloy $\mathrm{B}$ and alloy $\mathrm{C}$ specimens tested at elevated temperatures were much less oxidized than the other alloys, see Figure 5-17, Figure 5-18, Figure 5-23 and Figure 5-24. Alloy C exhibited relatively good wear resistance at high temperatures; see Figure 5-7(c). Its better oxidation resistance may be the main contribution. In the meanwhile, it has higher tungsten content, which enhanced the high temperature performance of this alloy such as hardness and wear resistance. 


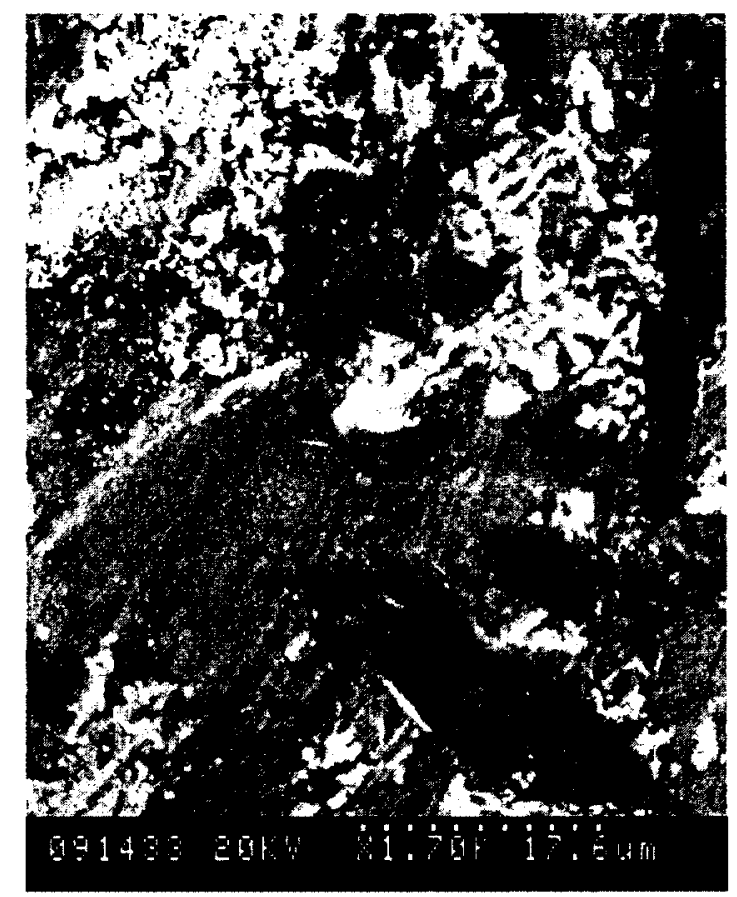

(a)

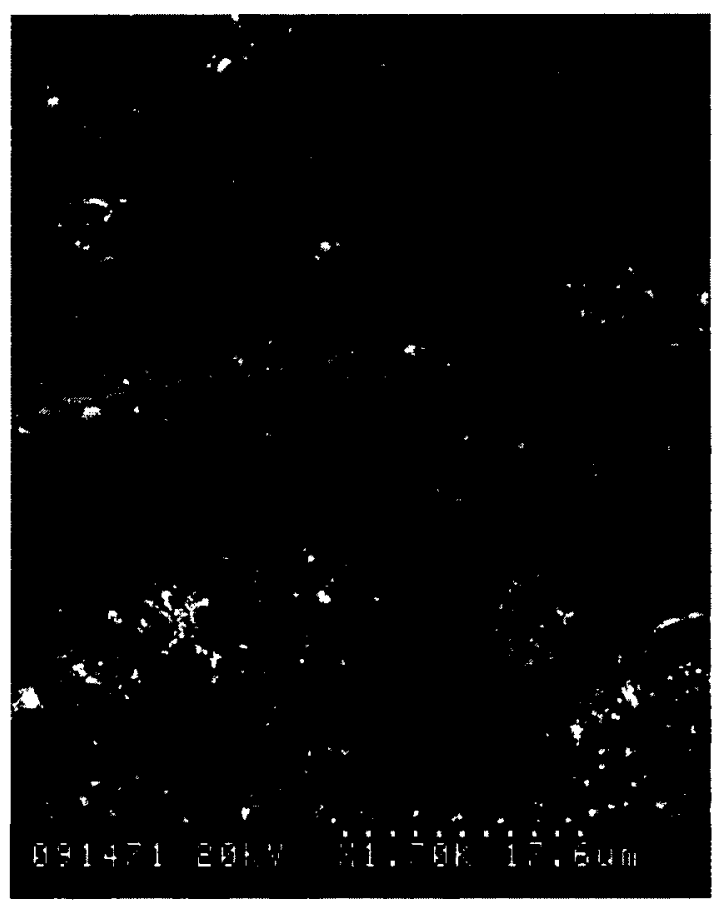

(b)

Figure 6-3: Worn surface images showing cracks: (a) alloy A and (b) alloy C. 
Alloy E exhibited the best wear resistance at the higher temperature $450^{\circ} \mathrm{C}$ among the alloys being studied, as seen in Figure 5-7(c). Possible reasons can be summarized as follows. This alloy also has better wear resistance at room temperature owing to the high carbon and tungsten contents; see Figure 5-7(a). The high tungsten content maintained the good properties of the solid solution such as hardness and wear resistance at high temperatures. Although this alloy was oxidized at $450^{\circ} \mathrm{C}$, the oxidation was less than that of alloy A and alloy F, as seen in Figure 5-26. The very high chromium content was beneficial for its better oxidation resistance. Cracking of carbides also occurred in this alloy, as shown in Figure 6-4. However, compared with alloy A, cracks in alloy $\mathrm{E}$ worn surface are less because the volume fraction of carbides in alloy $E$ is less than that in alloy A. Less cracks would resulted in less damage of the worn surface, thus less wear loss. Between alloy $C$ and alloy $E$, they have similar wear resistance at $450^{\circ} \mathrm{C}$, but the latter is slightly better than the former. Considering high-temperature oxidation, alloy $\mathrm{C}$ seemed better from both the indentation test and worn surface analysis. Regarding the hardness and strength of solid solution, it can be deduced from Figure 6-2 that the solid solution of alloy $\mathrm{E}$ is harder and more strengthened due to its higher tungsten content. Finally, the higher carbon content determines the higher wear resistance of alloy $\mathrm{E}$ than alloy $\mathrm{C}$ at room temperature, as illustrated in Figure 5-7(a). However, alloy $\mathrm{C}$ exhibited less reduction of wear resistance with temperature. This can be attributed to its higher oxidation resistance and less cracking/fracture/spalling-off of carbides at high temperatures. 


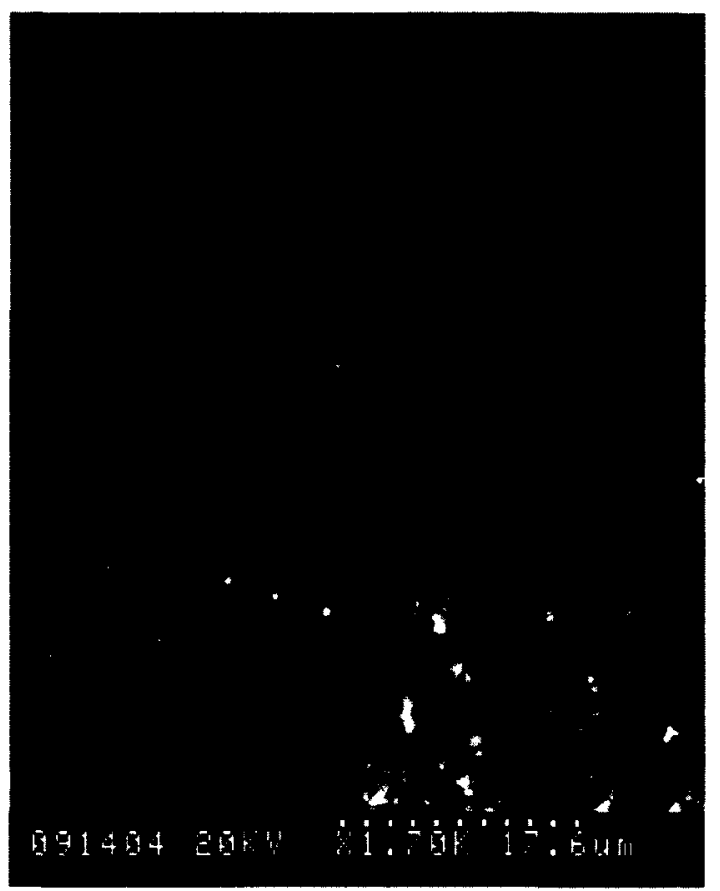

Figure 6-4: Cracks in the worn surface of alloy E specimen. 


\section{Chapter: Conclusions and Further Work}

\subsection{Summary}

Six different Stellite alloys that cover main features of Stellite alloy family have been studied in this research. For the most important agent, carbon, in Stellite alloys, the six alloys vary between $0.25 \sim 2.4 \mathrm{wt} \%$, that is, they are classified into low-carbon, medium-carbon and high-carbon Stellite alloys, respectively. For the main alloying element, chromium, these alloys have a content between $22 \sim 33.5 \mathrm{wt} \%$. For another important alloying element, tungsten, they have a content between $0 \sim 32 \%$. The hardness and tribological behaviour of these alloys was investigated at both room temperature and at elevated temperatures $\left(450-650^{\circ} \mathrm{C}\right)$. The relationships between chemical composition, microstructure, hardness and wear resistance of these alloys were studied, with focus on thermal-dependence on these relations. In summary, the following conclusions can be derived from this research:

1. Verified that the carbon content of a Stellite alloy determines the volume fraction of carbides in its microstructure. The higher the carbon content, the larger the volume fraction of carbides is. Increase of chromium content enhances the high-temperature oxidation resistance of Stellite alloys and increase of tungsten content enhances the performance at high temperatures of Stellite alloys. Tungsten in Stellite alloys serves to provide additional strength to the solution matrix, but when present in large quantities, it participates in the formation of carbides.

2. Verified that the cobalt solid solutions of Stellite alloys are much softer than the carbides dispersed in the solution matrices. The solid solutions can be softened at elevated temperatures and can also be hardened by the heating/cooling cycle (heat 
treatment). The solid solution of a Stellite alloy can be strengthened by adding more tungsten. Also, increasing the tungsten content can increase the hardness performance of the solid solution at high temperatures. However, the carbides in Stellite alloys are less sensitive to temperature; their hardness is almost not affected by temperature/thermal (up to $650^{\circ} \mathrm{C}$ ) effect.

3. The wear resistance of Stellite alloys at room temperature mainly depends on their carbon content. The higher the carbon content, the better the wear resistance of the alloy. However, the alloying element, tungsten, also plays an important role in controlling the wear resistance of Stellite alloys, because it not only enhances the solid solution matrix but also participates in the formation of carbides when present in large quantities in Stellite alloys.

4. The tribological behaviour of Stellite alloys at elevated temperatures $\left(450-650^{\circ} \mathrm{C}\right)$ is much more complex than that at room temperature. The carbon content effect on the wear resistance of Stellite alloys is not as significant at elevated temperatures as at room temperature, whereas material oxidation has greater effect on the wear resistance of Stellite alloys at high temperatures. Tungsten, with excellent high-temperature properties, also plays an important role in enhancing the hot wear resistance of Stellite alloys. Cracking/fracture/spalling-off of carbides is more prone to occur at high temperatures due to the softening of the solid solutions, which increases the wear loss of the material.

5. The wear resistance of Stellite alloys, in general, decreases with temperature. However, for low-carbon Stellite alloys, at high temperatures the wear resistance is increased. This abnormal behaviour can be attributed to the surface hardening, which 
results from three aspects: strain hardening (aggravated dislocations), the fcc $\rightarrow$ hcp transformation and "glazing" effect.

6. At room temperature, the wear resistance of Stellite alloys is mainly determined by the volume fraction of carbides in the alloys. Since carbides are harder than cobalt solid solution, the wear resistance of Stellite alloys at room temperature is generally proportional to their hardness. However, exceptions are also possible. For example, very high tungsten addition can enhance the wear resistance of the cobalt solid solution and form (W,Co) ${ }_{6} \mathrm{C}$ carbide, which provides increased overall wear resistance of the alloy. At high temperatures, the direct relation between hardness and wear resistance for Stellite alloys does not apply, due to the multiple and complex factors involved in the synergistic condition of temperature effect and mechanical load.

\subsection{Future Work}

1. Only six alloys were studied in this research, although they cover main features of Stellite alloy family. To further verify the conclusions summarized above. A wider range of alloys should be selected for study, with different combinations of constituents in chemical composition. Particularly alloys with varying amounts of carbon, chromium and tungsten.

2. Since material oxidation has significant influence on the wear resistance of Stellite alloys at high temperatures. The oxidation behaviour of these alloys needs to be specially investigated using the TGA technique.

3. The final goal of this project is to develop a mapping model, which represents material informatics. Using such a model, the temperature-dependent hardness and wear 
resistance of any alloy whose chemical composition is in the domain of the constituents of Stellite alloys can be predicted. This model can also be used as a guideline for material selection and design of Stellite alloys. 


\section{Appendix A: Hardness Indentations}

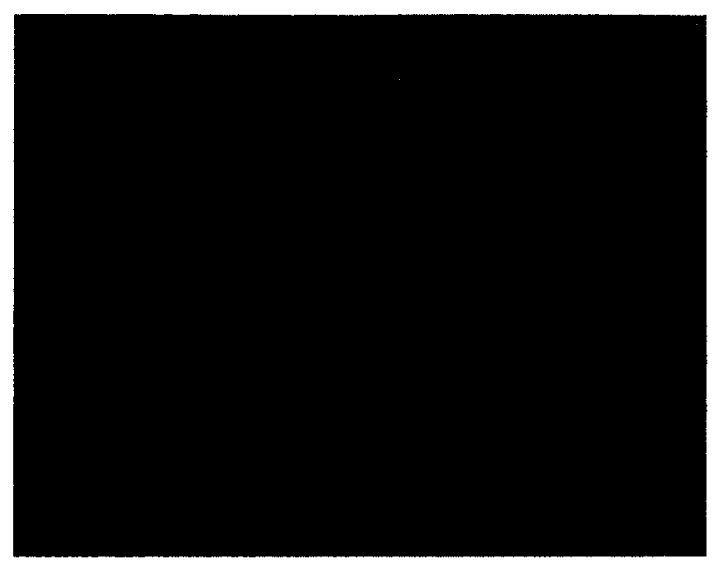

(a)

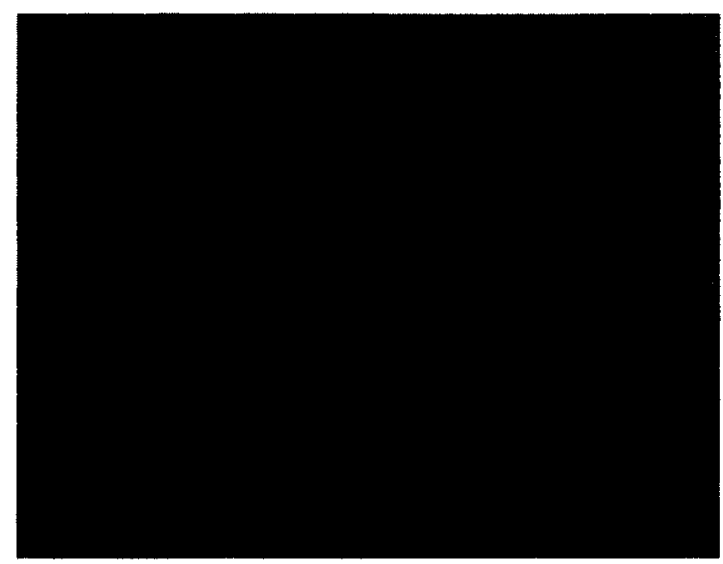

(b)

Figure 0-1: Microscopic images of indentation left in alloy A specimen tested at $20^{\circ} \mathrm{C}$ before heating: (a) solid solution and (b) carbides/solution mixture.

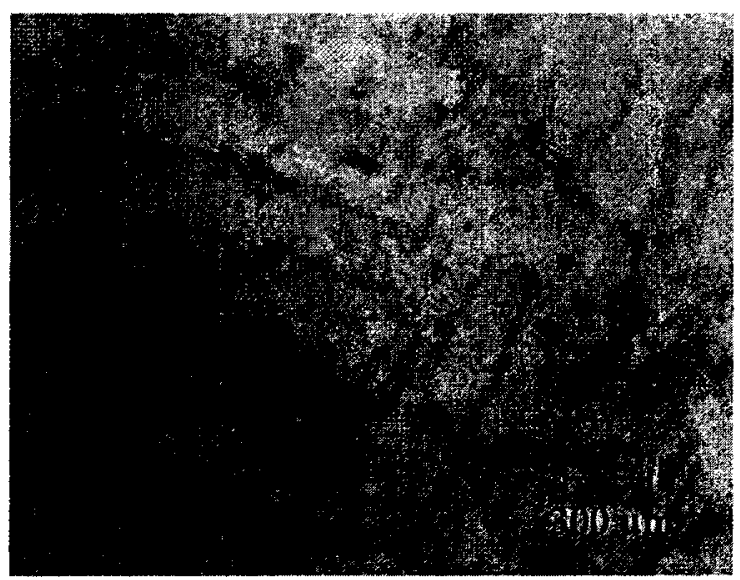

(a)

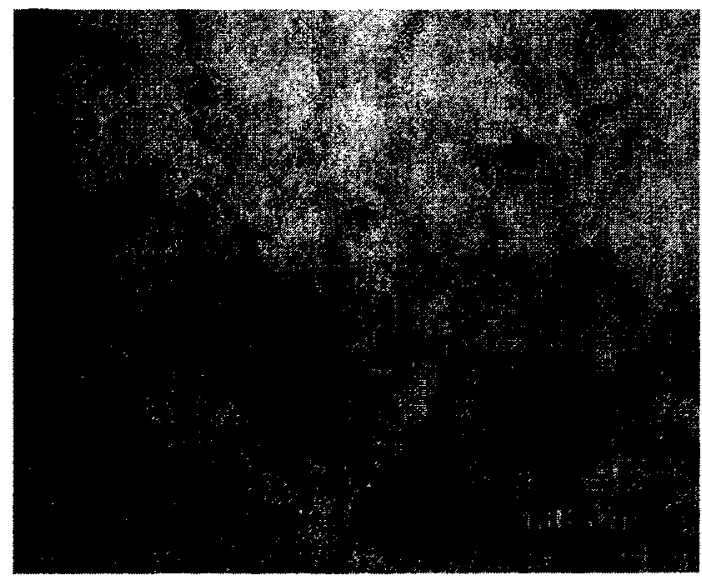

(b)

Figure 0-2: Microscopic images of indentation left in alloy A specimen tested at $250^{\circ} \mathrm{C}$ in heating cycle: (a) solid solution and (b) carbides/solution mixture. 


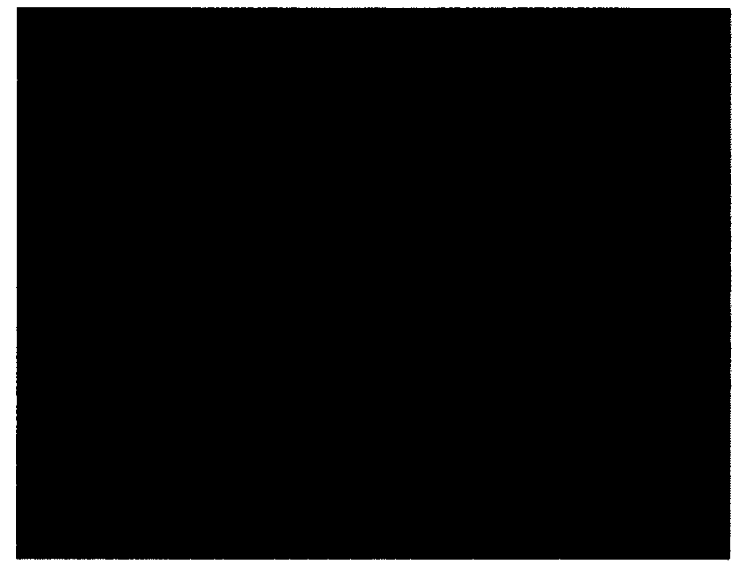

(a)

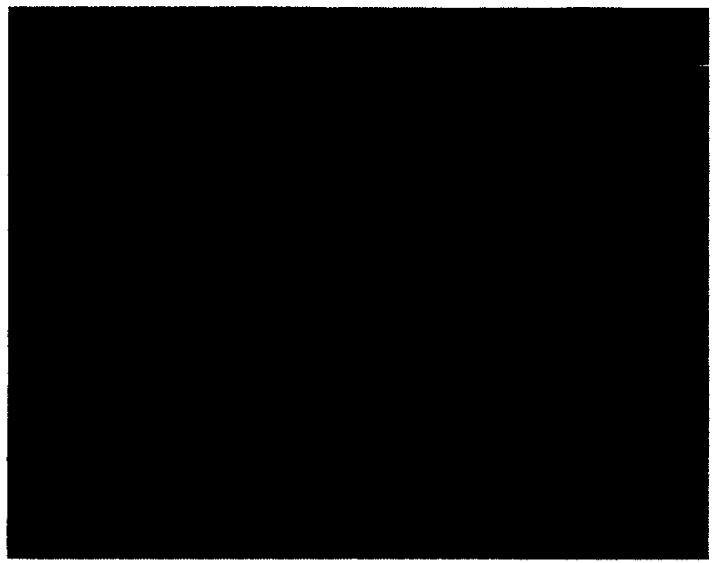

(b)

Figure 0-3: Microscopic images of indentation left in alloy A specimen tested at $450^{\circ} \mathrm{C}$ in heating cycle: (a) solid solution and (b) carbides/solution mixture.

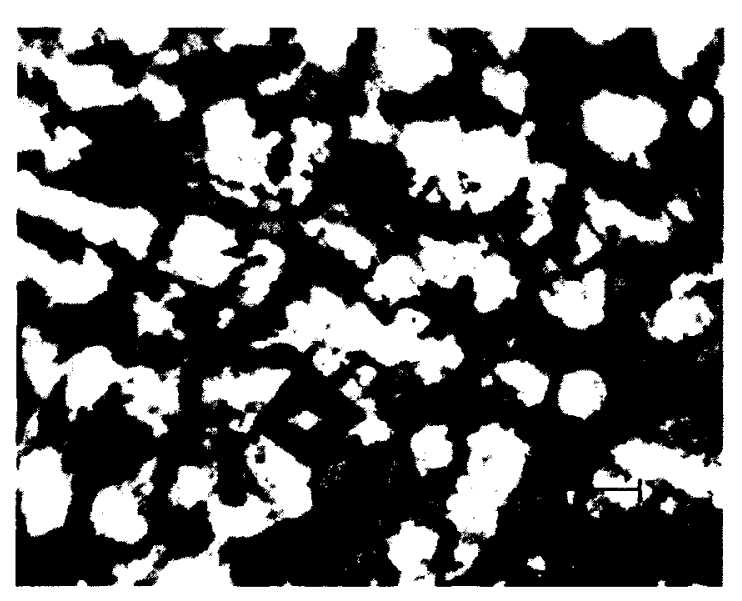

(a)

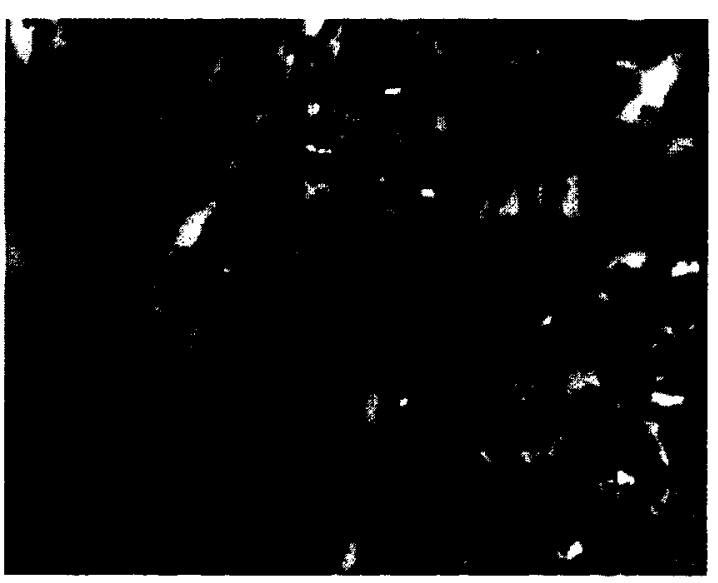

(b)

Figure 0-4:Microscopic images of indentation left in alloy A specimen tested at $650^{\circ} \mathrm{C}$ in heating cycle: (a) solid solution and (b) carbides/solution mixture. 


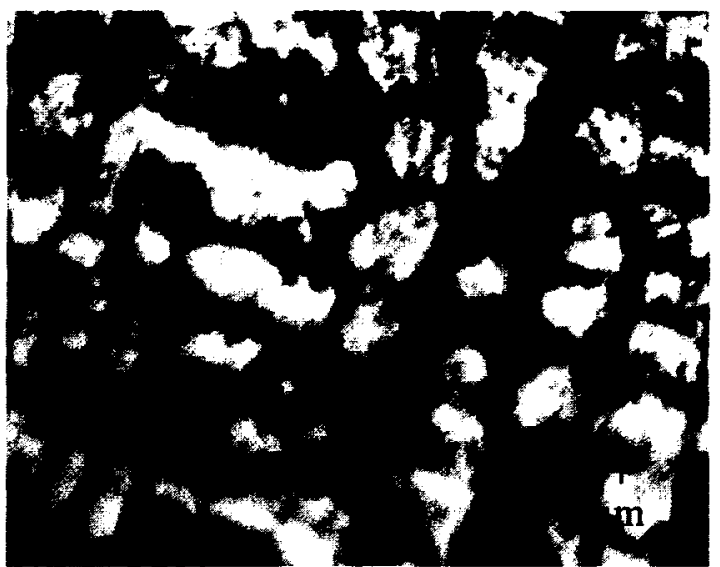

(a)

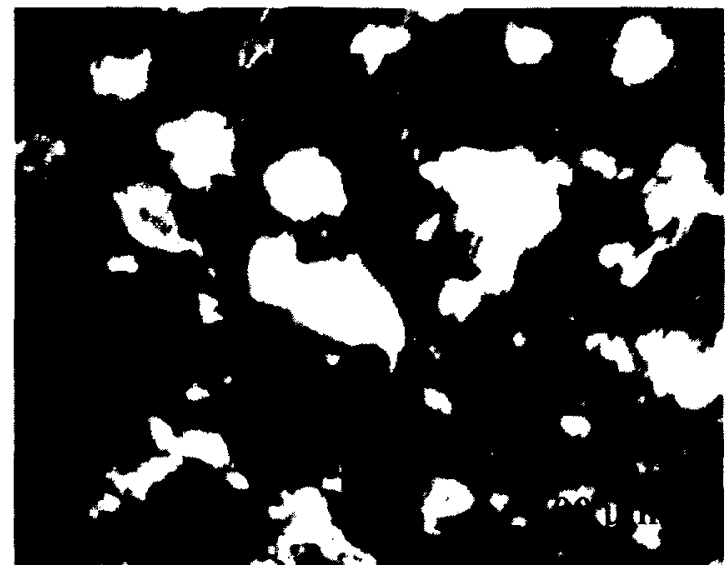

(b)

Figure 0-5: Microscopic images of indentation left in alloy A specimen tested at $450^{\circ} \mathrm{C}$ in cooling cycle: (a) solid solution and (b) carbides/solution mixture.

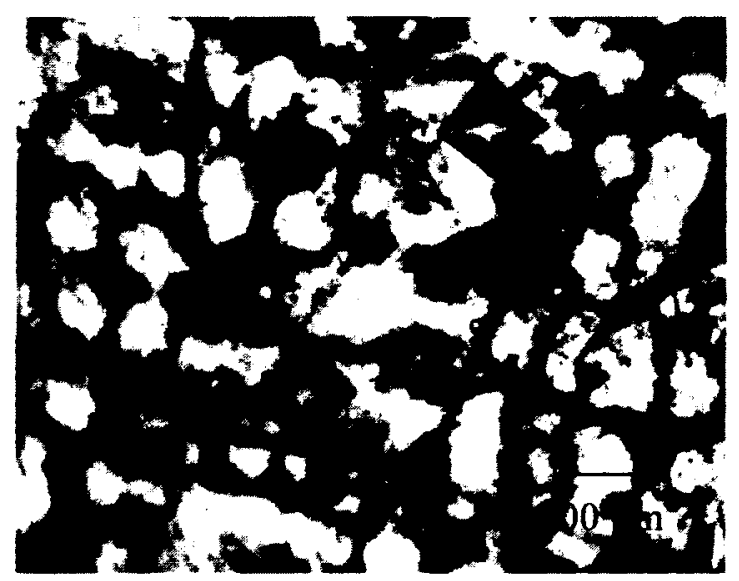

(a)

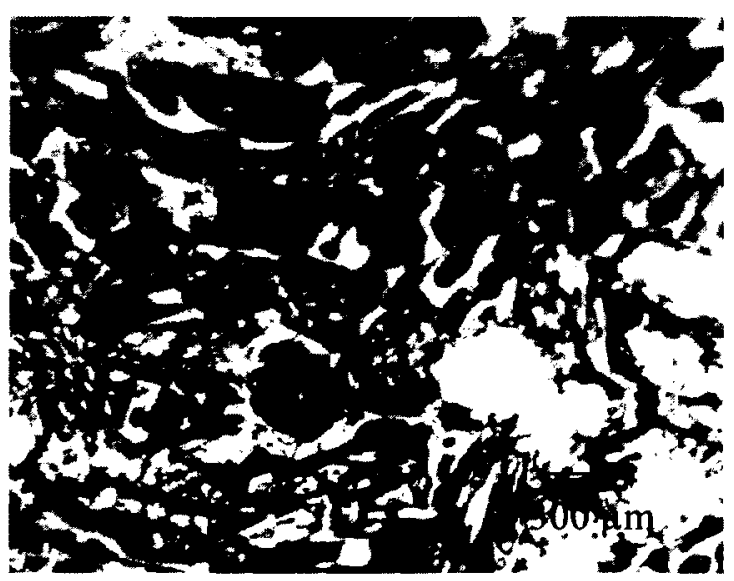

(b)

Figure 0-6: Microscopic images of indentation left in alloy A specimen tested at $250^{\circ} \mathrm{C}$ in cooling cycle: (a) solid solution and (b) carbides/solution mixture. 


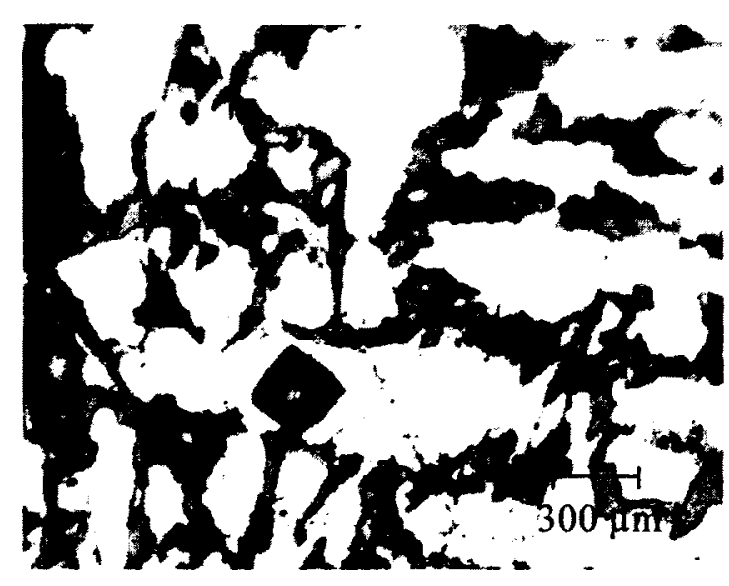

(a)

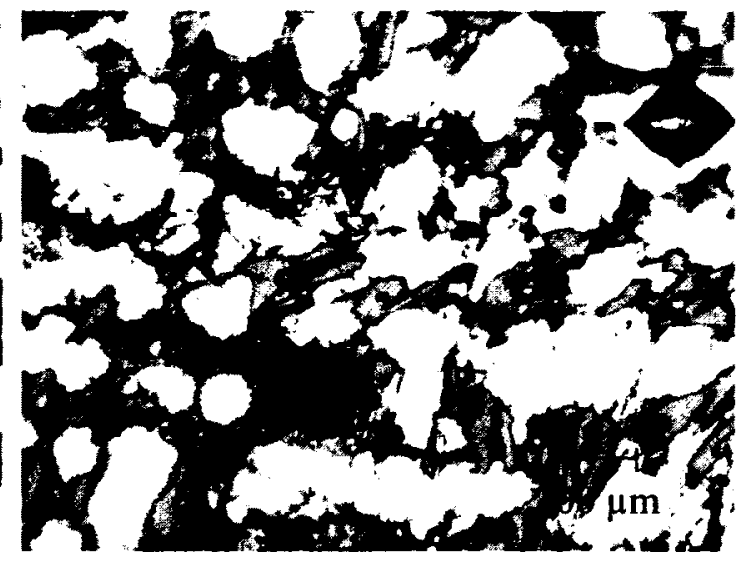

(b)

Figure 0-7: Microscopic images of indentation left in alloy A specimen tested at $20^{\circ} \mathrm{C}$ after heating/cooling: (a) solid solution and (b) carbides/solution mixture.

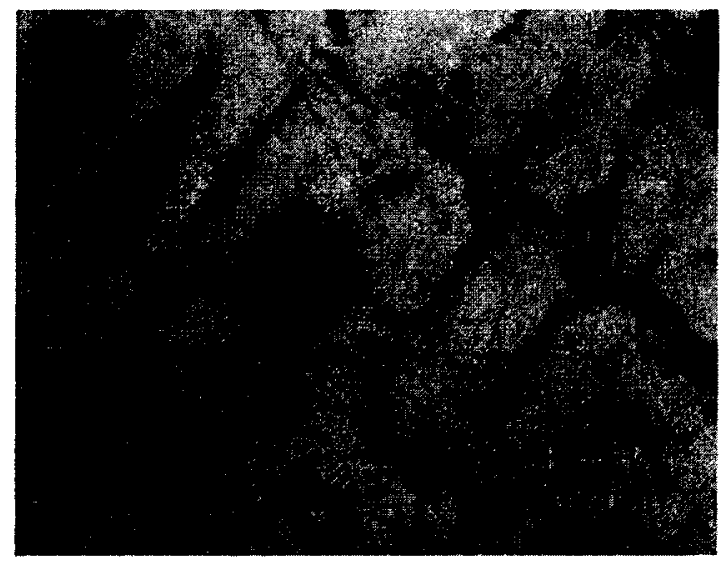

(a)

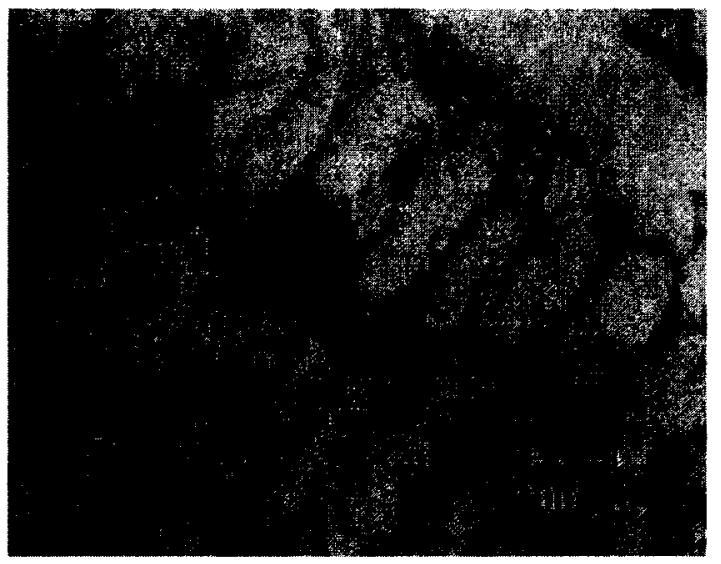

(b)

Figure 0-8: Microscopic images of indentation left in alloy B specimen tested at $20^{\circ} \mathrm{C}$ before heating: (a) solid solution and (b) carbide with minor solid solution. 


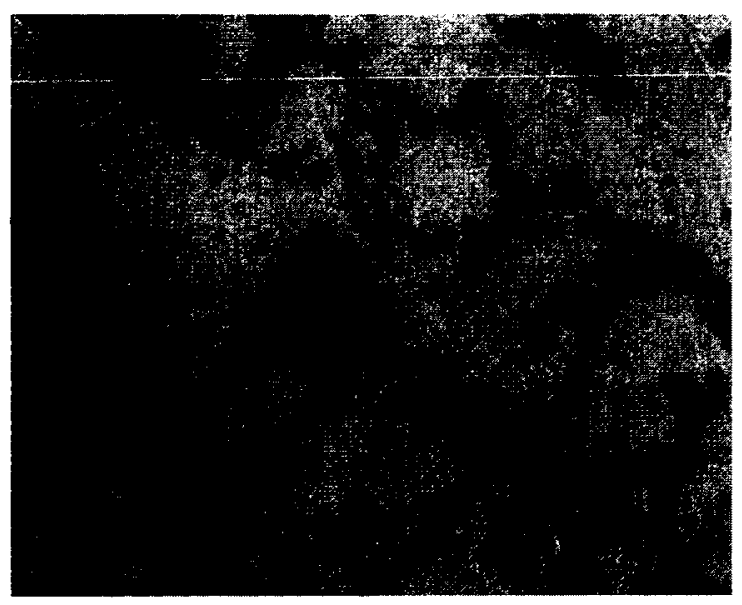

(a)

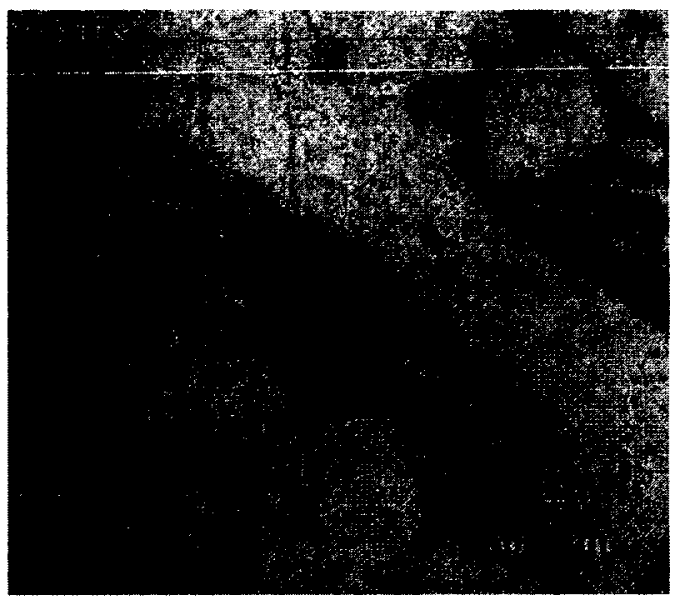

(b)

Figure 0-9: Microscopic images of indentation left in alloy B specimen tested at $250^{\circ} \mathrm{C}$ in heating cycle: (a) solid solution and (b) carbide with minor solid solution.

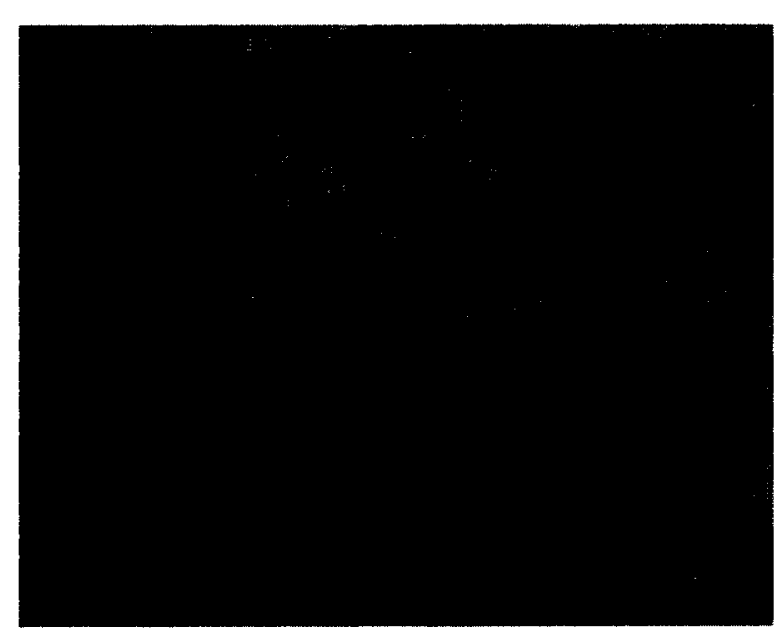

(a)

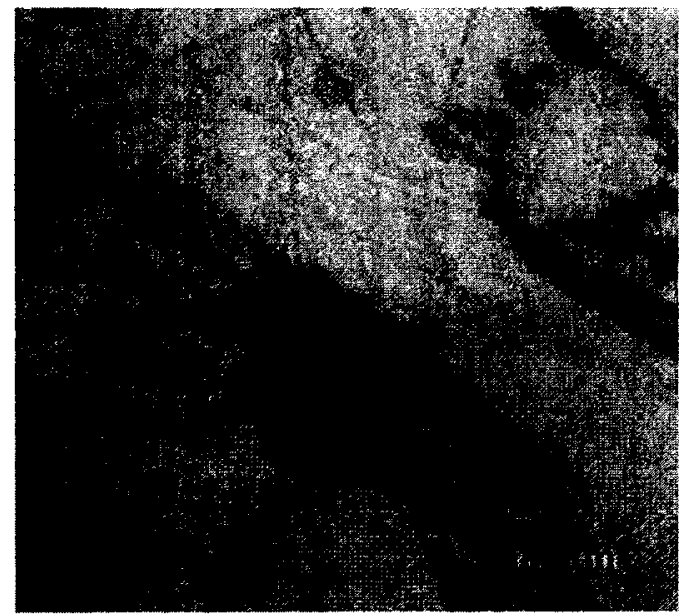

(b)

Figure 0-10: Microscopic images of indentation left in alloy B specimen tested at $450^{\circ} \mathrm{C}$ in heating cycle: (a) solid solution and (b) carbide with minor solid solution. 


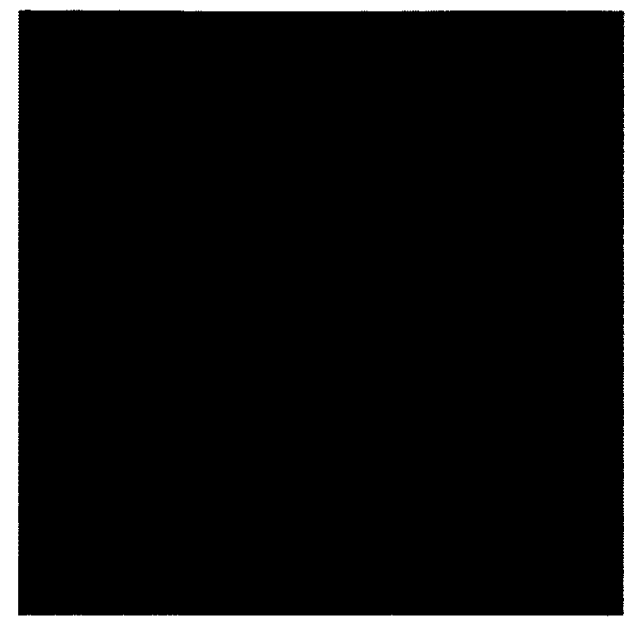

(a)

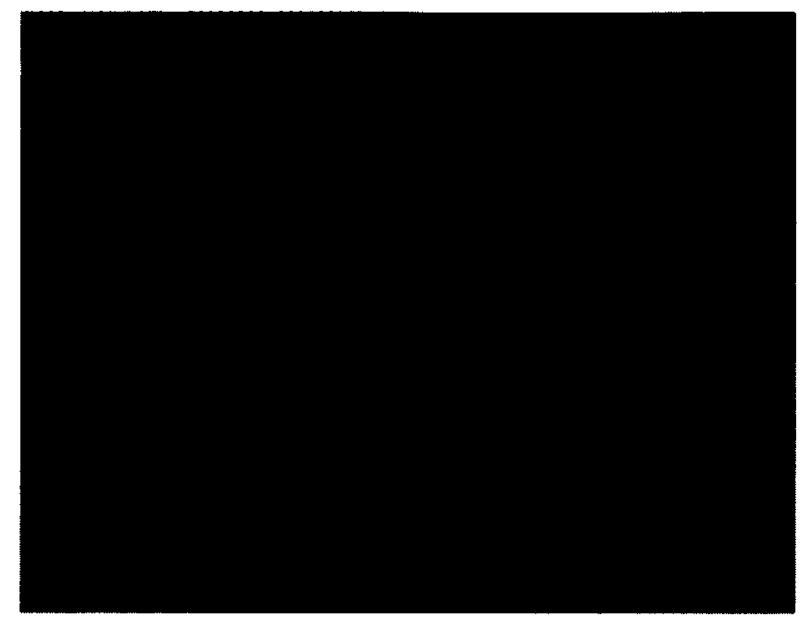

(b)

Figure 0-11: Microscopic images of indentation left in alloy $\mathrm{B}$ specimen tested at $650^{\circ} \mathrm{C}$ in heating cycle: (a) solid solution and (b) carbide with minor solid solution.

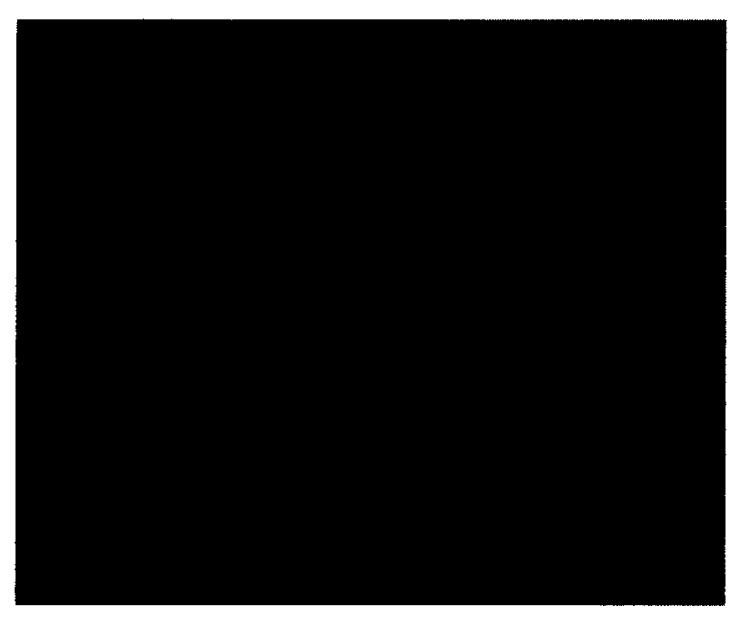

(a)

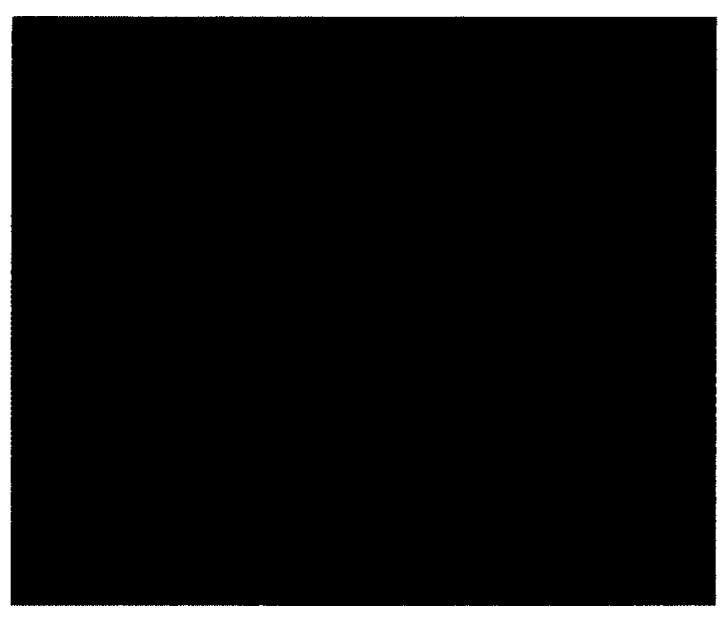

(b)

Figure 0-12: Microscopic images of indentation left in alloy $\mathrm{B}$ specimen tested at $450^{\circ} \mathrm{C}$ in cooling cycle: (a) solid solution and (b) carbide with minor solid solution. 


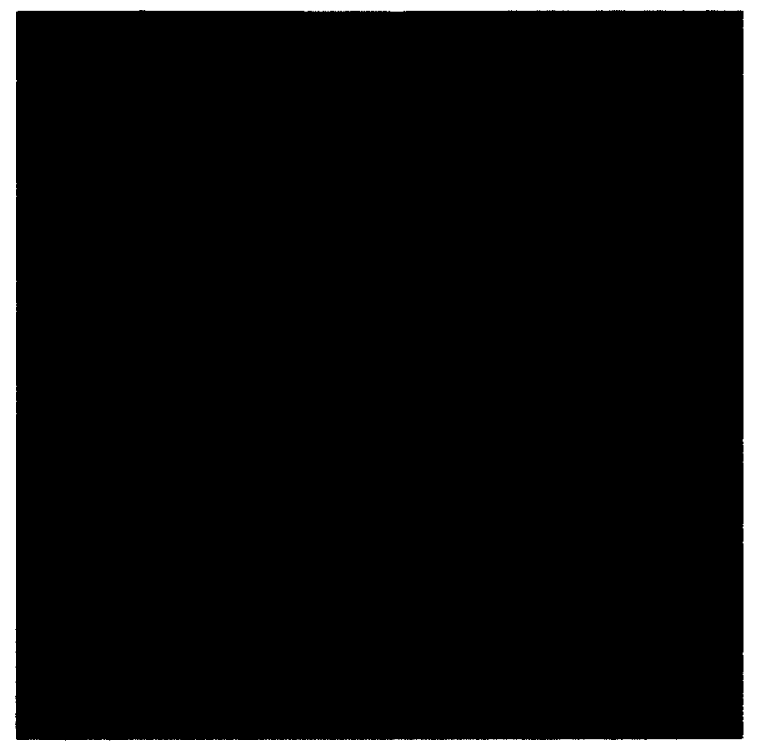

(a)

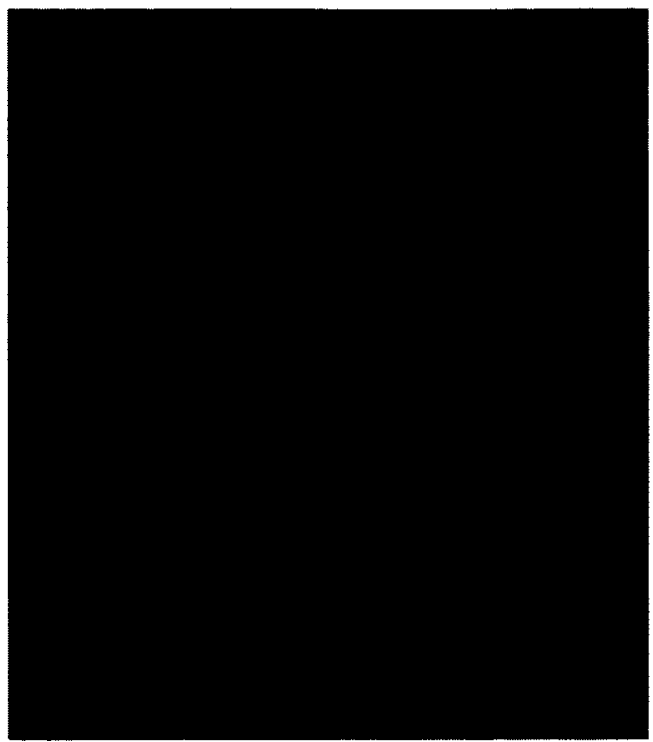

(b)

Figure 0-13: Microscopic images of indentation left in alloy B specimen tested at $250^{\circ} \mathrm{C}$ in cooling cycle: (a) solid solution and (b) carbide with minor solid solution.

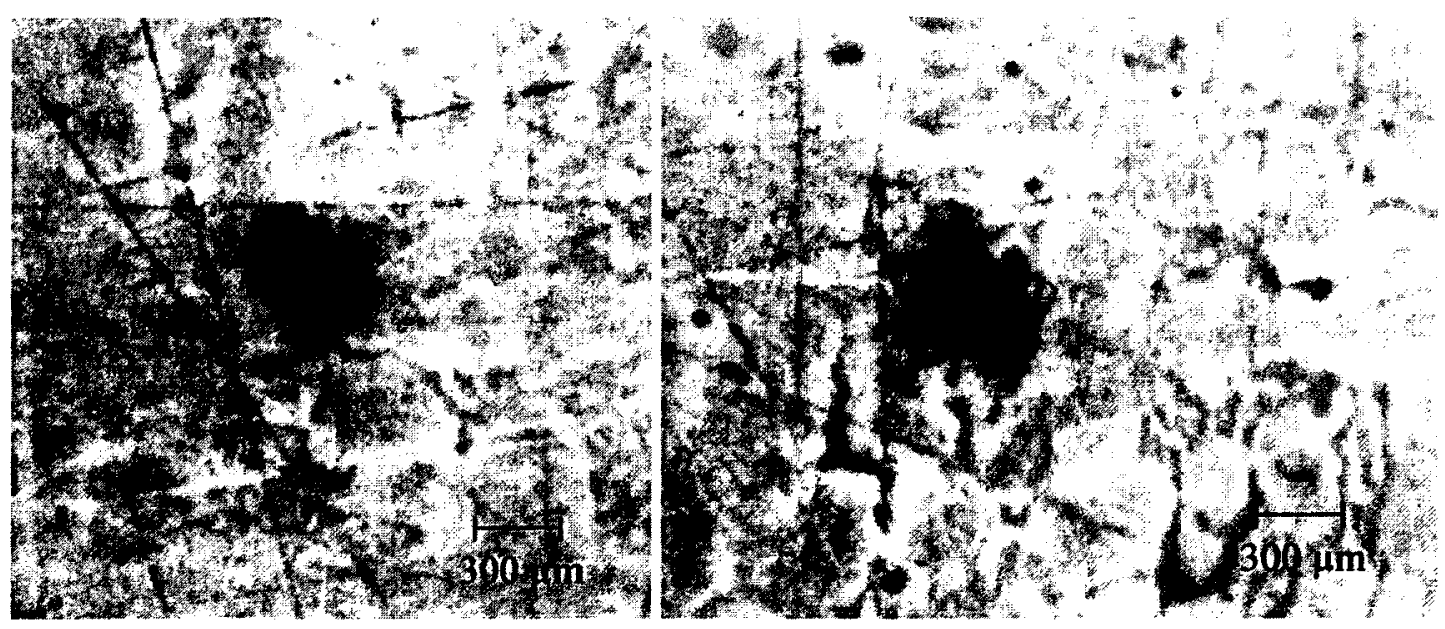

(a)

(b)

Figure 0-14: Microscopic images of indentation left in alloy B specimen tested at $20^{\circ} \mathrm{C}$ after heating/cooling: (a) solid solution and (b) carbide with minor solid solution. 


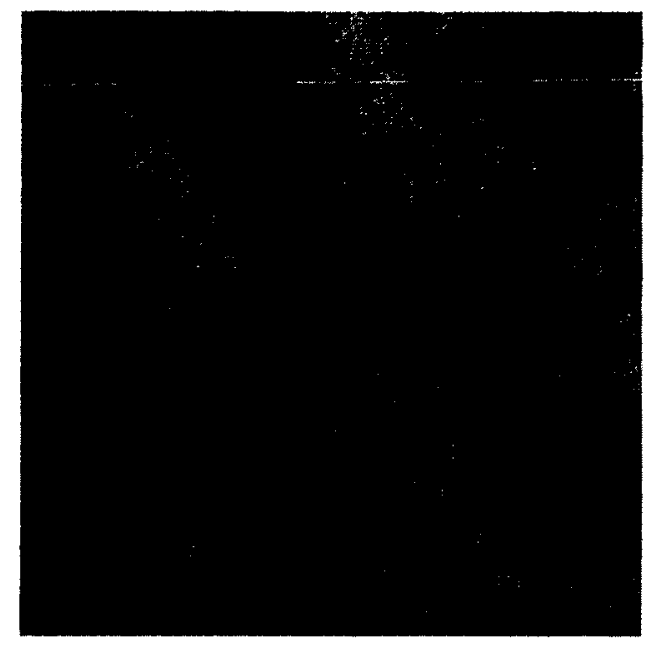

(a)

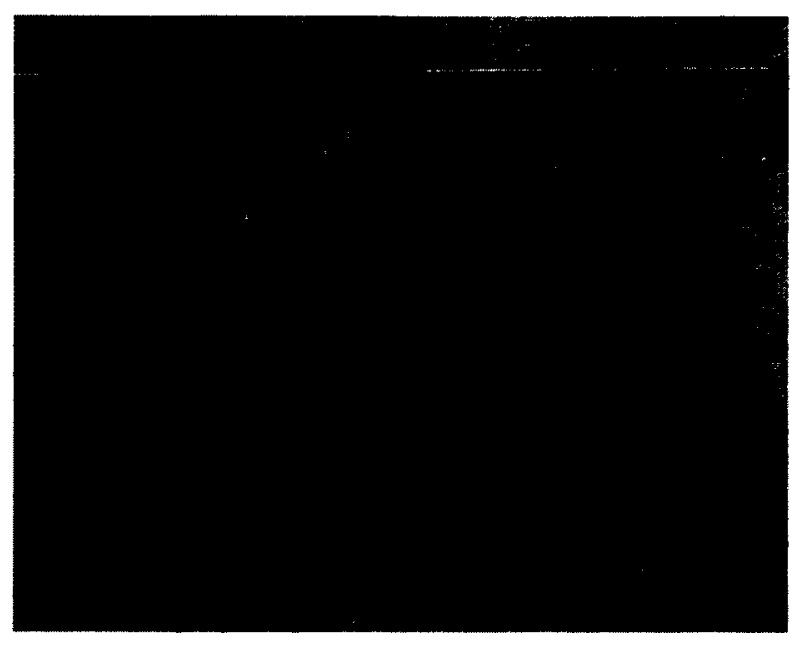

(b)

Figure 0-15: Microscopic images of indentation left in alloy $\mathrm{C}$ specimen tested at $20^{\circ} \mathrm{C}$ before heating: (a) solid solution and (b) carbide with minor solid solution.

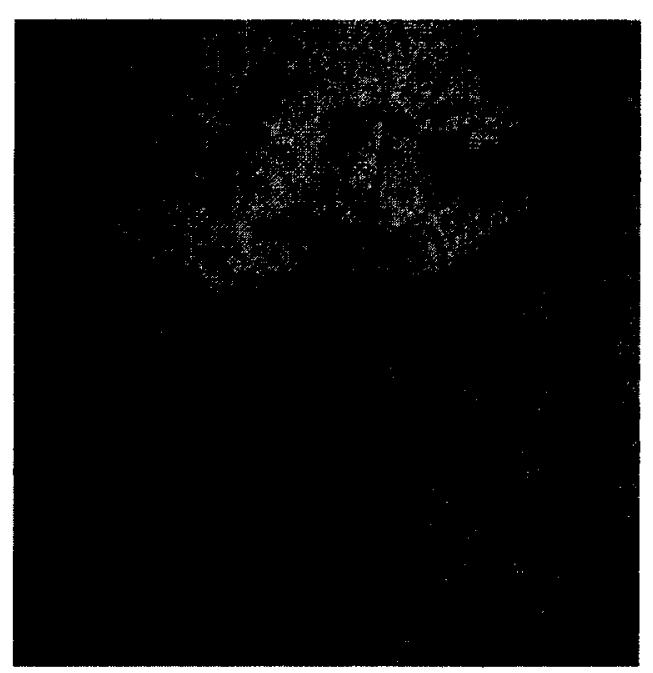

(a)

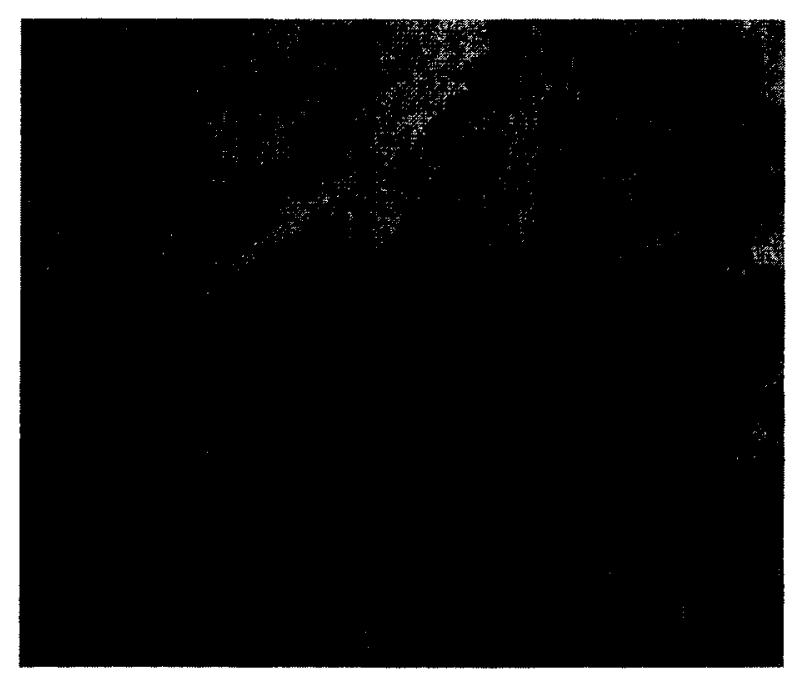

(b)

Figure 0-16: Microscopic images of indentation left in alloy $\mathrm{C}$ specimen tested at $250^{\circ} \mathrm{C}$ in heating cycle: (a) solid solution and (b) carbide with minor solid solution. 
(a)

(b)

Figure 0-17: Microscopic images of indentation left in alloy $\mathrm{C}$ specimen tested at $450^{\circ} \mathrm{C}$ in heating cycle: (a) solid solution and (b) carbide with minor solid solution.

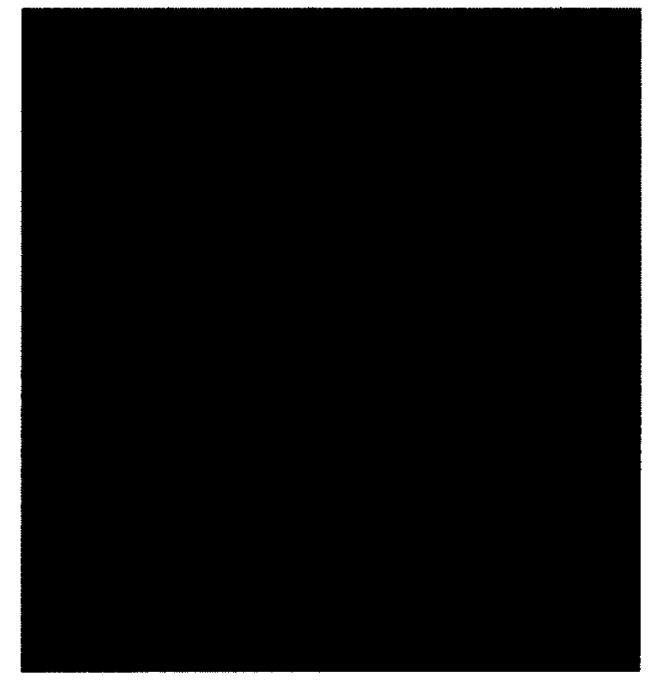

(a)

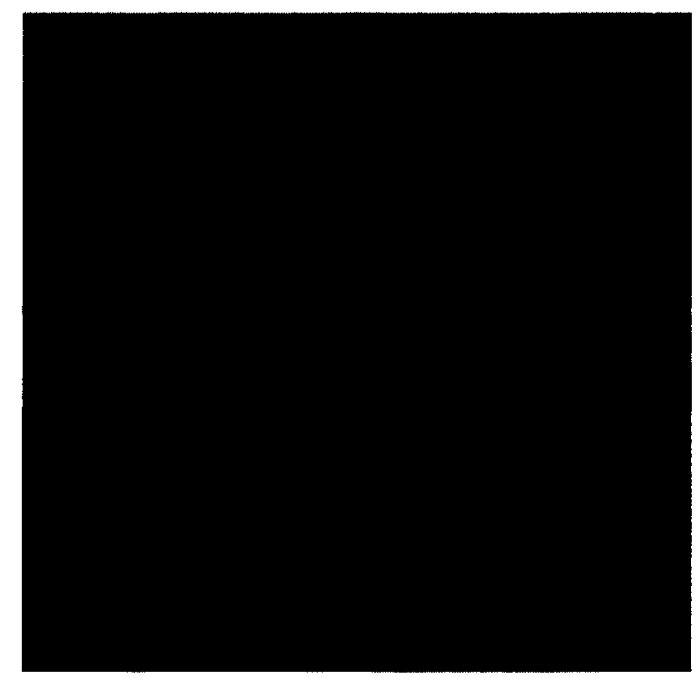

(b)

Figure 0-18: Microscopic images of indentation left in alloy $\mathrm{C}$ specimen tested at $650^{\circ} \mathrm{C}$ in heating cycle: (a) solid solution and (b) carbide with minor solid solution. 


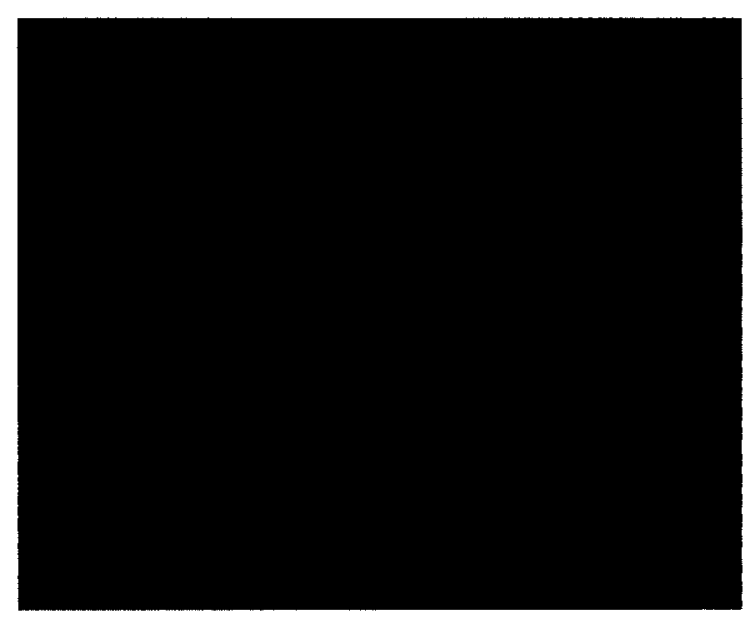

(a)

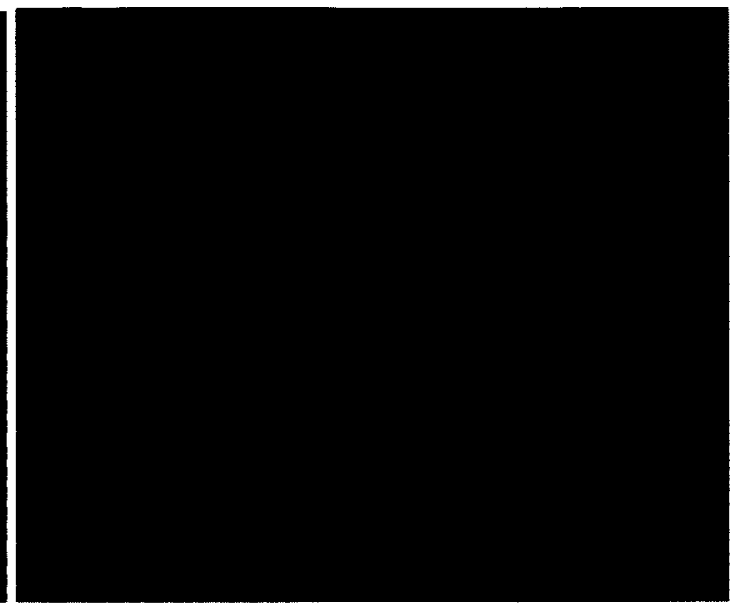

(b)

Figure 0-19: Microscopic images of indentation left in alloy $\mathrm{C}$ specimen tested at $450^{\circ} \mathrm{C}$ in cooling cycle: (a) solid solution and (b) carbide with minor solid solution.

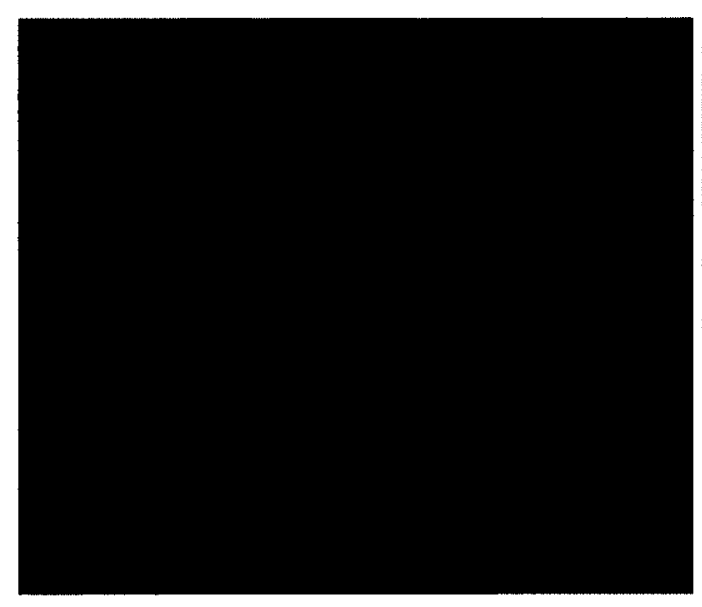

(a)

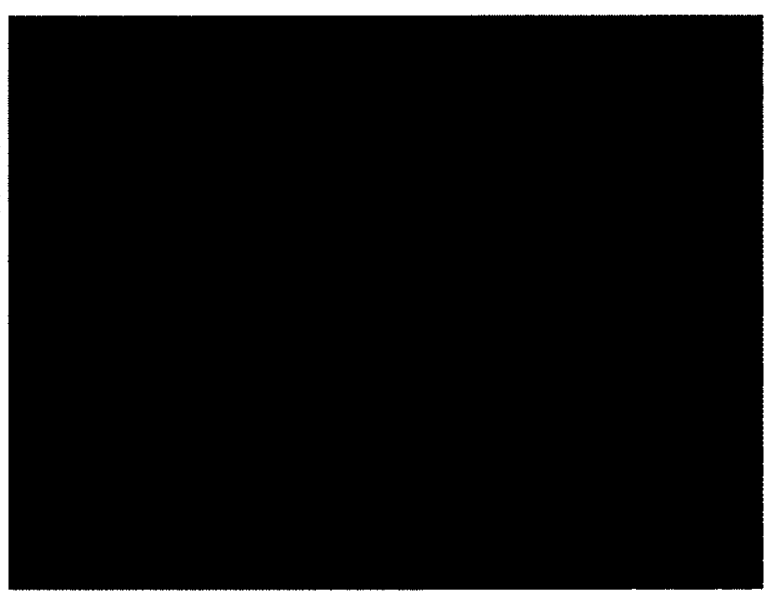

(b)

Figure 0-20: Microscopic images of indentation left in alloy $\mathrm{C}$ specimen tested at $250^{\circ} \mathrm{C}$ in cooling cycle: (a) solid solution and (b) carbide with minor solid solution. 


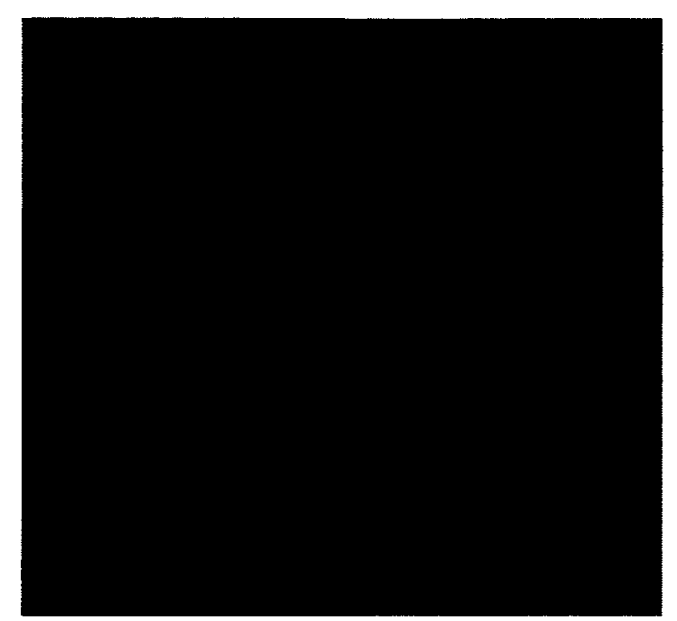

(a)

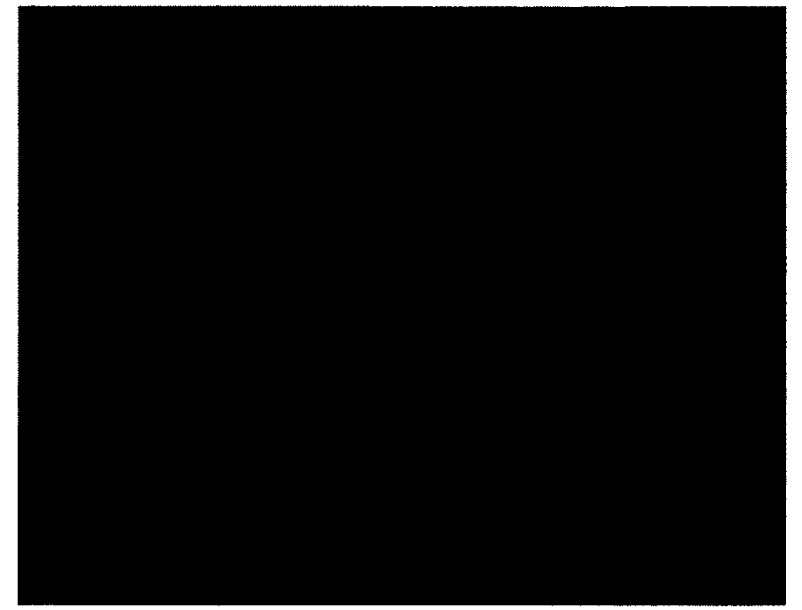

(b)

Figure 0-21: Microscopic images of indentation left in alloy $\mathrm{C}$ specimen tested at $20^{\circ} \mathrm{C}$ after heating/cooling: (a) solid solution and (b) carbide with minor solid solution.

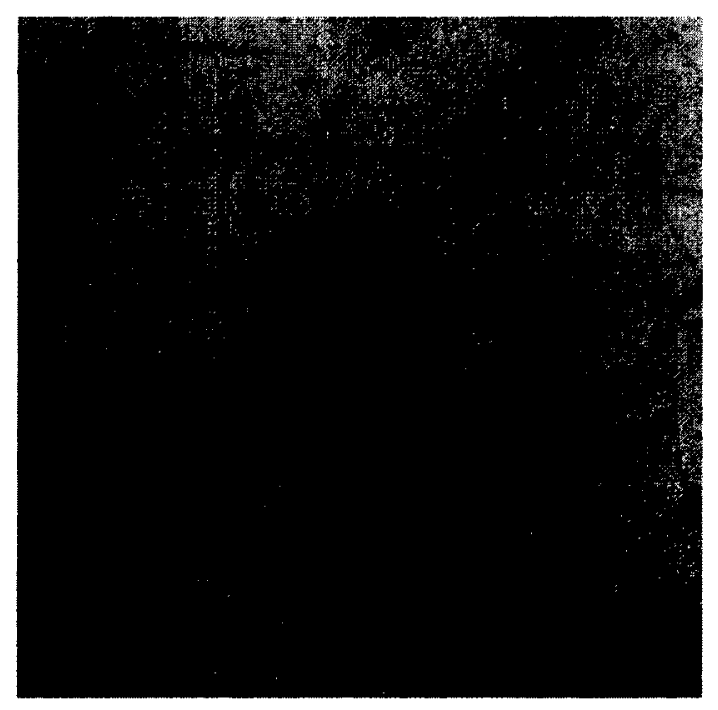

(a)

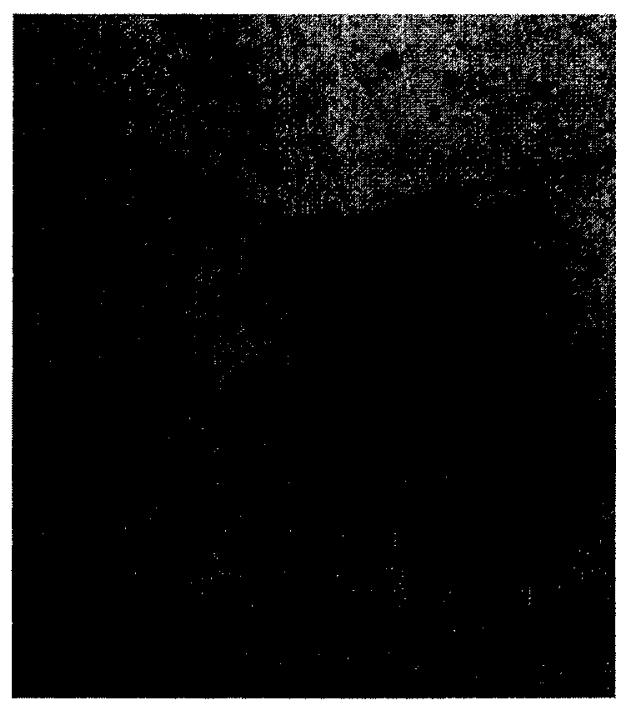

(b)

Figure 0-22: Microscopic images of indentation left in alloy D specimen tested at $20^{\circ} \mathrm{C}$ before heating: (a) solid solution and (b) carbides/solution mixture. 


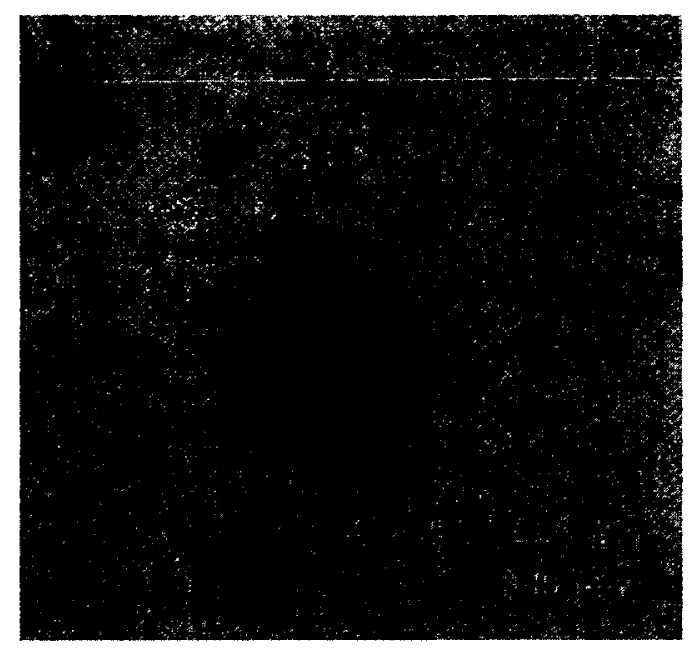

(a)

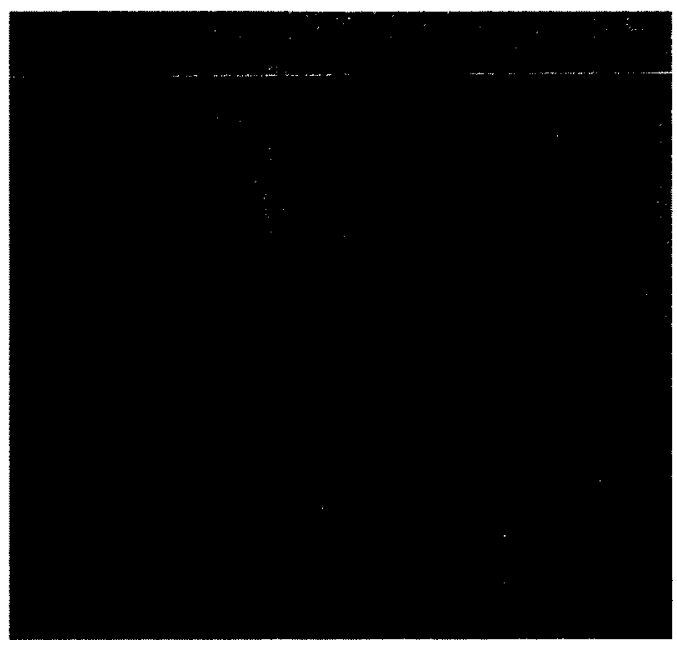

(b)

Figure 0-23: Microscopic images of indentation left in alloy $\mathrm{D}$ specimen tested at $250^{\circ} \mathrm{C}$ in heating cycle: (a) solid solution and (b) carbides/solution mixture.

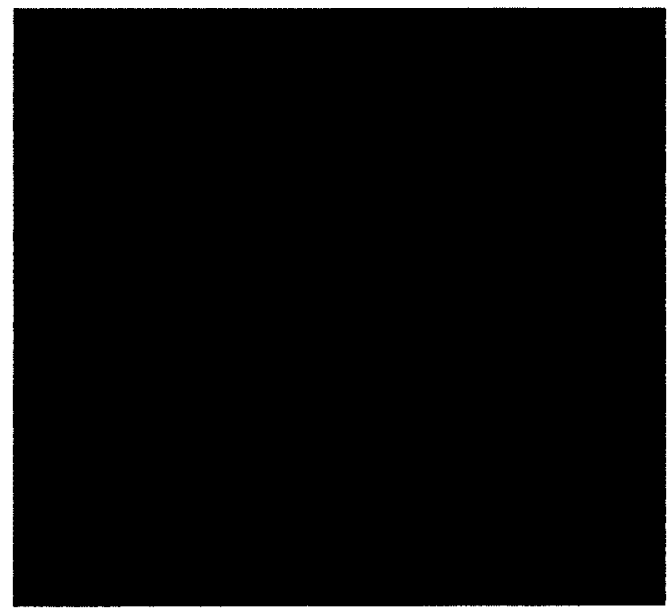

(a)

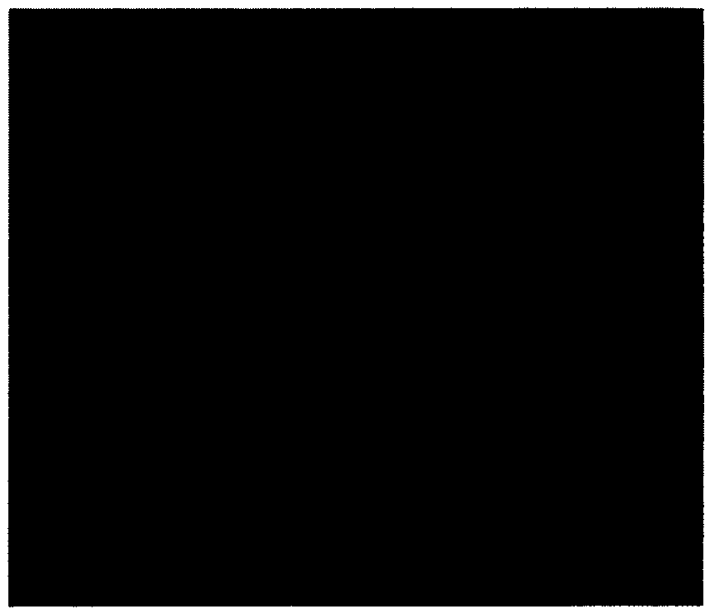

(b)

Figure 0-24: Microscopic images of indentation left in alloy $\mathrm{D}$ specimen tested at $450^{\circ} \mathrm{C}$ in heating cycle: (a) solid solution and (b) carbides/solution mixture. 


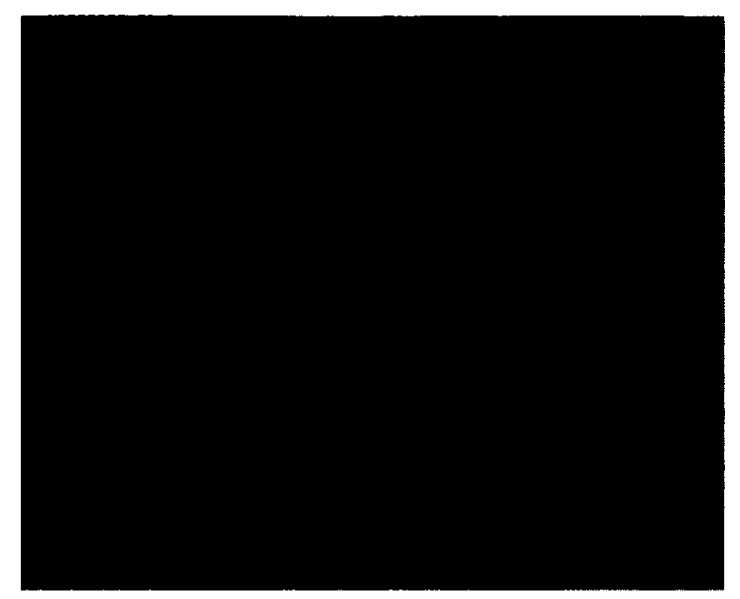

(a)

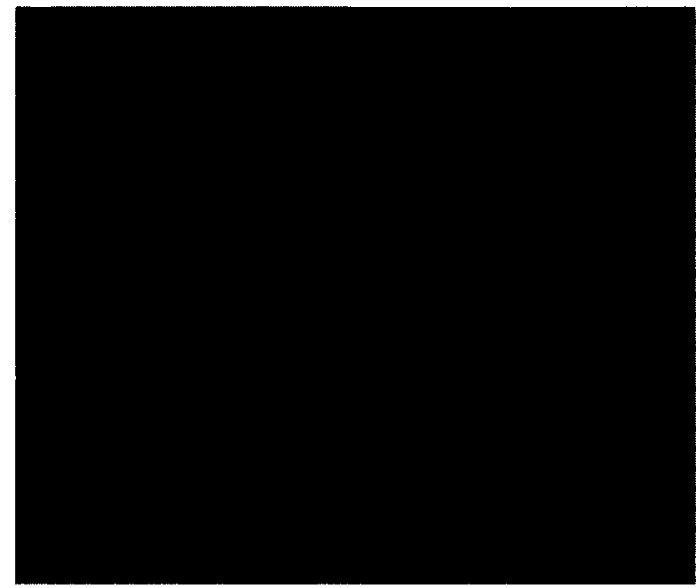

(b)

Figure 0-25: Microscopic images of indentation left in alloy D specimen tested at $650^{\circ} \mathrm{C}$ in heating cycle: (a) solid solution and (b) carbides/solution mixture.

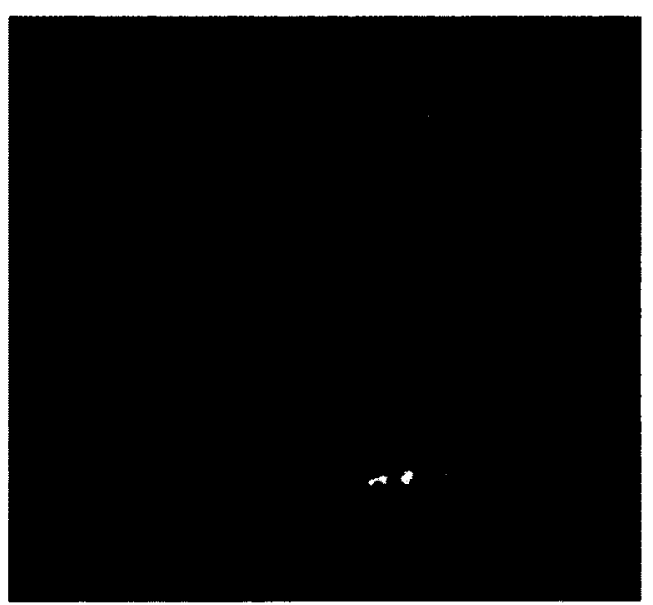

(a)

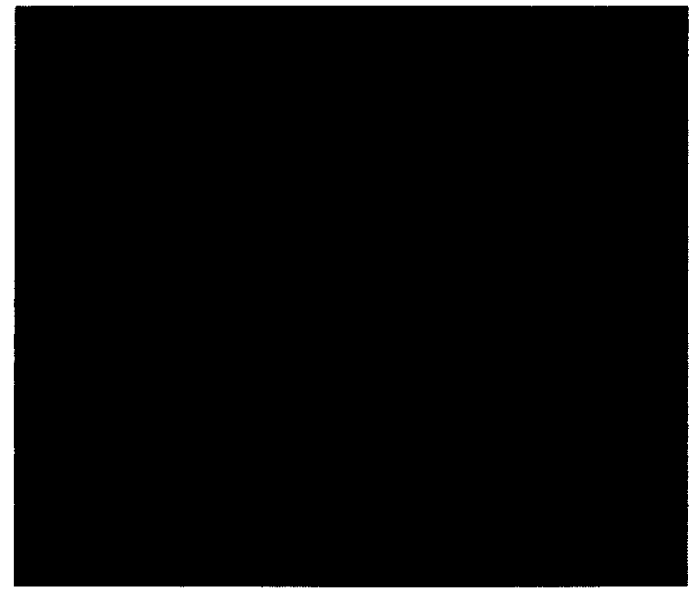

(b)

Figure 0-26: Microscopic images of indentation left in alloy $\mathrm{D}$ specimen tested at $450^{\circ} \mathrm{C}$ in cooling cycle: (a) solid solution and (b) carbides/solution mixture. 


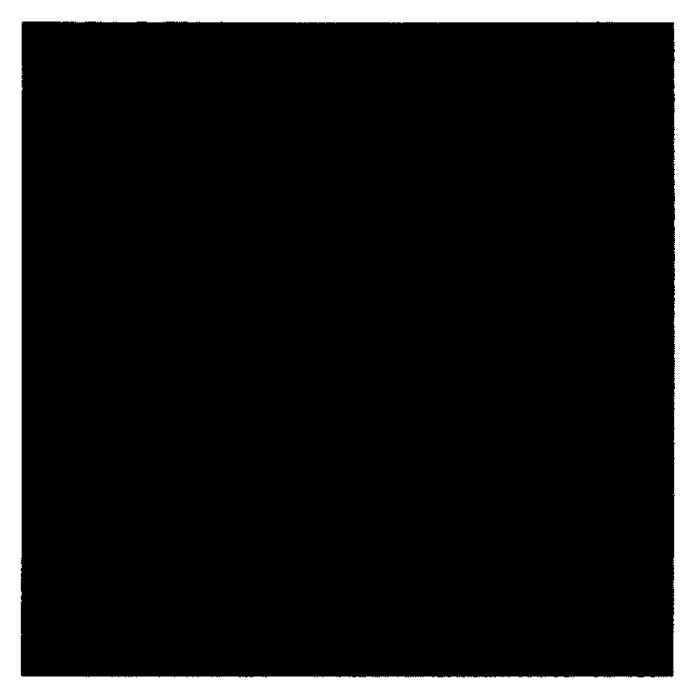

(a)

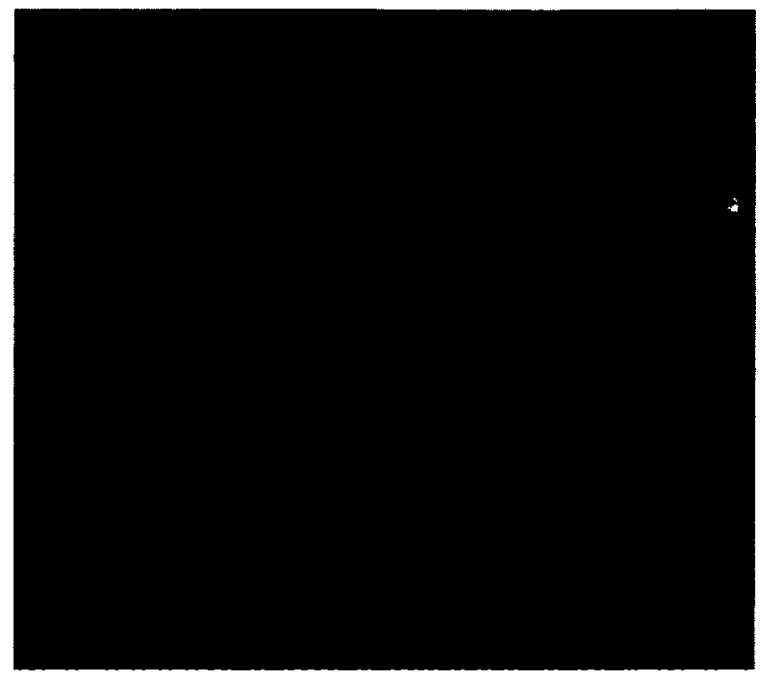

(b)

Figure 0-27: Microscopic images of indentation left in alloy D specimen tested at $250^{\circ} \mathrm{C}$ in cooling cycle: (a) solid solution and (b) carbides/solution mixture.

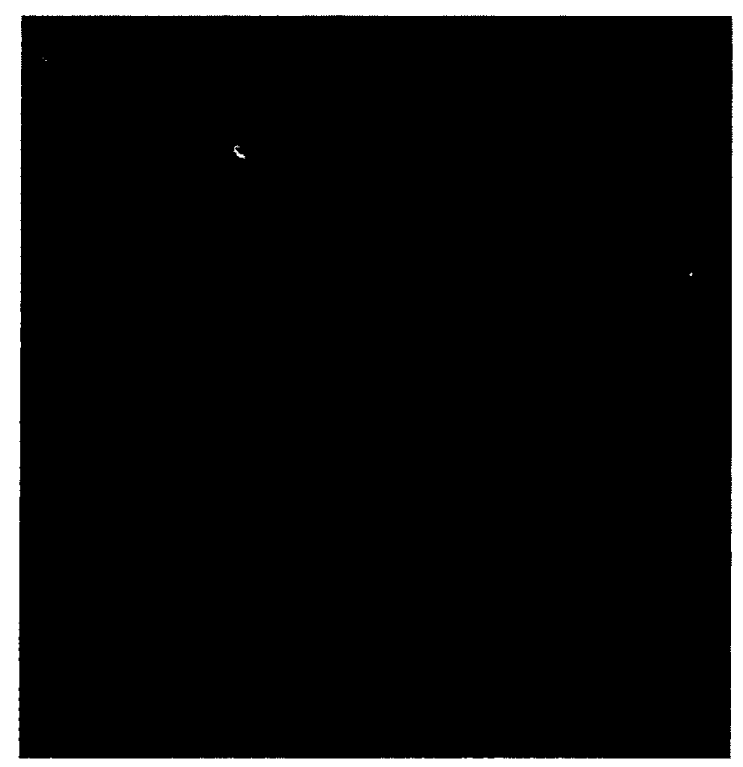

(a)

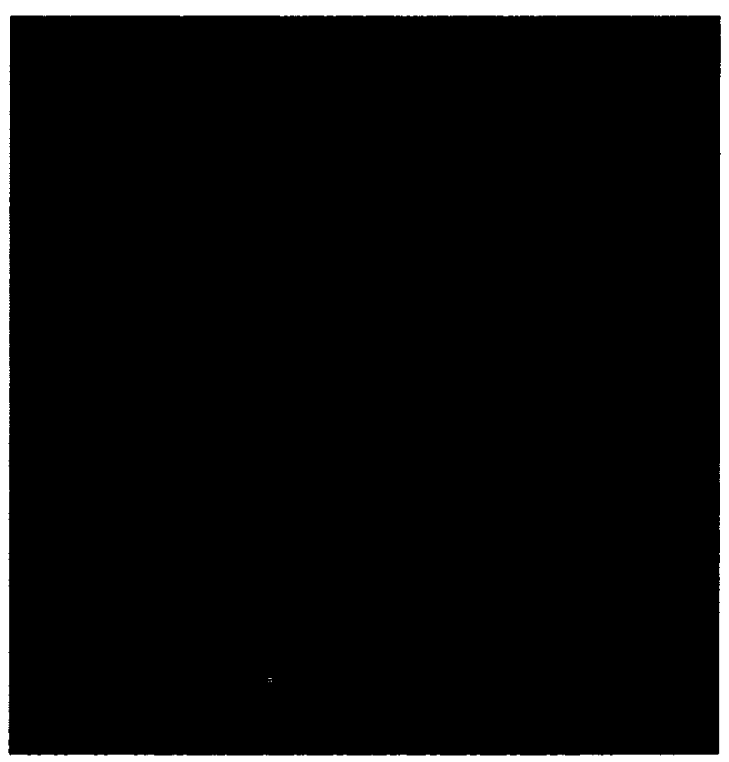

(b)

Figure 0-28: Microscopic images of indentation left in alloy D specimen tested at $20^{\circ} \mathrm{C}$ after heating/cooling: (a) solid solution and (b) carbides/solution mixture. 


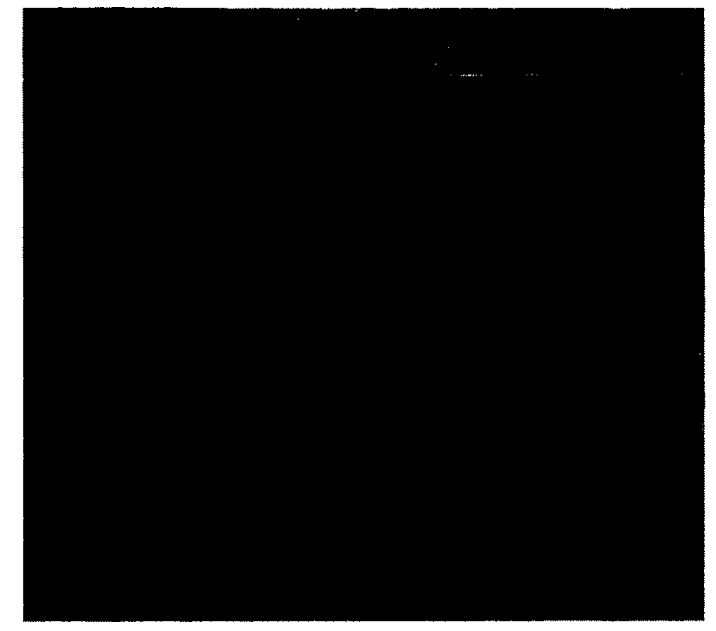

(a)

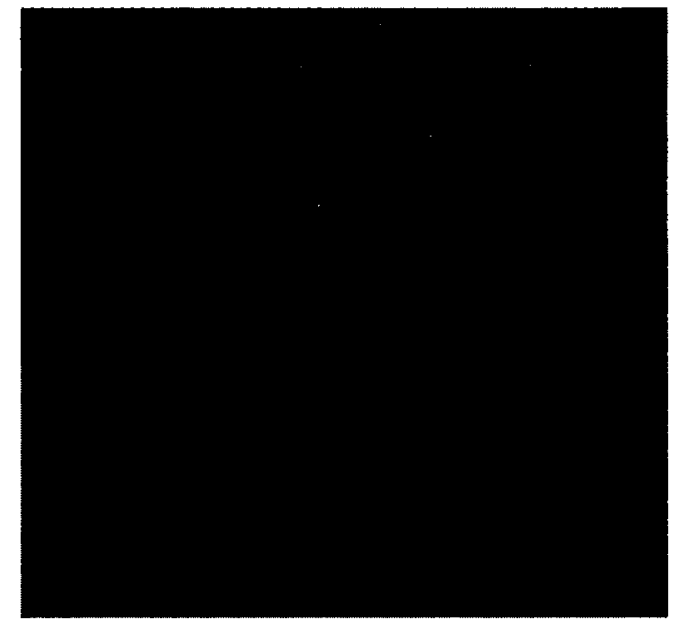

(b)

Figure 0-29: Microscopic images of indentation left in alloy $\mathrm{E}$ specimen tested at $20^{\circ} \mathrm{C}$ before heating: (a) carbide and (b) solid solution/carbide mixture.

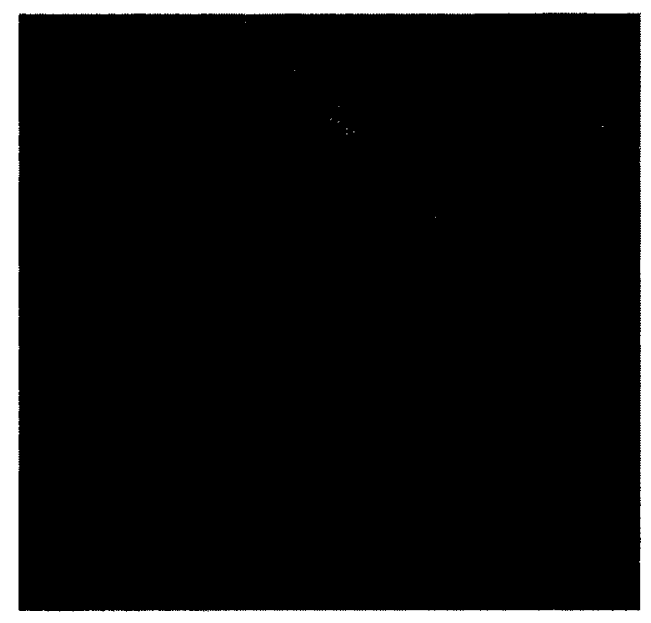

(a)

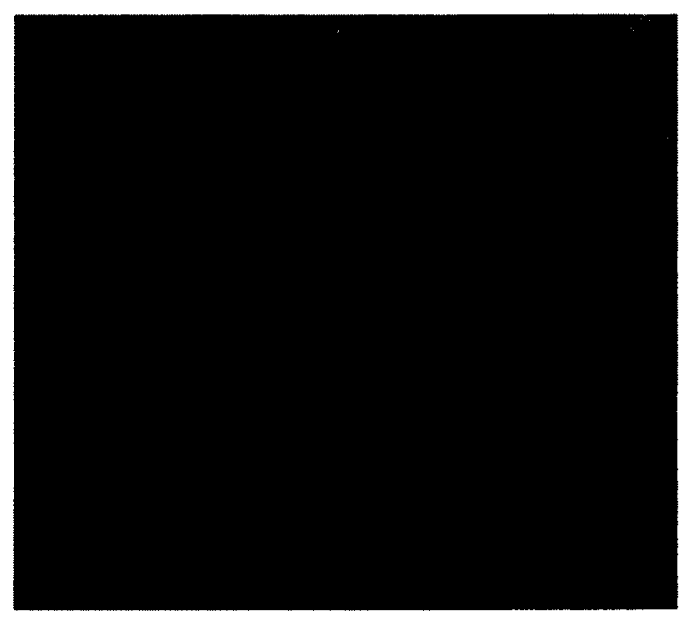

(b)

Figure 0-30: Microscopical images of indentation left in alloy $\mathrm{E}$ specimen tested at $250^{\circ} \mathrm{C}$ in heating cycle: (a) carbide and (b) solid solution/carbide mixture. 


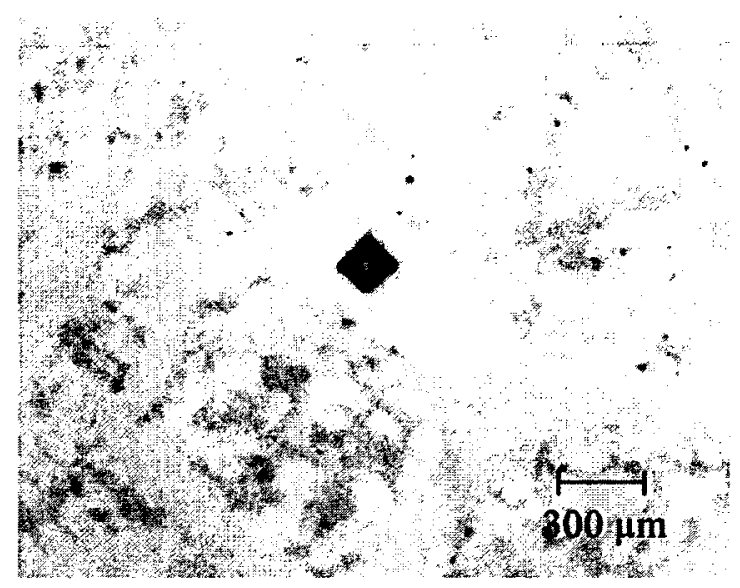

(a)

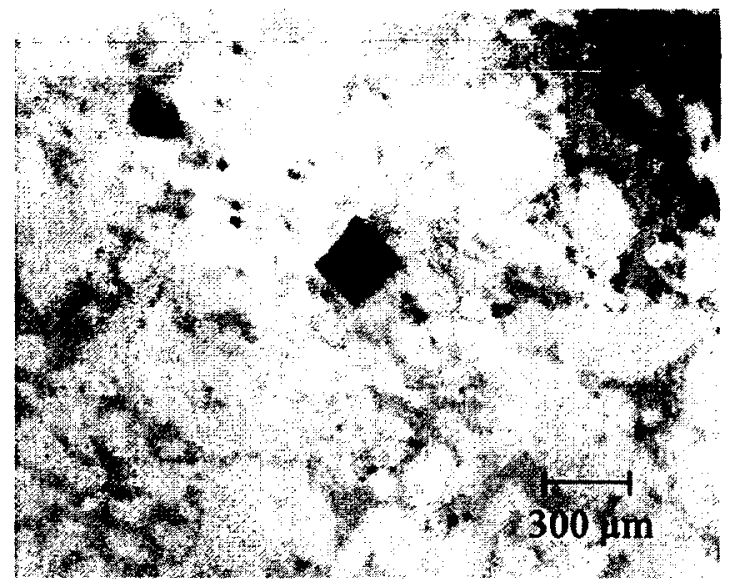

(b)

Figure 0-31: Microscopic images of indentation left in alloy $\mathrm{E}$ specimen tested at $450^{\circ} \mathrm{C}$ in heating cycle: (a) carbide and (b) solid solution/carbide mixture.

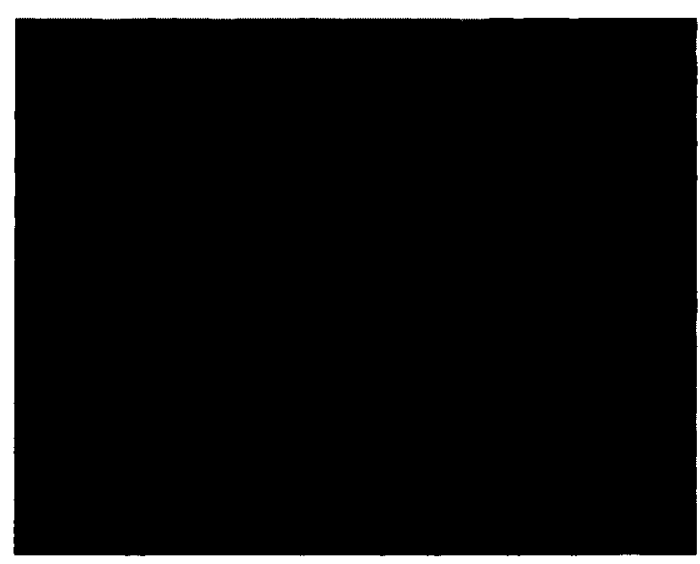

(a)

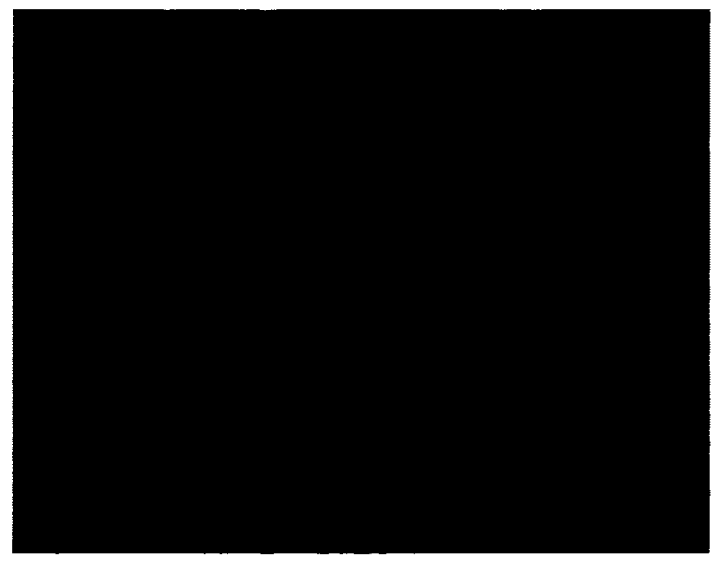

(b)

Figure 0-32: Microscopic images of indentation left in alloy $\mathrm{E}$ specimen tested at $650^{\circ} \mathrm{C}$ in heating cycle: (a) carbide and (b) carbides/solution mixture. 


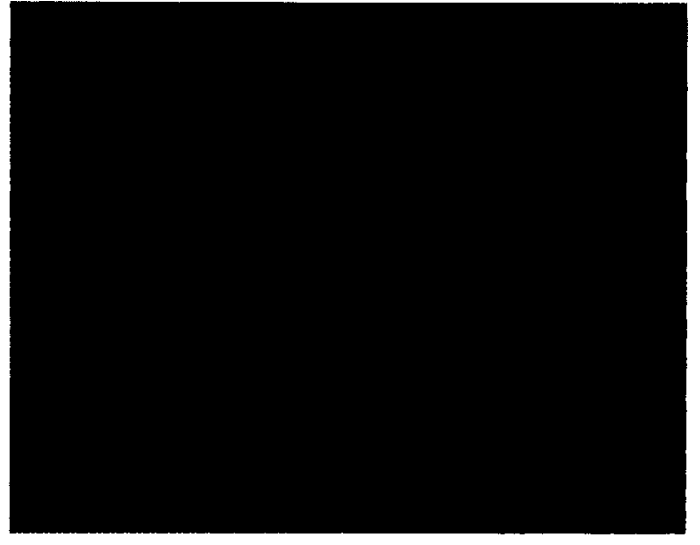

(a)

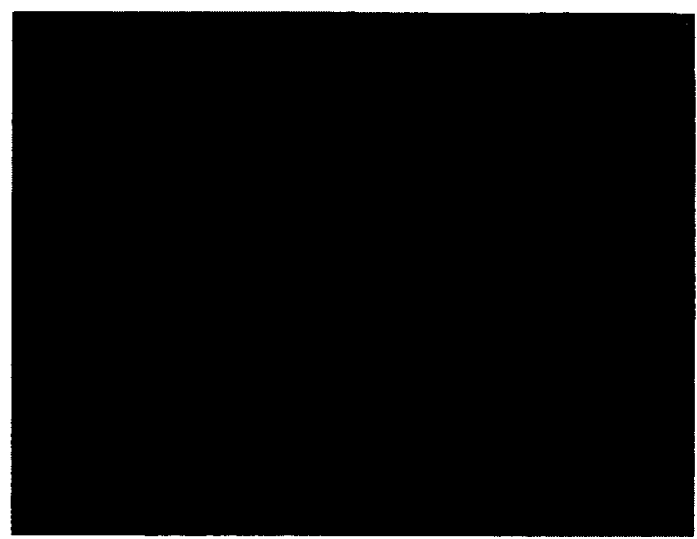

(b)

Figure 0-33: Microscopic images of indentation left in alloy $\mathrm{E}$ specimen tested at $450^{\circ} \mathrm{C}$ in cooling cycle: (a) carbide and (b) solid solution/carbide mixture.

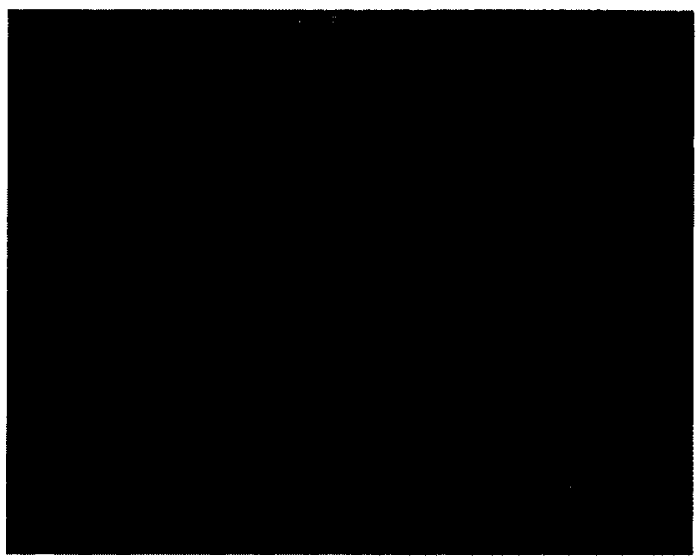

(a)

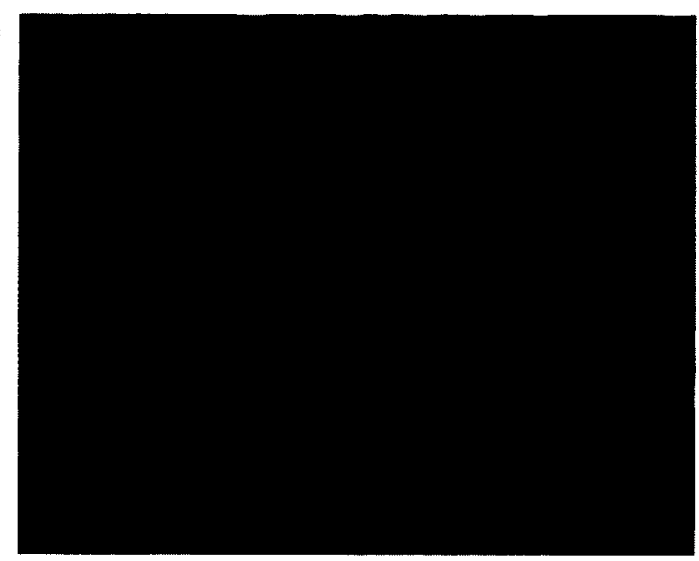

(b)

Figure 0-34: Microscopic images of indentation left in alloy $\mathrm{E}$ specimen tested at $250^{\circ} \mathrm{C}$ in cooling cycle: (a) carbide and (b) solid solution/carbide mixture. 


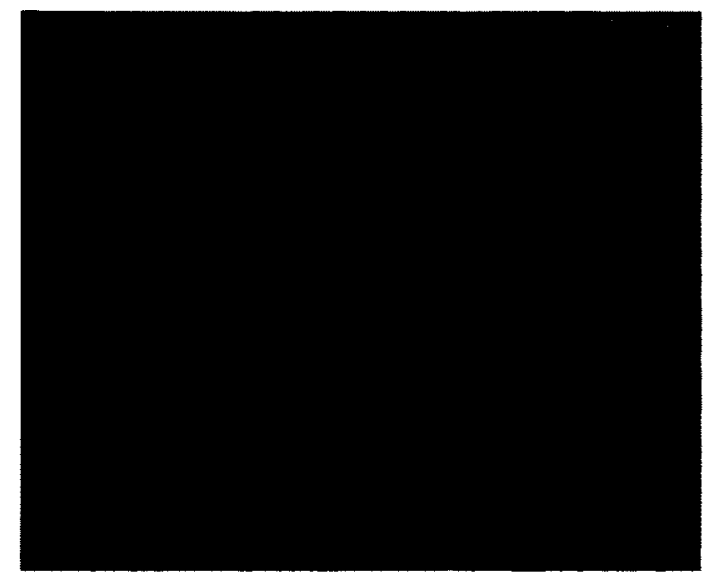

(a)

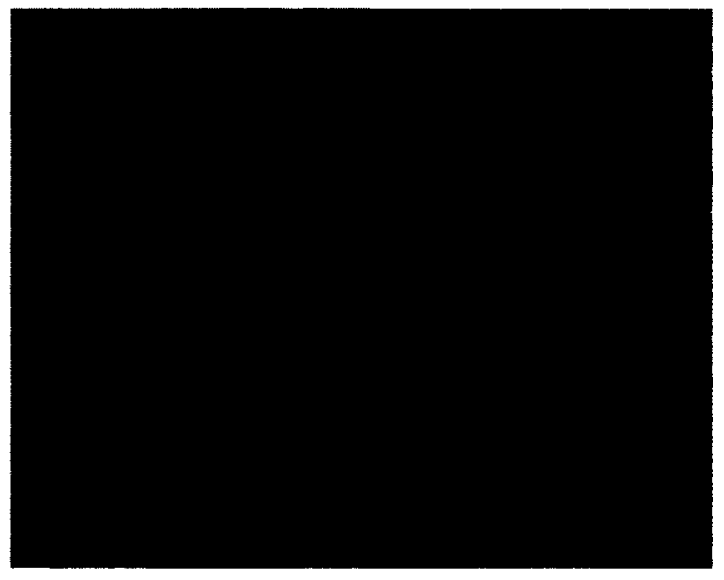

(b)

Figure 0-35: Microscopic images of indentation left in alloy $\mathrm{E}$ specimen tested at $20^{\circ} \mathrm{C}$ after heating/cooling: (a) carbide and (b) solid solution/carbide mixture.

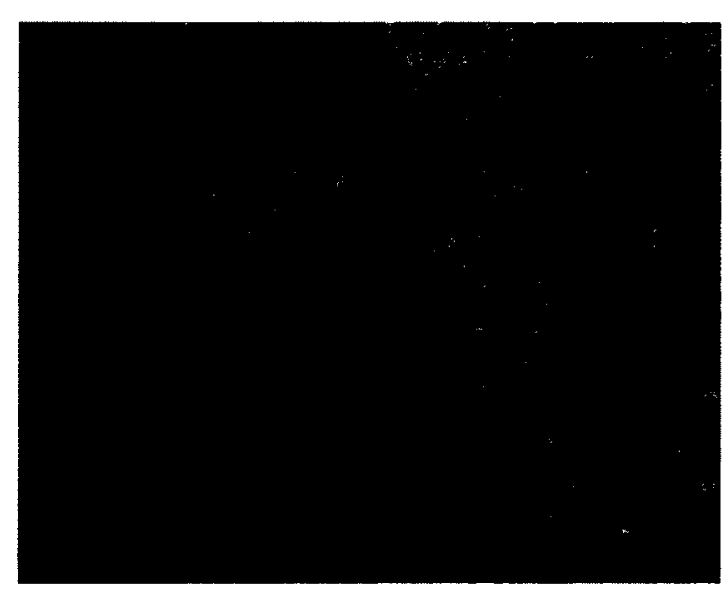

(a)

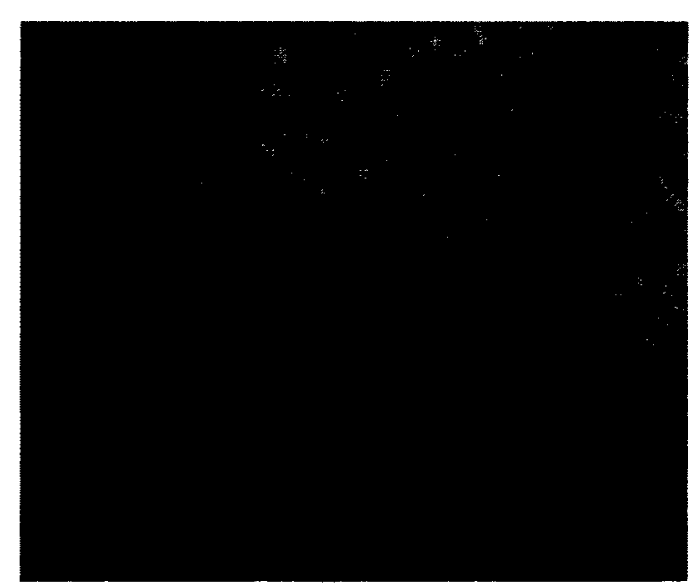

(b)

Figure 0-36: Microscopic images of indentation left in alloy $\mathrm{F}$ specimen tested at $20^{\circ} \mathrm{C}$ before heating: (a) carbide and (b) solid solution/carbide mixture. 


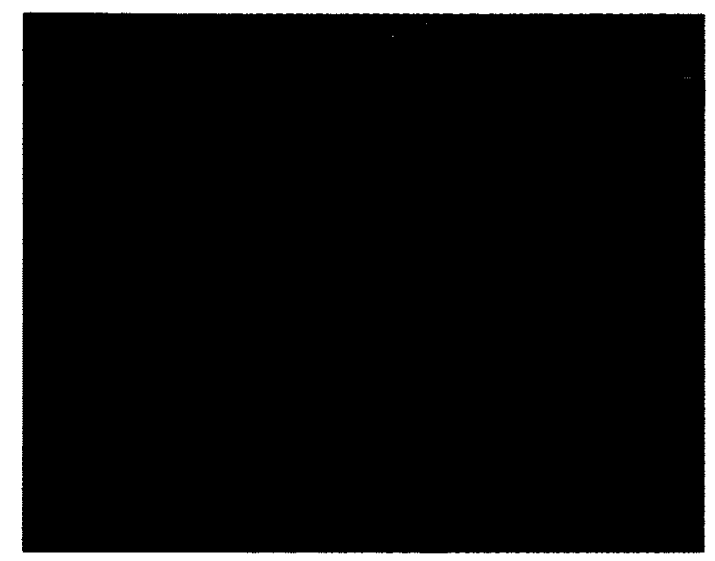

(a)

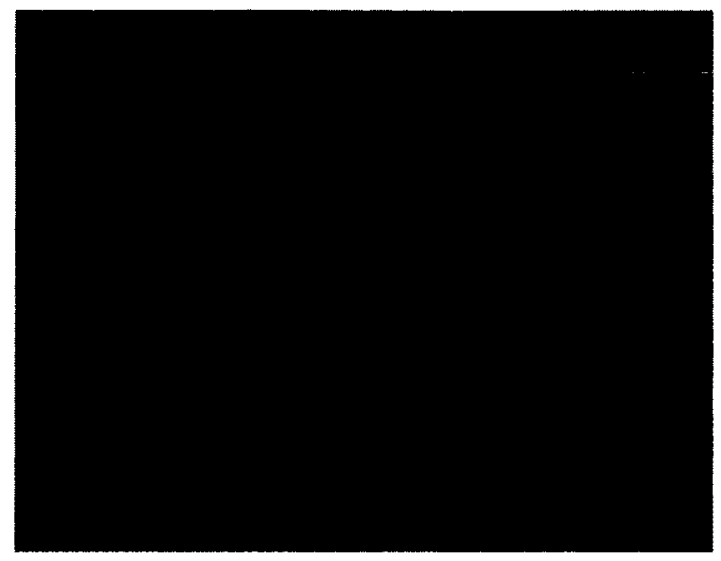

(b)

Figure 0-37: Microscopic images of indentation left in alloy $\mathrm{F}$ specimen tested at $250^{\circ} \mathrm{C}$ in heating cycle: (a) carbide and (b) solid solution/carbide mixture.

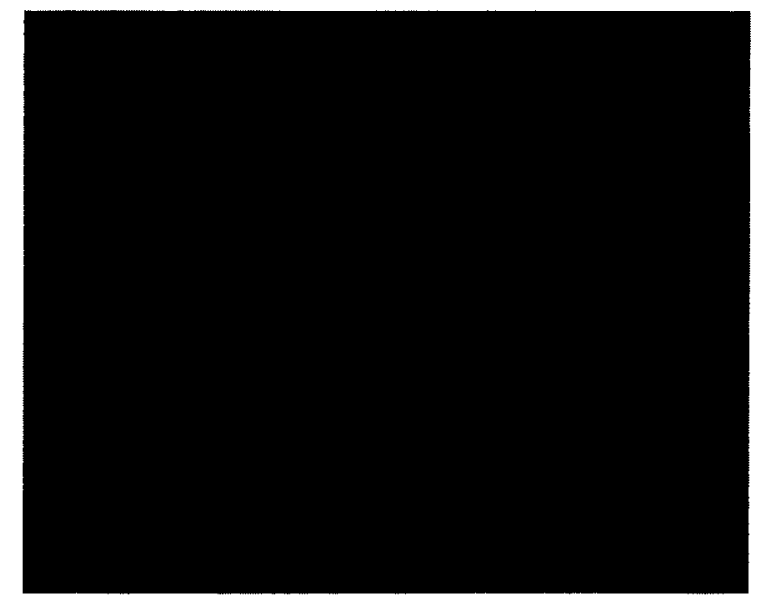

(a)

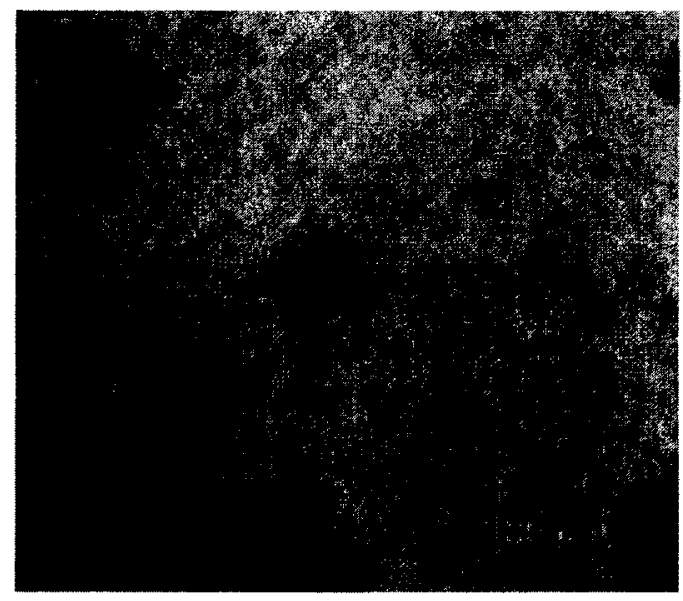

(b)

Figure 0-38: Microscopic images of indentation left in alloy $\mathrm{F}$ specimen tested at $450^{\circ} \mathrm{C}$ in heating cycle: (a) carbide and (b) solid solution/carbide mixture. 


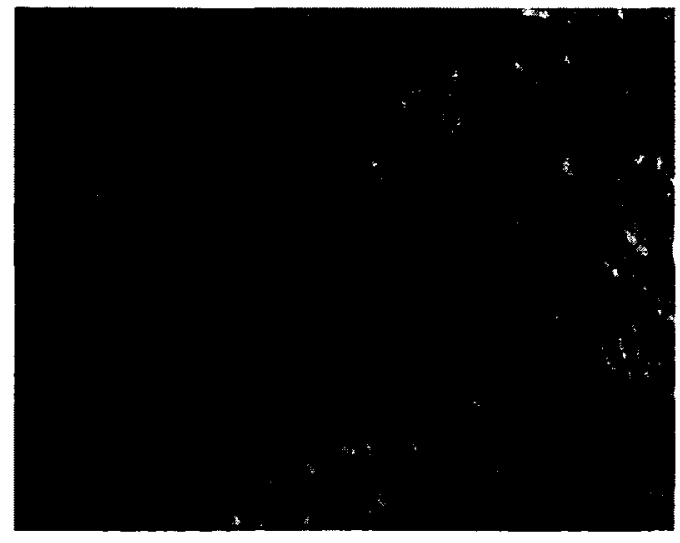

(a)

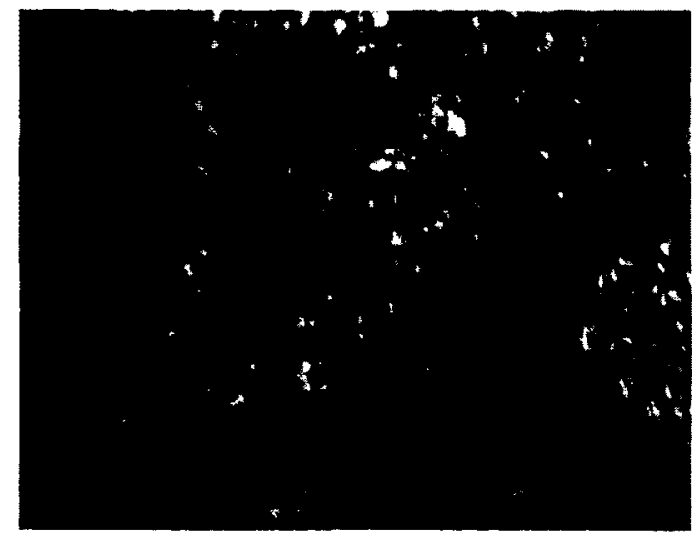

(b)

Figure 0-39: Microscopic images of indentation left in alloy $\mathrm{F}$ specimen tested at $650^{\circ} \mathrm{C}$ in heating cycle: (a) carbide and (b) solid solution/carbide mixture.

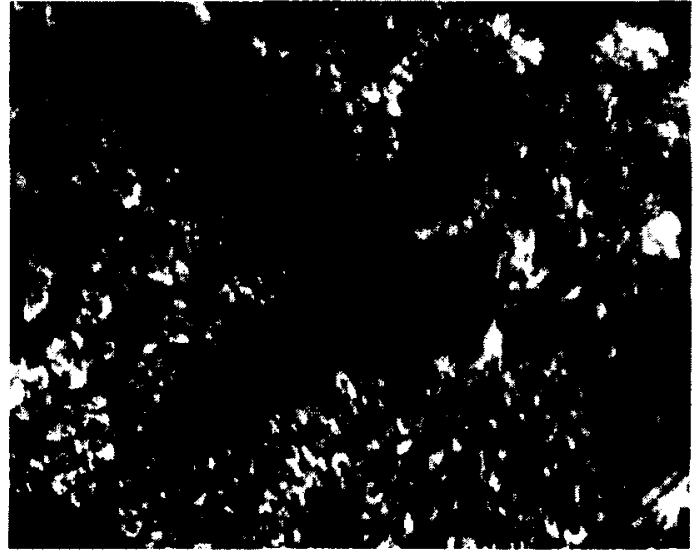

(a)

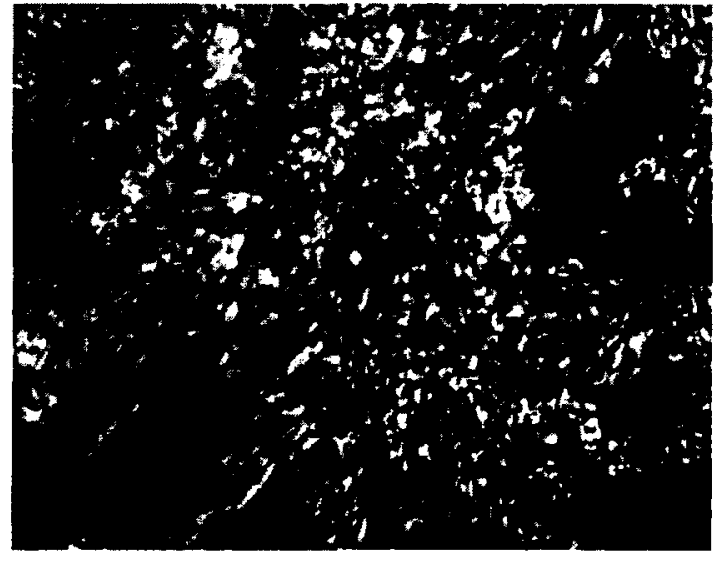

(b)

Figure 0-40: Microscopic images of indentation left in alloy $\mathrm{F}$ specimen tested at $450^{\circ} \mathrm{C}$ in cooling cycle: (a) carbide and (b) solid solution/carbide mixture. 


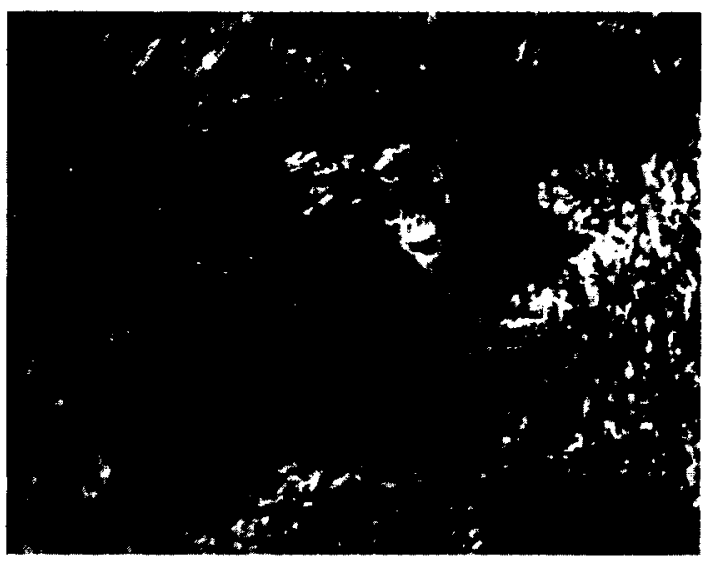

(a)

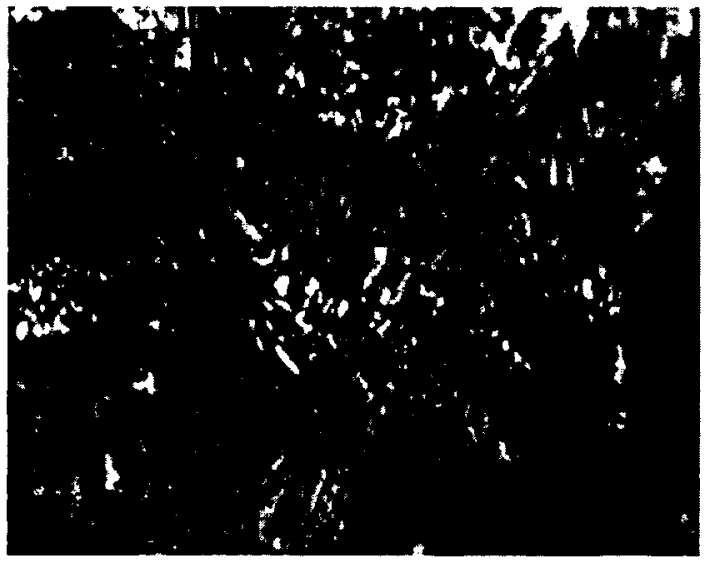

(b)

Figure 0-41: Microscopic images of indentation left in alloy $\mathrm{F}$ specimen tested at $250^{\circ} \mathrm{C}$ in cooling cycle: (a) carbide and (b) solid solution/carbide mixture.

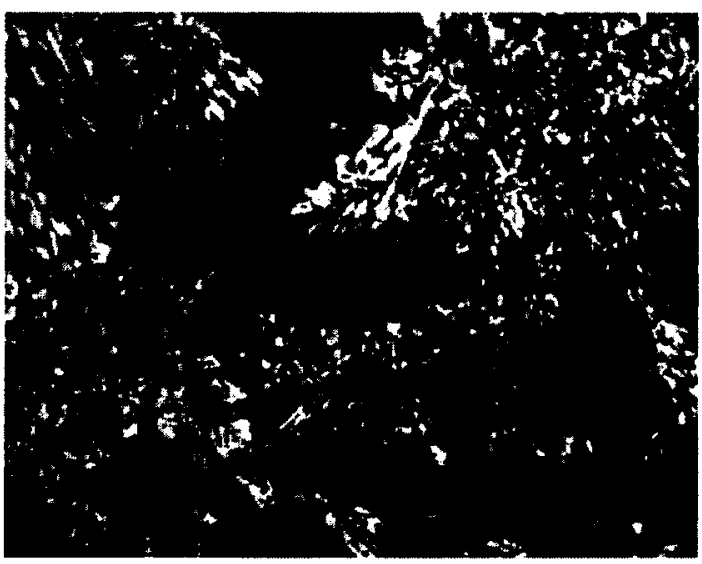

(a)

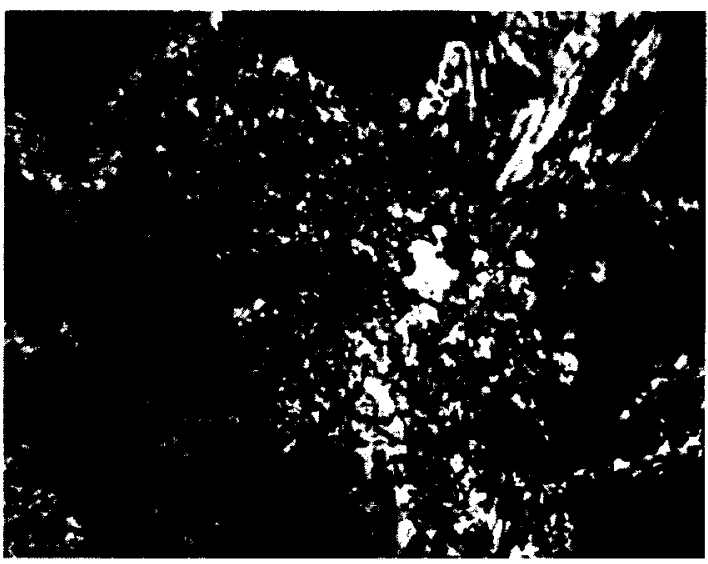

(b)

Figure 0-42: Microscopic images of indentation left in alloy $\mathrm{F}$ specimen tested at $20^{\circ} \mathrm{C}$ after heating/cooling: (a) carbide and (b) solid solution/carbide mixture. 


\section{Appendix B: Wear Track Cross Section Profiles}

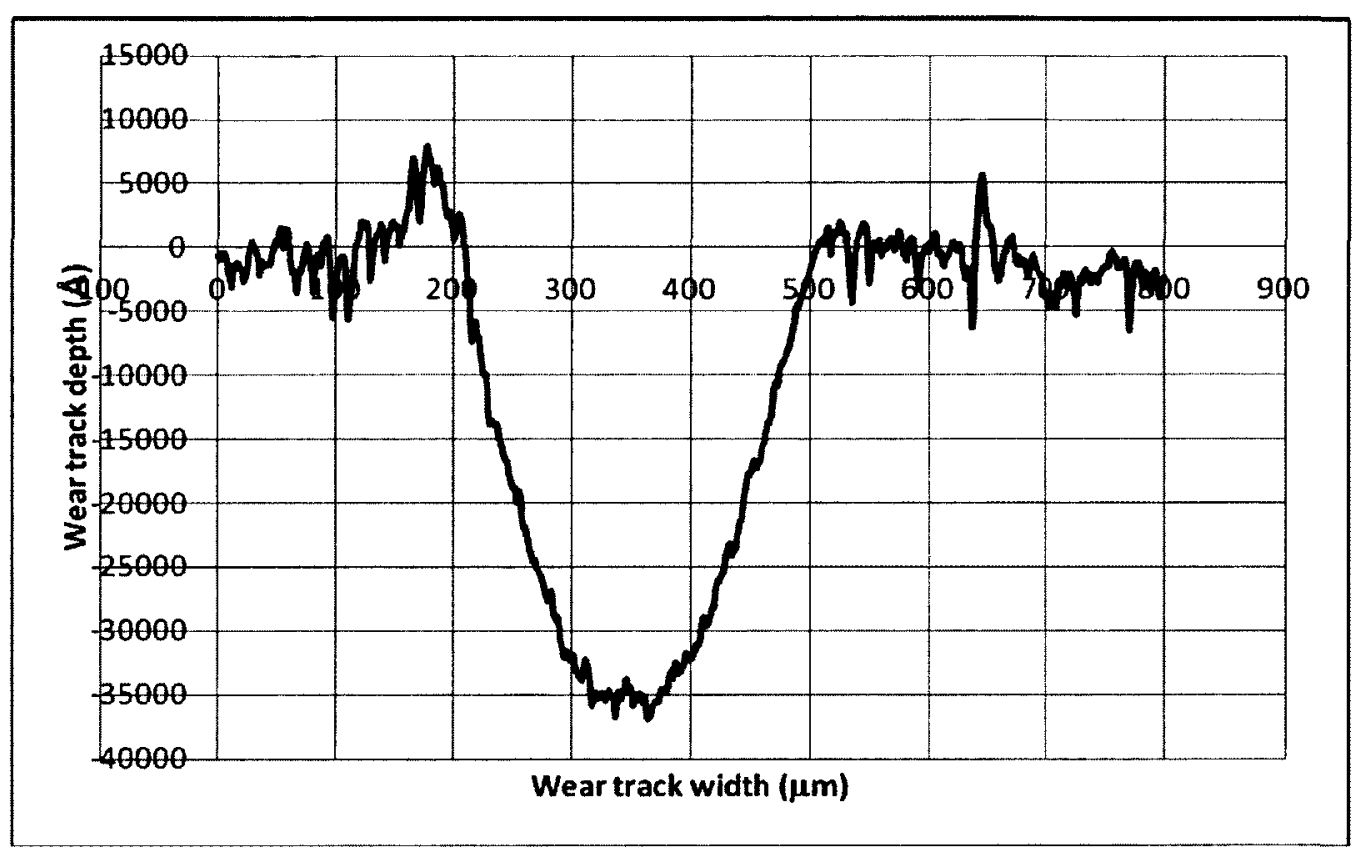

(a)

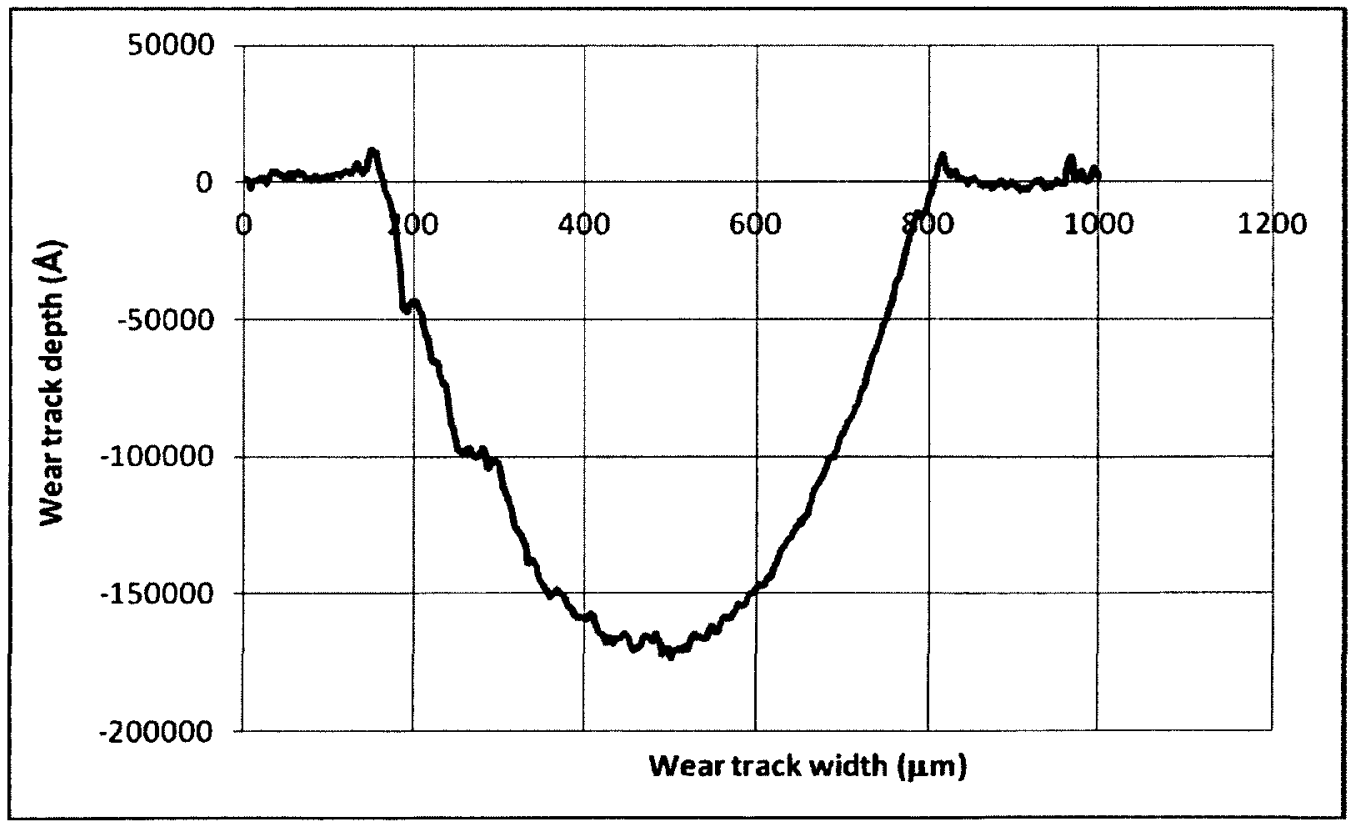

(b) 


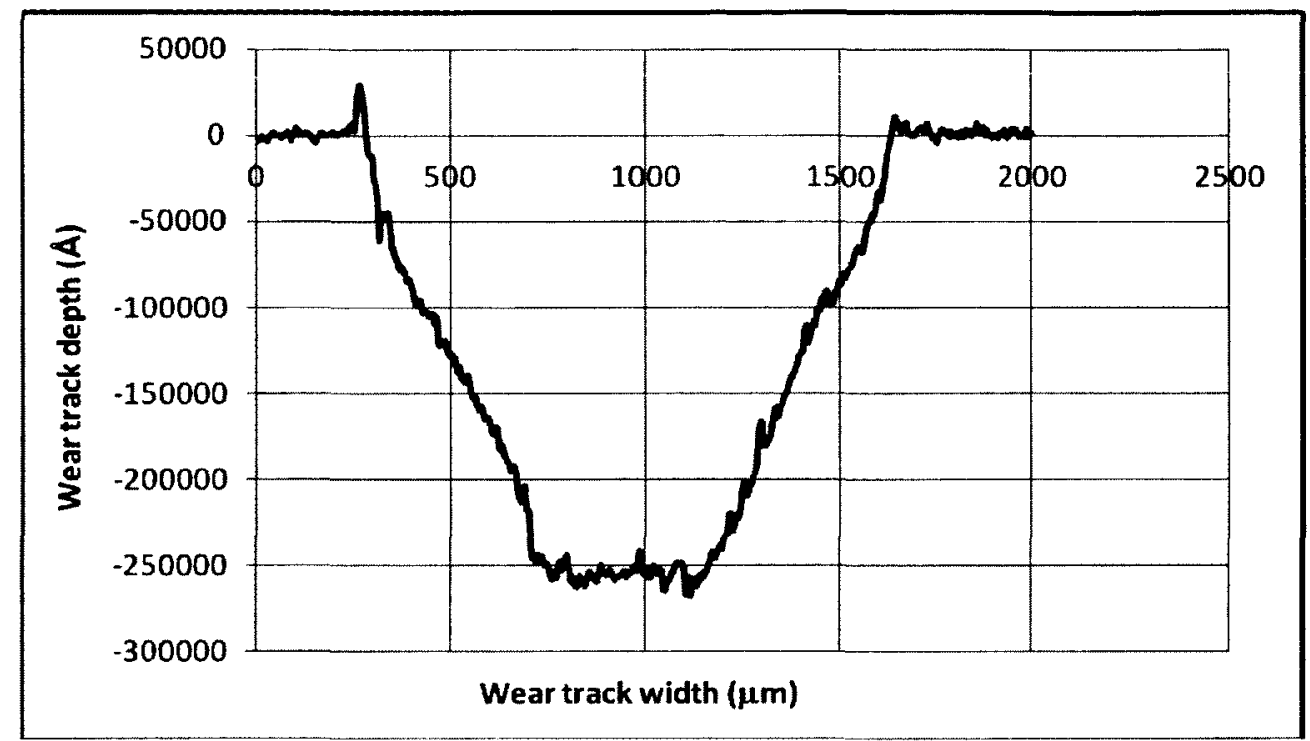

(c)

Figure 0-1: Cross section profiles of wear tracks in alloy A specimen tested: (a) at room temperature, (b) at $250^{\circ} \mathrm{C}$ and (c) at $450^{\circ} \mathrm{C}$.

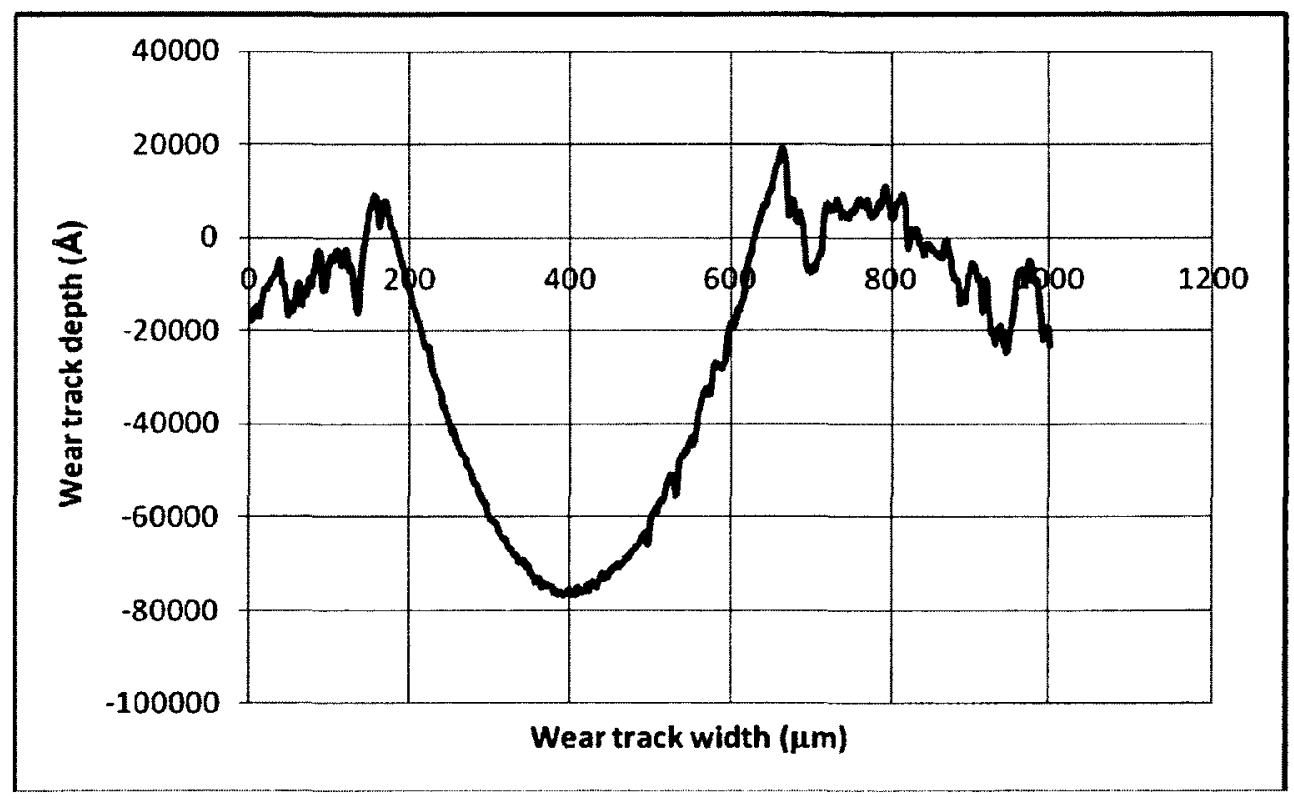

(a) 


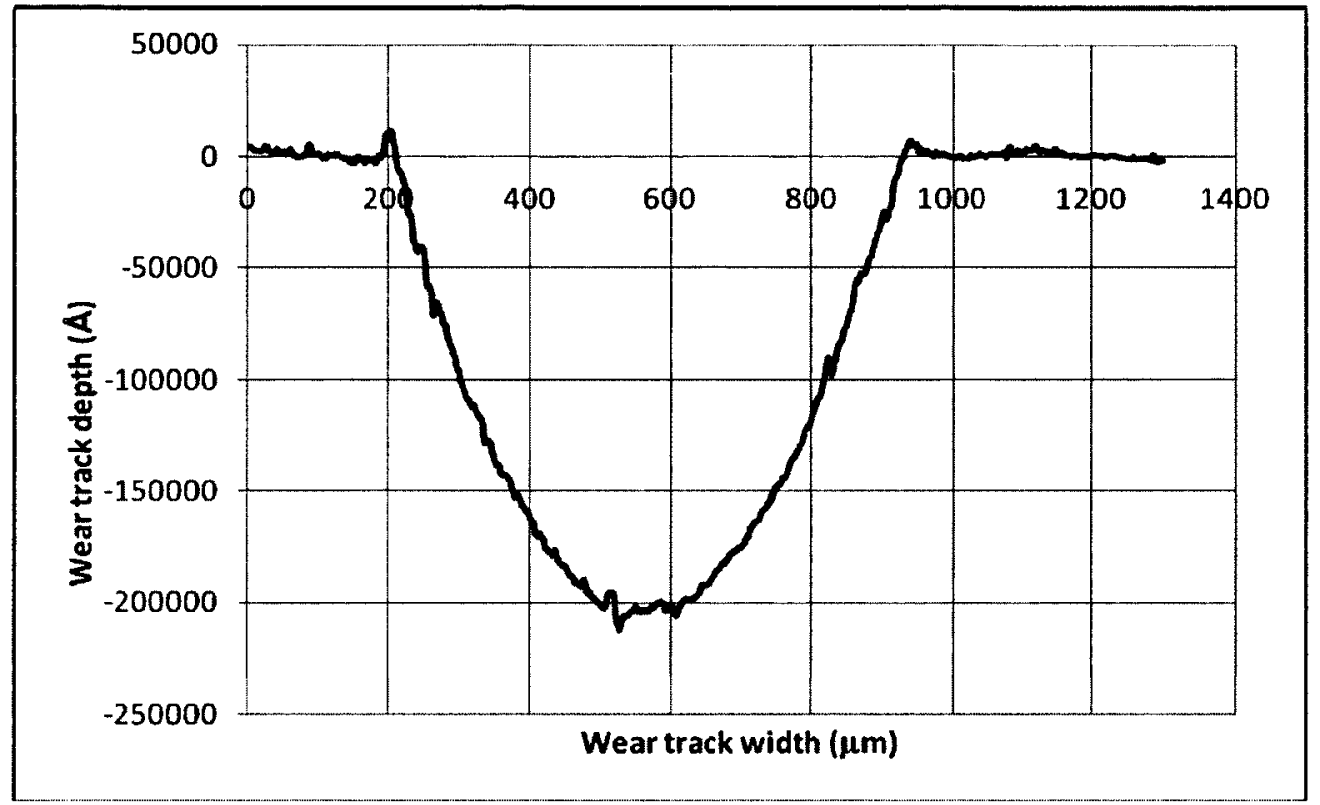

(b)

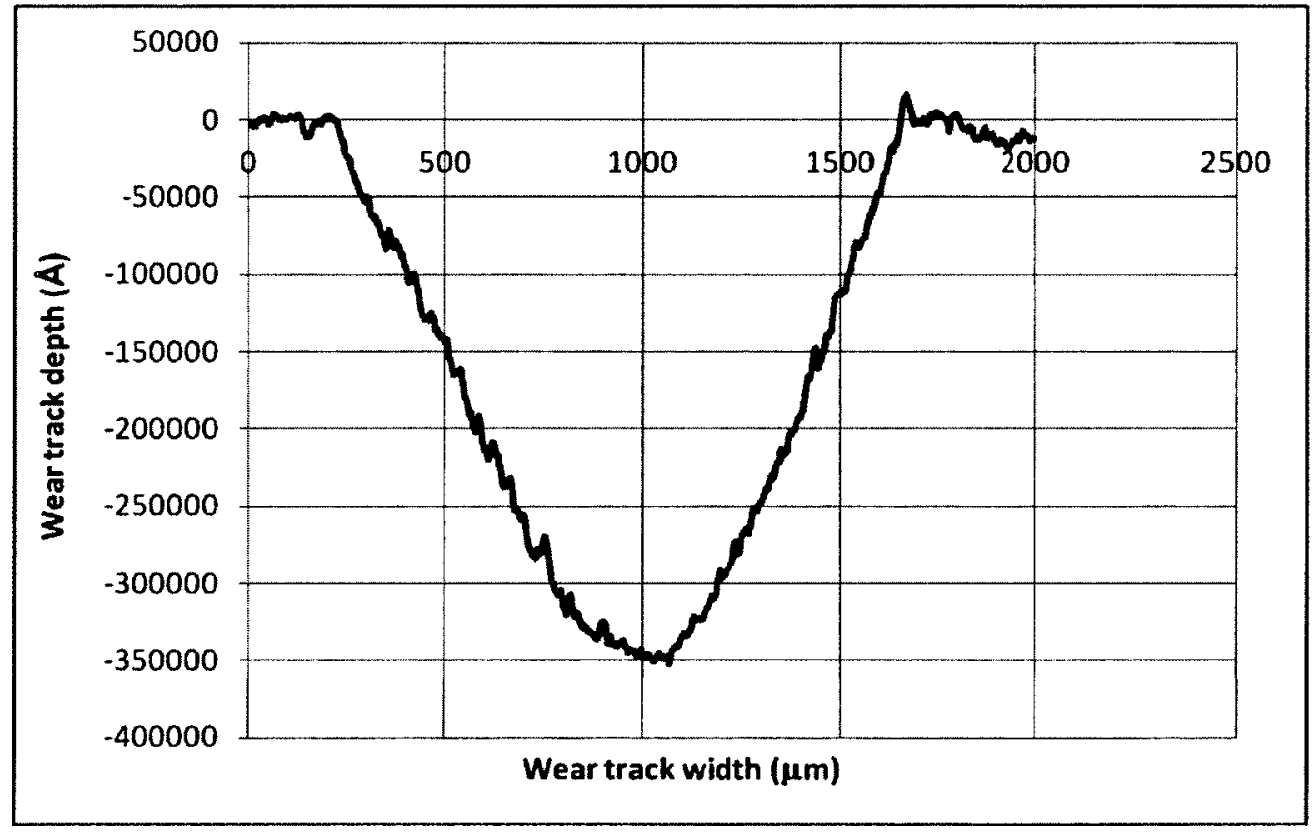

(c)

Figure 0-2: Cross section profiles of wear tracks in alloy B specimen tested: (a) at room temperature, (b) at $250^{\circ} \mathrm{C}$ and (c) at $450^{\circ} \mathrm{C}$. 

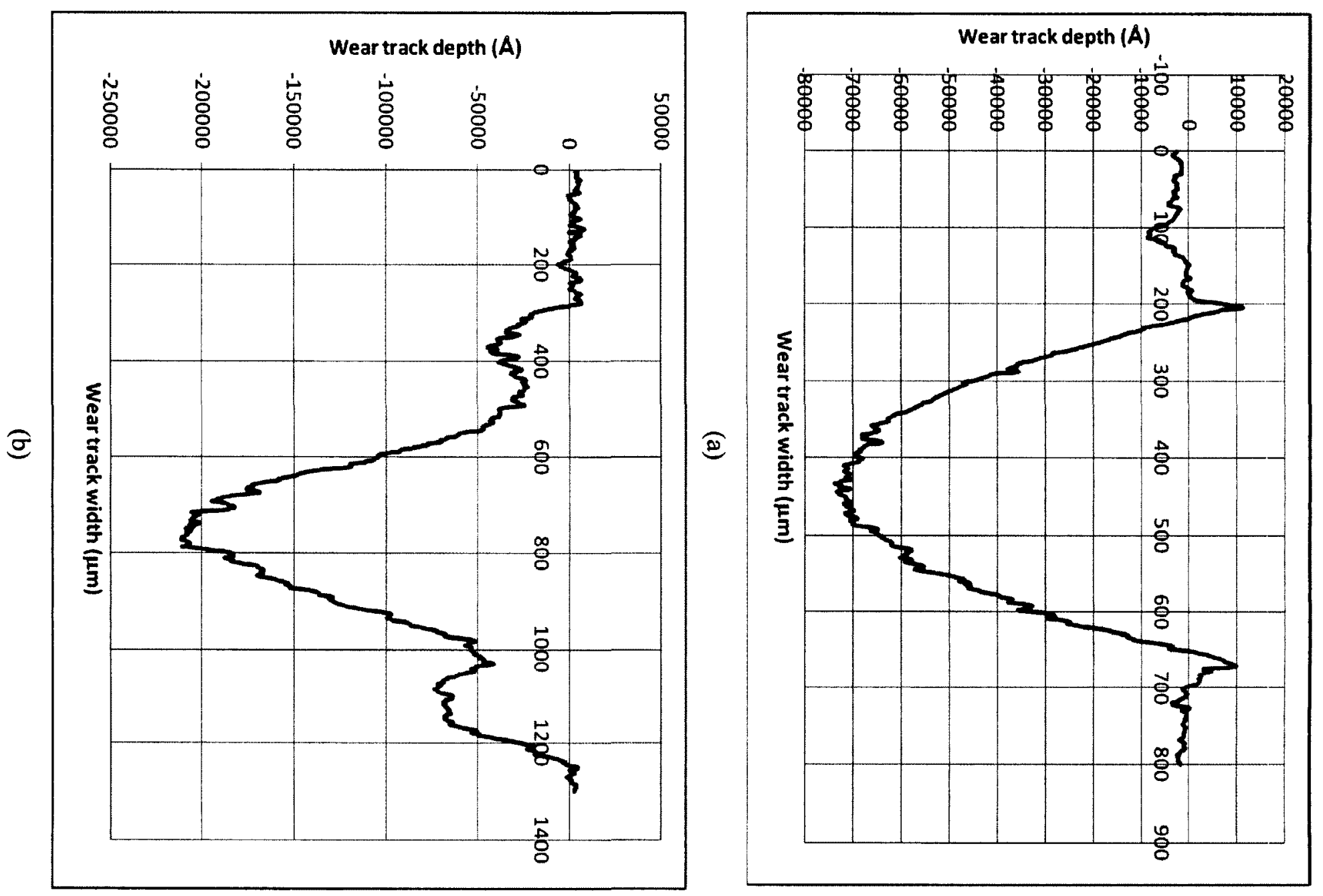


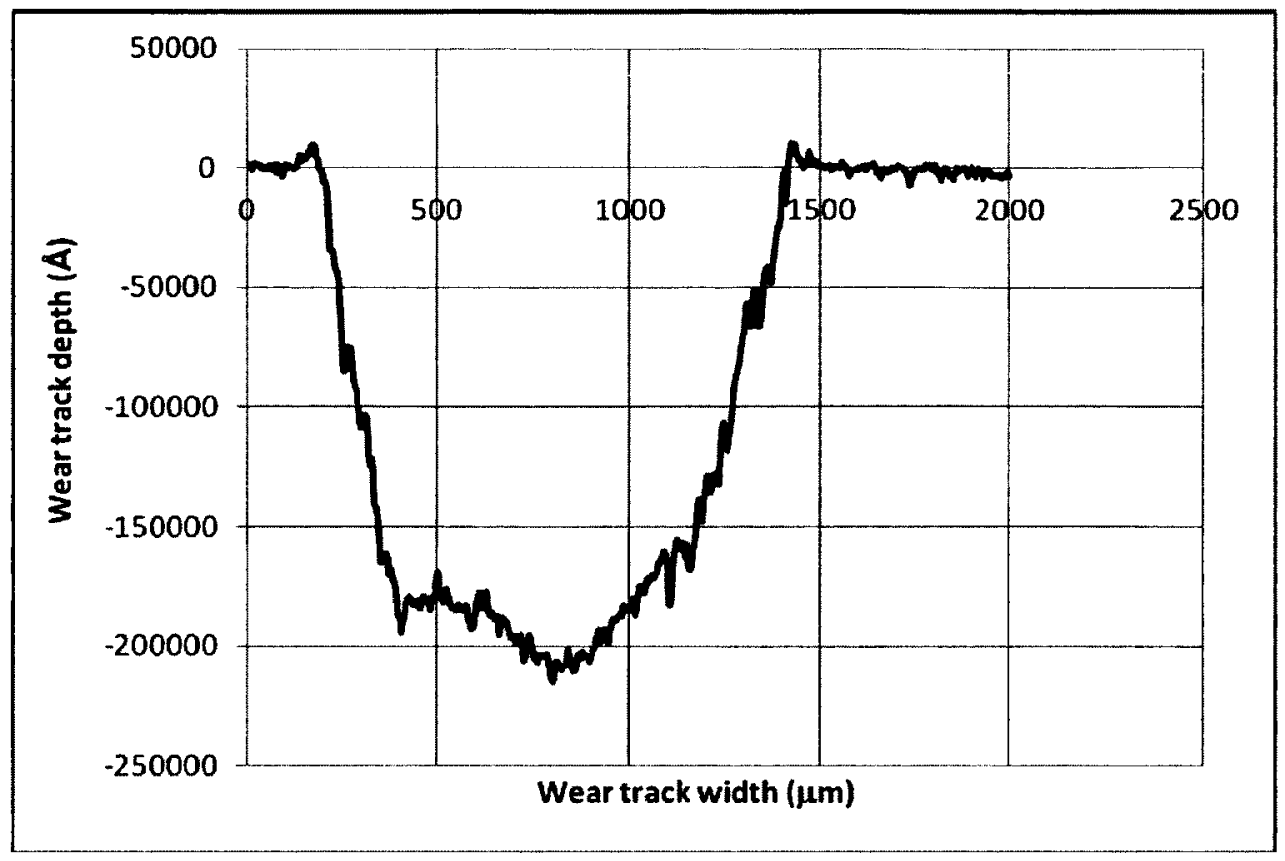

(c)

Figure 0-3: Cross section profiles of wear tracks in alloy $\mathrm{C}$ specimen tested: (a) at room temperature, (b) at $250^{\circ} \mathrm{C}$ and (c) at $450^{\circ} \mathrm{C}$.

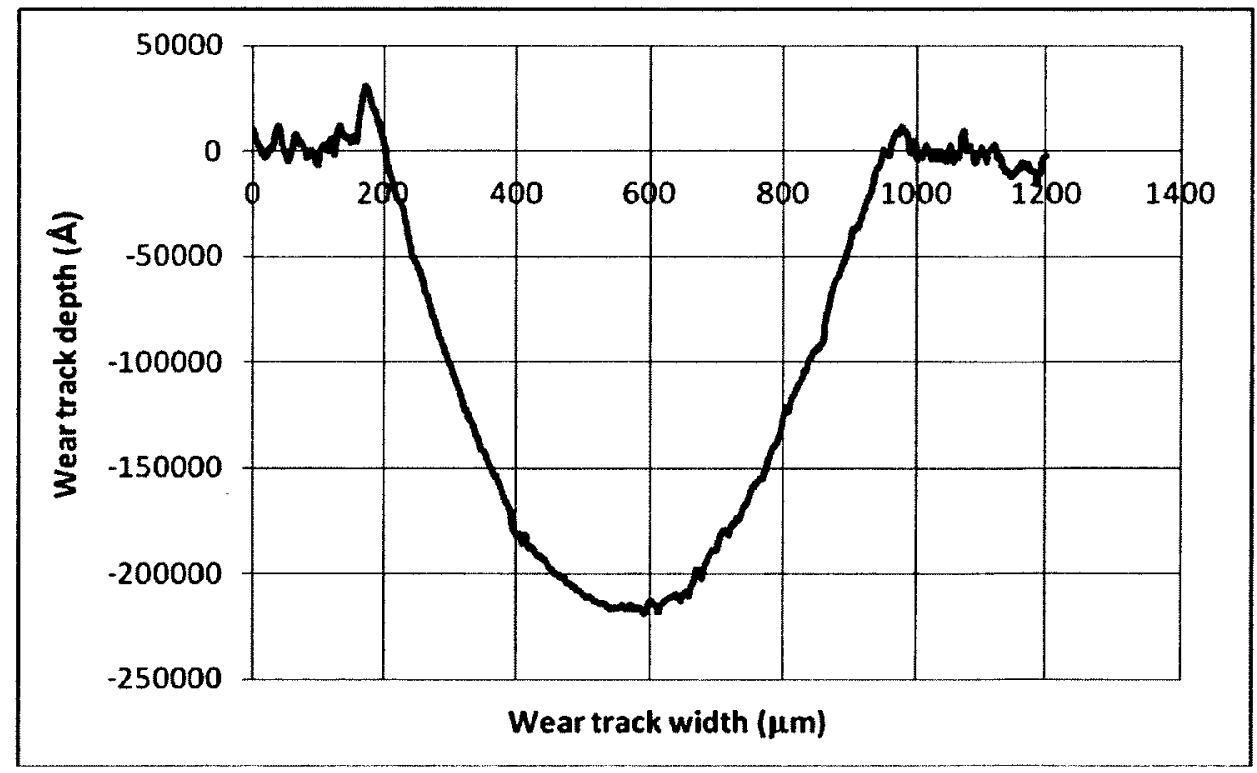

(a) 


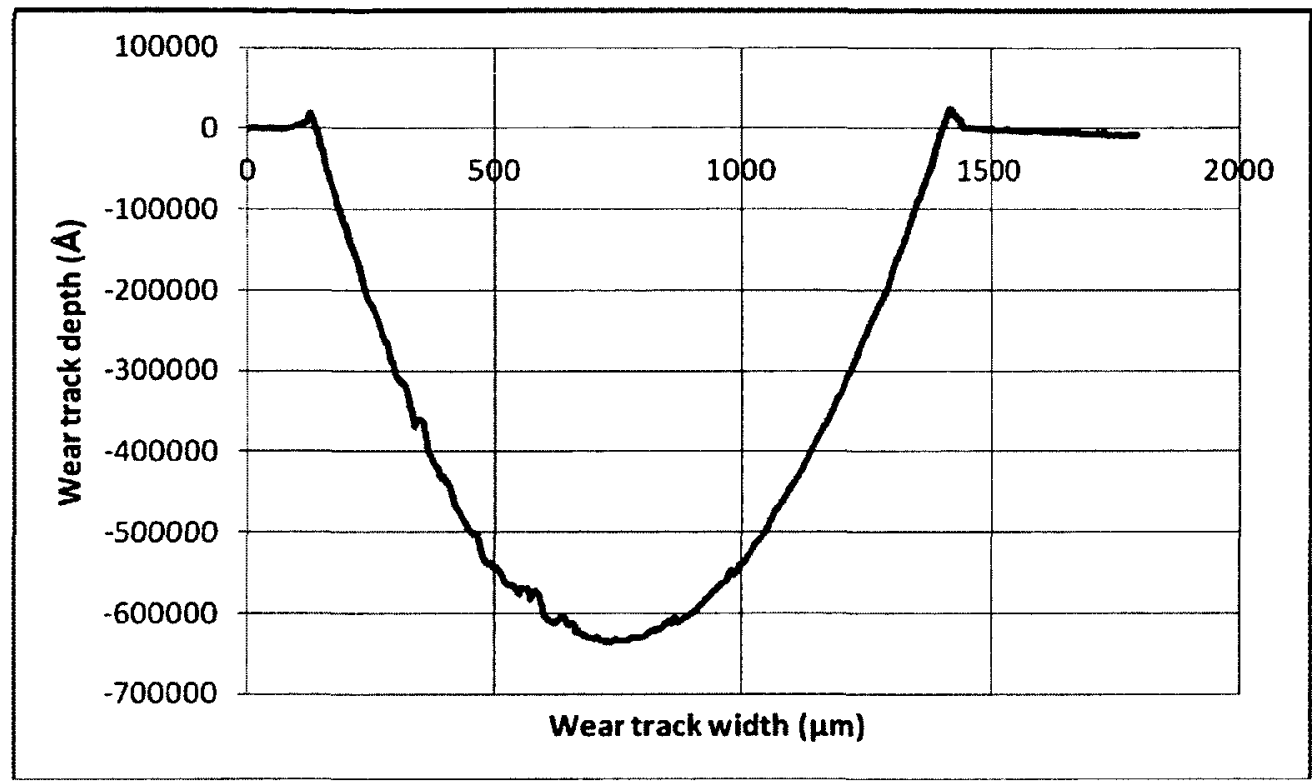

(b)

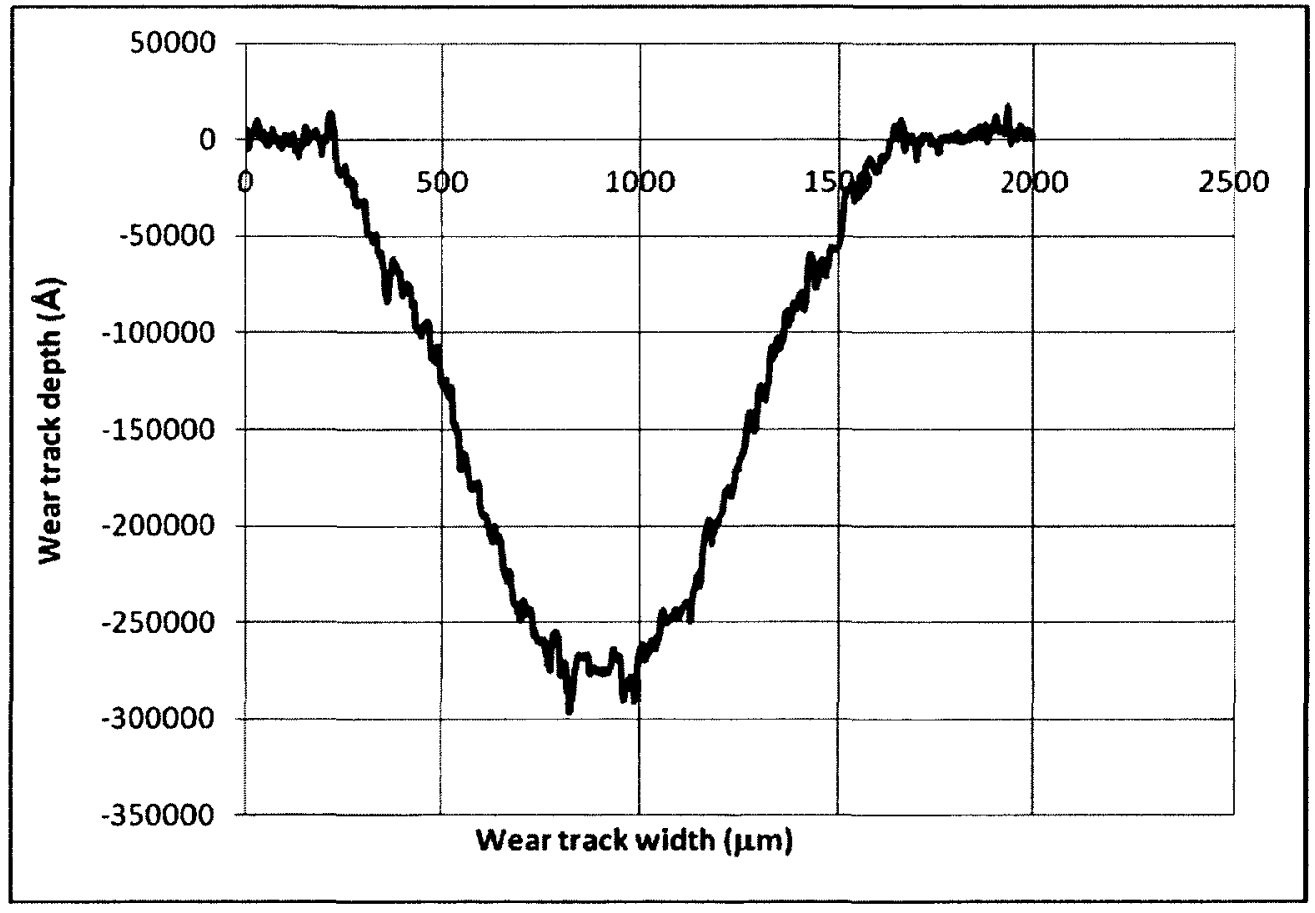

(c)

Figure 0-4: Cross section profiles of wear tracks in alloy D specimen tested: (a) at room temperature, (b) at $250^{\circ} \mathrm{C}$ and (c) at $450^{\circ} \mathrm{C}$. 


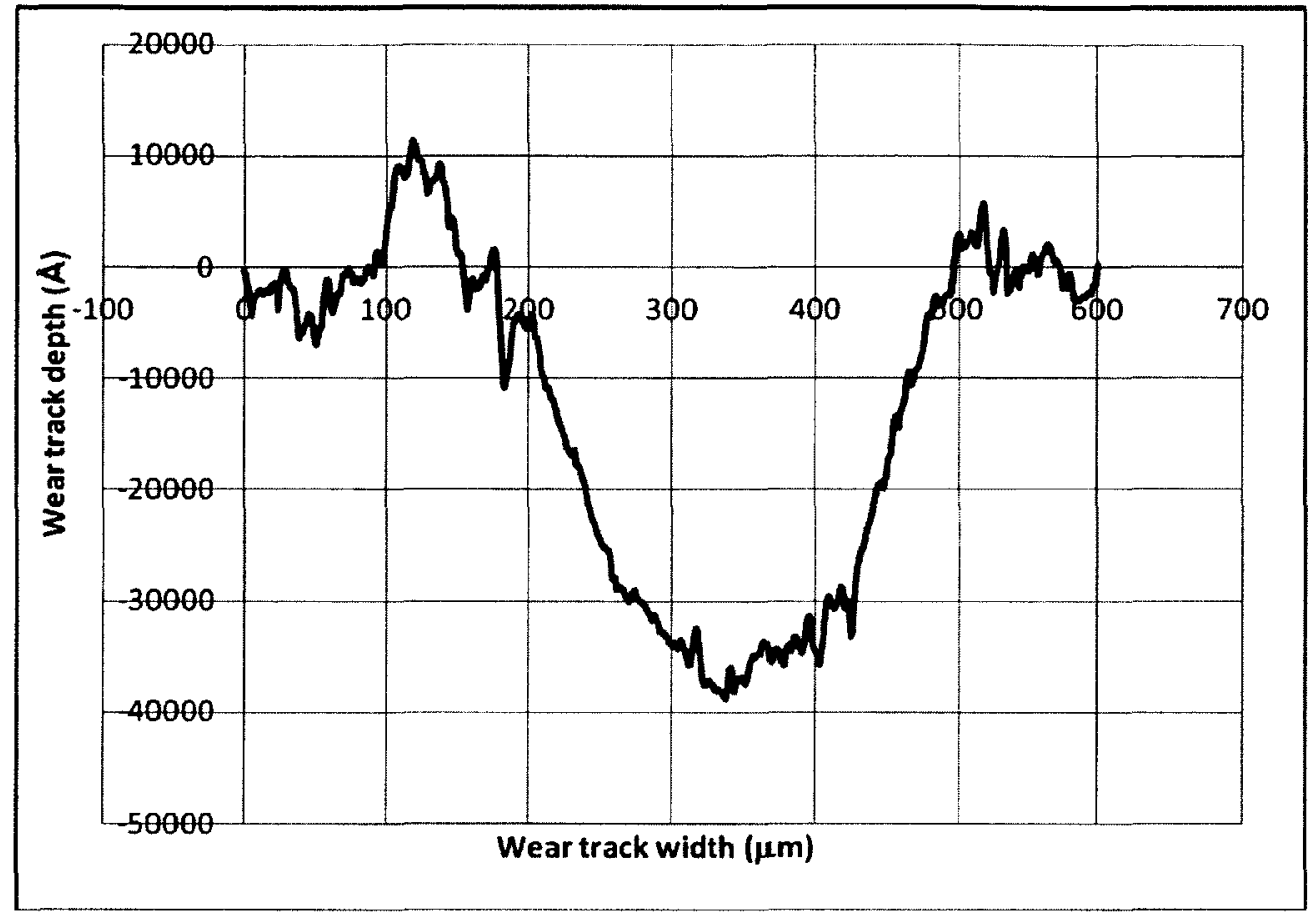

(a)

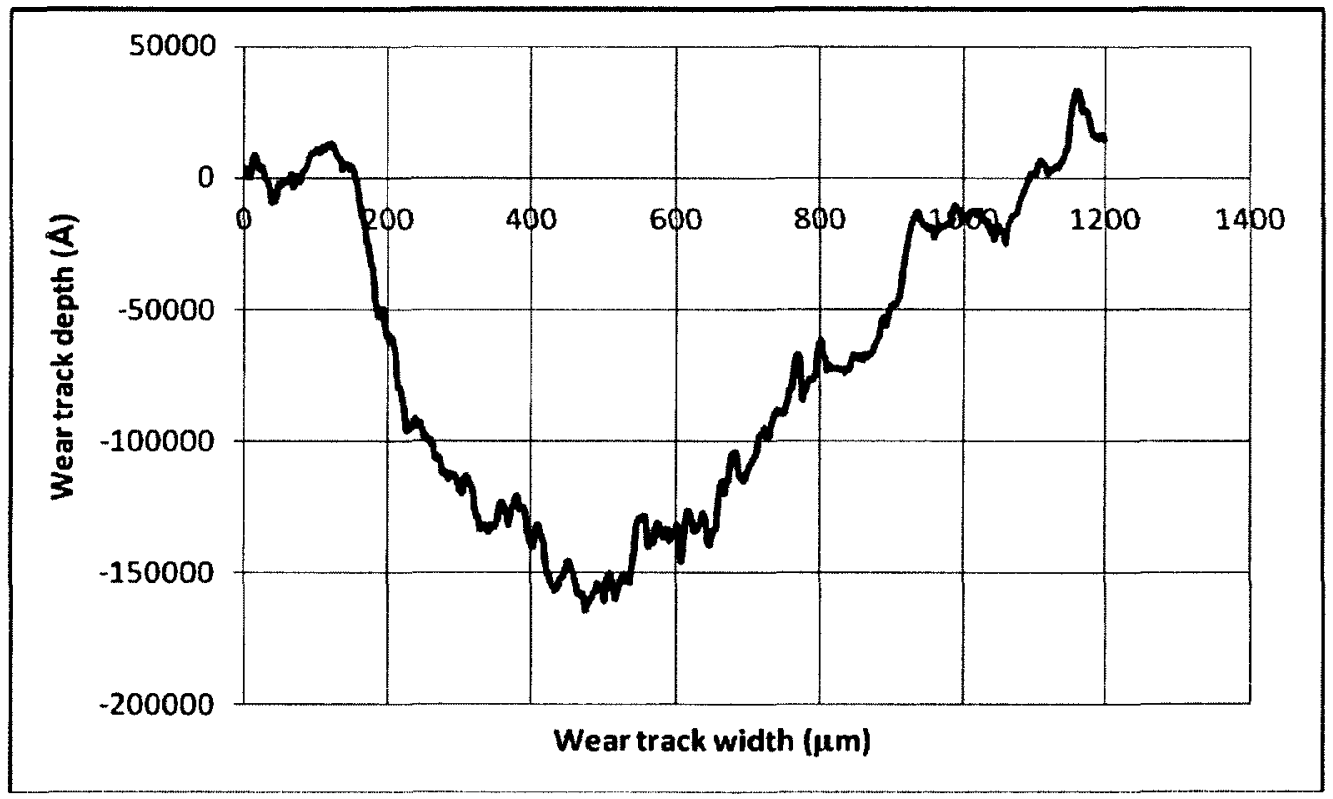

(b) 


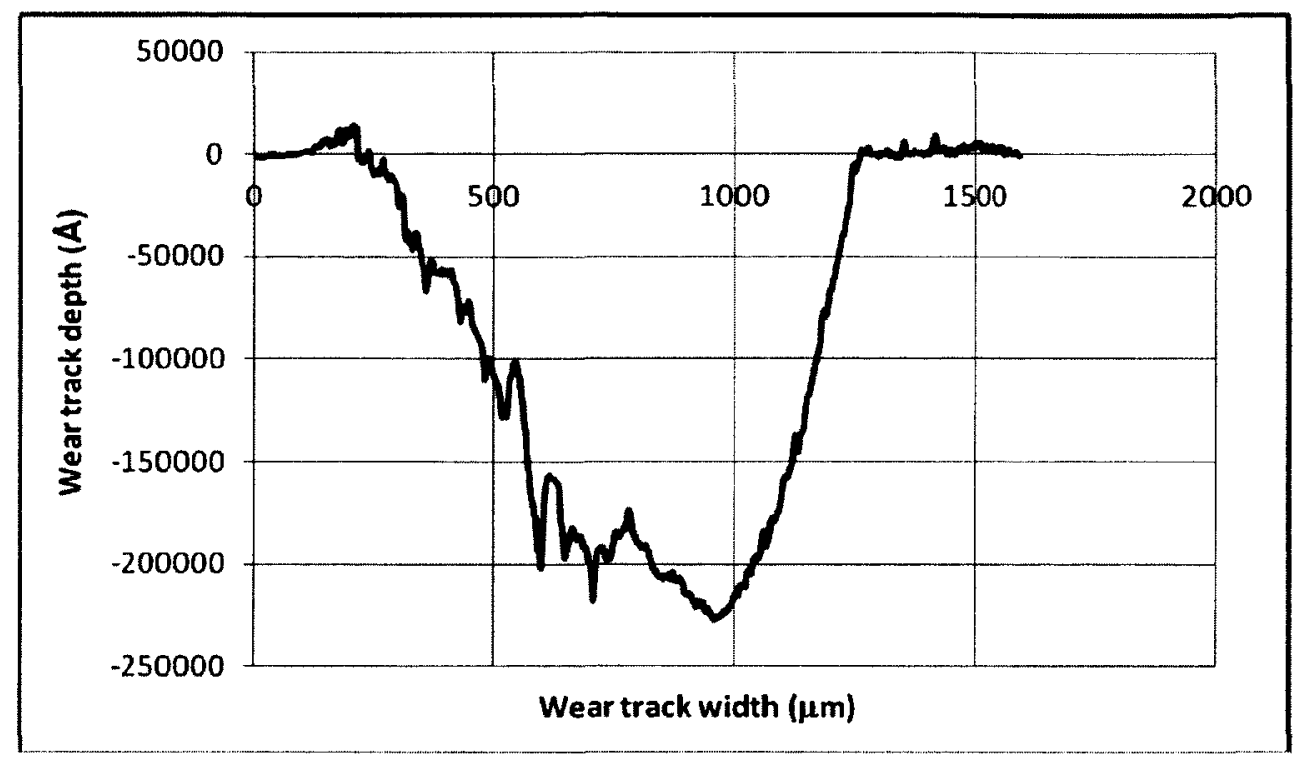

(c)

Figure 0-5: Cross section profiles of wear tracks in alloy E specimen tested: (a) at room temperature, (b) at $250^{\circ} \mathrm{C}$ and (c) at $450^{\circ} \mathrm{C}$.

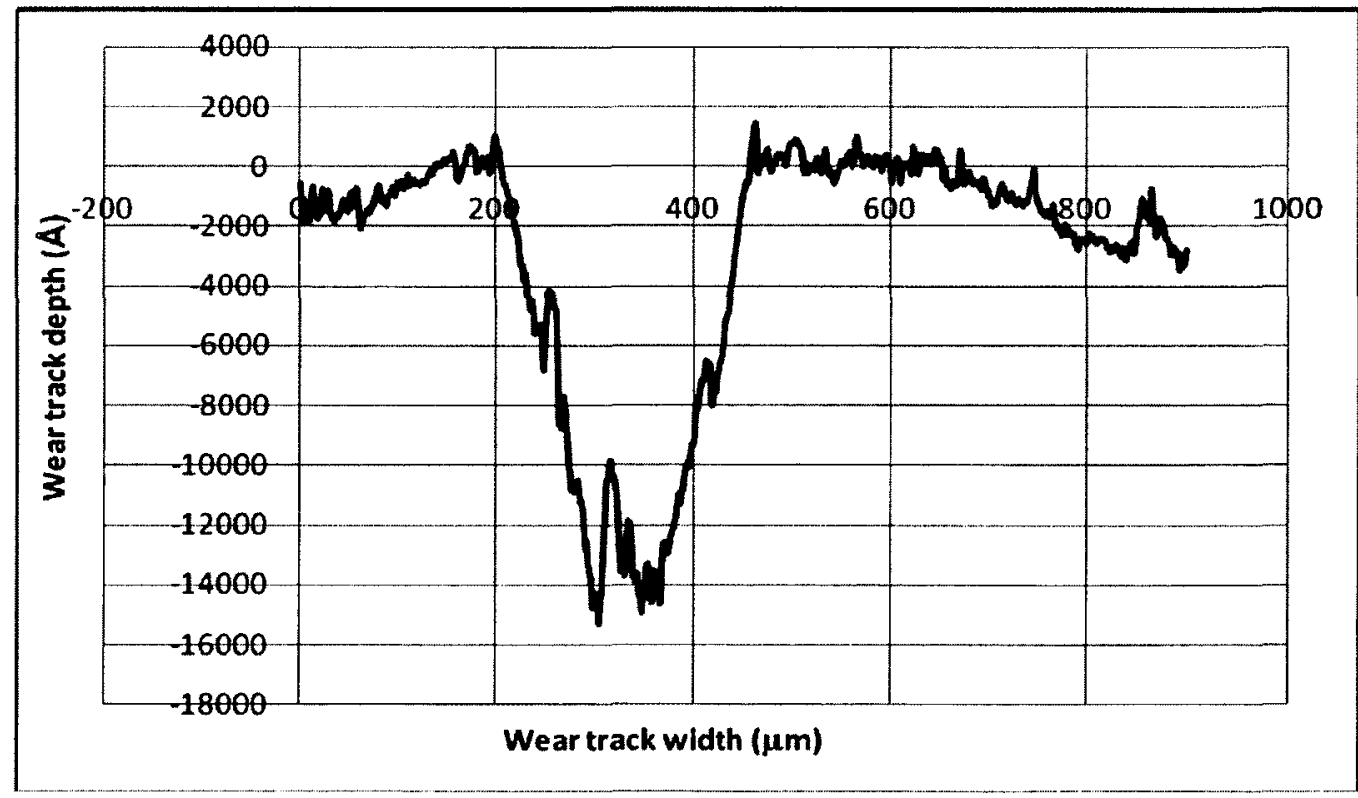

(a) 


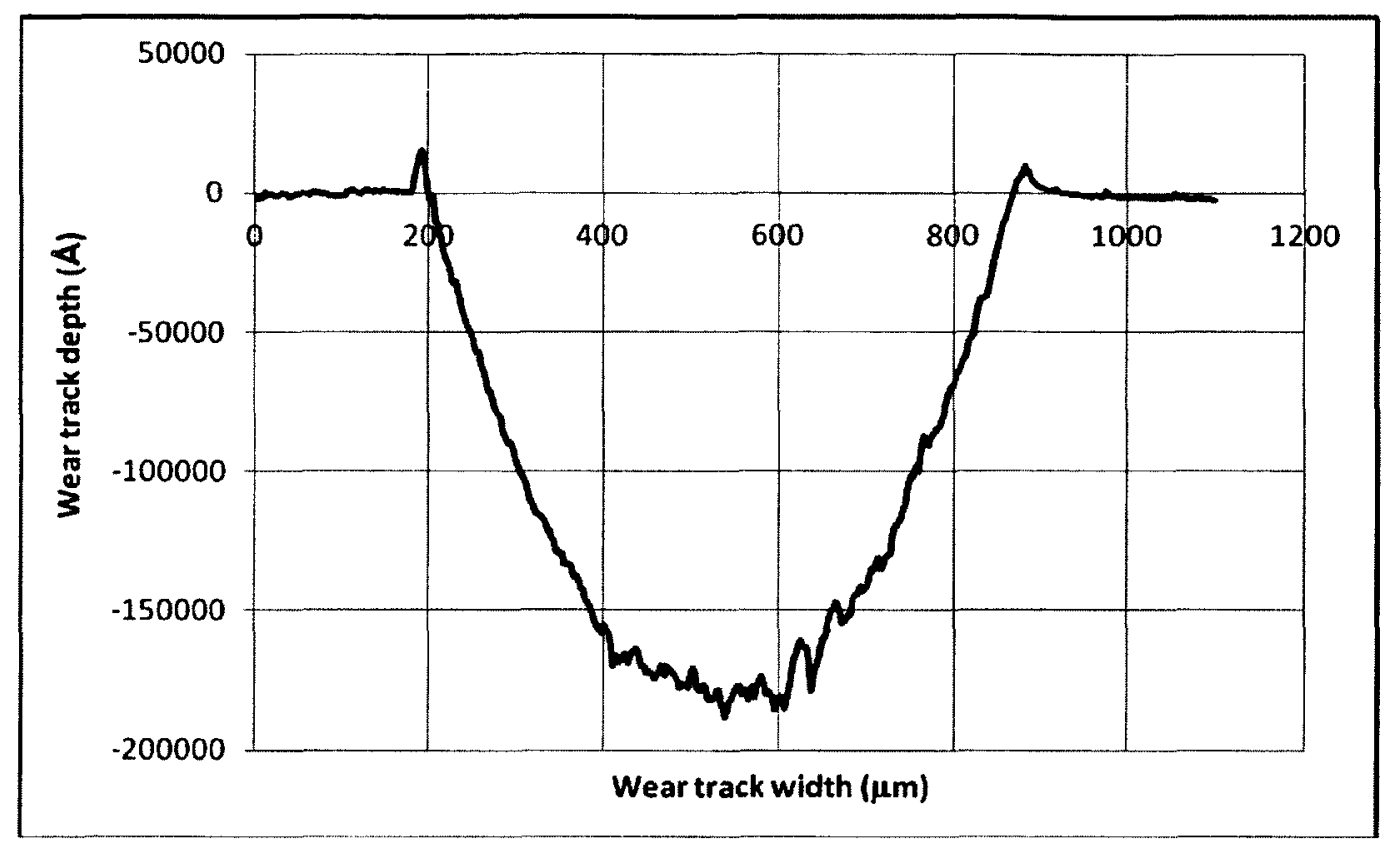

(b)

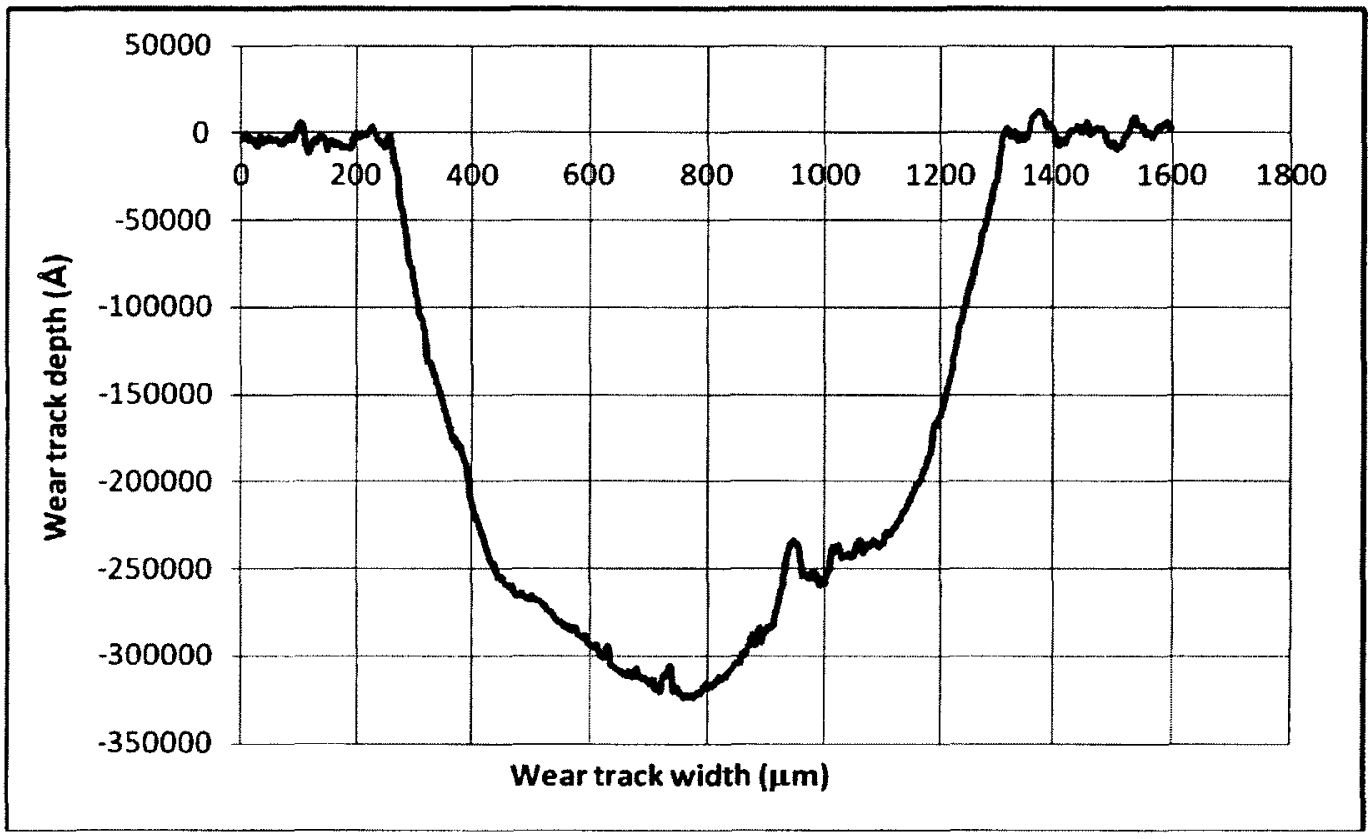

(c)

Figure 0-6: Cross section profiles of wear tracks in alloy $F$ specimen tested: (a) at room temperature, (b) at $250^{\circ} \mathrm{C}$ and (c) at $450^{\circ} \mathrm{C}$. 


\section{Bibliography}

[1] J. Davis, Cobalt-base alloys, in Nickel, Cobalt, and Their Alloys, Materials Park: ASM International, 2000.

[2] W. Betteridge, Cobalt and Its Alloys, Chichester: Halted Press, 1982.

[3] M. Amateau and G. W.A., "Survey of Materials for High-Temperature Bearing and Sliding Applications," Wear, 7, pp. 385-418, 1964.

[4] C. Opris, R. Liu, M. Yao and X. Wu, "Development of Stellite alloy composites with sintering/HIPing technique for wear-resistant applications," Materials and Design, 28, pp. 581-591, 2007.

[5] I. Inman, S. Rose and P. Datta, "Development of a simple 'temperature versus sliding speed' wear map for the sliding wear behaviou of dissimilar metallic interfaces," Wear, 260, pp. 919-932, 2006.

[6] P. Blau, M. Yao and J. Wu, "Use of multiple criteria to map the high-temperature scuffing behaviour of Co-based superalloys," Wear, 267, pp. 374-379, 2009.

[7] C. J. Heathcock and A. Ball, "Cavitation Erosion of Cobalt-based Stellite Alloys, Cemented Carbides and Surface-treated Low Alloy Steels," Wear. 74, pp. 11-26, $1981-1982$.

[8] R. Jeshvaghani, M. Shamanian and M. Jaberzadeh, "Enhancement of wear resistance of ductile iron surface alloyed by stellite 6," Materials and Design, 2 , pp. 2028-2033, 2011.

[9] C. K. Harris, J. P. Broussard and J. K. Keska, "Determination of Wear in a 
Tribo-System," in 2002 ASEE Gulf-Southwestern Annual Conference, Lafayette, Louisiana, 2002.

[10] A. W. J. Frenk, "Laser cladding with cobalt-based hardfacing," J. Phys. IV France, 1(C7), pp. 65-68, 1991.

[11] U. Malayoglu and A. Neville, "Mo and W as alloying elements in Co-based alloystheir effects on erosion-corrosion resistance," Wear, 259, pp. 219-229, 2005.

[12] A. Frenk and W. Kurz, "Microstructural effects on the sliding wear resistance of a cobalt-based alloy," Wear, 174, pp. 81-91, 1994.

[13] J.-C. Shin, J.-M. Doh, J.-K. Yoon, D.-Y. Lee and J.-S. Kim, "Effect of molybdenum on the microstructure and wear resistance of cobalt-base Stellite hardfacing alloys," Surface and Coatings Technology, 166, pp. 117-126, 2003.

[14] I. Radu, D. Li and R. Llewellyn, "Tribological behaviour of Stellite 21 modified with Yttrium," Wear, 257, pp. 1154-1166, 2004.

[15] M. Yao, J. Wu and Y. Xie, "Wear, corrosion and cracking resistance of some W- or Mo-containing Stellite hardfacing alloys," Materials Science and Engineering, A 407, pp. 234-244, 2005.

[16] I. M. Hutchings, Tribology: friction and wear of engineering materials, Boston: Butterworth-Heinemann, 2003.

[17] University of Duisburg-Essen, "University of Duisburg-Essen," [Online]. Available: http://www.unidue.de/imperia/md/content/werkstofftechnik/sk_hwt_06_wearmechanisms_ss08.pd f. [Accessed 1812012$]$. 
[18] D. Klarstrom, "Wrought cobalt-base superalloys," J. Mater. Eng. Performance, 2(4), pp. 523-530, 1993.

[19] Y. Birol, "Thermal fatigue testing of Inconel 617 and Stellite 6 alloys as potential tooling materials for thixoforming of steels," Mater. Sci. Eng. A, 527 (7-8), pp. 1938-1945, 2010.

[20] A. Davin and D. Coutsouradis, "Development of abrasion-and corrosions-resitant alloys for use in aqueous media," Cobalt, 52, pp. 160-161, 1971.

[21] C. Sims, "A contemorary view of of cobalt-base alloys," JOM, 21, pp. 27-42, 1969.

[22] R. B. Herchenroeder, S. Matthew, J. Tackett and S. Wlodek, "Haynes alloy No. 188," Cobalt, 52, pp. 160-161, 1971.

[23] G. Lai, J. Barnes and J. Barnes, "A burner rig investigation of the hot corrosion behaviour of several wrought superalloys and intermetallics," ASME, 91-GT-21, 1991.

[24] B. Boeck, T. Sanders Jr., V. Anand, J. Hickl and J. Kumar, "Relationships between processing, microstructure, and tensile properties of a Co-Cr-Mo alloy," Powd. Metall., 28(2), pp. 97-104, 1985.

[25] L. Wang and D. Li, "Effects of yttrium on microstructure, mechanical properties and high temperature wear behaviour of cast Stellite 6 alloy," Wear, 255, pp. 535544, 2003.

[26] I. Radu and D. Li, "Investigation of the role of oxide scale on Stellite 21 modified with yttrium in resisting wear at elevated temperatures," Wear, 259, pp. 453-458, 2005 . 
[27] I. Radu and D. Li, "The wear performance of yttrium-modified Stellite 712 at elevated temperatures," Tribology International, 40, pp. 254-265, 2007.

[28] H. Celik and M. Kaplan, "Effects of silicon on the wear behaviour of cobalt-based alloys at elevated temperature," Wear, 257, pp. 606-611, 2004.

[29] I. Campos, G. Ramirez, U. Figueroa, J. Martinez and O. Morales, "Evaluation of Boron Mobility on the phases FeB, Fe2B and Diffusion Zone in AISI 1045 and M2 steels," Appl. Surf. Sci., 253 (7), pp. 2469-3475, 2007.

[30] R. Liu, X. Qi, S. Kapoor and X. Wu, "Investigation of solidification behaviour and associate microstructures of $\mathrm{Co}-\mathrm{Cr}-\mathrm{W}$ and $\mathrm{Co}-\mathrm{Cr}-\mathrm{Mo}$ alloy systems using DSC technique," Journal of Materials Science, 45(22), pp. 6225-6234, 2010.

[31] F. Stott, D. Lin and G. Wood, "'Glazes" produced on Nickel-base Alloys during High Temperature Wear," Nature Physical Science, 242, pp. 75-77, 1973.

[32] I. Campos, R. G., U. Figueroa and C. Velazquez, "Paste Bonding Process: Evaluation of Boron Mobility on Bordided Steels," Surf. Eng., 23(3), pp. 216-222, 2007.

[33] G. Stachowiak, Wear-Materials, Mechanisms and Practice, Hoboken, NJ: Wiley, 2005 .

[34] R. Liu and D. Li, "A finite element model study on wear resistence of pesudoelastic TiNi alloy," Mater. Sci. Eng. A., 277, pp. 169-175, 2000.

[35] D. Li and R. Liu, "The mechanism responsible for high wear resistence of pseudoelastic TiNi alloy - A novel tribo-material," Wear, Vols. 225-229, pp. 777-783, 1999. 
[36] Y. Liu, H. Yang, G. Tan, S. Miyazaki, B. Jiang and Y. Liu, "Stress-induced FCC $\rightarrow$ HCP martensitic transformation in CoNi," J. Alloy. Comp., 368 (1-2), pp. 157$163,2004$.

[37] K. Ando, T. Omori, J. Sato, Y. Sutou, K. Oikawa, R. Kainuma and K. Ishida, "Effect of Alloying ELements on fcc/hcp Martensitic Transformation and Shape Memory Properties in Co-Al alloys," Mater. Trans., 47 (9), pp. 2381-2386, 2006.

[38] B. Bhushan, Principles and Applications of Tribology, New York: John Wiley \& Sons, 1999.

[39] J. Wu, "Deloro Stellite," 14 November 2007. [Online]. Available: http://www.stellite.com/Portals/0/Microsoft\%20PowerPoint\%20\%20Deloro\%20Stellite\%20Advances\%20in\%20Wear\%20Resistant\%20Alloys\%20 and\%20Products.pdf. [Accessed 26 November 2011].

[40] C. Fan, M.-C. Chen, C.-M. Chang and W. Wu, "Microstructure change caused by $(\mathrm{Cr}, \mathrm{Fe}) 23 \mathrm{C} 6$ carbides in high chromium $\mathrm{Fe}-\mathrm{Cr}-\mathrm{C}$ hardfacing alloys," Surface \& Coatings Technology, 201, pp. 908-912, 2006. 